\title{
CONSTRAINING CIRCULATION CHANGES THROUGH THE LAST DEGLACIATION WITH DEEP-SEA CORAL RADIOCARBON AND SEDIMENTARY ${ }^{231} \mathrm{~Pa} /{ }^{230} \mathrm{Th}$
}

\author{
By \\ Andrea Burke \\ B.A., Williams College, 2006 \\ Submitted in partial fulfillment of the requirements for the degree of \\ Doctor of Philosophy \\ at the \\ MASSACHUSETTS INSTITUTE OF TECHNOLOGY \\ and the \\ WOODS HOLE OCEANOGRAPHIC INSTITUTION
}

February 2012

(C) Andrea Burke

All rights reserved.

The author hereby grants to MIT and WHOI permission to reproduce and to distribute publicly paper and electronic copies of this thesis document in whole or in part in any medium now known or hereafter created.

Signature of Author

Joint Program in Oceanography/Applied Ocean Science and Engineering Massachusetts Institute of Technology and Woods Hole Oceanographic Institution

Certified by

Dr. Laura F. Robinson

Thesis Co-Supervisor

Dr. Olivier Marchal Thesis Co-Supervisor

Accepted by

Dr. Rob L. Evans

Chair, Joint Committee for Marine Geology and Geophysics

Woods Hole Oceanographic Institution 



\title{
Constraining Circulation Changes Through the Last Deglaciation with Deep-sea Coral Radiocarbon and Sedimentary ${ }^{231} \mathrm{~Pa} /{ }^{230} \mathrm{Th}$
}

\author{
By \\ Andrea Burke \\ Submitted to the MIT/WHOI Joint Program in Oceanography/Applied Ocean Science \\ and Engineering on October 4, 2011 in partial fulfillment of the requirements for the \\ degree of Doctor of Philosophy
}

\begin{abstract}
Radioactive isotopes can be used in paleoceanography both for dating samples and as tracers of ocean processes. Here I use radiocarbon and uranium series isotopes to investigate the ocean's role in climate change over the last deglaciation. I present a new method for rapid radiocarbon analyses as a means of age-screening deep-sea corals for further study. Based on age survey results, I selected forty corals from the Drake Passage and thirteen from the Reykjanes Ridge off Iceland and dated them with uranium series isotopes. The uranium series dates give independent ages that allow radiocarbon to be used as a tracer of circulation and carbon cycle changes. The radiocarbon records generated from the Drake Passage corals show increased stratification in the Southern Ocean during the last glacial maximum (LGM) that disappeared during the start of the deglaciation as atmospheric $\mathrm{CO}_{2}$ began to rise during Heinrich Stadial $1(\mathrm{H} 1)$. Considering these data and using a simple mass budget calculation, I show that the drop in atmospheric radiocarbon activity during $\mathrm{H} 1$ can be explained given direct carbon exchange between the radiocarbon-depleted deep ocean and atmosphere, e.g. through the Southern Ocean. The Drake Passage radiocarbon records also show evidence for decreased air-sea gas exchange in the Southern Ocean during the Antarctic Cold Reversal/Bølling-Allerød coincident with the hiatus in the deglacial $\mathrm{CO}_{2}$ rise. During this time period in the North Atlantic, radiocarbon reconstructions from deep-sea corals collected from off Iceland show a similar ventilation rate to that observed today and during the Holocene. To further investigate changes in North Atlantic ventilation over the last deglaciation, I used an inverse model to assess the consistency of sedimentary ${ }^{231} \mathrm{~Pa} /{ }^{230} \mathrm{Th}$ ratios from the Holocene, $\mathrm{H} 1$, and the LGM with the modern circulation. Although sedimentary ${ }^{231} \mathrm{~Pa} /{ }^{230} \mathrm{Th}$ has been used to infer changes in the strength of the meridional overturning circulation in the past, I find that published data are consistent with the modern circulation during the LGM and H1. These findings highlight the importance of giving due regard to the uncertainties in the behavior and spatial distribution of paleoceanographic tracers.
\end{abstract}

Thesis Supervisors: Dr. Laura F. Robinson (Associate Scientist in Marine Chemistry and Geochemistry) and Dr. Olivier Marchal (Associate Scientist with Tenure in Geology and Geophysics) 


\section{Acknowledgements}

First off, I would like to thank my advisors Laura Robinson and Olivier Marchal, without whom this work would not have been possible. Their generosity with their time, enthusiasm for my work, and encyclopedic knowledge has been greatly appreciated. I cannot begin to describe the depth of my gratitude for their support. I'd also like to thank my committee members Ed Boyle, Bill Curry, and Bill Jenkins, and my thesis defense chair Delia Oppo. Their collective expertise is phenomenal, and I only wish I had taken greater advantage of it. Thanks also to my co-authors for their comments and help with the preparation of the manuscripts that make up this thesis.

Many people have helped with various aspects of the laboratory work done for this thesis. The entire staff at the National Ocean Sciences Accelerator Mass Spectrometry Facility has been extremely helpful, knowledgeable, and friendly. It was always a joy to do lab work there. I would like to thank Ann McNichol for her radiocarbon expertise, Mark Roberts and Josh Burton for their long hours running my reconnaissance samples on CFAMS, and Dana Gerlach for her supervision in the lab and trouble-shooting during my first project. Thanks to Jerzy Blusztajn for all of his help trouble-shooting the Neptune. And a special thank you to Maureen Auro, who solved every lab problem I threw at her, no matter the time constraints!

I would like to thank the scientific staff and crew of cruises LMG06-05, NBP08-05, CE08-06 and MV1007, and in particular Rhian Waller, Nicky White, and Stephen Cairns for supplying samples used in this thesis. And I would like to give an additional thank you to Rhian Waller for help with coral identification, and Tamara Catanach for help cutting and organizing coral samples.

I'd like to thank my fellow JP students and the WHOI community for an excellent five years. Thank you Susie and Maya for always making your homes feel welcome and for your never-failing friendship. Thanks Caroline for sticking by me through three time zones and my tendency to not stay in touch. Thanks Elizabeth and the Dorans for providing me a home away from home. An additional thanks goes to Laura, who has been much more than an advisor for me. Thanks to you I now know: how to drive stickshift, which color is the best, what penguins look like from an icebreaker, and a very fun Scotsman. A very special thanks goes to James who has made writing up my thesis surprisingly fun. It follows that you will make everything in life fun, and I cannot wait. And finally, thanks especially to my wonderful, loving, and very funny family. This thesis is dedicated to my parents who have always supported me, to James who has supported me since the minute I met him, and to my brother Nate who almost always supports me, except in board games and debates about the Oxford comma. This thesis should be full of them (the Oxford commas, not the board games unfortunately).

This research was supported by a National Science Foundation Graduate Student Fellowship, NSF-OCE grants 0623107 and 82492700, NSF-ANT grants 0636787 and 80295700 (ARRA funding), and the USGS-WHOI Co-operative agreement. 


\section{Table of Contents}

$\begin{array}{ll}\text { Chapter 1. Introduction } & \mathbf{7}\end{array}$

1. Dating methods: radiocarbon and uranium series............................11

1.1 Radiocarbon ........................................................ 11

1.2 Uranium series isotopes.............................................14

2. Radiocarbon and uranium series isotopes as paleoceanographic tracers...........18

2.1 Radiocarbon in the modern ocean ......................................... 18

2.2 Reconstructing past radiocarbon activities of the atmosphere and ocean.....19

2.3 Changes in atmospheric and oceanic radiocarbon over last deglaciation....21

2.4 Sedimentary ${ }^{231} \mathrm{~Pa}^{230}$ Th as a paleoceanographic tracer.....................24

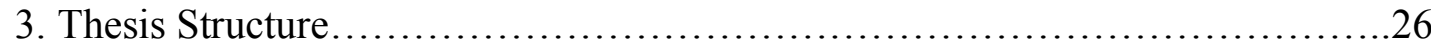

\section{Chapter 2. Reconnaissance dating: A new radiocarbon method applied to assessing the temporal distribution of Southern Ocean deep-sea} corals $\quad 32$

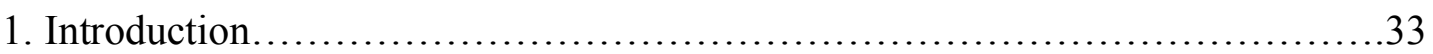

2. Sample selection................................................... 34

3. Analytical methods.................................................... 36

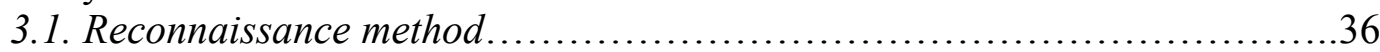

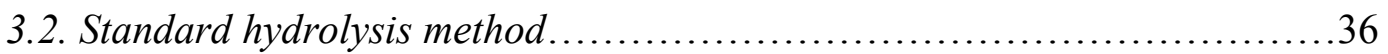

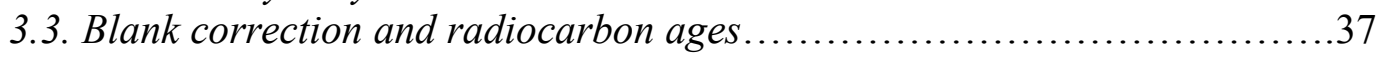

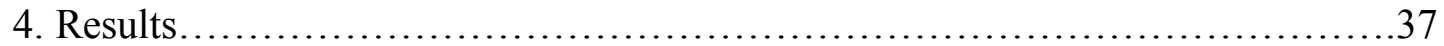

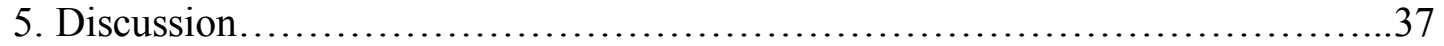

5.1. Carbon isotope fractionation effects ........................................ 37

5.2. Agreement of reconnaissance dating with standard hydrolysis procedures..38

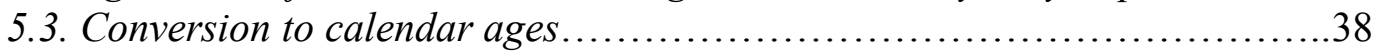

5.4. Age distribution of corals from the Drake Passage .........................40

6. Conclusions and perspectives............................................. 41

\section{Chapter 3. The Southern Ocean's role in carbon exchange during the} last deglaciation $\quad 44$

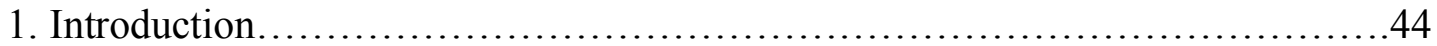

2. Sample Description and Results........................................46

3. Discussion............................................................. 47

3.1. A note on Antarctic Intermediate Water................................50

3.2. The Mystery Interval...............................................50

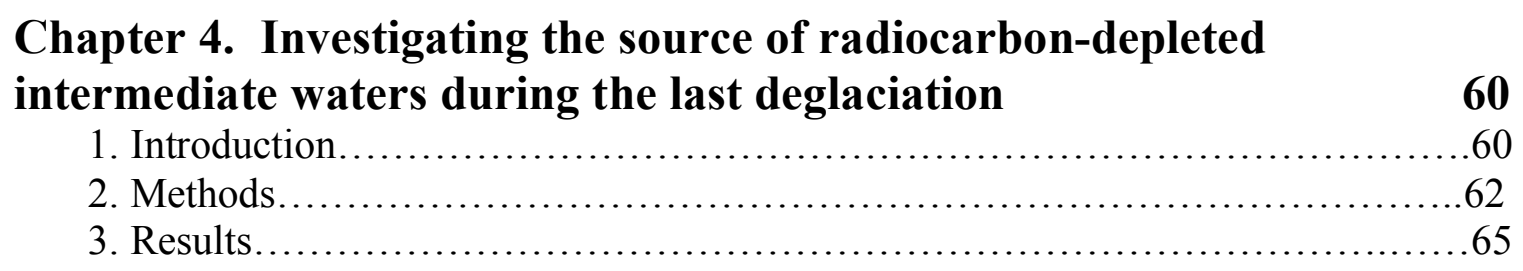




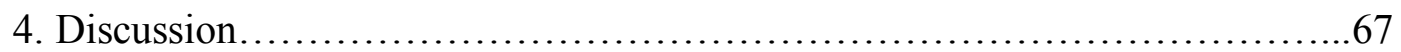

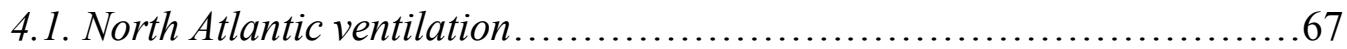

4.2. A common water mass? ..................................................69

4.3. Potential biases in foraminiferal records .............................72

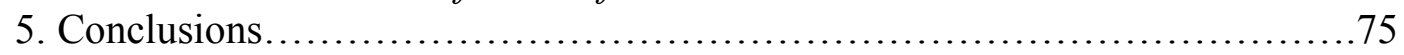

Chapter 5. Application of an inverse method to interpret ${ }^{231} \mathrm{~Pa} /{ }^{230} \mathrm{Th}$ $\begin{array}{lc}\text { observations from marine sediments } & 87\end{array}$

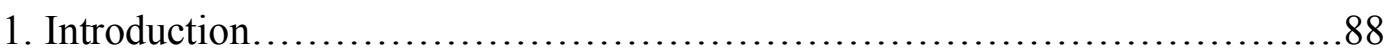

2. Estimation of the Abyssal Circulation in the Modern Atlantic...................90

2.1. Method ................................................................... 90

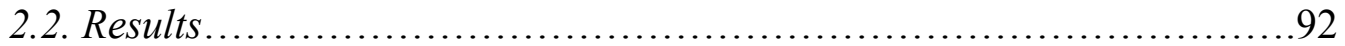

3. Analysis of Water Column ${ }^{231} \mathrm{~Pa}$ Data................................... 93

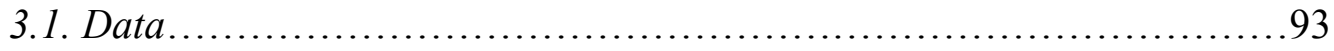

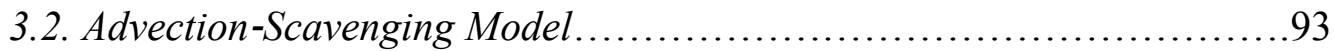

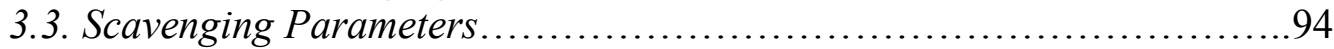

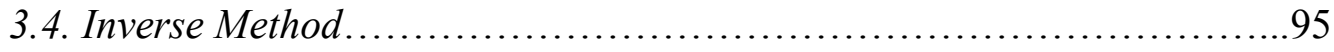

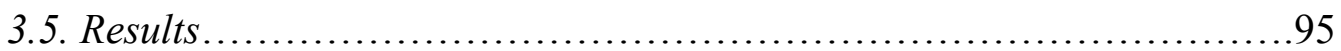

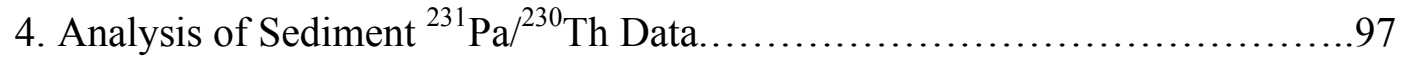

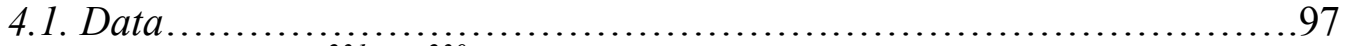

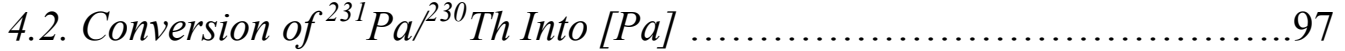

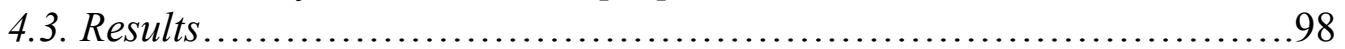

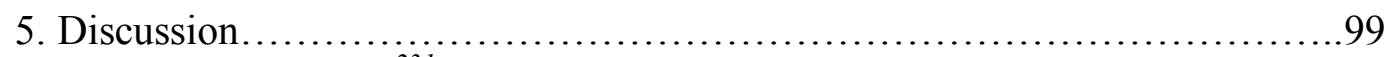

5.1. Water Column ${ }^{231} \mathrm{~Pa}$ Data........................................................99

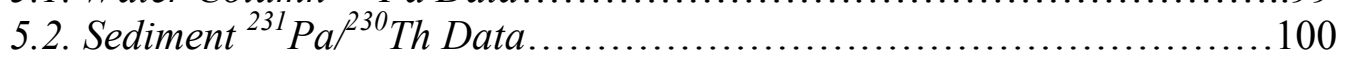

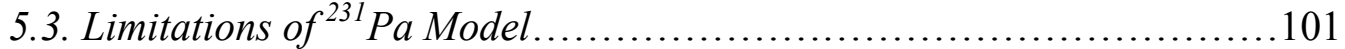

6. Conclusions and Perspectives........................................ 101

\section{$\begin{array}{ll}\text { Chapter 6. Conclusions and Perspectives } & 105\end{array}$}

Appendix A1. Data Table for Chapter 2 108

Appendix A2. Supplementary Information and Data Tables for Chapter $3 \quad 112$ Appendix A3. Data Tables for Chapter 4. 129

Appendix A4. Supplementary Information for Chapter 5. 135

Appendix A5. Reconnaissance ${ }^{14} \mathrm{C}$ data and uranium series data on Galapagos corals 


\section{Chapter 1. Introduction}

Records of atmospheric $\mathrm{CO}_{2}$ from bubbles trapped in ice cores show large $(\sim 80$ ppm) variations in $\mathrm{CO}_{2}$ over the past $800 \mathrm{ky}$, with the glacial periods characterized by low atmospheric $\mathrm{CO}_{2}$ and the interglacial periods characterized by high atmospheric $\mathrm{CO}_{2}$ [Luthi et al., 2008]. The strong correlation of atmospheric $\mathrm{CO}_{2}$ with Antarctic temperature (Fig. 1) over these timescales is compelling evidence for the link between $\mathrm{CO}_{2}$ and climate, and understanding these natural (pre-anthropogenic) carbon cycle variations will help with predictions of the response of climate to increased anthropogenic carbon emissions. The oceans are thought to be fundamental in driving these glacial-interglacial $\mathrm{CO}_{2}$ variations because the $\sim 100 \mathrm{ky}$ timescale of these cycles is too short to be explained by tectonic processes and the deep ocean reservoir of carbon is much larger than the terrestrial and re-equilibrates with the atmosphere on timescales of a thousand years [Broecker, 1982]. Thus, understanding how ocean circulation has changed in the past is crucial for determining the processes by which carbon was transferred from the ocean to the atmosphere from glacial to interglacial periods.

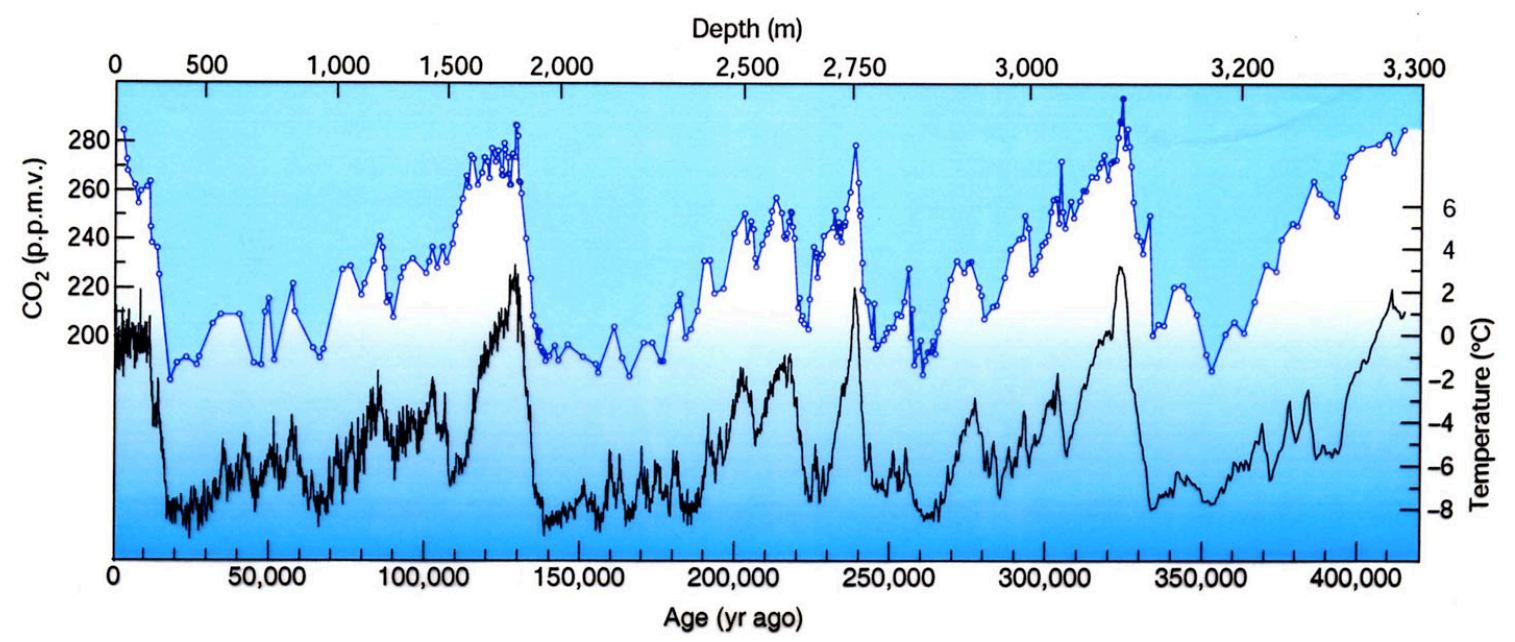

Figure 1. From Kump [2002]. Variations in atmospheric $\mathrm{CO}_{2}$ and Antarctic temperature over the past 400,000 years from the Vostok, Antarctica ice core [Petit et al., 1999].

The most recent transition from a glacial to interglacial state (the last deglaciation) started at about $18 \mathrm{ka}$ (thousand years ago) and was finished by the start of the Holocene at about $10 \mathrm{ka}$. The deglaciation was punctuated by periods of abrupt climate change. Heinrich Stadial 1 (H1, 17.8-14.7) was an extreme cooling event in the 
Northern Hemisphere associated with large bands of ice-rafted debris (Heinrich layers) throughout the northern North Atlantic as a result of massive iceberg discharge (Fig. 2). This period also coincided with a postulated weakening of the East Asian monsoon and the initial deglacial rise in atmospheric $\mathrm{CO}_{2}$ and Antarctic temperature [Wang et al., 2001]. H1 was followed by the Bolling-Allerod (BA, 14.7-12.8 ka), during which the Northern Hemisphere experienced warmer temperatures and there was a pause in the rise of Antarctic temperatures and atmospheric $\mathrm{CO}_{2}$ (the Antarctic Cold Reversal, Fig. 2). The Bolling-Allerod was followed by a return to more glacial conditions in the Northern Hemisphere during the Younger Dryas (YD, 12.8-11.6 ka), and a resumption of the rise in Antarctic temperatures and atmospheric $\mathrm{CO}_{2}$ (Fig. 2).

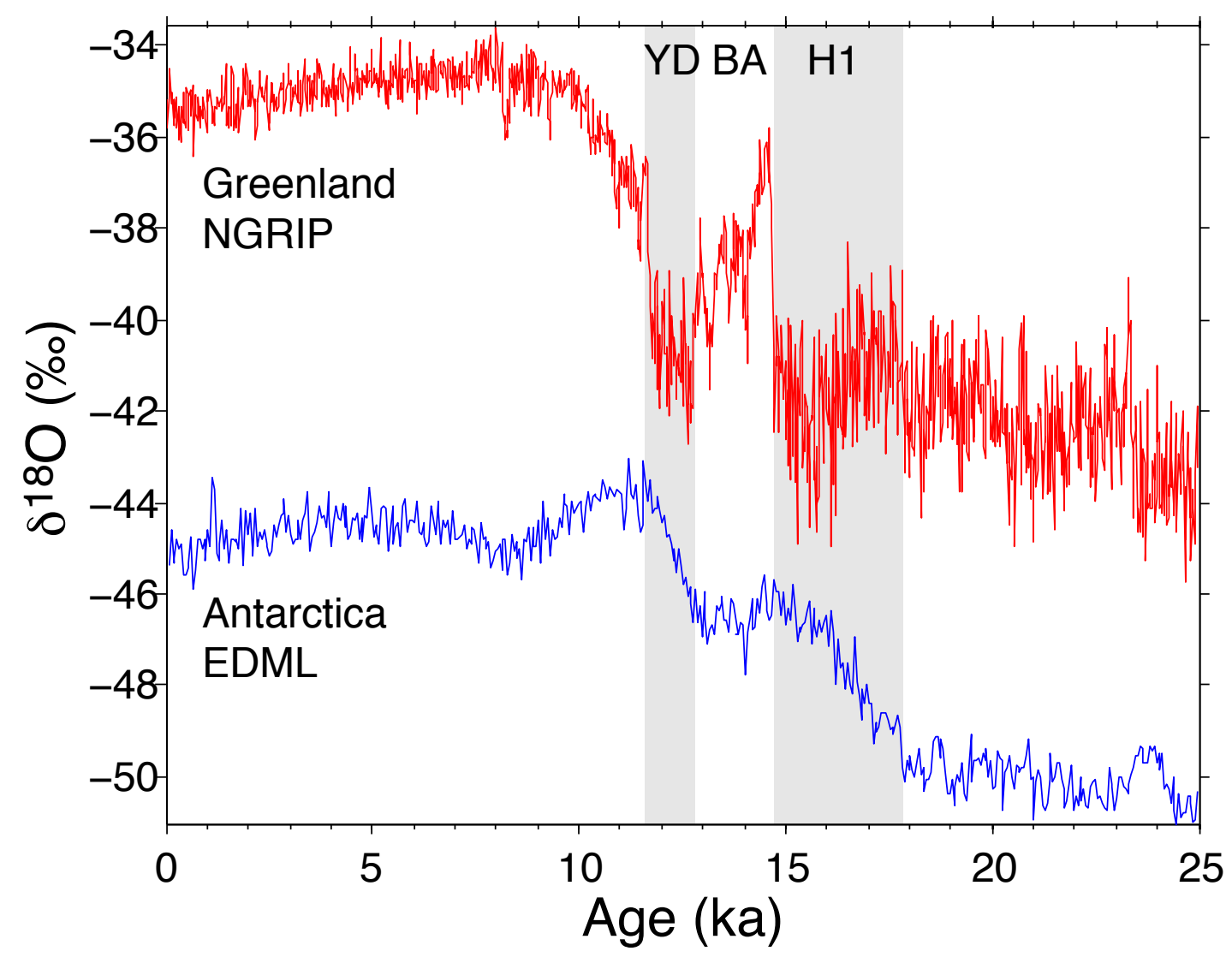

Figure 2. Oxygen isotope records from the NGRIP ice core from Greenland [NGRIP, 2004] (red) and the EDML ice core from Antarctica [EPICA, 2006] (blue) over the last deglaciation. Records are plotted on the GICC05-synchronized age model of LemieuxDudon et al. [2010]. $\delta^{18} \mathrm{O}$ is a proxy for temperature, with less negative oxygen isotope ratios corresponding to warmer temperatures. Note the anti-phased millennial temperature changes in the Northern and Southern Hemispheres during Heinrich Stadial 1 (H1), the Bølling-Allerød (BA), and the Younger Dryas (YD). 
Widespread variations in the chemical characteristics of the ocean accompanied these abrupt climate changes. Valuable insights to these variations are provided by records of radiocarbon content in the atmosphere and the ocean, and by the behavior of uranium-series isotopes. For instance, high-frequency variation in the radiocarbon content of dissolved inorganic carbon (DIC) during the last deglaciation in the intermediate and deep Northwest Atlantic has been reconstructed from benthic foraminifera and deep-sea corals (Fig. 3). The oldest DIC is observed during the cold periods of $\mathrm{H} 1$ and the $\mathrm{YD}$, whereas the $\mathrm{BA}$ is characterized by relatively young DIC throughout the water column, up to more than $3500 \mathrm{~m}$ depth [Robinson et al., 2005]. These variations could result from either a change in the ventilation rate or a change in the source of the waters at that site, or some combination of the two.

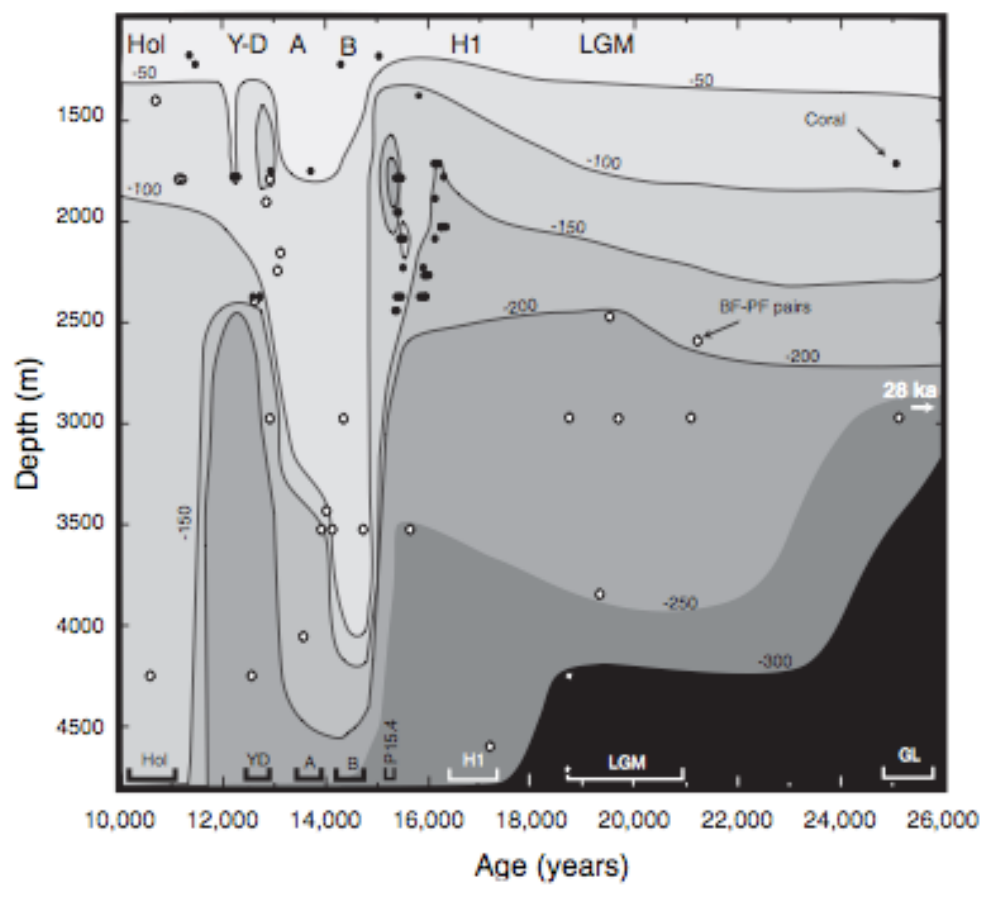

Figure 3. From Robinson et al. [2005]. Contour plot of the radiocarbon content $\left(\Delta^{14} \mathrm{C} \%\right.$; see Box 1$)$ in the Northwest Atlantic from $10-26 \mathrm{ka}$. These data were obtained from measurements on deep-sea corals and benthic-planktic foraminiferal pairs.

Another example of abrupt oceanic changes during the last deglaciation comes from the ratio of 231-protactinium to 230-thorium (radioactive daughter products of 235uranium and 234-uranium, respectively) in deep North Atlantic sediments from the Bermuda Rise (Fig. 4). Sedimentary ${ }^{231} \mathrm{~Pa} /{ }^{230} \mathrm{Th}$ increased dramatically at the start of $\mathrm{H} 1$, fell back down to pre-H1 values during the BA, and then had another increase during the YD [McManus et al., 2004]. These increases in the sedimentary ${ }^{231} \mathrm{~Pa} /{ }^{230} \mathrm{Th}$ ratio are thought to reflect a reduction in the export of ${ }^{231} \mathrm{~Pa}$ to the Southern Ocean due to a slow- 
down of the Atlantic meridional overturning circulation (AMOC). Freshwater discharge in the North Atlantic at the start of the deglaciation (H1) is hypothesized to have lowered the salinity (and hence density) in the deep-water formation regions, thus reducing the strength of North Atlantic Deep Water (NADW) formation. This would reduce the amount of heat transport from the Equator to the North Atlantic associated with the North Atlantic Current, potentially explaining the relatively cold temperatures observed in the Northern Hemisphere at this time.

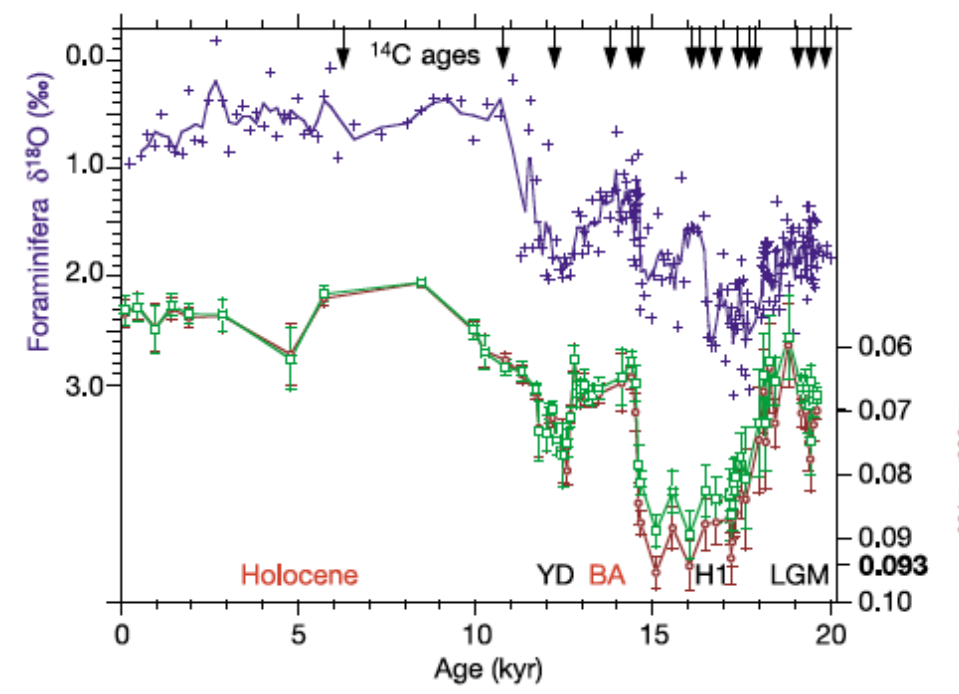

Figure 4. From McManus et al. [2004]. Oxygen isotope from planktonic foraminifera reflecting sea surface temperature, salinity and global ice volume (purple) and sedimentary ${ }^{231} \mathrm{~Pa} /{ }^{230} \mathrm{Th}$ from the Bermuda rise $(4,550 \mathrm{~m})$. The similarity between these two records hints at a potential connection between deep circulation and climate. The radiocarbon ages used to construct the age model are indicated by arrows.

In this thesis I combine both data collection and modeling of the two isotope systems mentioned above-radiocarbon and uranium series - to further investigate climate events during the last deglaciation. As both of these systems contain radioactive isotopes, they can be used to date geological samples. In Chapter 2 of this thesis, I develop an efficient method of preparing samples for radiocarbon analysis, and apply this method to conduct age surveys on a suite of deep-sea corals from the Drake Passage in the Southern Ocean. However, the usefulness of radiocarbon and U-series isotopes goes beyond generating dates for geological samples. When combined with an independent estimate of sample age, these isotopes can potentially be used as tracers of ocean circulation and the carbon cycle. For example, by pairing U-series ages with radiocarbon measurements on deep-sea corals, I reconstructed the radiocarbon activity of DIC in the Drake Passage (Chapter 3) and off Iceland in the North Atlantic (Chapter 4). The Drake Passage radiocarbon record suggests significant changes in vertical stratification and 
carbon exchange between different water masses in the Southern Ocean during the last glacial and deglacial periods. The radiocarbon record from the North Atlantic indicates that ventilation near Iceland was similar during the Bolling-Allerod compared to today. Finally, in Chapter 5, I use a compilation of sedimentary ${ }^{231} \mathrm{~Pa}{ }^{230} \mathrm{Th}$ ratios from the Atlantic during the last glacial maximum (LGM, between $\sim 19-23 \mathrm{ka}$ ), H1, and the Holocene with an inverse modeling approach to test the (in)consistency of these records with an estimate of the modern circulation. By giving due regard to the uncertainties both in the spatial distribution and behavior of ${ }^{231} \mathrm{~Pa}$ and ${ }^{230} \mathrm{Th}$ in the ocean, I assess the robustness of the circulation changes that have been inferred from these records. Together, these chapters provide insights into climate changes during the last deglaciation, as well as the use of these tracers in paleoceanography.

\section{Dating methods: radiocarbon and uranium series}

\subsection{Radiocarbon}

Radiocarbon $\left({ }^{14} \mathrm{C}\right)$ decays to ${ }^{14} \mathrm{~N}$ with a half life of $5730 \pm 40$ years [Godwin, 1962], and thus can be used to date samples up to $\sim 40$ ka ( $\sim 7$ half-lives, Box 1). Radiocarbon is produced in the atmosphere primarily by the interaction of nitrogen nuclei with protons produced by cosmic rays. The ${ }^{14} \mathrm{C}$ is oxidized to form ${ }^{14} \mathrm{CO}_{2}$ and then is incorporated into the carbon cycle (i.e. into the surface ocean DIC pool by air-sea gas exchange). Thus radiocarbon provides a useful means with which to date carboncontaining samples with ages less than $40 \mathrm{ka}$. However, since the activity of radiocarbon in the atmosphere is not constant with time and by convention the half-life used to report radiocarbon ages is not correct (Box 1), radiocarbon ages are not true ages and need to be calibrated to calendar ages.

Once in the ocean, the radiocarbon of DIC in the surface ocean can transported by the circulation to the deep ocean carbon reservoir. In general, surface waters are the most enriched in radiocarbon because of air-sea gas exchange, whereas deep waters are more depleted (older) because of their isolation from radiocarbon production in the atmosphere. Mixing of surface waters with low radiocarbon deep water, in addition to the finite rate of air-sea gas exchange, results in surface water radiocarbon values that are 


\section{Box 1. Radiocabon systematics}

The ${ }^{14} \mathrm{C} /{ }^{12} \mathrm{C}$ of a sample is measured with an accelerator mass spectrometer. Radiocarbon results are normalized to a ${ }^{13} \mathrm{C}=-25 \%$ and are reported as fraction modern ( $\mathrm{fm}$ ), where 'modern' is defined as $95 \%$ of the 1950 AD radiocarbon concentration of NBS Oxalic Acid I (NIST-SRM-4990) normalized to a $\delta^{13} \mathrm{C}=-19 \%$ [Olsson, 1970]. By convention, fraction modern is then converted into a radiocarbon age using the Libby half-life [5568 y; Stuiver and Polach, 1977; Stuiver, 1980], which differs from the true half-life (5730 y) by $3 \%$, and the following equation:

Radiocarbon age $=-8033^{*} \ln (\mathrm{fm})$.

The notation $\Delta^{14} \mathrm{C}(\%)$ is used to represent the relative difference between radiocarbon in the absolute international standard in 1950 and radiocarbon in the sample, corrected for $\delta^{13} \mathrm{C}$ and age (to account for decay between measurement and time of collection or age of the sample) [Stuiver and Polach, 1977]. It is described by the following equation:

$\Delta^{14} \mathrm{C}=\left(\mathrm{fm}^{*} \mathrm{e}^{\lambda \mathrm{t}}-1\right)^{*} 1000 \%$

where $\lambda$ is $1 /$ the true mean-life of radiocarbon (1/8266 $\mathrm{y})$ and $t$ is the age of the sample (years before 1950 A. D.).

Radiocarbon decays with a half-life of 5730 years, so it can be used to date carbon containing materials if the initial activity of radiocarbon is known. The graph below shows the fraction modern as a function of time after the carbon was incorporated into a hypothetical sample with initial $\mathrm{fm}=1$.
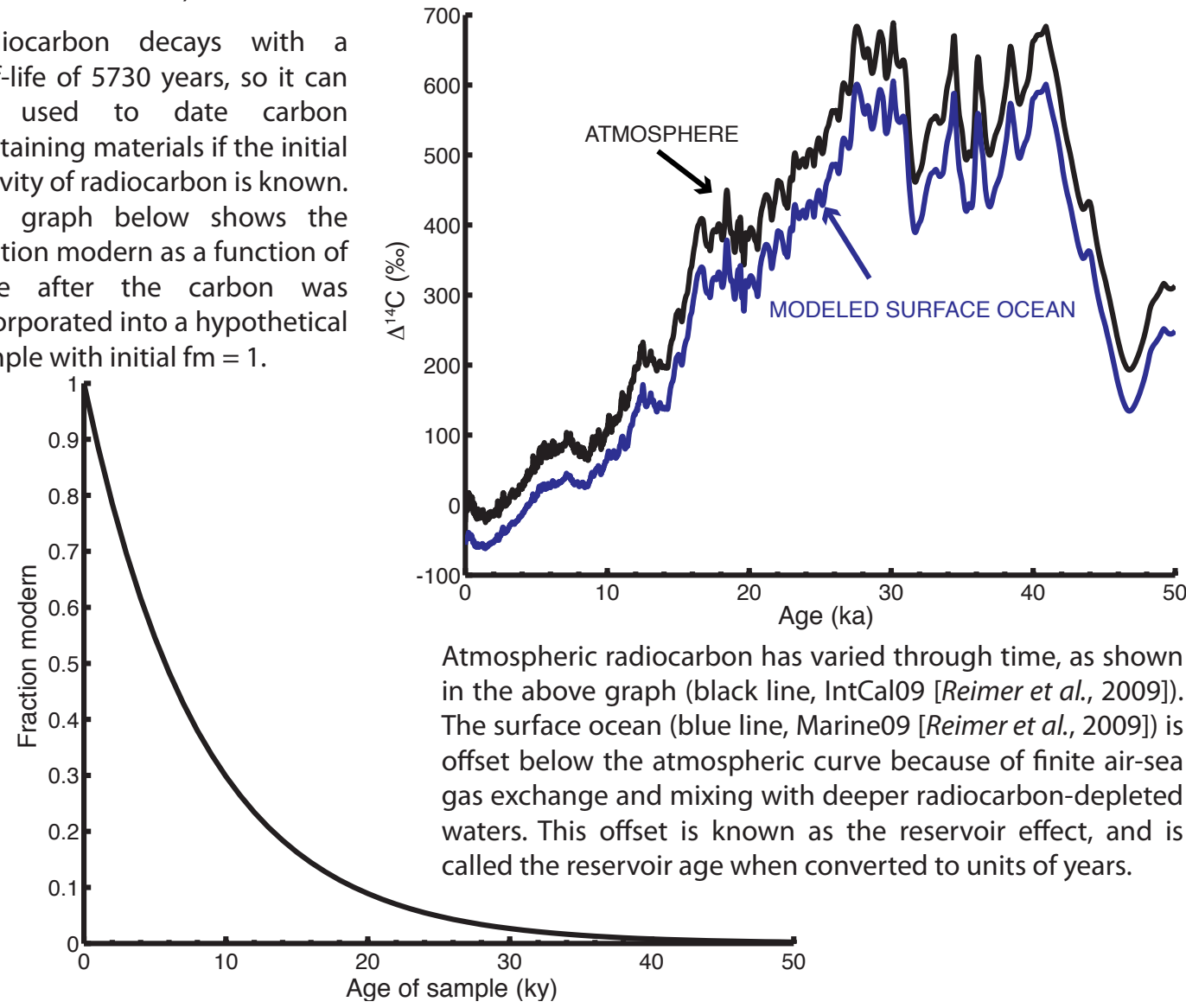

Atmospheric radiocarbon has varied through time, as shown (black line, IntCal09 [Reimer et al., 2009]). The surface ocean (blue line, Marine09 [Reimer et al., 2009]) is offset below the atmospheric curve because of finite air-sea gas exchange and mixing with deeper radiocarbon-depleted waters. This offset is known as the reservoir effect, and is called the reservoir age when converted to units of years. 
more depleted (older) than the contemporaneous atmosphere. This apparent age is known as the reservoir effect, and the age offset between carbon in the atmosphere and marine samples from the same time is known as the reservoir age [Stuiver et al., 1986]. Thus, an accurate estimate of the reservoir age from a sample location is necessary to determine an accurate calendar age from radiocarbon (Box 1).

Some of the benefits of radiocarbon dating include a relatively small sample size and relatively easy sample preparation (compared, for example, to dating with uranium series). Samples can contain as little as 25 micrograms of carbon (0.21 $\mathrm{mg}$ carbonate), which is orders of magnitude less than what is needed for uranium series dating (generally $>100 \mathrm{mg}$ carbonate, and preferably $>300 \mathrm{mg}$ carbonate). Whereas sample preparation for uranium series is extensive, for radiocarbon analysis it is more straightforward. Uranium series measurements require an extensive chemical cleaning to remove surface thorium contamination, the use of radioactive spikes, iron coprecipitation to remove the carbonate matrix, and column chemistry to isolate the different isotopes for measurement on a multi-collector inductively coupled plasma mass spectrometer (MC-ICP-MS). Radiocarbon preparation is simpler, consisting of an abbreviated chemical cleaning, conversion of carbonate to carbon dioxide gas, and, typically, conversion of this gas to graphite for measurement by an accelerator mass spectrometer (AMS).

In Chapter 2, I present a new and efficient method for preparing graphite targets for radiocarbon analysis. This new method combines combustion of the carbonate with an Elemental Analyzer and conversion of the resultant $\mathrm{CO}_{2}$ with a sealed-tube zinc reduction method. This new method gives percent level precision and samples can be prepared rapidly ( 20 samples/day). This technique is especially useful for conducting reconnaissance age surveys of deep-sea corals. One difficulty with using deep-sea corals as a paleoceanographic archive is that generally there is no a priori knowledge of the relative ages of samples. With sediment cores, the stratigraphic sequence of the samples allows for quick determination of relative ages. However, unless the deep-sea corals come from drilled cores themselves [Frank et al., 2004; Kano et al., 2007], that age information is not readily available for deep-sea corals. As a single dredge can bring up 
thousands of corals, it is not time- or cost-effective to precisely date all of the samples. With the new method presented in Chapter 2, I generated approximate ages (with percent level precision) for a suite of more than 100 deep-sea corals from the Drake Passage to identify which samples would be suitable for reconstruction of radiocarbon through the last deglaciation (Chapter 3).

Following this initial study, I have been involved in developing an even more efficient method to generate approximate radiocarbon ages of samples with more than 20 mg of carbonate [McIntyre et al., in press]. This method consists of hydrolysis of the carbonate with $85 \%$ phosphoric acid in vacutainer (air-tight) tubes, and then direct measurement of the resultant $\mathrm{CO}_{2}$ gas on a continuous flow accelerator mass spectrometer (CFAMS, [Roberts et al., 2009]). With this new gas ion source (GIS) method, it is possible to run $\sim 40$ samples per day. However, the large sample mass requirement for the GIS method limits its use to carbonate samples that are not mass limited (e.g. deep-sea corals), whereas the method presented in Chapter 2 can be used on as little as $2.5 \mathrm{mg}$ carbonate, as well as organic carbon samples containing at least $300 \mu \mathrm{g}$ of carbon. The GIS method was used for reconnaissance age surveys of a suite of 88 corals from the Reykjanes Ridge off Iceland (Chapter 4), and a suite of 40 corals from the Galapagos (Appendix A5). These radiocarbon age surveys help narrow down the coral samples selected for uranium series dating.

\subsection{Uranium series isotopes}

The radioactive decay of 238-uranium and 235-uranium provides an excellent tool for dating geological samples since these parent isotopes have much longer half-lives than any of the intermediate daughter isotopes in their decay chains (Box 2). Uranium series disequilibrium occurs when one of the isotopes in the decay chain is fractionated from the other isotopes, resulting in a non-steady state between a parent and a daughter nuclide. The return of the decay chain to steady state, or secular equilibrium, is a function of the half-life of the daughter isotope, and it is this return to secular equilibrium that can provide an age.

The primary decay chain used in uranium-series dating of marine carbonates is the ${ }^{238} \mathrm{U}_{-}{ }^{234} \mathrm{U}^{2}{ }^{230} \mathrm{Th}$ chain. After initial fractionation, the in-growth of ${ }^{230} \mathrm{Th}$ from the 
radioactive decay of ${ }^{234} \mathrm{U}$ can be used to generate an age for the sample. ${ }^{230} \mathrm{Th}$ has a half-

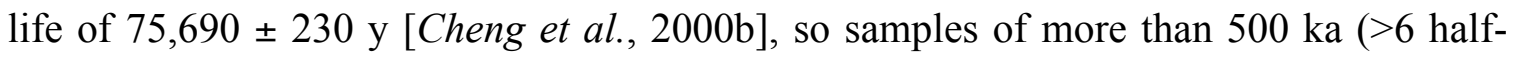
lives) can be dated with these isotopes [Stirling et al., 2001; Andersen et al., 2008]. In addition, 235-uranium decays to 231-protactinium with a half-life of 32,760 $\pm 220 \mathrm{y}$ [Robert et al., 1969], and thus the ${ }^{231} \mathrm{~Pa}^{235} \mathrm{U}$ ratio can be used to date samples with ages up to $250 \mathrm{ka}$ [Edwards et al., 1997]. In this thesis, I used uranium series methods to date the aragonitic skeletons of deep-sea corals collected from the Drake Passage region of the Southern Ocean (Chapter 3) and the Reykjanes Ridge off Iceland (Chapter 4). Since uranium is much more soluble in seawater than thorium, there is an initial fractionation that results in seawater that has a ${ }^{230} \mathrm{Th} /{ }^{238} \mathrm{U}$ ratio significantly lower than expected from secular equilibrium [Edwards et al., 2003]. Therefore, when deep-sea corals incorporate these isotopes into their skeletons from seawater, the initial concentrations of uranium $(\sim 3 \mathrm{ppm})$ are several orders of magnitude greater than the concentrations of ${ }^{230} \mathrm{Th}(\sim 2-10$ $\mathrm{x} 10^{-4} \mathrm{ppb}$ ), allowing deep sea corals to be radiometrically dated up to several hundred thousand years [Cheng et al., 2000a]. This range of ages is much larger than can be dated with radiocarbon techniques $(<40 \mathrm{ka})$ and uranium series methods do not require an assumption of reservoir age. However, there are different assumptions that need to be considered for dating deep-sea corals with uranium series.

First of all, while the assumption of negligible initial ${ }^{230} \mathrm{Th}\left(\right.$ or ${ }^{231} \mathrm{~Pa}$ ) in surface corals is valid, in deep-sea corals the initial ${ }^{230} \mathrm{Th}\left({ }^{231} \mathrm{~Pa}\right)$ incorporated into the skeleton can be significant. The activity of ${ }^{230} \mathrm{Th}$ and ${ }^{231} \mathrm{~Pa}$ generally increases with depth in the ocean, both in its dissolved and particulate phases, due to reversible exchange of these nuclides on falling particles [e.g. Bacon and Anderson, 1982; Anderson et al., 1983; Nozaki et al., 1987; Moran et al., 1995]. Indeed, it is because of the particle-reactive behavior of thorium and protactinium, as well as their differing ocean residence times, that they can be used together as a tracer of paleocirculation (see Section 2.4). However, unless the presence of initial ${ }^{230} \mathrm{Th}\left({ }^{231} \mathrm{~Pa}\right)$ in the coral skeleton is accounted for, the calculated ${ }^{230} \mathrm{Th} /{ }^{238} \mathrm{U}\left({ }^{231} \mathrm{~Pa} /{ }^{235} \mathrm{U}\right)$ age will be too old since it has apparently more of the daughter isotope. 
Box 2. Uranium series systematics

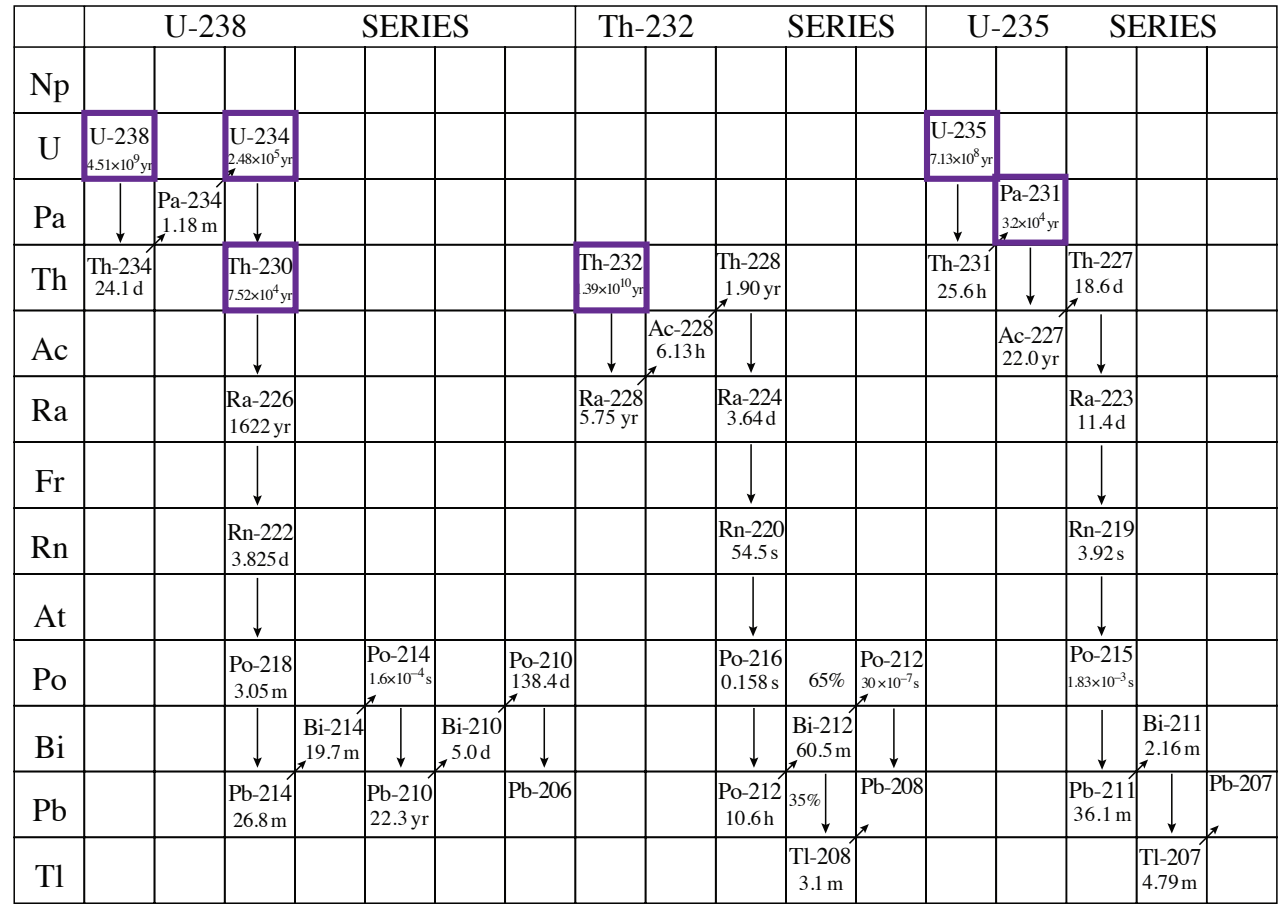

The above table [Turekian and Bacon, 2003] shows the radioactive decay chains with the half-lives of each nuclide listed below the isotope name. Isotopes used in uranium series dating of marine carbonates are highlighted in purple.

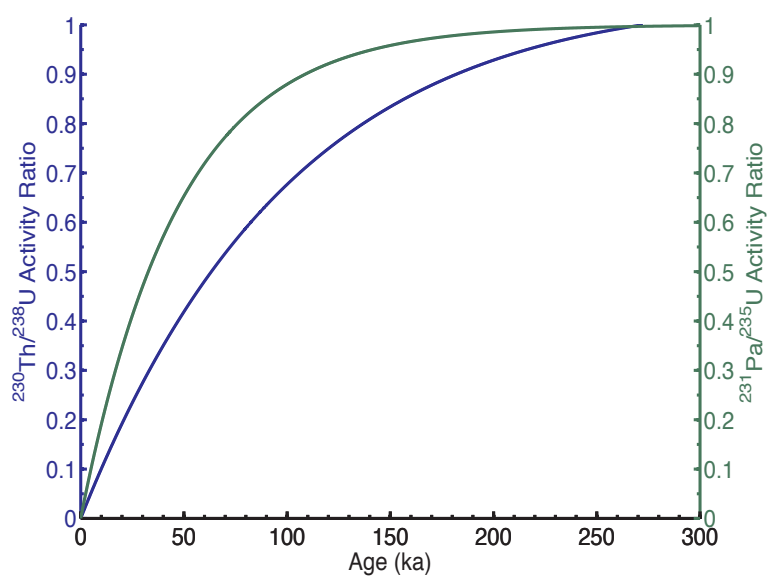

The plot to the left shows the in-growth of ${ }^{230} \mathrm{Th}$ (blue) and ${ }^{231} \mathrm{~Pa}$ (green) as a function of age, assuming no initial daughter isotopes. If the samples had initial ${ }^{230} \mathrm{Th}$ or ${ }^{231} \mathrm{~Pa}$, these curves would move up and thus the age would be younger for a given activity ratio.

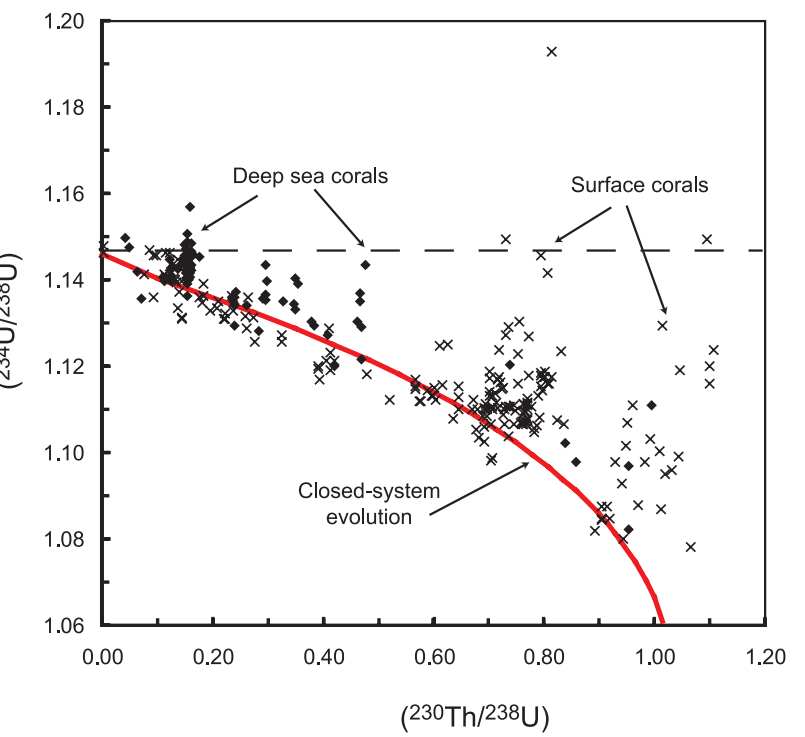


Thus, an assumption needs to be made about the initial ${ }^{230} \mathrm{Th} /{ }^{238} \mathrm{U}\left({ }^{231} \mathrm{~Pa} /{ }^{235} \mathrm{U}\right)$ ratio incorporated into the coral skeleton in order to determine the age. This assumption is not trivial. For U-Th dating, ${ }^{232} \mathrm{Th} /{ }^{238} \mathrm{U}$ can be measured in the coral, and an initial ${ }^{230} \mathrm{Th} /{ }^{232} \mathrm{Th}$ ratio can be assumed to get at the initial ${ }^{230} \mathrm{Th} /{ }^{238} \mathrm{U}$ ratio. The following equation can then be used to solve for age:

$\left[\frac{{ }^{230} T h}{{ }^{238} U}\right]-\left[\frac{{ }^{232} T h}{{ }^{238} U}\right]\left[\frac{{ }^{230} T h}{{ }^{232} T h}\right]_{i}\left(e^{-\lambda_{230} t}\right)=1-e^{-\lambda_{230} t}+\left(\frac{\delta^{234} U_{m}}{1000}\right)\left(\frac{\lambda_{230}}{\lambda_{230}-\lambda_{234}}\right)\left(1-e^{-\left(\lambda_{230}-\lambda_{234}\right) t}\right)$

where brackets denote activity ratios, $\lambda$ represents decay constants, $\delta^{234} U_{m}$ is the measured deviation (\%o) of the ${ }^{234} \mathrm{U} /{ }^{238} \mathrm{U}$ ratio from secular equilibrium, and $t$ is age [Edwards et al., 2003]. The second term on the left-hand side of the equation is the contribution of initial ${ }^{230} \mathrm{Th}$. The difficulty comes in estimating the initial ${ }^{230} \mathrm{Th} /{ }^{232} \mathrm{Th}$ ratio because ${ }^{230} \mathrm{Th} /{ }^{232} \mathrm{Th}$ ratios can be highly variable both in time and space. Initial thorium can be of two origins: from the water column and from terrestrial detrital particles. The atomic ratio of ${ }^{230} \mathrm{Th} /{ }^{232} \mathrm{Th}$ in the water column ranges from about $10 \mathrm{x}$ $10^{-6}$ in the surface ocean [Cochran et al., 1987; Nozaki et al., 1987; Guo et al., 1995] to greater than $700 \times 10^{-6}$ in the deep North Pacific [Moore, 1981]. Continentally derived detrital particles are expected to have an atomic ratio of $4 \times 10^{-6}$ based on the assumption of secular equilibrium and a ${ }^{232} \mathrm{Th} /{ }^{238} \mathrm{U}$ value of 3.8 [Taylor and McLennan, 1985]. The ${ }^{230} \mathrm{Th} /{ }^{232} \mathrm{Th}$ ratio in deep-sea corals should lie between these two extremes. Using development diagrams on a suite of modern deep sea corals collected from the Atlantic, Pacific, and Southern Oceans, Cheng et al. [2000a] determined that the initial atomic ${ }^{230} \mathrm{Th} /{ }^{232} \mathrm{Th}$ ratio was $80 \pm 80 \times 10^{-6}$. Using isochron techniques, Goldstein et al. [2001] calculated initial ${ }^{230} \mathrm{Th} /{ }^{232} \mathrm{Th}$ ratios in deep sea corals that were consistent with the Cheng et al. [2000a] estimates.

Accounting for initial ${ }^{231} \mathrm{~Pa}$ is slightly more difficult. Without a long-lived stable isotope of protactinium (analogous to ${ }^{232} \mathrm{Th}$ ), the correction for initial ${ }^{231} \mathrm{~Pa}$ relies on an assumption of the initial $\left[{ }^{231} \mathrm{~Pa} /{ }^{230} \mathrm{Th}\right]$ incorporated into the coral, as well as the initial $\left[{ }^{230} \mathrm{Th} /{ }^{238} \mathrm{U}\right]$ calculated from the assumption of an initial $\left[{ }^{230} \mathrm{Th} /{ }^{232} \mathrm{Th}\right]$ and the 
measurement of $\left[{ }^{232} \mathrm{Th} /{ }^{238} \mathrm{U}\right]$ as described above. Given the above assumptions, ${ }^{231} \mathrm{~Pa} /{ }^{235} \mathrm{U}$ ages can then be calculated from the following equation:

$$
\left[\frac{{ }^{231} \mathrm{~Pa}}{{ }^{235} \mathrm{U}}\right]-\left[\frac{{ }^{238} \mathrm{U}}{{ }^{235} \mathrm{U}}\right]\left[\frac{{ }^{232} \mathrm{Th}}{{ }^{238} \mathrm{U}}\right]\left[\frac{{ }^{230} \mathrm{Th}}{{ }^{232} \mathrm{Th}}\right]_{i}\left[\frac{{ }^{231} \mathrm{~Pa}}{{ }^{230} \mathrm{Th}}\right]_{i}\left(e^{-\lambda_{231} t}\right)=1-e^{-\lambda_{231} t}
$$

where brackets denote activity ratios, $\lambda_{231}$ is the decay constant of ${ }^{231} \mathrm{~Pa}, t$ is age, and $\left[{ }^{238} \mathrm{U} /{ }^{235} \mathrm{U}\right]$ is a constant (21.78) [Edwards et al., 2003]. The second term on the left side of the above equation is the correction for initial ${ }^{231} \mathrm{~Pa}$ incorporated into the coral skeleton.

The second assumption that needs to be considered for uranium series dating of deep-sea corals is that the coral skeleton is a closed system (Box 2). Sometimes corals exhibit open system behavior and uranium is added or lost from the coral framework, e.g. due to recoil effects from high energy $\alpha$-decay [Robinson et al., 2006]. This process can occur in both deep-sea corals and surface corals. Open system behavior is suspected if the initial $\delta^{234} U$ of the coral $\left(\delta^{234} U=\left[{ }^{234} U /{ }^{238} U\right]-1\right) \times 1000 \%$ o $)$ is not within error of the modern seawater $\delta^{234} \mathrm{U}$, which is not thought to have changed more than $15 \%$ over the past 360 ky [Henderson, 2002]. Open system behavior can also be tested by comparing ${ }^{238} \mathrm{U}_{-}{ }^{230} \mathrm{Th}$ ages with ${ }^{235} \mathrm{U}_{-}{ }^{231} \mathrm{~Pa}$ ages to ensure that they are in agreement.

\section{Radiocarbon and uranium series isotopes as paleoceanographic tracers}

\subsection{Radiocarbon in the modern ocean}

Since the half-life of radiocarbon [5730 y, Godwin, 1962] is of the order of the mixing time of the ocean ( $\sim 1000$ years), radiocarbon is present throughout the ocean and its spatial distribution reflects key aspects of global ocean circulation. For instance, in the modern Atlantic, the warm salty surface water flowing north that feeds NADW formation is at the surface long enough to obtain high radiocarbon activities from air-sea gas exchange with the atmosphere, resulting in relatively young reservoir ages [ 400 y, Bard, 1988]. This surface water in the Atlantic is among the most radiocarbon-enriched water in the ocean [Key et al., 2004]. The formation of NADW in the North Atlantic leads to the transport of this water into the abyssal ocean, resulting in high radiocarbon activities near the formation site of the deep water, and more depleted values (older radiocarbon ages) farther south as the radiocarbon decays away and the waters mix with more 
depleted abyssal waters (Fig. 5). In contrast, waters that upwell in the Southern Ocean are not at the surface long enough to re-equilibrate with the atmosphere before becoming Antarctic Intermediate or Antarctic Bottom Water (AAIW or AABW). As a result the deep water formed in this region is relatively depleted in radiocarbon and the surface reservoir ages in the Southern Ocean are the oldest observed today [Fig. 5; Key et al., 2004].
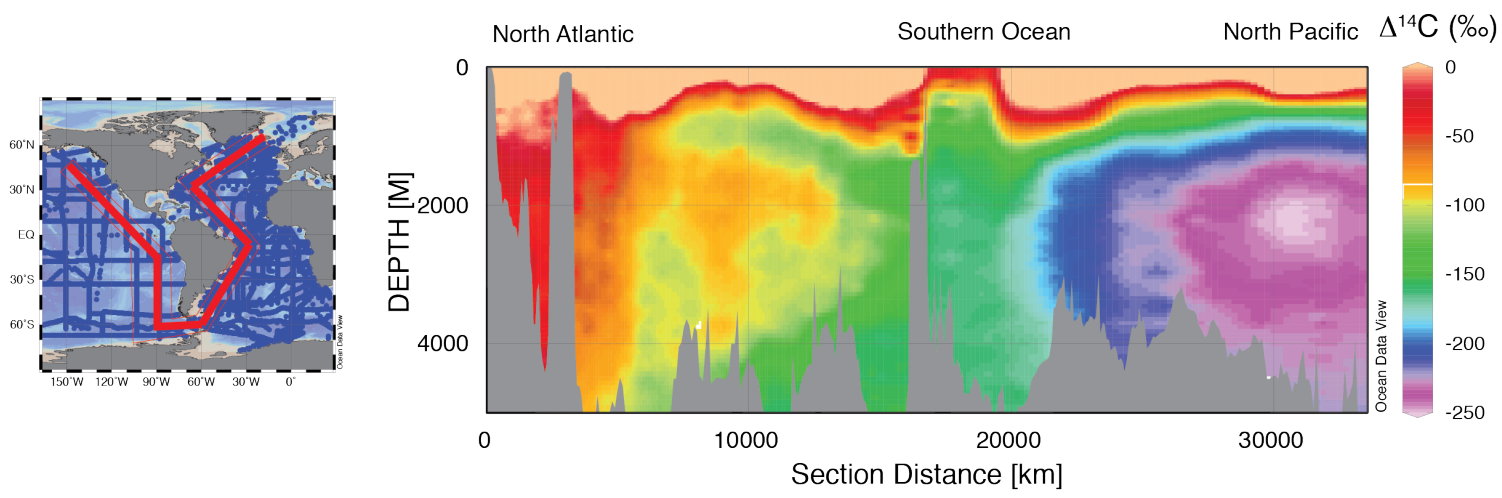

Figure 5. Radiocarbon of DIC $\left(\Delta^{14} C\right)$ plotted against depth along a section starting in the North Atlantic, going through the Drake Passage, and ending in the North Pacific. Nuclear bomb testing during the late 1950s and early 1960s resulted in a spike in atmospheric radiocarbon values. This signal (high values of $\Delta{ }^{14} \mathrm{C}$ ) has penetrated into the surface ocean. Deep water formation in the North Atlantic has propagated that signal into the deep ocean as well. Data is from the GLODAP database [Key et al., 2004] and plotted with Ocean Data View.

Ocean circulation changes have the potential to alter the distribution of radiocarbon in the ocean. Variations in air-sea gas exchange, especially in deep-water formation regions [e.g. Schmittner, 2003] would also affect the spatial distribution of radiocarbon in the ocean. These changes would also be reflected in the atmospheric radiocarbon record since the ocean contains $\sim 60$ times more carbon than the atmosphere. Thus reconstructing the distribution of radiocarbon in the atmosphere and ocean provides valuable information on circulation and carbon cycle changes over the past $40 \mathrm{ka}$, a time period that includes the end of the last glaciation, the deglaciation, and the Holocene.

\subsection{Reconstructing past radiocarbon activities of the atmosphere and ocean}

Atmospheric radiocarbon has varied through time due to changes in $(i){ }^{14} \mathrm{C}$ production caused by variations in the flux of incoming cosmic radiation and (ii) the 
partitioning of carbon in different carbon reservoirs ${ }^{1}$. The history of atmospheric radiocarbon can be reconstructed using a variety of different sources. From present to $\sim 12.59 \mathrm{ka}$, atmospheric radiocarbon can be continuously reconstructed from tree rings [Friedrich et al., 2004]. Tree ring records can be used before $12.59 \mathrm{ka}$, but their ages are more uncertain since their chronology does not extend into the present (i.e. it is "floating") and thus must be correlated to other climate records [e.g. Muscheler et al., 2008]. After $12.59 \mathrm{ka}$, the atmospheric radiocarbon record is mostly based on a combination of terrestrial speleothem and marine radiocarbon records. Both of these methods have greater uncertainties than the tree ring data since they record the radiocarbon in local DIC as opposed to the radiocarbon in the atmospheric carbon reservoir. In the case of the speleothem records, an assumption needs to be made about the dead carbon fraction incorporated into the speleothem from the radiocarbon-free bedrock [e.g. Hoffmann et al., 2010]. In the case of the marine radiocarbon records which are generated either from planktic foraminifera collected from sediment cores with an independent age scale or U-Th dated surface corals, an assumption needs to be made about the local reservoir age through time [e.g. Hughen et al., 2004b]. Both of these assumptions have the potential to greatly bias the atmospheric radiocarbon record.

A time series of atmospheric radiocarbon activity over the last $50 \mathrm{ka}$ has been published by an intercalibration group (IntCal) which compiled reliable data and assessed the various assumptions used in generating the atmospheric radiocarbon record. While many atmospheric radiocarbon records exist, for simplicity I use the IntCal09 atmospheric radiocarbon record [Reimer et al., 2009] throughout the thesis, with the caveat that the earliest half of the record (older than $12.55 \mathrm{ka}$ ) is a work in progress and is likely to change as more data become available. In particular, many atmospheric $\Delta^{14} \mathrm{C}$ reconstructions differ during Heinrich Stadial 1 between $\sim 18-15$ ka (e.g. Fig. 6). However, the size and nature of the potential changes to the atmospheric radiocarbon record are unlikely to affect the main conclusions presented in this thesis.

The ${ }^{14} \mathrm{C}$ activity of DIC at intermediate and abyssal depths in the ocean is reconstructed using carbonate-forming benthic organisms, most commonly with benthic

\footnotetext{
${ }^{1}$ Human activity has also altered the relative amount of radiocarbon in the atmosphere and oceans from fossil fuel burning ('the Suess effect', [Tans et al., 1979]) and nuclear bomb testing (see caption of Fig. 4).
} 
foraminifera or deep-sea corals (Fig. 3). The use of benthic foraminifera for reconstructing radiocarbon is complicated by the difficulty of determining an accurate age model for the sediment core from which the foraminifera are obtained. Foraminiferal tests in the sediment are also subject to the effects of bioturbation, which can create large biases in radiocarbon records [Peng and Broecker, 1984]. A more detailed discussion of some of the difficulties associated with the use of benthic foraminifera can be found in Chapter 4 of this thesis. The radiocarbon reconstructions generated for this thesis, however, utilize scleractinian deep-sea corals.

The aragonitic skeletons of deep-sea corals record the $\Delta^{14} \mathrm{C}$ of the DIC in the seawater in which they grow [Adkins et al., 2002]. Both the radiocarbon age of the coral and the amount of time elapsed since the death of the coral (the calendar age) are needed to calculate the $\Delta^{14} \mathrm{C}$ of seawater:

$$
\left.\Delta^{14} C_{\text {sea water }}=\left(\frac{e^{-14 \text { Cage/8033 }}}{e^{- \text {calage/ } / 8266}}-1\right) \times 1000 \quad \text { [Adkins and Boyle, } 1997\right] .
$$

The calendar age of a deep-sea coral skeleton can be determined with uranium-thorium ages (as described above). This independent age determination allows $\Delta^{14} \mathrm{C}$ to be calculated while avoiding reservoir age assumptions and issues associated with sediment bioturbation, which are two challenges that accompany $\Delta{ }^{14} \mathrm{C}$ estimates from benthicplanktonic foraminiferal pairs. Additionally, the skeletons of deep-sea corals can be more resistant than foraminifera to dissolution from corrosive waters, so samples can be found in areas where sediment contains a small amount of carbonate, such as in the Southern Ocean.

\subsection{Changes in atmospheric and oceanic radiocarbon over the last deglaciation}

A major feature of the atmospheric radiocarbon record is the long-term decrease from the end of the last glacial period to pre-industrial levels (Fig. 6). While decreased production from cosmogenic rays (reconstructed from paleomagnetic data and the accumulation of another cosmogenic nuclide, ${ }^{10} \mathrm{Be}$, in sediment and ice cores in Greenland) can explain more than half of the $\sim 800 \%$ decrease over the past $30 \mathrm{ky}$, it does not account for all of it, suggesting that there must have been a significant redistribution of carbon between the different reservoirs [Frank et al., 1997; Laj et al., 
2002; Hughen et al., 2004a; Muscheler et al., 2004]. Intriguingly, the decrease in atmospheric radiocarbon activity coincides with the rise in atmospheric $\mathrm{CO}_{2}$ concentration from the last glacial period to today (Fig. 6). This correlation has led to speculation that the upwelling of a long-isolated (and hence radiocarbon-depleted, or old) deep-ocean carbon reservoir caused both the rise in atmospheric $\mathrm{CO}_{2}$ and the fall in atmospheric radiocarbon [Marchitto et al., 2007]. Extreme radiocarbon depletions have been recorded at intermediate depths $(705 \mathrm{~m})$ off the coast of Baja California that coincide with the two-step rise in atmospheric $\mathrm{CO}_{2}$ (Fig. 6). Upwelling in the Southern Ocean has been hypothesized to be the source of this radiocarbon-depleted water via transport by Antarctic Intermediate Water (AAIW).

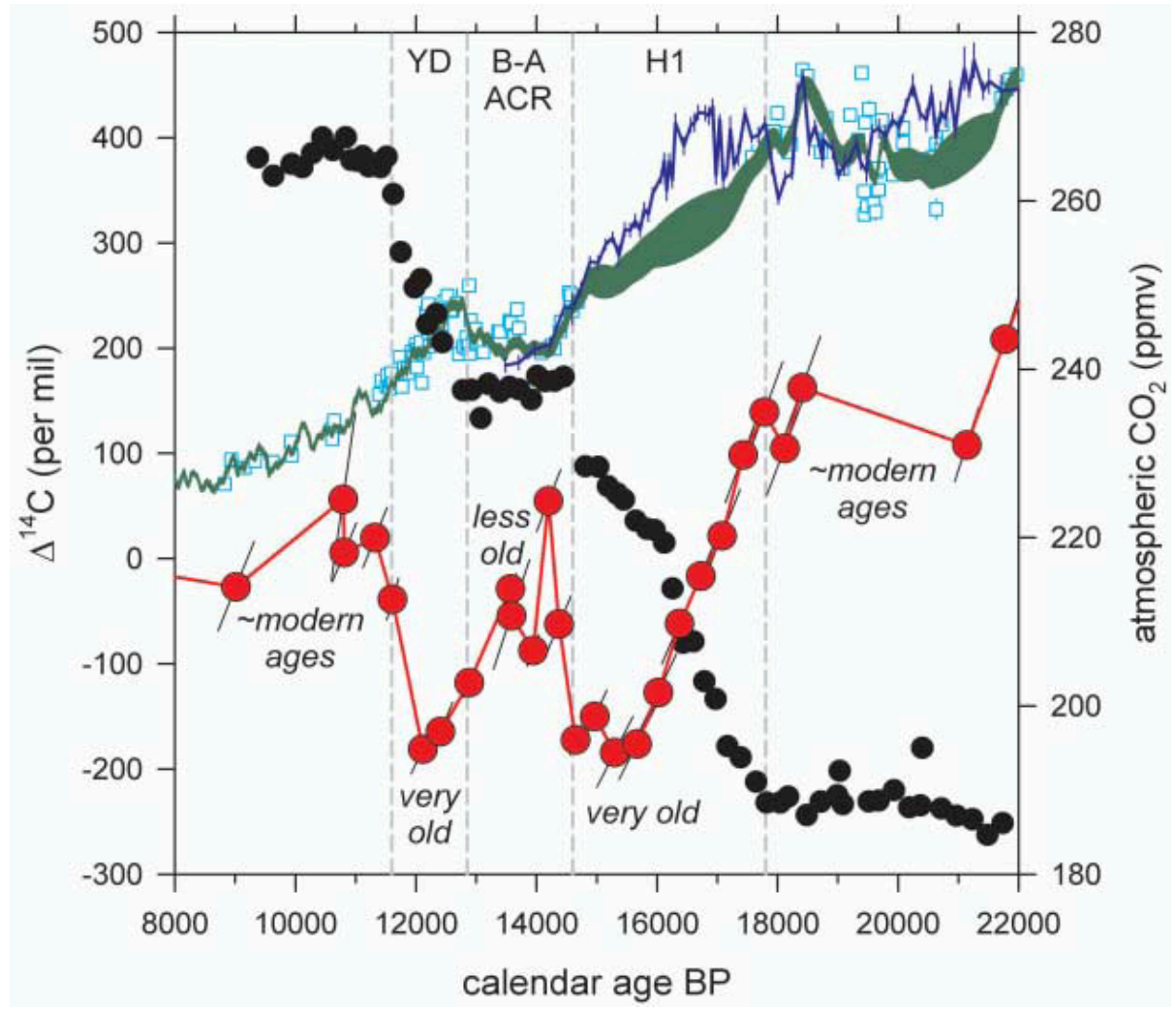

Figure 6. From Marchitto et al. [2007]. Record of the atmospheric $\mathrm{CO}_{2}$ rise over the last deglaciation (black circles) from bubbles in the Antarctic Dome $\mathbf{C}$ ice core [Monnin et al., 2001]. Three different atmospheric $\Delta^{14} \mathrm{C}$ reconstructions are shown for comparison: from U-Th dated surface corals (light blue squares, [Fairbanks et al., 2005]), from Cariaco basin planktic foraminifera (dark blue line, [Hughen et al., 2006]), and from the 2004 radiocarbon intercalibration compilation (IntCal04, dark green, [Reimer et al., 2004]). The red circles are a reconstruction of $\Delta^{14} \mathrm{C}$ of DIC at intermediate depths $(705 \mathrm{~m})$ in the North Pacific off Baja California [Marchitto et al., 2007]. 
This hypothesis is tested in Chapter 3 by combining U-series ages with radiocarbon measurements on 40 deep-sea corals collected from $318-1750 \mathrm{~m}$ water depth in the Drake Passage to reconstruct $\Delta^{14} \mathrm{C}$ in this region over the last $25 \mathrm{ka}$. Most of the corals come from depths corresponding today to Upper Circumpolar Deep Water (UCDW). UCDW in the modern ocean is entrained into the Antarctic Circumpolar Current from the deep waters of the Indian and Pacific Oceans, and thus can be identified by its relative maxima in phosphate and nitrate and a dissolved oxygen minimum [Callahan, 1972]. The radiocarbon reconstructions from corals corresponding to these depths show that the glacial equivalent of UCDW was more radiocarbon-depleted from the contemporaneous atmosphere during the last glacial period. This indicates that the carbon at these depths was more isolated from the atmosphere than it is today. In contrast, after the start of the Bolling-Allerod ( $\sim 14.6 \mathrm{ka})$, we find that radiocarbon in this depth range becomes more similar to values observed today, indicating a large increase in Southern Ocean ventilation at this time. Additionally, comparing our record with a radiocarbon record reconstructed from benthic foraminifera from a site in the South Atlantic bathed today by Lower Circumpolar Deep Water (LCDW) [Skinner et al., 2010] suggests the possibility that the glacial Southern Ocean was more stratified than today, and that this stratification was eroded away during the start of the deglaciation as $\mathrm{CO}_{2}$ began to rise. Thus, although such inference should be viewed as speculative at this point (e.g. $\Delta^{14} \mathrm{C}$ data from other locations in the Southern Ocean would be needed to assess the large-scale significance of existing data), our record is consistent with the idea of a more isolated carbon reservoir in the deep-ocean that was subsequently ventilated to the atmosphere during the deglaciation, and could potentially explain the drop in atmospheric $\Delta^{14} \mathrm{C}$ over Heinrich Stadial 1.

The rest of the corals analyzed from this region are from depths bathed today by Antarctic Intermediate Water (AAIW). The radiocarbon record of AAIW (or its glacial equivalent) does not show any large depletions of the magnitude reconstructed from the North Pacific [Marchitto et al., 2007], implying that AAIW could not be the source of these depletions. However, similar extreme depletions are observed at intermediate depths elsewhere [Stott et al., 2009; Bryan et al., 2010; Mangini et al., 2010; Thornalley et al., 2011], showing that the extreme depletions found off Baja California are not 
unique. Of particular interest is a record that was reconstructed from benthic foraminifera picked from sediment cores between 1237 - 2303 m water depth off Iceland [Thornalley et al., 2011]. This record shows high frequency and extreme radiocarbondepletions throughout the deglaciation that are interpreted as reductions in open-ocean convection in regions where deep waters are formed. In Chapter 4, deep-sea corals from the Reykjanes Ridge off Iceland (672 - $1550 \mathrm{~m}$ water depth) are used to reconstruct radiocarbon, and this radiocarbon record is compared with the nearby foraminifera record of Thornalley et al. [2011]. Based on the deep-sea coral radiocarbon record, it does not appear that the ventilation rate in the North Atlantic differed greatly from that observed today during the time span of our deep-sea coral data. However, our radiocarbon record does not provide conclusive evidence against a reduction in deep-water formation in the North Atlantic because of the ages of the corals and the sparse nature of the record. Thus, I turn to a different isotope system and paleoceanographic tracer-sedimentary ${ }^{231} \mathrm{~Pa} /{ }^{230} \mathrm{Th}$ - to investigate potential changes in the Atlantic meridional overturning circulation at important periods of deglacial climate change.

\subsection{Sedimentary ${ }^{231} \mathrm{~Pa}{ }^{230}$ Th as a paleoceanographic tracer}

${ }^{231} \mathrm{~Pa}$ and ${ }^{230} \mathrm{Th}$ are produced in seawater in a nearly constant ratio $(0.093)$ from the radioactive decay of ${ }^{235} \mathrm{U}$ and ${ }^{234} \mathrm{U}$ respectively [Yu et al., 1996]. As mentioned previously, both isotopes are particle reactive, but ${ }^{230} \mathrm{Th}$ is more readily adsorbed onto particles, resulting in an estimated shorter residence time $(\sim 20 \mathrm{y})$ for ${ }^{230} \mathrm{Th}$ than that for ${ }^{231} \mathrm{~Pa}(\sim 100 \mathrm{y})$ [Yu et al., 1996]. Since the residence time of ${ }^{231} \mathrm{~Pa}$ is the same order of magnitude as the time it takes modern-day North Atlantic Deep Water (NADW) to ventilate the deep Atlantic Ocean (Broecker 1979), a significant amount ( 45\%) of ${ }^{231} \mathrm{~Pa}$ is exported to the Southern Ocean [Fig. 7; Yu et al., 1996]. As a result, modern sediments in the North Atlantic have ${ }^{231} \mathrm{~Pa}{ }^{230} \mathrm{Th}$ ratios that are about half of the production ratio [Fig. 7; Yu et al., 1996]. Thus, if there was less (more) deepwater formation and export of NADW to the Southern Ocean, then the sedimentary ${ }^{231} \mathrm{~Pa} /{ }^{230} \mathrm{Th}$ ratio of Atlantic sediments would increase (decrease). Under such circumstances, the ${ }^{231} \mathrm{~Pa} /{ }^{230} \mathrm{Th}$ of these sediments (corrected for various effects such as radioactive decay since deposition) could 
be used as a proxy for NADW export and perhaps, by extension, of the strength of the Atlantic meridional overturning circulation (AMOC) in the past.

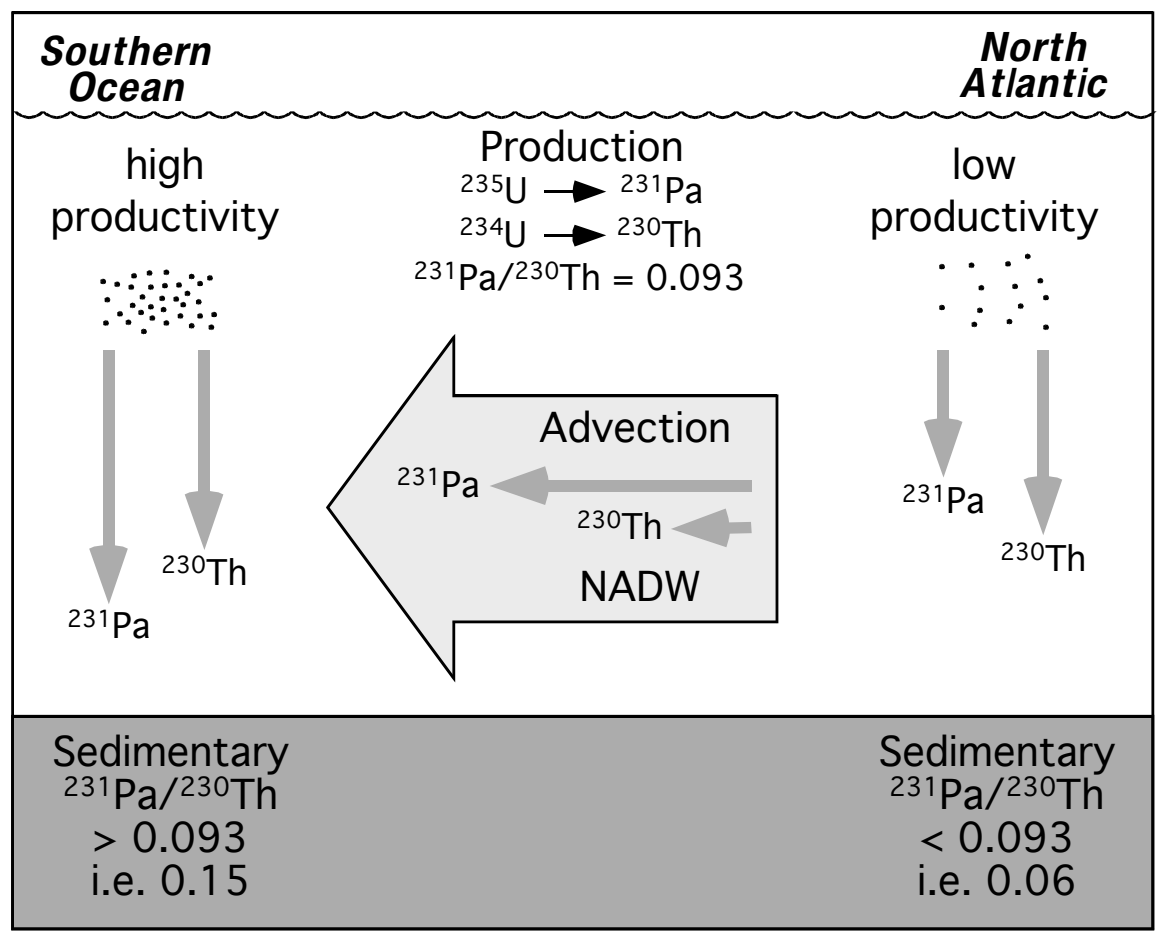

Figure 7. From Henderson and Anderson [2003]. Schematic of ${ }^{231} \mathrm{~Pa}$ and ${ }^{230} \mathrm{Th}$ behavior in the modern Atlantic Ocean. These nuclides are produced in a constant ratio $(0.093)$ in the ocean. ${ }^{230} \mathrm{Th}$ is readily scavenged out of the water column even in regions of low productivity. ${ }^{231} \mathrm{~Pa}$ is less particle-reactive and may be exported from the North Atlantic by circulation to be scavenged in regions of higher particle flux (or greater opal content), such as in the Southern Ocean. This results in core-top sedimentary ${ }^{231} \mathrm{~Pa} /{ }^{230} \mathrm{Th}$ ratios that are less than the production ratio in the North Atlantic and greater than the production ratio in the Southern Ocean.

Several inferences about the paleocirculation in the Atlantic Ocean have been made over the last decade from ${ }^{231} \mathrm{~Pa} /{ }^{230} \mathrm{Th}$ measurements on sediments. High ${ }^{231} \mathrm{~Pa} /{ }^{230} \mathrm{Th}$ ratios approaching the production ratio $(0.093)$ in Bermuda Rise sediments $(4550 \mathrm{~m})$ at the start of the deglaciation were interpreted as a shut-down of the AMOC [McManus et al., 2004]. Records from cores that come from different locations were used to form a depth profile of ${ }^{231} \mathrm{~Pa} /{ }^{230} \mathrm{Th}$ in the North Atlantic, which was interpreted as evidence for a vigorous intermediate water circulation throughout the deglacation [Gherardi et al., 2009]. More recently, relatively low ${ }^{231} \mathrm{~Pa} /{ }^{230} \mathrm{Th}$ ratios in the South Atlantic compared to the North Atlantic during the glacial period have been interpreted as a reversal in the flow direction of the deep circulation [Negre et al., 2010]. 
Although this proxy has been used widely, there are still significant uncertainties regarding the use of ${ }^{231} \mathrm{~Pa}^{230} \mathrm{Th}$ as a paleocirculation proxy [e.g. Keigwin and Boyle, 2008; Lippold et al., 2009]. In Chapter 5, I combine ${ }^{231} \mathrm{~Pa} /{ }^{230} \mathrm{Th}$ data for different time intervals of the geologic past with an estimate of the modern abyssal circulation in the Atlantic to determine how much these data need to be adjusted to make them consistent with the modern circulation. This calculation is conducted on ${ }^{231} \mathrm{~Pa} /{ }^{230} \mathrm{Th}$ ratios from three climatically important intervals: the Holocene, Heinrich Stadial 1, and the last glacial maximum. In contrast to prior work, our approach gives due regard to the uncertainties both in the behavior and in the distribution of these nuclides in the ocean during the past. Given these uncertainties, we find that most of the sediment ${ }^{231} \mathrm{~Pa} /{ }^{230} \mathrm{Th}$ data for each interval do not require significant adjustments to be consistent with the modern circulation. This result does not imply that the circulation must have been the same as modern during the three intervals, but rather that the uncertainties in applying ${ }^{231} \mathrm{~Pa} /{ }^{230} \mathrm{Th}$ as a paleocirculation proxy are currently large enough to warrant caution when interpreting the ${ }^{231} \mathrm{~Pa} /{ }^{230} \mathrm{Th}$ ratios.

\section{Thesis Structure}

In this thesis, I generate new data and combine data with models to describe and interpret paleoceanographic changes, in particular in the North Atlantic and the Southern Ocean, over the last deglaciation. I use radiocarbon and uranium series both as methods to date marine carbonates and as tracers for ocean circulation and carbon cycling. The thesis is organized as follows:

Chapter 2 describes an efficient method for preparing graphite targets for radiocarbon dating. This method is applied to conduct an age survey of deep-sea corals from the Drake Passage.

Chapter 3 presents radiocarbon reconstructions from U-series dated deep-sea corals from water depths presently dominated by Antarctic Intermediate Water and Upper Circumpolar Deep Water in the Drake Passage. These records suggest significant changes in stratification and ventilation during the last deglaciation.

Chapter 4 presents a radiocarbon reconstruction from U-series dated deep-sea corals from the Reykjanes Ridge off Iceland in the North Atlantic. This record suggests that the 
ventilation of the North Atlantic during the Bolling-Allerod (at $~ 14.5 \mathrm{ka}$ ) was similar to today.

Chapter 5 uses an inverse modeling technique to quantitatively assess the consistency of sedimentary ${ }^{231} \mathrm{~Pa} /{ }^{230} \mathrm{Th}$ ratios from the Holocene, Heinrich Stadial 1, and the Last Glacial Maximum with the modern circulation. This approach provides a test of the hypothesis that changes in the Atlantic meridional overturning circulation are required to explain the ${ }^{231} \mathrm{~Pa} /{ }^{230} \mathrm{Th}$ records, given uncertainties in the spatial distribution and behavior of these two nuclides.

Chapter 6 summarizes the conclusions of the previous chapters and elaborates on future research directions.

Appendix A1 is a data table of the reconnaissance radiocarbon ages of the deep-sea corals from Chapter 2.

Appendix A2 is the supplementary information from Chapter 3. It also contains uranium series and radiocarbon data tables.

Appendix A3 is a data table of the reconnaissance radiocarbon ages of the suite of corals collected from the Reykjanes Ridge. In addition it includes a data table of the uranium series and radiocarbon measurements made on a subset of these corals.

Appendix A4 is supplementary information for Chapter 5. It includes the finite difference forms of the equations used to constrain the modern circulation and describes our model of scavenging of ${ }^{231} \mathrm{~Pa}$ by particles. It also includes supplementary figures $\mathrm{S} 1$ to S6.

Appendix A5 is a data table of the reconnaissance radiocarbon ages of a suite of corals collected from the Eastern Equatorial Pacific near Galapagos. These corals were not used in radiocarbon reconstructions since the age survey did not show any deglacial-aged corals. Accordingly, data from these corals are not discussed in this thesis. Also included in the appendix are uranium series data that were measured on five of these corals. 


\section{References}

Adkins, J. F., and E. A. Boyle (1997), Changing atmospheric Delta C-14 and the record of deep water paleoventilation ages, Paleoceanography, 12(3), 337-344.

Adkins, J. F., et al. (2002), Radiocarbon dating of deep-sea corals, Radiocarbon, 44(2), 567-580.

Andersen, M. B., et al. (2008), High-precision U-series measurements of more than 500,000 year old fossil corals, Earth and Planetary Science Letters, 265(1-2), 229-245.

Anderson, R. F., et al. (1983), Removal of 230Th and 231Pa from the open ocean, Earth and Planetary Science Letters, 62(1), 7-23.

Bacon, M. P., and R. F. Anderson (1982), Distribution of Thorium Isotopes between Dissolved and Particulate Forms in the Deep-Sea, Journal of Geophysical Research-Oceans and Atmospheres, 87(Nc3), 2045-2056.

Bard, E. (1988), Correction of Accelerator Mass Spectrometry 14C Ages Measured in Planktonic Foraminifera: Paleoceanographic Implications, Paleoceanography, 3.

Broecker, W. S. (1982), Ocean chemistry during glacial time, Geochimica Et Cosmochimica Acta, 46(10), 1689-1705.

Bryan, S. P., et al. (2010), The release of (14)C-depleted carbon from the deep ocean during the last deglaciation: Evidence from the Arabian Sea, Earth and Planetary Science Letters, 298(1-2), 10.1016/j.eps1.2010.08.025, 244-254.

Callahan, J. E. (1972), The structure and circulation of deep water in the Antarctic, Deep Sea Research and Oceanographic Abstracts, 19(8), 563-575.

Cheng, H., et al. (2000a), U-Th dating of deep-sea corals, Geochimica Et Cosmochimica Acta, 64(1-4), 2401-2416.

Cheng, H., et al. (2000b), The half-lives of uranium-234 and thorium-230, Chemical Geology, 169(1-2), 17-33.

Cochran, J. K., et al. (1987), Natural and anthropogenic radionuclide distributions in the Northwest Atlantic Ocean, Earth and Planetary Science Letters, 84(2-3), 135152.

Edwards, R. L., et al. (2003), Uranium-series dating of Marine and Lacustrine Carbonates, Reviews in Mineralogy and Geochemistry, 52, 363-405.

Edwards, R. L., et al. (1997), Protactinium-231 dating of carbonates by thermal ionization mass spectrometry: Implications for quaternary climate change, Science, 276(5313), 782-786.

EPICA (2006), One-to-one coupling of glacial climate variability in Greenland and Antarctica, Nature, 444(7116), Doi 10.1038/Nature05301, 195-198.

Fairbanks, R. G., et al. (2005), Radiocarbon calibration curve spanning 0 to 50,000 years BP based on paired Th-230/U-234/U-238 and C-14 dates on pristine corals, Quaternary Science Reviews, 24(16-17), 10.1016/j.quascirev.2005.04.007, 17811796.

Frank, M., et al. (1997), A $200 \mathrm{kyr}$ record of cosmogenic radionuclide production rate and geomagnetic field intensity from Be-10 in globally stacked deep-sea sediments, Earth and Planetary Science Letters, 149(1-4), 121-129. 
Frank, N., et al. (2004), Eastern North Atlantic deep-sea corals: tracing upper intermediate water Delta C-14 during the Holocene, Earth and Planetary Science Letters, 219(3-4), 10.1016/s0012-821x(03)00721-0, 297-309.

Friedrich, M., et al. (2004), The 12,460-year Hohenheim oak and pine tree-ring chronology from central Europe - A unique annual record for radiocarbon calibration and paleoenvironment reconstructions, Radiocarbon, 46(3), 11111122.

Gherardi, J. M., et al. (2009), Glacial-interglacial circulation changes inferred from Pa231/Th-230 sedimentary record in the North Atlantic region, Paleoceanography, 24.

Godwin, H. (1962), Half-life of Radiocarbon, Nature, 195(4845), 984-984.

Goldstein, S. J., et al. (2001), Uranium-series and radiocarbon geochronology of deep-sea corals: implications for Southern Ocean ventilation rates and the oceanic carbon cycle, Earth and Planetary Science Letters, 193(1-2), 167-182.

Guo, L., et al. (1995), Distribution of dissolved and particulate 230Th and 232Th in seawater from the Gulf of Mexico and off Cape Hatteras as measured by SIMS, Earth and Planetary Science Letters, 133(1-2), 117-128.

Henderson, G. M. (2002), Seawater (234U/238U) during the last 800 thousand years, Earth and Planetary Science Letters, 199(1-2), 97-110.

Henderson, G. M., and R. F. Anderson (2003), The U-series toolbox for paleoceanography, Reviews in Mineralogy and Geochemistry, 53, 493-531.

Hoffmann, D. L., et al. (2010), Towards radiocarbon calibration beyond 28 ka using speleothems from the Bahamas, Earth and Planetary Science Letters, 289(1-2), 10.1016/j.epsl.2009.10.004, 1-10.

Hughen, K., et al. (2006), Marine-derived C-14 calibration and activity record for the past 50,000 years updated from the Cariaco Basin, Quaternary Science Reviews, 25(23-24), 10.1016/j.quascirev.2006.03.014, 3216-3227.

Hughen, K., et al. (2004a), C-14 activity and global carbon cycle changes over the past 50,000 years, Science, 303(5655), 202-207.

Hughen, K. A., et al. (2004b), Marine04 marine radiocarbon age calibration, 0-26 cal kyr BP, Radiocarbon, 46(3), 1059-1086.

Kano, A., et al. (2007), Age constraints on the origin and growth history of a deep-water coral mound in the northeast Atlantic drilled during Integrated Ocean Drilling Program Expedition 307, Geology, 35(11), 10.1130/G23917A.1, 1051-1054.

Keigwin, L. D., and E. A. Boyle (2008), Did North Atlantic overturning halt 17,000 years ago?, Paleoceanography, 23(1).

Key, R. M., et al. (2004), A global ocean carbon climatology: Results from Global Data Analysis Project (GLODAP), Global Biogeochemical Cycles, 18(4), Gb4031 Artn gb4031.

Kump, L. R. (2002), Reducing uncertainty about carbon dioxide as a climate driver, Nature, 419(6903), 10.1038/nature01087, 188-190.

Laj, C., et al. (2002), Geomagnetic field intensity, North Atlantic Deep Water circulation and atmospheric Delta C-14 during the last $50 \mathrm{kyr}$, Earth and Planetary Science Letters, 200(1-2), Pii S0012-821x(02)00618-0, 177-190. 
Lemieux-Dudon, B., et al. (2010), Consistent dating for Antarctic and Greenland ice cores, Quaternary Science Reviews, 29(1-2), 10.1016/j.quascirev.2009.11.010, 820.

Lippold, J., et al. (2009), Does sedimentary Pa-231/Th-230 from the Bermuda Rise monitor past Atlantic Meridional Overturning Circulation?, Geophysical Research Letters, 36, L12601 10.1029/2009g1038068.

Luthi, D., et al. (2008), High-resolution carbon dioxide concentration record 650,000800,000 years before present, Nature, 453(7193), 379-382.

Mangini, A., et al. (2010), Deep sea corals off Brazil verify a poorly ventilated Southern Pacific Ocean during $\mathrm{H} 2, \mathrm{H} 1$ and the Younger Dryas, Earth and Planetary Science Letters, 293(3-4), 269-276.

Marchitto, T. M., et al. (2007), Marine Radiocarbon Evidence for the Mechanism for deglacial atmospheric CO2 rise, Science, 316, 1456-1459.

McIntyre, C. P., et al. (in press), Rapid radiocarbon (14C) analysis of coral and carbonate samples using a continuous-flow accelerator mass spectrometry (CFAMS) system, Paleoceanography, doi:10.1029/2011PA002174.

McManus, J. F., et al. (2004), Collapse and rapid resumption of Atlantic meridional circulation linked to deglacial climate changes, Nature, 428, 824-837.

Monnin, E., et al. (2001), Atmospheric CO2 concentrations over the last glacial termination, Science, 291(5501), 112-114.

Moore, W. S. (1981), The Thorium Isotope Content of Ocean Water, Earth and Planetary Science Letters, 53(3), 419-426.

Moran, S. B., et al. (1995), High-precision Th-230 and Th-232 in the Norwegian Sea and Denmark by thermal ionization mass spectrometry, Geophysical Research Letters, 22(19), 2589-2592.

Muscheler, R., et al. (2008), Tree rings and ice cores reveal C-14 calibration uncertainties during the Younger Dryas, Nature Geoscience, 1(4), 10.1038/ngeo128, 263-267.

Muscheler, R., et al. (2004), Changes in the carbon cycle during the last deglaciation as indicated by the comparison of Be-10 and C-14 records, Earth and Planetary Science Letters, 219(3-4), 10.1016/s0012-821x(03)00722-2, 325-340.

Negre, C., et al. (2010), Reversed flow of Atlantic deep water during the Last Glacial Maximum, Nature, 468, 84-88.

NGRIP (2004), High-resolution record of Northern Hemisphere climate extending into the last interglacial period, Nature, 431(7005), 10.1038/nature02805, 147-151.

Nozaki, Y., et al. (1987), Scavenging of Thorium in the Ocean, Journal of Geophysical Research-Oceans, 92(C1), 772-778.

Peng, T.-H., and W. S. Broecker (1984), The impacts of bioturbation on the age difference between benthic and planktonic foraminifera in deep sea sediments, Nuclear Instruments and Methods in Physics Research Section B: Beam Interactions with Materials and Atoms, 5(2), 346-352.

Petit, J. R., et al. (1999), Climate and atmospheric history of the past 420,000 years from the Vostok ice core, Antarctica, Nature, 399(6735), 429-436.

Reimer, P. J., et al. (2004), IntCal04 Terrestrial Radiocarbon Age Calibration, 0-26 cal kyr BP, Radiocarbon, 46(3), 1029-1059.

Reimer, P. J., et al. (2009), IntCal09 and Marine09 Radiocarbon age calibration curves, 0-50,000 years cal BP, Radiocarbon, 51(4), 1111-1150. 
Robert, J., et al. (1969), Mesure de la periode du protactinium-231 par microcalorimetrie., Radiochim Acta, 11, 104-108.

Roberts, M. L., et al. (2009), A High-performance 14-C accelerator mass spectrometry system, paper presented at 20th International Radiocarbon Conference, Radiocarbon, Kona, HI.

Robinson, L. F., et al. (2005), Radiocarbon variability in the Western North Atlantic during the last deglaciation, Science, 310, 1469-1473.

Robinson, L. F., et al. (2006), Primary U-distribution in scleractinian corals and its implications for U-series dating, Geochemistry Geophysics Geosystems, 7, Q05022, doi:05010.01029/02005GC001138.

Schmittner, A. (2003), Southern Ocean sea ice and radiocarbon ages of glacial bottom waters, Earth and Planetary Science Letters, 213(1-2), 10.1016/s0012$821 \times(03) 00291-7,53-62$.

Skinner, L. C., et al. (2010), Ventilation of the Deep Southern Ocean and Deglacial CO2 Rise, Science, 328(5982), 1147-1151.

Stirling, C. H., et al. (2001), Orbital forcing of the marine isotope stage 9 interglacial, Science, 291(5502), 290-293.

Stott, L., et al. (2009), Radiocarbon age anomaly at intermediate water depth in the Pacific Ocean during the last deglaciation, Paleoceanography, 24, -.

Stuiver, M., et al. (1986), Radiocarbon Age Calibration of Marine Samples Back to 9000 Cal Yr Bp, Radiocarbon, 28(2B), 980-1021.

Tans, P. P., et al. (1979), Natural atmospheric 14-C variation and the Suess effect, Nature, 280(5725), 826-828.

Taylor, S. R., and S. M. McLennan (1985), The continental crust: its composition and evolution, 311 pp., Blackwell, Oxford.

Thornalley, D. J. R., et al. (2011), The Deglacial Evolution of North Atlantic Deep Convection, Science, 331(6014), 10.1126/science.1196812, 202-205.

Wang, Y. J., et al. (2001), A high-resolution absolute-dated Late Pleistocene monsoon record from Hulu Cave, China, Science, 294(5550), 2345-2348.

Yu, E. F., et al. (1996), Similar rates of modern and last-glacial ocean thermohaline circulation inferred from radiochemical data, Nature, 379(6567), 689-694. 


\section{Chapter 2. Reconnaissance dating: A new radiocarbon method applied to assessing the temporal distribution of Southern Ocean deep-sea corals}

Reproduced by permission of Elsevier.

Burke, A., Robinson, L.F., McNichol, A.P., Jenkins, W.J., Scanlon, K.M., and Gerlach, D.S. (2010), Reconnaissance dating: A new radiocarbon method applied to assessing the temporal distribution of Southern Ocean deep-sea corals, Deep-Sea Research Part I-

Oceanographic Research Papers, 57(11), Doi 10.1016/J.Dsr.2010.07.010, 1510-1520. 


\title{
Reconnaissance dating: A new radiocarbon method applied to assessing the temporal distribution of Southern Ocean deep-sea corals ${ }^{\text {th }}$
}

\author{
Andrea Burke ${ }^{\mathrm{a}, *}$, Laura F. Robinson ${ }^{\mathrm{b}}$, Ann P. McNichol ${ }^{\mathrm{c}}$, William J. Jenkins ${ }^{\mathrm{b}}$, \\ Kathryn M. Scanlon ${ }^{\mathrm{d}}$, Dana S. Gerlach ${ }^{\mathrm{c}}$
}

${ }^{\text {a } M I T / W H O I ~ J o i n t ~ P r o g r a m, ~ D e p a r t m e n t ~ o f ~ M a r i n e ~ G e o l o g y ~ a n d ~ G e o p h y s i c s, ~ W o o d s ~ H o l e ~ O c e a n o g r a p h i c ~ I n s t i t u t i o n, ~} 360$ Woods Hole Road, MS\#24, Woods Hole, MA 02543, USA ${ }^{\mathrm{b}}$ Department of Marine Chemistry and Geochemistry, Woods Hole Oceanographic Institution, 360 Woods Hole Road, MS\#25, Woods Hole, MA 02543, USA

${ }^{\mathrm{c}}$ Department of Marine Geology and Geophysics, Woods Hole Oceanographic Institution, 360 Woods Hole Road, MS\#8, Woods Hole, MA 02543, USA

${ }^{\mathrm{d}}$ US Geological Survey, 384 Woods Hole Road, Woods Hole, MA 02543, USA

\section{A R T I C L E I N F O}

\section{Article history:}

Received 9 February 2010

Received in revised form

15 July 2010

Accepted 21 July 2010

Available online 3 August 2010

Keywords:

Deep-sea corals

Age survey

Radiocarbon dating

Biogeography

\begin{abstract}
A B S T R A C T
We have developed a rapid 'reconnaissance' method of preparing graphite for ${ }^{14} \mathrm{C} /{ }^{12} \mathrm{C}$ analysis. Carbonate $(\sim 15 \mathrm{mg})$ is combusted using an elemental analyzer and the resulting $\mathrm{CO}_{2}$ is converted to graphite using a sealed tube zinc reduction method. Over $85 \%$ ( $n=45$ replicates on twenty-one individual corals) of reconnaissance ages measured on corals ranging in age from 500 to 33,000 radiocarbon years (Ryr) are within two standard deviations of ages generated using standard hydrolysis methods on the same corals, and all reconnaissance ages are within 300 Ryr of the standard hydrolysis ages. Replicate measurements on three individual aragonitic corals yielded ages of $1076 \pm 35 \mathrm{Ryr}$ (standard deviation; $n=5), 10,739 \pm 47 \operatorname{Ryr}(n=8)$, and 40,146 $\pm 3500 \operatorname{Ryr}(n=9)$. No systematic biases were found using different cleaning methods or variable sample sizes. Analysis of ${ }^{13} \mathrm{C} /{ }^{12} \mathrm{C}$ was made concurrently with the ${ }^{14} \mathrm{C} /{ }^{12} \mathrm{C}$ measurement to correct for natural fractionation and for fractionation during sample processing and analysis. This technique provides a new, rapid method for making accurate, percent-level ${ }^{14} \mathrm{C} /{ }^{12} \mathrm{C}$ analyses that may be used to establish the rates and chronology of earth system processes where survey-type modes of age estimation are desirable. For example, applications may include creation of sediment core-top maps, preliminary age models for sediment cores, and growth rate studies of marine organisms such as corals or mollusks. We applied the reconnaissance method to more than 100 solitary deep-sea corals collected in the Drake Passage in the Southern Ocean to investigate their temporal and spatial distribution. The corals used in this study are part of a larger sample set, and the subset that was dated was chosen based on species as opposed to preservation state, so as to exclude obvious temporal biases. Similar to studies in other regions, the distribution of deep-sea corals is not constant through time across the Drake Passage. Most of the corals from the Burdwood Bank (continental shelf of Argentina) have ages ranging between 0 and 2500 calendar years, whereas most of the corals from the Sars Seamount in the Drake Passage have ages between 10,000 and 12,500 calendar years. Such differences may be caused in part by sampling biases, but may also be caused by changes in larval transport, nutrient supply, or other environmental pressures.
\end{abstract}

(c) 2010 Elsevier Ltd. All rights reserved.

\section{Introduction}

Radiocarbon provides a tool for dating carbon-containing materials from the last 50,000 years, and is used in a wide range of fields to trace the rate, mechanisms, and pathways of processes

\footnotetext{
Reference to any specific commercial product by trade name, trademark, manufacturer, or otherwise does not necessarily constitute or imply its endorsement, recommendation, or favoring by the United States Government or any agency thereof. * Corresponding author. Tel.: +1 508289 3692; fax: +508 4572150.

E-mail addresses: aburke@whoi.edu (A. Burke), lrobinson@whoi.edu (L.F. Robinson), amcnichol@whoi.edu (A.P. McNichol), wjenkins@whoi.edu (W.J. Jenkins), kscanlon@usgs.gov (K.M. Scanlon), dgerlach@whoi.edu (D.S. Gerlach).
}

0967-0637/\$-see front matter ๔ 2010 Elsevier Ltd. All rights reserved. doi:10.1016/j.dsr.2010.07.010 in which carbon is involved. While the details of sample preparation for accelerator mass spectrometry (AMS) vary, all methods convert samples to $\mathrm{CO}_{2}$, and then in most cases reduce the $\mathrm{CO}_{2}$ to filamentous carbon, commonly referred to as graphite, before analysis (e.g., Vogel et al., 1984). Despite its wide application, preparation and analysis of the ${ }^{14} \mathrm{C} /{ }^{12} \mathrm{C}$ ratios remain a time consuming and costly process. We report here a new method combining use of an elemental analyzer with sealed tube zinc reduction (Jull et al., 1986; Slota et al., 1987; Vogel, 1992; Ognibene et al., 2003; Xu et al., 2007) with the aim of rapid and less labor-intensive graphite preparation. We test this method on a set of modern and fossil deep-sea scleractinian corals.

Deep-sea corals are found in all of the major ocean basins and grow at a large range of depths (0-6200 m) (Freiwald, 2003). 
Coral skeletons produce readily dateable, high-resolution chemical archives of their lives. The skeletons are preserved when the corals die, allowing us to reconstruct past seawater compositions and to explore population dynamics over long timescales. Individual corals can live from hundreds (Adkins et al., 2004) to thousands of years (Roark et al., 2009) and combining analyses from multiple samples can provide a record of seawater changes over even longer timescales (Adkins et al., 1998).

Some deep-sea corals, such as Lophelia pertusa, are colonial and form carbonate mounds (Freiwald, 2003). Cores drilled into these mounds can be dated at selected depths and the age can be interpolated between these depths to produce a preliminary chronology (e.g., Frank et al., 2004; Kano et al., 2007). However, for solitary corals, such as Desmophyllum dianthus, there is no a priori age information so each individual must be dated separately. Since hundreds or even thousands of corals can be collected from a single site, there is a need for an efficient method of dating large numbers of these corals. Not only are such age surveys useful for selecting samples for paleoceanographic studies, they can also address how coral populations have changed through time (e.g., Schröder-Ritzrau et al., 2005; Robinson et al., 2007). The age distributions of fossil corals provide unique biogeographical information that may help clarify how and why deep-sea coral ecosystems have changed over geologic and recent history. For example, $\sim 100$ deep-sea corals collected from the New England Seamounts reveal that most of the corals grew during glacial conditions at times of abrupt climate change, indicating a potential connection between ocean circulation changes and coral growth (Robinson et al., 2007). In a similar fashion, the ages of $\sim 40$ deep-sea corals collected from the seafloor in the Northeast Atlantic appear to exhibit a latitudinal dependence. Corals from north of $50^{\circ} \mathrm{N}$ are all from the Holocene, but corals from lower latitudes (from seamounts off Northwest Africa and from the Mediterranean) have a broader age distribution, with apparently continuous coral growth for the past 53.5 thousand years (ky) (Schröder-Ritzrau et al., 2005). Changes in ocean circulation may provide a control on the distributions of these communities, perhaps through availability of detrital food or other environmental parameters.

The Robinson et al. (2007) and Schröder-Ritzrau et al. (2005) age survey studies utilized high-precision U-Th analyses, whereby the corals were dated from the ingrowth of ${ }^{230} \mathrm{Th}$ from ${ }^{234} \mathrm{U}$ originally incorporated into the coral skeleton. Scleractinian deepsea corals are suited to this dating method because of their high concentrations $(\sim 3 \mathrm{ppm})$ of uranium and relatively low initial ${ }^{230}$ Th concentrations (Cheng et al., 2000). Precise measurements can provide ages up to and beyond half a million years (Cheng et al., 2000; Andersen et al., 2008). The samples dated in these age survey studies represent significant effort because of the need to perform extensive cleaning, the use of relatively large samples (up to $1 \mathrm{~g}$ ), the use of radioactive spikes, and analysis by either multicollector inductively coupled plasma mass spectrometry (MC-ICPMS) or thermal ionization mass spectrometry (TIMS). Adkins and Boyle (1999) developed a more efficient age-screening method for deep-sea corals (over an age range of $130 \mathrm{ky}$ ) using ${ }^{238} \mathrm{U}$ and ${ }^{230} \mathrm{Th}$ measured with ICP-MS. Ages from U-Th analyses, however, can be biased by diagenesis and the contribution of initial ${ }^{230} \mathrm{Th}$. Furthermore, U-Th based methods are not well suited for dating calcitic gorgonian corals because of severe diagenesis (Robinson et al., 2007).

Alternatively, deep-sea corals can be dated using radiocarbon (e.g., Roark et al., 2009). This approach is less time consuming than using U-Th analyses, and requires a smaller amount of sample. However, it is necessary to convert radiocarbon age to calendar age because of the varying atmospheric ${ }^{14} \mathrm{C}$ content through time. For marine samples, this conversion requires an assumption about the 'reservoir age', or the offset in age between organisms that grow in the atmosphere and those that grow in a different carbon reservoir, such as the ocean (Stuiver et al., 1986). Unconstrained temporal and geographic variations in the reservoir age introduce an additional source of uncertainty, and could potentially bias results by hundreds of years (e.g., Cao et al., 2007). However, even with those uncertainties, radiocarbon dating provides a sufficient method for generating suitable dates for age surveys.

In this study, we focus on improving the efficiency of radiocarbon measurements by using a commercial elemental analyzer to combust carbonate before graphitizing, and by measuring $\delta^{13} \mathrm{C}$ of the graphite concurrently on the accelerator mass spectrometer. We test and apply the method to a suite of corals collected from the Drake Passage region of the Southern Ocean. As the Drake Passage is a conduit of the Antarctic Circumpolar Current, corals collected from this region are well suited to address questions regarding Southern Ocean paleoceanography, biogeography, and paleo-ecology.

\section{Sample selection}

Solitary scleractinian corals (Fig. 1) were collected with Blake trawls, otter trawls, and dredges during two cruises to the Southern Ocean (LMG06-05: R/V Laurence M. Gould, May 13-June 14, 2006, and NBP08-05: R/V Nathaniel B. Palmer, April 18-May 25, 2008). The trawls sampled about 2000 horizontal meters of the seafloor with each deployment, compared to only 500 horizontal meters with dredges. Vertical depth ranges did not exceed $120 \mathrm{~m}$. Depths given in Table 1 are the averages of the depths over which the dredge or trawl was on the seafloor.

For this initial study, 101 corals were dated using the reconnaissance method, out of a sample set of more than 6000 solitary corals. Approximately half of the samples collected from LMG06-05 were selected for dating. Samples from NBP08-05 were labeled at sea according to their preservation appearance: pristine, normal, and corroded. To avoid temporal biases relating to the appearance of coral preservation, we selected corals by species, not by location or preservation. We chose to analyze all of the $D$. dianthus (formerly known as $D$. cristigalli) collected during cruise NBP08-05, excluding fragments (incomplete coral skeletons) at sites where multiple fragments were collected. In total, we analyzed seventy-six corals (Balanophyllia malouinensis, Flabellum curvatum, and $D$. dianthus) from five stations on the Argentine continental shelf (Burdwood Bank), twenty-four $D$. dianthus from eight stations in the Drake Passage, and one F. curvatum from the northern tip of the Antarctic Peninsula (Fig. 2, Table 1). Nineteen of these corals were also dated using the standard hydrolysis protocol (Section 3.2) in order to compare the two methods. Two previously radiocarbon-dated corals were reconnaissance dated to ensure a large age range for accuracy
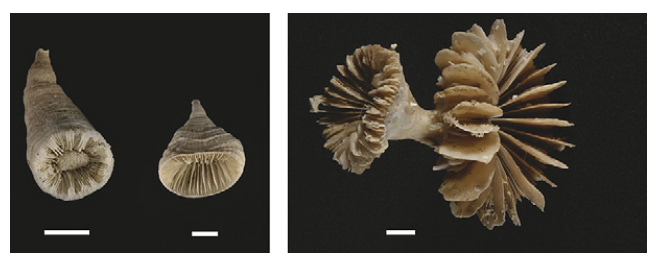

Fig. 1. Deep-Sea Scleractinian Corals. (left to right) Fossil Balanophyllia malouinensis, Flabellum curvatum, and two individual Desmophyllum dianthus corals connected to one another, where one coral grew on the other one. White scale bars correspond to $1 \mathrm{~cm}$. Photos by Dann Blackwood, USGS. 
Table 1

Coral collection locations.

\begin{tabular}{|c|c|c|c|c|c|c|c|c|}
\hline \multirow[t]{2}{*}{ Cruise } & \multirow[t]{2}{*}{ Station } & \multirow{2}{*}{$\begin{array}{l}\text { Latitude } \\
\left({ }^{\circ}\right)\end{array}$} & \multirow{2}{*}{$\begin{array}{l}\text { Longitude } \\
\left({ }^{\circ} \mathrm{E}\right)\end{array}$} & \multirow{2}{*}{$\begin{array}{l}\text { Water depth } \\
\text { (m) }\end{array}$} & \multirow[t]{2}{*}{ Location } & \multicolumn{3}{|c|}{ Specimens analyzed } \\
\hline & & & & & & B. malouinensis & D. dianthus & F. curvatum \\
\hline LMG06-05 & 21 & -63.147 & -57.124 & 146 & Antarctic Peninsula & - & - & 1 \\
\hline LMG06-05 & 2 & -53.786 & -64.887 & 442 & Burdwood Bank & 2 & - & - \\
\hline LMG06-05 & 3 & -53.770 & -61.860 & 120 & Burdwood Bank & 3 & - & - \\
\hline LMG06-05 & 5 & -53.763 & -59.622 & 854 & Burdwood Bank & 11 & _- & 9 \\
\hline LMG06-05 & 9 & -54.485 & -62.214 & 318 & Burdwood Bank & 4 & - & 1 \\
\hline NBP08-05 & ТВ04 & -54.734 & -62.216 & 816 & Burdwood Bank & 2 & 44 & - \\
\hline NBP08-05 & DR23 & -60.182 & -57.834 & 819 & Shackleton Fracture Zone & - & 2 & - \\
\hline NBP08-05 & DR27 & -60.547 & -65.949 & 1134 & Interim Seamount & - & 1 & - \\
\hline NBP08-05 & DR34 & -59.733 & -68.743 & 869 & Sars Seamount & - & 2 & - \\
\hline NBP08-05 & DR35 & -59.723 & -68.881 & 695 & Sars Seamount & - & 13 & - \\
\hline NBP08-05 & DR36 & -59.707 & -69.008 & 1750 & Sars Seamount & - & 3 & - \\
\hline NBP08-05 & DR38 & -59.743 & -68.898 & 978 & Sars Seamount & - & 1 & - \\
\hline NBP08-05 & DR39 & -59.729 & -68.901 & 798 & Sars Seamount & - & 1 & - \\
\hline NBP08-05 & DR40 & -59.732 & -68.933 & 1323 & Sars Seamount & - & 1 & - \\
\hline
\end{tabular}

a
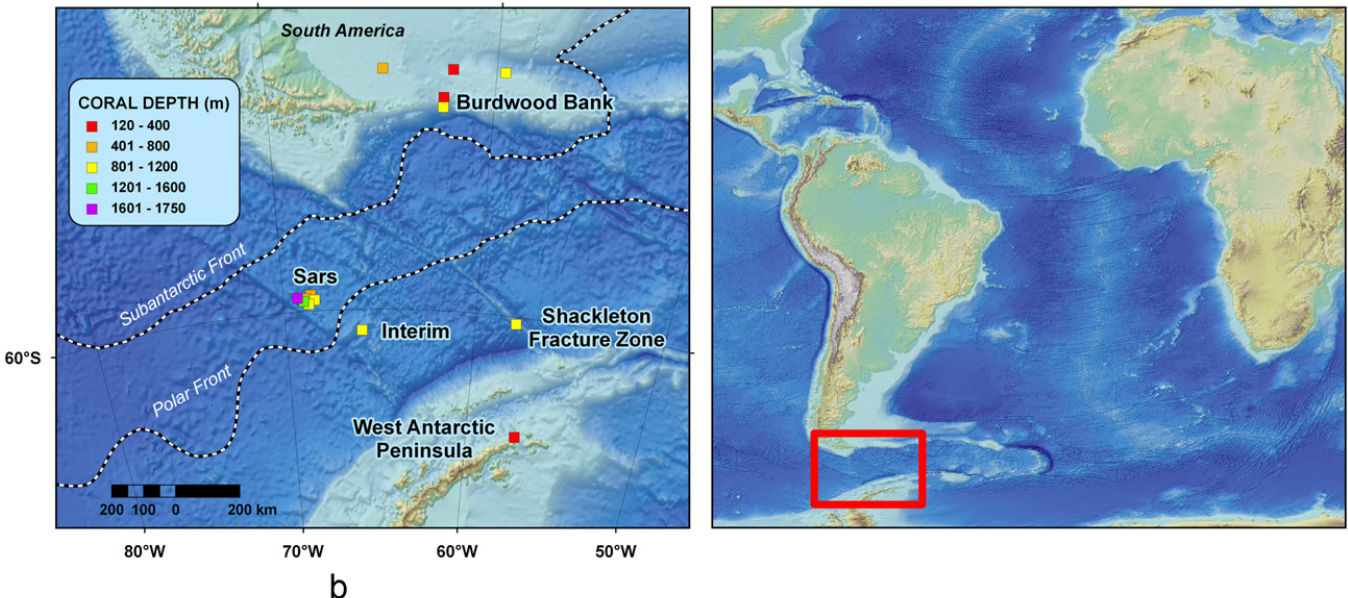

b

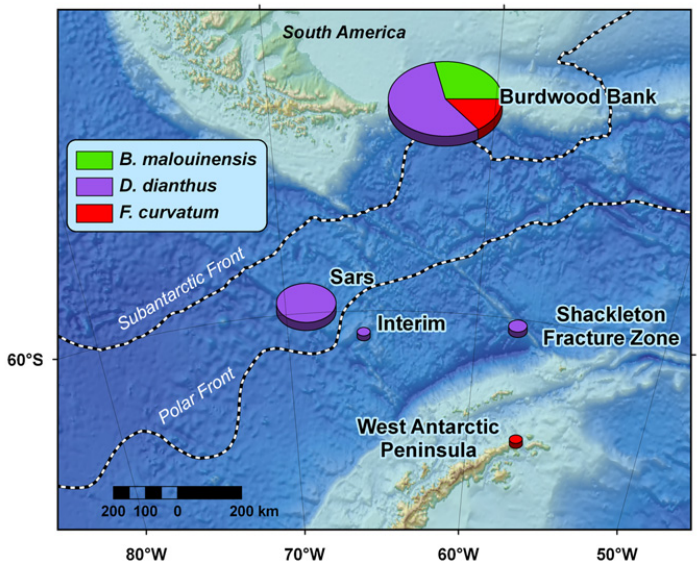

Fig. 2. Station locations. (a) Map of station locations color-coded by depth. Burdwood Bank, Sars Seamount, Interim Seamount, Shackleton Fracture Zone, and West Antarctic Peninsula are labeled. The locations of the Subantarctic and Polar fronts are from Orsi et al. (1995). (b) Map of species dated in this study at each location, with the size of the pie chart proportional to the total number of specimens dated at the site (Burdwood Bank - 76; Sars - 17; Shackleton Fracture Zone - 2; Interim - 1; West Antarctic Peninsula - 1). Bathymetry is from ETOPO2. 
assessment: a $\sim 21,200$ Ryr $D$. dianthus collected from the New England Seamounts on an Alvin dive (Cruise AT7-35), and a $\sim 14,800$ Ryr $D$. dianthus from Sars Seamount in the Drake Passage on loan from the Smithsonian Museum of Natural History (Robinson et al., 2005; Robinson and van de Flierdt, 2009). Finally, a radiocarbon-dead (U-Th dated to be $225.2 \mathrm{ky}$ ) D. dianthus collected on an Alvin dive (Cruise AT7-35) from the New England Seamounts was used for a blank correction (Eltgroth et al., 2006; Robinson et al., 2007).

\section{Analytical methods}

Aragonite subsamples ranging in size from 10 to $55 \mathrm{mg}$ were cut from the outer skeleton of each coral using a Dremel tool. Where possible, the subsample was taken from within the top $1 \mathrm{~cm}$ of the skeleton to yield the most recently grown carbonate. The pieces were physically cleaned with a Dremel tool by shaving down and removing sediment, ferromanganese oxides, or obvious areas of recalcification (e.g., from boring organisms). Two different methods of chemical cleaning were compared: a simple methanol wash, and a more extensive oxidative cleaning procedure (Shen and Boyle, 1988; Adkins et al., 2002). For the methanol wash, the corals were ultrasonicated in Milli-Q water for $20 \mathrm{~min}$ repeatedly until the water was no longer cloudy. The corals were then ultrasonicated in methanol for $5 \mathrm{~min}$ and then finally in Milli-Q water for $3 \times 20 \mathrm{~min}$. The oxidative cleaning procedure began with the methanol cleaning, but after the second Milli-Q wash, the samples were ultrasonicated in an oxidizing solution ( $1: 130 \%$ hydrogen peroxide and $1 \mathrm{~N}$ sodium hydroxide) for $20 \mathrm{~min}$. The samples were resuspended in Milli-Q water three times and then ultrasonicated in Milli-Q water for $2 \times 20 \mathrm{~min}$. The samples were then ultrasonicated in a perchloric acid solution for $1 \mathrm{~min}$ ( $1: 130 \%$ hydrogen peroxide and $1 \%$ perchloric acid), resuspended in Milli- $Q$ water three times and then finally ultrasonicated in Milli-Q water for $2 \times 20 \mathrm{~min}$. After cleaning, samples were dried and weighed.

\subsection{Reconnaissance method}

Weighed samples were placed in tin capsules and converted to $\mathrm{CO}_{2}$ using a modified commercial elemental analyzer (EA, Fisons $\mathrm{NA} 1500 \mathrm{NC}$ ). The resulting $\mathrm{CO}_{2}$ gas was cryogenically separated from the carrier gas (He) stream. After pumping the He away, the gas was passed through a line cooled by a dry ice and isopropanol slurry to remove water vapor before being frozen down into a graphite reaction tube with liquid nitrogen. The $\mathrm{CO}_{2}$ was reduced to graphite with a zinc reduction method (Xu et al., 2007). The reaction tube was a $150-\mathrm{mm}$-long $(9 \mathrm{~mm}$ outer diameter) Pyrex test tube containing $30-35 \mathrm{mg}$ zinc and $10-15 \mathrm{mg}$ titanium hydride. The tube had an indentation approximately $2 \mathrm{~cm}$ above the bottom, which supported a smaller 50 - $\mathrm{mm}$-long glass tube (6 mm outer diameter) containing 3-5 mg of iron (Fig. 3). Once the $\mathrm{CO}_{2}$ was frozen down into the outer tube, the tube was flamesealed and stored upright. Sealed tubes were baked at $500{ }^{\circ} \mathrm{C}$ for $3 \mathrm{~h}$ and at $550{ }^{\circ} \mathrm{C}$ for $4 \mathrm{~h}$ and then cooled slowly overnight. Graphite formed on the surface of the iron in the small tube. Reaction yields cannot be determined with the sealed-tube graphite preparation method. Graphite was stored in the sealed reaction tubes until immediately prior to pressing graphite into targets.

Samples were analyzed on two different machines at the National Ocean Sciences Accelerator Mass Spectrometry Facility (NOSAMS). Gas splits were not taken for $\delta^{13} \mathrm{C}$, except during a specific test to locate where carbon isotope fractionation occurs during the analytical procedure (see Section 5.1). First, 44 graphite

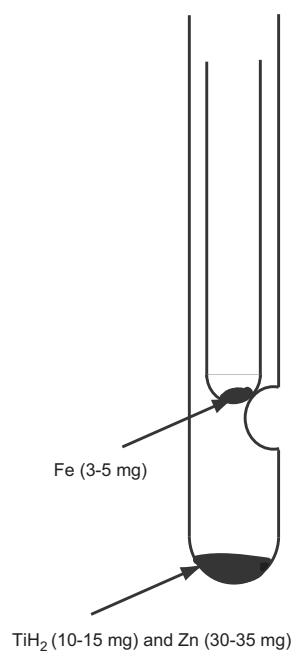

Fig. 3. Diagram of reaction tube. The $150 \mathrm{~mm}$ tube contains $10-15 \mathrm{mg}$ of $\mathrm{TiH}_{2}$ and $30-35 \mathrm{mg}$ of $\mathrm{Zn}$. An indentation $2 \mathrm{~cm}$ above the bottom supports a $50 \mathrm{~mm}$ tube with $3-5 \mathrm{mg}$ of Fe. The graphite forms on the surface of the Fe in the smaller tube.

samples were analyzed for ${ }^{14} \mathrm{C} /{ }^{12} \mathrm{C}$ on a $2.5 \mathrm{MV}$ tandetron accelerator mass spectrometer (AMS-1). The other 97 samples were analyzed on a $500 \mathrm{kV}$ compact pelletron accelerator (CFAMS, Roberts et al., 2009). During CFAMS measurements ${ }^{13} \mathrm{C} /{ }^{12} \mathrm{C}$ was measured concurrently with a precision of $\sim 3 \%$.

Primary and secondary standards were prepared following the reconnaissance procedure. Secondary standards were analyzed with every batch of 8-10 samples. The primary standard was NBS Oxalic Acid I (NIST-SRM-4990, henceforth HOxI; Fm=1.0397). Secondary standards were IAEA C-2 (fraction modern (Fm) 0.4114, Rozanski et al., 1992), TIRI-I $(\mathrm{Fm}=0.2524$, Scott, 2003), and FIRI-C $(\mathrm{Fm}=0.1041$, Boaretto et al., 2002) carbonate materials, and a radiocarbon-dead deep-sea coral (ALV-3884-153-003-011, Eltgroth et al., 2006). The blank correction for all reconnaissance coral samples was based on analyses of nine radiocarbon-dead replicates of ALV-3884-153-003-011 analyzed on CFAMS.

Radiocarbon results were reported as the Fraction modern (Fm) of the sample normalized to a $\delta^{13} \mathrm{C}=-25 \%$, where modern is defined as $95 \%$ of the $1950 \mathrm{AD}$ radiocarbon concentration of HOxI, after normalizing to $\delta^{13} \mathrm{C}=-19 \%$ (Olsson, 1970). Normalizations of the data to a constant $\delta^{13} \mathrm{C}$ were made using an assumed $\delta^{13} \mathrm{C}$ value of $0 \%$ for the AMS-1 samples and concurrent machine-measured $\delta^{13} \mathrm{C}$ values for the CFAMS samples. CFAMS data were reduced using Lawrence Livermore National Laboratory's analysis software (Santos et al., 2007); AMS-1 data were reduced using NOSAMS analysis software (Schneider et al., 1995).

\subsection{Standard hydrolysis method}

For the standard hydrolysis procedure, $\sim 40 \mathrm{mg}$ of coral were cut and chemically cleaned with the oxidative procedure. Immediately prior to dissolution, the coral was etched in $\mathrm{HCl}$ until at least $50 \%$ of the material had dissolved. The sample was dissolved in concentrated phosphoric acid on a vacuum line and a split of the $\mathrm{CO}_{2}$ gas was removed for $\delta^{13} \mathrm{C}$ measurement on a VG Prism-II Stable Isotope Ratio Mass Spectrometer (SIRMS). The remaining $\mathrm{CO}_{2}$ gas was combined with $\mathrm{H}_{2}$ gas and heated in the presence of an iron catalyst to make graphite. The graphite was then analyzed for ${ }^{14} \mathrm{C} /{ }^{12} \mathrm{C}$ on AMS-1. Radiocarbon results were 
reported as the fraction modern (Fm) using the externally measured $\delta^{13} \mathrm{C}$ value to correct to $-25 \%$ (Schneider et al., 1995).

\subsection{Blank correction and radiocarbon ages}

Prior to calculating radiocarbon ages for our samples, a blank correction was made to Fm values. This blank has two contributions: one analytical, and one inherent to the coral skeletons themselves. We assumed that the contaminating carbon had a $\mathrm{Fm}=1$. The average $\mathrm{Fm}$ of replicate measurements of the radiocarbon-dead coral was subtracted from the measured Fm of the sample and was scaled so that a coral with a $\mathrm{Fm}=1$ would remain at a $\mathrm{Fm}=1$ (nothing subtracted) and a radiocarbon-dead coral would have a $\mathrm{Fm}=0$, resulting in a blank-corrected value referred to as $\mathrm{Fm}_{\mathrm{c}}$. This correction was appropriate because the coral samples and the radiocarbon-dead coral samples were approximately the same size. The magnitude of this blank correction was two times bigger for the reconnaissance method compared to the standard hydrolysis method (see Section 4, and Supplementary Table 1).

Radiocarbon ages were calculated from $\mathrm{Fm}_{\mathrm{c}}$ using the Libby half-life of 5568 years (Stuiver and Polach, 1977; Stuiver, 1980), and the equation

Radiocarbon age $=-8033 \ln \left(\mathrm{Fm}_{\mathrm{c}}\right)$

\section{Results}

Graphite made using the sealed-tube method performed better on CFAMS than on AMS-1, consistently producing higher currents for longer periods of time and with fewer non-performers. Of the 146 standards and samples analyzed with CFAMS, there were six targets that did not produce enough current to be measured, resulting in a failure rate of $4 \%$.

Five replicate samples of a single $D$. dianthus fossil collected from Burdwood Bank (TB04 Dp-A-7) with an average Fm of 0.8625 yielded a standard deviation of $0.0094 \mathrm{Fm}(1.1 \%)$ assuming $\delta^{13} \mathrm{C}=0 \%$. When using $\delta^{13} \mathrm{C}$ values measured on CFAMS, the standard deviation decreased to $0.0038 \mathrm{Fm}$ (0.4\%; Fig. 4a). Eight replicate samples of an older $D$. dianthus from Burdwood Bank (TB04 Dn-E-3) with an average Fm of 0.2636 yielded a standard deviation of $0.0018 \mathrm{Fm}(0.7 \%)$ assuming $\delta^{13} \mathrm{C}=0 \%$. Using the measured $\delta^{13} \mathrm{C}$ values decreased the standard deviation to 0.0015 Fm (0.6\%).

Within analytical error, there was no systematic relationship between the size of samples and Fm over a range of masses from 10 to $55 \mathrm{mg}$ in three F. curvatum and one B. malouinensis collected from the Burdwood Bank (Fig. 4b). There was no offset between samples cleaned in different ways (Fig. 4c). Eleven replicate analyses on a single $B$. malouinensis (Station 5, \#18) using the two different cleaning methods yielded results within error of each other: $\mathrm{Fm}=0.8827 \pm 0.0091$ ( $n=9$, standard deviation) for the methanol wash and $\mathrm{Fm}=0.8825+0.0124(n=2$, standard deviation) for the oxidative wash. These values are both within the reported accelerator analysis error of the Fm measured using the standard hydrolysis procedure $(\mathrm{Fm}=0.8800 \pm 0.0031, n=1)$.

The average $\mathrm{Fm}$ of the nine reconnaissance replicates of the radiocarbon-dead coral was $0.0073 \pm 0.0028$ (39,500 Ryr). This value was used as the blank correction for reconnaissance samples, and it corresponds to an age correction of $\sim 10$ Ryr for modern corals, and $\sim 3000$ Ryr for a 30,000 Ryr coral. The average Fm from the five replicates on the radiocarbon-dead coral using the standard hydrolysis procedure was about 50\% smaller $(0.0038 \pm 0.0017 ; 44,800 \mathrm{Ryr})$. There are a number of possible sources for the high Fm of the radiocarbon-dead corals observed when using the reconnaissance method, including modern contamination during the EA combustion process. The EA process blank (acetanilide, $0.0048 \pm 0.0027$ ) was 0.0035 Fm greater than the long-term NOSAMS average of calcite blank (IAEA C-1) prepared using the standard hydrolysis procedure and measured on AMS-1 (0.0013 $\pm 0.0006 ; 53,400 \mathrm{Ryr}$ ) (Fig. 5). This difference is similar to the difference between the measured $\mathrm{Fm}$ of the radiocarbon-dead corals for the two methods. This result indicates that modern contamination during the EA combustion process is a major contribution to the difference in background Fm between these two procedures. However, adsorption of modern $\mathrm{CO}_{2}$ onto the surface of the coral might also contribute to the high background Fm since the reconnaissance samples were not etched with $\mathrm{HCl}$ immediately prior to graphitization (Adkins et al., 2002).

A total of 101 corals of unknown age from a depth range of 120-1750 $\mathrm{m}$ was successfully dated, and their ages range from older than 40 ka to modern (Supplementary Table 1).

\section{Discussion}

\subsection{Carbon isotope fractionation effects}

Since the goal of the method development was to improve the efficiency of sample processing and analysis, we did not collect a gas split for $\delta^{13} \mathrm{C}$ analysis. For the first set of analyses made on AMS-1, a typical marine $\delta^{13} \mathrm{C}$ of $0 \%$ was assumed (Boutton, 1991). Using this assumption, eleven replicates of $B$. malouinensis yielded a $\mathrm{Fm}=0.8746 \pm 0.0213$ (standard deviation corresponds to $198 \mathrm{Ryr}$, or about $20 \%$ of the age). The average analytical error on these measurements was only $0.0029 \mathrm{Fm}$, corresponding to approximately $26 \mathrm{Ryr}$ or only $3 \%$ of the age. It is known that biologically mediated 'vital effects' can cause the $\delta^{13} \mathrm{C}$ of marine organisms to deviate significantly from $0 \%$. For example, a single D. dianthus specimen can have a $\delta^{13} \mathrm{C}$ range of up to $12 \%$ (Adkins et al., 2003), which could result in apparent age offsets of up to 200 Ryr, potentially accounting for most of the variability in our replicate analyses.

In addition to natural variability within the coral skeleton, isotopic fractionation can occur during graphitization and within the accelerator. For example Xu et al. (2007) showed that incomplete graphitization and methane formation within the reaction tube can lead to ${ }^{13} \mathrm{C}$ depletion. We observed a -39 to $-12 \%$ range in the $\delta^{13} \mathrm{C}$ measured on the accelerator of the primary standard (HOxI) prepared using the sealed tube graphitization, much larger than the expected value of $-19 \pm 2 \%$ (Fig. 6 , Supplementary Table 2). To investigate the cause of this fractionation, splits of the $\mathrm{CO}_{2}$ gas combusted by EA from three samples of the same $B$. malouinensis were taken before graphitization and analyzed for $\delta^{13} \mathrm{C}$ by VG Prism-II SIRMS (with a typical precision of better than $0.1 \%$ ). The range of $\delta^{13} \mathrm{C}$ values $(-2.9$ to $-4.6 \%$ ) is smaller than that of the graphite made from that same gas and measured by CFAMS ( -6.8 to $-26.2 \%$ ). These results demonstrate that the fractionation is occurring after the coral has been converted to $\mathrm{CO}_{2}$.

Since $\delta^{13} \mathrm{C}$ can deviate significantly from zero, we measured ${ }^{13} \mathrm{C} /{ }^{12} \mathrm{C}$ concurrently with ${ }^{14} \mathrm{C} /{ }^{12} \mathrm{C}$ on all CFAMS analyses. CFAMS $\delta^{13} \mathrm{C}$ measurements are reproducible to $\sim 3 \%$, translating to a potential age bias of $\sim 35$ Ryr for a $\sim 1000$ Ryr old coral (3.5\% error). This uncertainty is similar to AMS uncertainties reported for each individual sample. The uncertainties from the $\delta^{13} \mathrm{C}$ correction are larger for older corals, increasing to 50 Ryr for a coral of $\sim 10,000 \operatorname{Ryr}(0.5 \%$ error $)$. 
a

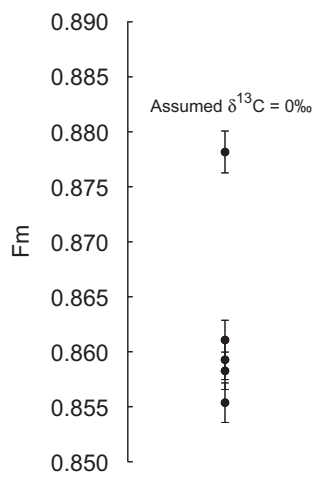

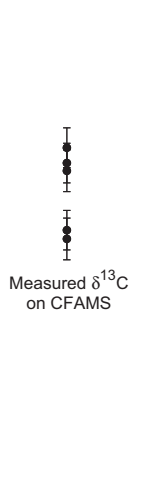

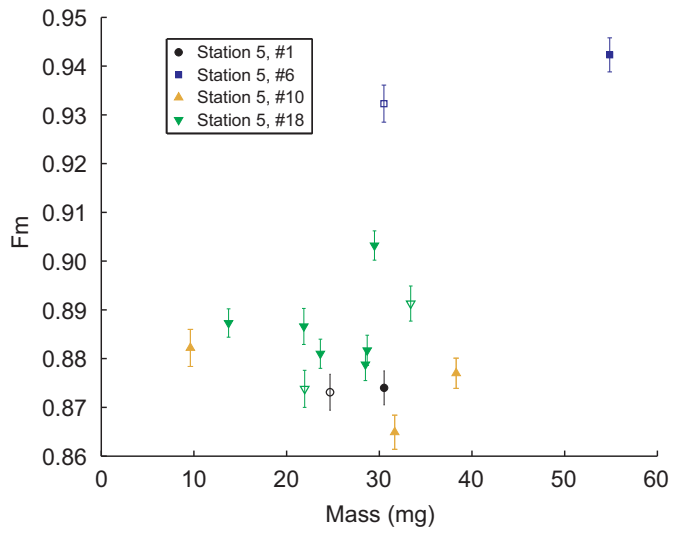

C

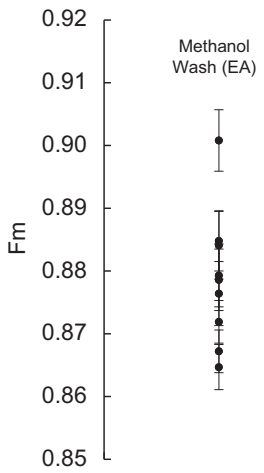




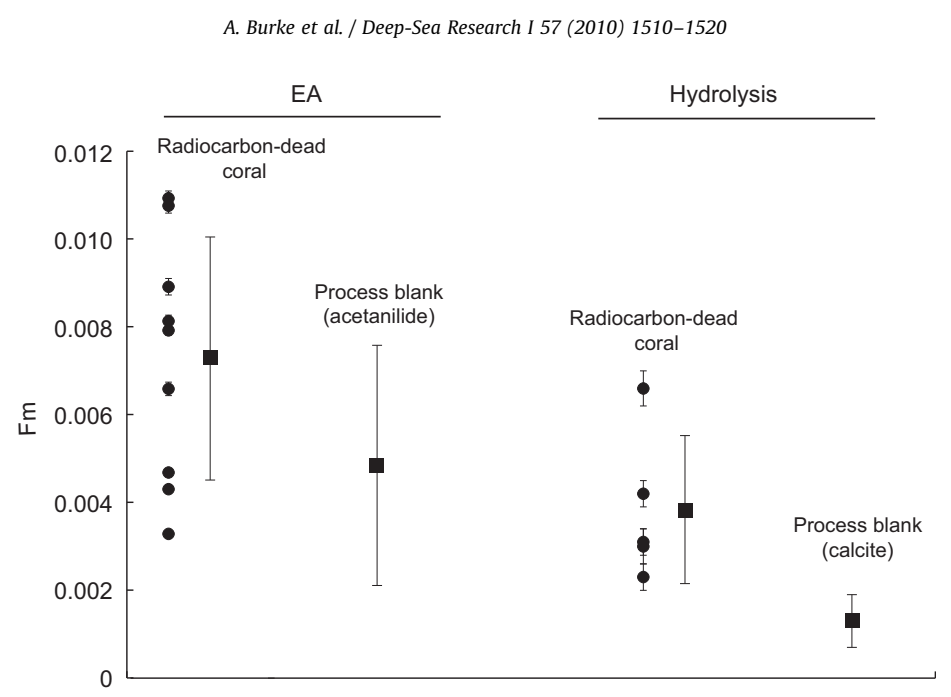

Fig. 5. Comparison of background correction for reconnaissance and hydrolysis methods. Fraction modern (Fm) of radiocarbon-dead samples measured with different procedures. On the left are samples graphitized with the elemental analyzer (EA) procedure, and on the right are samples graphitized using standard hydrolysis procedures. For both methods, the Fm of a radiocarbon-dead deep-sea coral (U-Th dated to be around $220 \mathrm{ky}$ ) and the Fm of the process blank (long-term NOSAMS average) are shown. Circles represent individual replicates and the squares represent the average. Error bars represent one standard deviation.

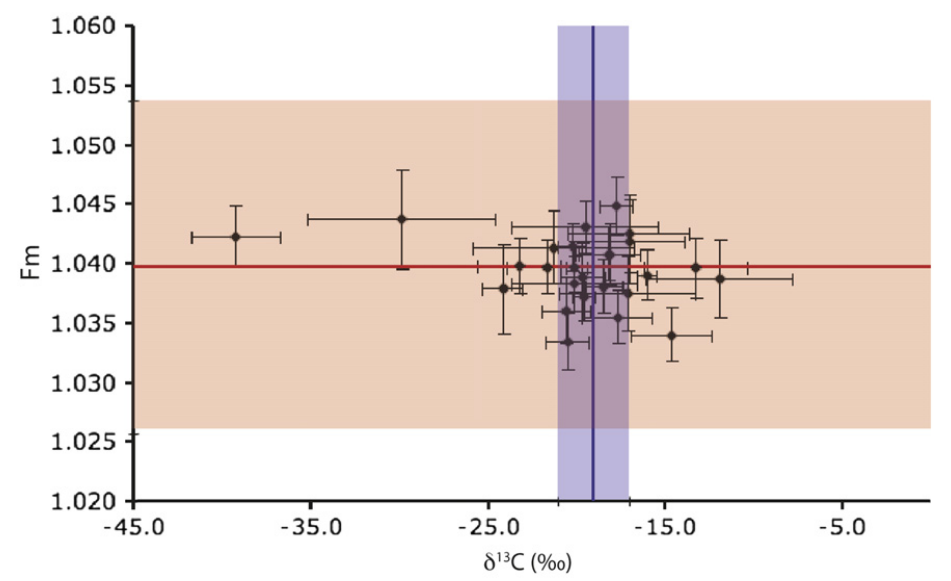

Fig. 6. Comparison of primary standard with expected values. Fraction modern (Fm) of the primary standard HOxI plotted against $\delta^{13} \mathrm{C}$ measured concurrently on CFAMS Error bars represent one standard deviation. Solid red (blue) line represents the expected Fm $\left(\delta^{13} \mathrm{C}\right.$ ) value, and the shaded range represents the NOSAMS long-term erro (standard deviation) from that expected value. (For interpretation of the references to color in this figure legend, the reader is referred to the web version of this article.)

marine mollusk shells that were collected live between 1917 and $1940(\Delta R=956 \pm 40 \mathrm{Ryr}, \Delta R=1016 \pm 39 \mathrm{Ryr}, 25-30 \mathrm{~m}$ depth $)$ (Berkman and Forman, 1996), and brachiopod shells that were deposited between 1949 and $1953(\Delta R=872 \pm 45 \mathrm{Ryr}, \Delta R=701 \pm$ $45 \mathrm{Ryr}, \Delta R=831 \pm 50 \mathrm{Ryr}$ ) (Peck and Brey, 1996).

The samples in this study do not come from the surface ocean, but from as deep as $1750 \mathrm{~m}$, so these surface water reservoir age corrections are too small. Today the radiocarbon content of waters in Drake Passage varies with depth and latitude, so we use two separate reservoir corrections $(\Delta R): 780 \pm 100 \mathrm{y}$ for the Burdwood Bank stations and $930 \pm 100 \mathrm{y}$ for the Drake Passage and West Antarctic Peninsula stations. These values are calculated from averages of pre-bomb $\Delta \Delta^{14} \mathrm{C}(\%)(-122 \%$ for Burdwood Bank and $-138 \%$ for the Drake Passage) from the gridded GLODAP data closest to sampling stations in geographic location and depth (Key et al., 2004). These pre-bomb $\Delta{ }^{14} \mathrm{C}$ values give total reservoir ages of 1050 and $1200 \mathrm{y}$.

Consistent with Intcal09 (Reimer et al., 2009), in this study we assumed that the reservoir correction $(\Delta R)$ is constant through time. It is unlikely that this is actually the case because changes in upwelling, water mass mixing, and air-sea gas exchange all affect the reservoir age of an area. These effects are especially important in the Southern Ocean. The shallow carbonate compensation depth in some areas of the Southern Ocean results in the dissolution of foraminifera, and as a result there is little constraint on past oceanic reservoir ages in this region. The only two deglacial radiocarbon data points from the Southern Ocean come from two U-series-dated $D$. dianthus from $\sim 1000 \mathrm{~m}$ depth from 
the Sars Seamount in the Drake Passage. Both corals indicate that the difference between radiocarbon in the atmosphere and the Southern Ocean was greater during Heinrich Event 1 than it is today (Goldstein et al., 2001; Robinson and van de Flierdt, 2009), resulting in reservoir ages ranging between 2000 and $2800 \mathrm{y}$ at $1000 \mathrm{~m}$ depth. Thus, our assumption of a constant reservoir age during this period would most likely result in calendar ages that are too old. We likely overestimated calendar ages throughout the deglaciation when upwelling in the Southern Ocean is thought to have increased (Anderson et al., 2009). Coral-based evidence from the Ross Sea region of the Southern Ocean indicates that the reservoir age remained constant for the past $6000 \mathrm{y}$ suggesting that our assumptions about reservoir age through the Holocene are more robust (Hall et al., 2010).

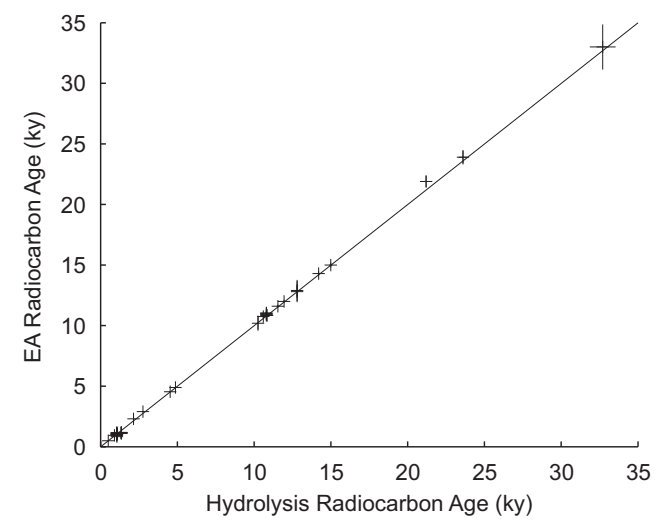

Fig. 7. Comparison of reconnaissance ages with hydrolysis ages. Reconnaissance radiocarbon ages (in thousand Ryr) from the EA method plotted against the standard hydrolysis radiocarbon ages (in thousand Ryr) for 21 different corals Replicate measurements are plotted individually. Solid line represents the $1: 1$ correlation line. Error bars are one standard deviation and are not visible if they are smaller than the symbol size.
The largest source of uncertainty on our final calendar ages comes from the conversion of radiocarbon age to calendar age, and not from the analytical uncertainty of the reconnaissance method. In areas where reservoir age variability is better constrained, or in studies in which the ${ }^{14} \mathrm{C} /{ }^{12} \mathrm{C}$ ratio is being used to examine processes rather than determine ages, the calendar age conversion will be either less important or not even relevant.

\subsection{Age distribution of corals from the Drake Passage}

After conversion to calendar age, we examine the age distribution of corals across the Drake Passage. The ages span 0 to $>40 \mathrm{ky}$ (radiocarbon-dead), and include samples from 120 to $1750 \mathrm{~m}$ depths (Fig. 8). Seventy D. dianthus specimens from NBP08-05 were dated. The corals are divided into age bins of 2500 years and plotted as histograms for each coral species and each location. It is clear from this analysis that the distribution of deepsea corals is not constant through time (Fig. 9). Specifically, the age distribution of the $D$. dianthus fossils collected from Burdwood Bank differs greatly from that of the $D$. dianthus collected from Sars Seamount in the Drake Passage. The D. dianthus fossils from Burdwood Bank are biased toward modern ages, with 32 of the 45 fossils collected (71\%) having calendar ages between 0 and $2.5 \mathrm{ky}$ (none of the coral specimens represented in these histograms were collected live, although live specimens were recovered). Although fewer individuals were dated, the pattern observed for Flabellum and Balanophyllia at the Burdwood Bank is consistent with the $D$. dianthus data. Burdwood Bank is a sediment-covered continental shelf, so it is possible that older fossils have been covered and were not fully represented at the surface. To test this hypothesis, coring at Burdwood Bank would be required.

In contrast to Burdwood Bank, no live Desmophyllum, Flabellum, or Balanophyllia were recovered from Sars Seamount, and more than half of the fossils from six different dredges yield late deglacial/early Holocene calendar ages of between 10 and $12.5 \mathrm{ky}$. Three of these corals grew on other corals (Fig. 1) presenting a possible sampling bias, but even if these corals are not included we still see a strong pulse of growth between 10 and $12.5 \mathrm{ky}$ at

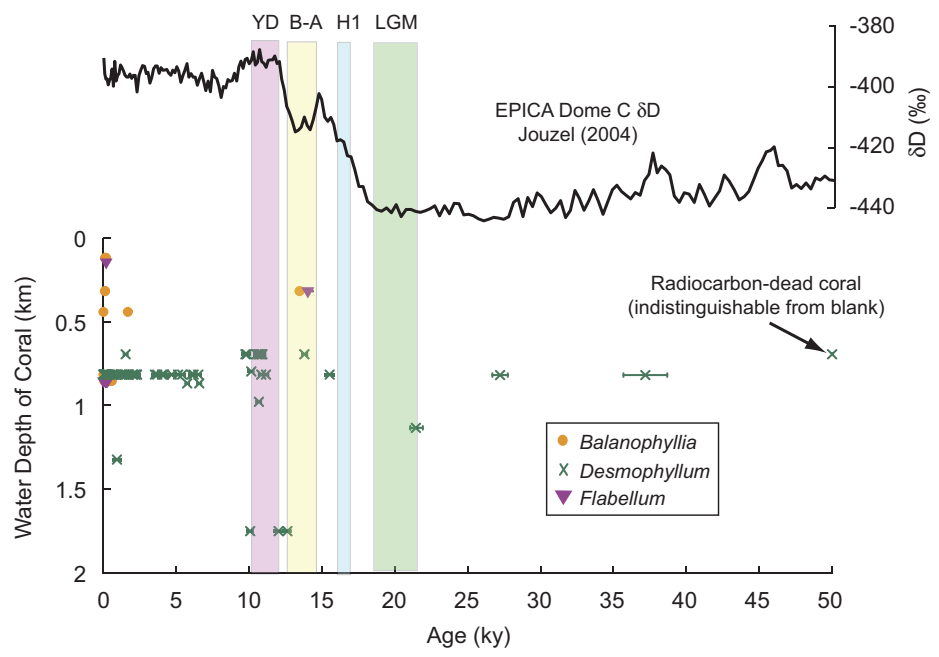

Fig. 8. Age survey. Calendar age of dated fossils (Balanophyllia (orange circles), Desmophyllum (green x's), and Flabellum (purple triangles)) plotted against water depth from where the fossils were collected. For reference, the EPICA Dome C $\delta \mathrm{D}(\%)$ record (Jouzel (2004)) is plotted above. The Younger Dryas (YD, pink), Bolling-Allerod (B-A, yellow), Heinrich event 1 (H1, blue), and Last Glacial Maximum (LGM, green) are outlined in shaded boxes. (For interpretation of the references to color in this figure legend, the reader is referred to the web version of this article.) 

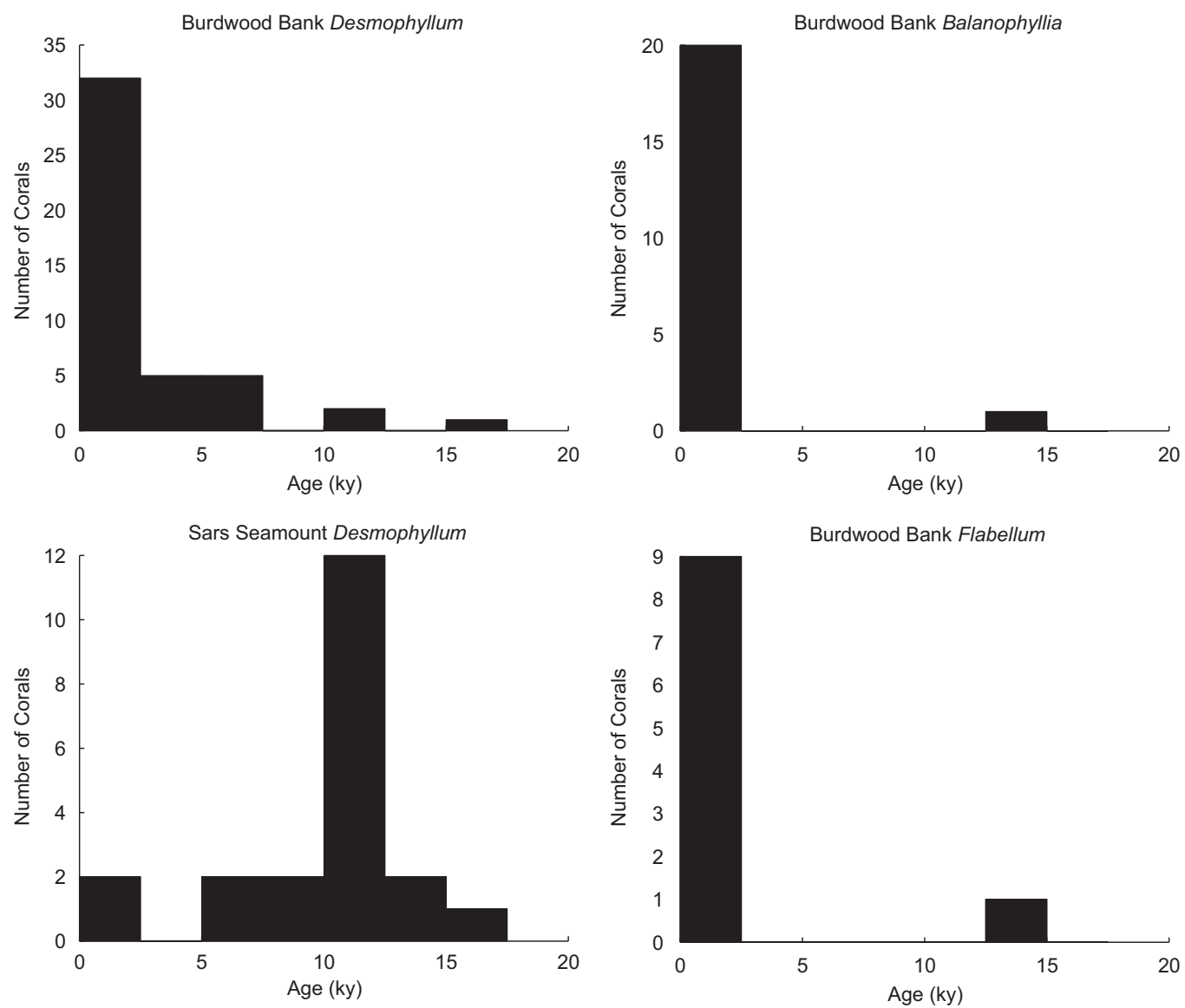

Fig. 9. Fossil age distributions. Histogram of the age distributions of $D$. dianthus from Burdwood Bank (top left) and from Sars Seamount (bottom left). Not included in the Sars Seamount histogram is one $D$. dianthus specimen that had a radiocarbon measurement that was indistinguishable from background (older than 44 ky). The H1-aged coral from Sars Seamount from Robinson and van de Flierdt (2009) is included. Histograms of the age distribution of B. malouinensis (top right) and F. curvatum (bottom right) from Burdwood Bank are also shown.

Sars Seamount, during the later stages of the last deglaciation. The two $D$. dianthus that were measured from the Shackleton Fracture Zone had ages of $27.1 \pm 0.7$ and $36.2 \pm 1.5 \mathrm{ky}$, and the one coral measured from Interim Seamount had an age of $21.5 \pm 0.5 \mathrm{ky}$. Irrespective of possible sampling biases on Burdwood Bank, the geographical distribution of deep-sea coral populations in the central Drake Passage has clearly changed over time.

It is certainly likely that changes in ocean circulation could affect the biogeography of deep-sea corals in this region by changing ocean chemistry or food supply, or even by altering larval distribution patterns. The peak in coral population during the Younger Dryas at Sars Seamount is coincident with a peak in population at the New England Seamounts in the North Atlantic (Robinson et al., 2007). At the New England Seamounts, similar peaks are seen during other periods of abrupt climate change during the last glacial as well. The Younger Dryas was a relatively cold period in the North Atlantic, but a time of warming in Antarctica (Sowers and Bender, 1995; Broecker, 1998), perhaps not surprisingly suggesting that temperature alone is not controlling the growth phases during this time. The Younger Dryas was a time of intense reorganization in the global ocean (e.g., McManus et al., 2004; Anderson et al., 2009), and these large scale changes in the deep ocean (e.g., in ocean chemistry or biological productivity) may be important factors in controlling deep-sea coral populations in both hemispheres at this time.

\section{Conclusions and perspectives}

Our new radiocarbon reconnaissance method provides an accurate and efficient method for age surveys of fossil corals or other carbonate samples that are younger than $40 \mathrm{ky}$. Whereas it can take from $\sim 20 \mathrm{~min}$ up to several hours to fully dissolve a carbonate sample using the standard hydrolysis method, the combustion time for this new method is only three minutes. Concurrent measurement of $\delta^{13} \mathrm{C}$ on CFAMS allows for correction of fractionation due to vital effects or during sample processing and analysis resulting in a standard deviation of $\sim 35 \mathrm{Ryr}$ for replicate samples of a $\sim 1000 \mathrm{Ryr}$ old coral, and a standard deviation of $\sim 50$ Ryr for replicate samples of a $\sim 10,000$ Ryr old coral. This standard deviation is within the range of the reported AMS uncertainties (25-35 Ryr) derived from counting statistics and repeat measurements on a single sample target. Possible errors involved in converting radiocarbon ages to calendar ages 
represent the largest uncertainty associated with this method. However, this conversion will be less problematic in areas where there are better constraints on how the reservoir age has changed in the past, and will not be an issue in studies that use ${ }^{14} \mathrm{C} /{ }^{12} \mathrm{C}$ to examine geologic processes.

The age survey of a suite of 101 solitary deep-sea corals from the Drake Passage area identified corals from climatically important time periods such as the Younger Dryas, Bølling-Allerød, and the Last Glacial Maximum. In future studies, absolute ages from U-Th measurements of these corals could be paired with radiocarbon to reconstruct radiocarbon profiles in this part of the Southern Ocean. Such measurements will help in understanding changes in the reservoir age and oceanography in this region. Consistent with the few existing studies, this age survey also shows that deep-sea coral distributions are not constant spatially or temporally. Determining how and why these biogeographical changes occurred could help with understanding how deep-sea coral ecosystems might respond to future environmental changes.

We envisage applications of this rapid analytical method to include age surveys of other carbonates for biogeographical and paleoceanographic studies. It could also be used as an efficient means of developing approximate age models for sediment cores.

\section{Acknowledgments}

We would like to acknowledge Rhian Waller, the members of cruises LMG06-05 and NBP08-05, and Stephen Cairns at the Smithsonian Museum of Natural History for supplying samples used in this study. We would also like to thank the crews of the $R / V$ Nathaniel B. Palmer and R/V Laurence M. Gould, NOSAMS staff, and Maureen Auro for help with this project. Financial support was provided by the USGS-WHOI Co-operative agreement, NSFOCE Grant no. 0623107, and NSF-ANT Grant nos. 0636787 and 80295700 (ARRA funding).

\section{Appendix A. Supporting information}

Supplementary data associated with this article can be found in the online version at doi:10.1016/j.dsr.2010.07.010.

\section{References}

Adkins, J.F., Boyle, E.A., 1999. Age screening of deep-sea corals and the record of deep North Atlantic circulation change at 15.4 ka. In: Abrantes, F., Mix, A.C. (Eds.), Reconstructing Ocean History. Kluwer Academic/Plenum Publishers, (Eds.), Reconstructing Oc

New York, pp. 103-120.
Adkins, J.F., Boyle, E.A., Curry, W.B., Lutringer, A., 2003. Stable isotopes in deep-sea corals and a new mechanism for "vital effects". Geochimica Et Cosmochimica Acta 67 (6), 1129-1143.

Adkins, J.F., Cheng, H., Boyle, E.A., Druffel, E.R.M., Edwards, R.L., 1998. Deep-sea coral evidence for rapid change in ventilation of the deep North Atlantic 15,400 years ago. Science 280 (5364), 725-728.

Adkins, J.F., Griffin, S., Kashgarian, M., Cheng, H., Druffel, E.R.M., Boyle, E.A., Edwards, R.L., Shen, C.C., 2002. Radiocarbon dating of deep-sea corals, Radiocarbon 44 (2), 567-580.

Adkins, J.F., Henderson, G.M., Wang, S.L., O'Shea, S., Mokadem, F., 2004. Growth rates of the deep-sea scleractinia Desmophyllum cristagalli and Enallopsammia rostrata. Earth and Planetary Science Letters 227 (3-4), 481-490.

Andersen, M.B., Stirling, C.H., Potter, E.K., Halliday, A.N., Blake, S.G., McCulloch, M.T., Ayling, B.F., O'Leary, M., 2008. High-precision U-series measurements of
M. more than 500,000 year old fossil corals. Earth and Planetary Science Letters 265 (1-2), 229-245.

Anderson, R.F., Ali, S., Bradtmiller, L.I., Nielsen, S.H.H., Fleisher, M.Q., Anderson, B.E., Burckle, L.H., 2009. Wind-driven upwelling in the Southern Ocean and the Deglacial rise in atmospheric $\mathrm{CO}_{2}$. Science 323 (5920), 1443-1448.

Berkman, P.A., Forman, S.L., 1996. Pre-bomb radiocarbon and the reservoir correction for calcareous marine species in the Southern Ocean. Geophysical Research Letters 23 (4), 363-366.
Bjorck, S., Hjort, C., Ingolfsson, O., Skog, G., 1991. Radiocarbon dates from the Antarctic Peninsula Region-problems and potential. In: Lowe, J.J. (Ed.), Radiocarbon Dating: Recent Applications and Future Potential. Quaternary Research Association, Cambridge, pp. 55-65.

Boaretto, E., Bryant, C., Carmi, I., Cook, G., Gulliksen, S., Harkness, D., Heinemeier, J., McClure, J., McGee, E., Naysmith, P., Possnert, G., Scott, M., van der Plicht, J., van Strydonck, M., 2002. Summary findings of the fourth international radiocarbon intercomparison (FIRI)(1998-2001). Journal of Quaternary Science 17 (7), 633-637.

Boutton, T.W., 1991. Stable carbon isotope ratios of natural materials: II. Atmospheric, Terrestrial, Marine, and Freshwater Environments. In: Coleman, D.C.a.B.F. (Ed.), Terrestrial, Marine, and Freshwater Environments. In: Coleman, D.C.a.B.F.
Carbon Isotope Techniques. Academic Press, New York, pp. 173-186.

Broecker, W.S., 1998. Paleocean circulation during the last deglaciation: a bipolar seesaw? Paleoceanography 13 (2) 119-121.

Cao, L., Fairbanks, R.G., Mortlock, R.A., Risk, M.J., 2007. Radiocarbon reservoir age of high latitude North Atlantic surface water during the last deglacial. Quaternary Science Reviews 26 (5-6), 732-742.

Cheng, H., Adkins, J., Edwards, R.L., Boyle, E.A., 2000. U-Th dating of deep-sea corals. Geochimica Et Cosmochimica Acta 64 (14), 2401-2416.

Eltgroth, S.F., Adkins, J.F., Robinson, L.F., Southon, J., Kashgarian, M., 2006. A deepsea coral record of North Atlantic radiocarbon through the Younger Dryas: evidence for intermediate water/deepwater reorganization. Paleoceanography 21 (4).

ETOPO2v2. Global Gridded 2-minute Database, National Geophysical Data Center, National Oceanic and Atmospheric Administration, U.S. Department of National Oceanic and Atmospheric Administration, U.S. Depa
Commerce $\langle$ http://www.ngdc.noaa.gov/mgg/global/etopo2.html $\rangle$.

Frank, N., Paterne, M., Ayliffe, L., van Weering, T., Henriet, J.P., Blamart, D., 2004. Eastern North Atlantic deep-sea corals: tracing upper intermediate water Delta C-14 during the holocene. Earth and Planetary Science Letters 219 (3-4), 297-309.

Freiwald, A., 2003. Reef-forming cold-water corals. In: Wefer, G. (Ed.), Ocean Margin Systems. Springer, Berlin, New York, pp. 365-385.

Goldstein, S.J., Lea, D.W., Chakraborty, S., Kashgarian, M., Murrell, M.T., 2001. Uranium-series and radiocarbon geochronology of deep-sea corals: implications for Southern Ocean ventilation rates and the oceanic carbon cycle. Earth and Planetary Science Letters 193 (1-2), 167-182.

Hall, B.L., Henderson, G.M., Baroni, C., Kellogg, T.B., 2010. Constant holocene Southern-Ocean $14 \mathrm{C}$ reservoir ages and ice-shelf flow rates. Earth and Planetary Science Letters 296, 115-123.

Hughen, K., Lehman, S., Southon, J., Overpeck, J., Marchal, O., Herring, C., Turnbull, J., 2004. C-14 activity and global carbon cycle changes over the past 50,000 years. Science 303 (5655), 202-207.

Jull, A.J.T., Donahue, D.J., Hatheway, A.L., Linick, T.W., Toolin, L.J., 1986. Production of graphite targets by deposition from $\mathrm{CO} / \mathrm{H}_{2}$ for precision accelerator $\mathrm{C} 14$ measurements. Radiocarbon 28 (2A), 191-197.

Jouzel, J., 2004. EPICA Dome C Ice Cores Deuterium Data. IGBP PAGES/World Data Center for Paleoclimatology, NOAA/NGDC Paleoclimatology Program.

Kano, A., Ferdelman, T.G., Williams, T., Henriet, J.P., Ishikawa, T., Kawagoe, N., Talkashima, C., Kakizaki, Y., Abe, K., Sakai, S., Browning, E.L., Li, X.H., Program, I.O.D., 2007. Age constraints on the origin and growth history of a deep-water I.O.D., 2007. Age constraints on the origin and growth history of a deep-water
coral mound in the northeast Atlantic drilled during integrated ocean drilling coral mound in the northeast Atlantic drilled during in
program expedition 307. Geology 35 (11), 1051-1054.

program expedition 307. Geology 35 (11), 1051-1054.
Key, R.M., Kozyr, A., Sabine, C.L., Lee, K., Wanninkhof, R., Bullister, J.L., Feely, R.A., Millero, F.J., Mordy, C., Peng, T.H., 2004. A global ocean carbon climatology: results from global data analysis project (GLODAP). Global Biogeochemical Cycles 18 (4).

McManus, J.F., Francois, R., Gherardi, J.M., Keigwin, L.D., Brown-Leger, S., 2004. Collapse and rapid resumption of Atlantic meridional circulation linked to deglacial climate changes. Nature 428 (6985), 834-837.

Ognibene, T.J., Bench, G., Vogel, J.S., Peaslee, G.F., Murov, S., 2003. A highthroughput method for the conversion of $\mathrm{CO}_{2}$ obtained from biochemical samples to graphite in septa-sealed vials for quantification of C-14 via accelerator mass spectrometry. Analytical Chemistry 75 (9), 2192-2196.

Olsson, I.U., 1970. The use of oxalic acid as a standard. In: Olsson, I.U. (Ed.) Radiocarbon variations and absolute chronology, Nobel Symposium, 12th Radiocarbon variations and absolute chronolog.

Orsi, A.H., Whitworth, T., Nowlin, W.D., 1995. On the meridional extent and fronts of the Antarctic circumpolar current. Deep-Sea Research Part I-Oceanographic Research Papers 42 (5), 641-673.

Peck, L.S., Brey, T., 1996. Bomb signals in old Antarctic brachiopods. Nature 380 (6571), 207-208.

Reimer, P.J., Baillie, M.G.L., Bard, E., Bayliss, A., Beck, J.W., Blackwell, P.G., Bronk Ramsey, C., Buck, C.E., Burr, G.S., Edwards, R.L., Friedrich, M., Grootes, P.M., Guilderson, T.P., Hajdas, I., Heaton, T.J., Hogg, A.G., Hughen, K., Kaiser, K.F. Kromer, B., McCormac, F.G., Manning, S.W., Reimer, R.W., Richards, D.A. Southon, J.R. Talamo, S. Turney, C.S.M van der Plicht J Weyhenmeyer, C.E. 2009. IntCal09 and Marine09 radiocarbon age calibration curves, 0-50,000 years cal BP. Radiocarbon 51 (4), 1111-1150.

Roark, E.B., Guilderson, T.P., Dunbar, R.B., Fallon, S.J., Mucciarone, D.A., 2009. Extreme longevity in proteinaceous deep-sea corals. Proceedings of the National Academy of Sciences of the United States of America 106 (13), 5204-5208.

Roberts, M.L., Burton, J.R., Elder, K.L., Longworth, B.E., McIntyre, C.P., von Reden, K.F., Han, B.X., Rosenheim, B.E., Jenkins, W.J., Galutschek, E., McNichol, A.P., 2009. A high-performance 14-C accelerator mass spectrometry system. In: Proceedings of the 20th International Radiocarbon Conference. Radiocarbon, Kona, HI. 
Robinson, L.F, Adkins, J.F., Keigwin, L.D., Southon, J., Fernandez, D.P., Wang, S.L., Scheirer, D.S., 2005. Radiocarbon variability in the Western North Atlantic Scheirer, D.S., 2005. Radiocarbon variability in the
during the last deglaciation. Science $310,1469-1473$.

Robinson, L.F., Adkins, J.F., Scheirer, D.S., Fernandez, D.P., Gagnon, A., Waller, R.G., 2007. Deep-sea scleractinian coral age and depth distributions in the northwest Atlantic for the last 225,000 years. Bulletin of Marine Science 81 (3), 371-391

Robinson, L.F., van de Flierdt, T., 2009. Southern Ocean evidence for reduced export of North Atlantic Deep Water during Heinrich event 1. Geology 37 (3), 195-198.

Rozanski, K., Stichler, W., Gonfiantini, R., Scott, E.M., Beukens, R.P., Kromer, B., van der Plicht, J., 1992. The IAEA C-14 intercomparison exercise 1990. Radiocarbon 34, 506-519.

Santos, G.M., Southon, J.R., Griffin, S., Beaupre, S.R., Druffel, E.R.M., 2007. Ultra small-mass AMS 14C sample preparation and analyses at KCCAMS/UCI Facility. Nuclear Instruments and Methods in Physics Research Section B: Beam Interactions with Materials and Atoms 259 (1), 293-302.

Schneider, R.J., McNichol, A.P., Nadeau, M.J., von Reden, K.F., 1995. Measurements of the oxalic acid II/oxalic acid I ratio as a quality control parameter at NOSAMS. Radiocarbon 37, 693-696.

Schröder-Ritzrau, A., Freiwald, A., Mangini, A., 2005. U/Th-dating of deep-water corals from the eastern North Atlantic and the western Mediterranean Sea In: Freiwald, A, Roberts, J. (Eds.), Cold-water Corals and Ecosystems. Springer, pp. 157-172.

Scott, E.M., 2003. The third international radiocarbon intercomparison (TIRI) and the fourth international radiocarbon intercomparison (FIRI), 1990-2002. Results, analyses, and conclusions. Radiocarbon 45 (2), 135-408.
Shen, G.T., Boyle, E.A., 1988. Determination of lead, cadmium and other tracemetals in annually-banded corals. Chemical Geology 67 (1-2), 47-62.

Slota, P.J., Jull, A.J.T., Linick, T.W., Toolin, L.J., 1987. Preparation of small samples fo C14 accelerator targets by catalytic reduction of CO. Radiocarbon 29 (2), 303-306. Sohn, R.A., Menke, W., 2002. Application of maximum likelihood and bootstrap methods to nonlinear curve-fit problems in geochemistry. Geochemistry, Geophysics and Geosystems, 3.

Sowers, T., Bender, M., 1995. Climate records covering the last deglaciation. Science 269 (5221), 210-214.

Stuiver, M., 1980. Workshop on 14C data reporting. Radiocarbon 22, 964-966.

Stuiver, M., Pearson, G.W., Braziunas, T., 1986. Radiocarbon age calibration of marine samples back to 9000 Cal Yr Bp. Radiocarbon 28 (2B), 980-1021.

Stuiver, M., Polach, H.A., 1977. Discussion: reporting of 14C data. Radiocarbon 19, 355-363.

Stuiver, M., Reimer, P.J., 1993. Extended C-14 data-base and revised calib 3.0 C-14 age calibration program. Radiocarbon 35 (1), 215-230.

Vogel, J.S., 1992. Rapid Production of Graphite Without Contamination for Biomedical AMS. University of Arizona, Department of Geosciences, pp. 344-350.

Vogel, J.S., Southon, J.R., Nelson, D.E., Brown, T.A., 1984. Performance of catalytically condensed carbon for use in accelerator mass spectrometry. Nuclear Instruments and Methods in Physics Research Section B-Beam Interactions with Materials and Atoms 5 (2), 289-293.

Xu, X.M. Trumbore, S.E. Zheng, S.H., Southon, J.R. McDuffee, K.E., Luttgen, M., Liu, J.C. 2007. Modifying a sealed tube zinc reduction method for preparation of AMS graphite targets: reducing background and attaining high precision. Nuclear Instruments and Methods in Physics Research Section B- Beam. Interactions with Materials and Atoms 259 (1), 320-329. 


\title{
Chapter 3. The Southern Ocean's role in carbon exchange during the last deglaciation
}

\begin{abstract}
Upwelling and degassing of carbon from the Southern Ocean is one of the leading hypotheses to help explain glacial-interglacial changes in atmospheric $\mathrm{CO}_{2}$. We present a 25,000-year-long radiocarbon record from uranium-thorium dated deep-sea corals collected from the Drake Passage in the Southern Ocean which shows the presence of radiocarbon-depleted waters and suggests enhanced stratification during the glacial period and persisting through the first half of the deglaciation. This depletion and apparent stratification disappeared by $\sim 14.6 \mathrm{ka}$ (thousand years ago) consistent with the transfer of carbon from the deep to the surface ocean and atmosphere via a Southern Ocean ventilation event. Given this direct evidence for carbon exchange in the Southern Ocean we show that our record and other deep-ocean radiocarbon records are sufficient to explain the $\sim 190 \%$ drop in atmospheric radiocarbon between $17.5-14.5 \mathrm{ka}$.
\end{abstract}

\section{Introduction}

The transition between the last glacial period $(\sim 20 \mathrm{ka})$ and the warm climate of the Holocene was accompanied by a $\sim 80 \mathrm{ppm}$ rise in atmospheric $\mathrm{CO}_{2}$ [Monnin et al., 2001], and a significant reduction in the ratio of radiocarbon $\left({ }^{14} \mathrm{C}\right)$ to ${ }^{12} \mathrm{C}$ in the atmosphere [Reimer et al., 2009]. Of particular interest is the rapid drop in atmospheric radiocarbon during the first pulse of $\mathrm{CO}_{2}$ rise at the last deglaciation, the so-called 'mystery interval' [Broecker, 2009]. One hypothesis that has been proposed to explain the rise in atmospheric $\mathrm{CO}_{2}$ and the fall in atmospheric radiocarbon content is the 'isolated reservoir' hypothesis, which relies on the deglacial ventilation of a carbon-rich and radiocarbon-depleted ocean water mass that was isolated from the atmosphere during the glacial period [e.g., Broecker and Barker, 2007]. Increased upwelling in the Southern Ocean has been suggested as a potential source of $\mathrm{CO}_{2}$ to the atmosphere during the last deglaciation [Anderson et al., 2009]. In this study we generate reconstructions of Southern Ocean radiocarbon to provide new insights into the storage and release of this hypothetical 'isolated reservoir'.

Radiocarbon is a useful tracer of carbon cycle processes since it is produced in the atmosphere, and is then transferred to other reservoirs where it decays away (with a half-life of 5730 years). The radiocarbon content of a water mass becomes increasingly 
more depleted with its time of isolation from the atmosphere. Isolation of deep water masses also allows for the sequestration of carbon away from the atmosphere. However, evidence to support the presence and subsequent ventilation of a carbon-rich and radiocarbon-depleted water mass during the glacial period remains controversial due to the challenges associated with producing reliable radiocarbon records. Radiocarbon reconstructions require accurate measurement of the ${ }^{14} \mathrm{C} /{ }^{12} \mathrm{C}$ ratio and, crucially, accurate and precise determinations of absolute (calendar) age. Deep-ocean radiocarbon records have been made successfully using benthic foraminifera [e.g., Galbraith et al., 2007], but dissolution of carbonate and the susceptibility of low sedimentation-rate cores to the mixing effects of bioturbation limit the availability of appropriate samples in deep water. Absolute age models in sediment cores often rely on radiocarbon analyses of planktonic foraminifera, which can be strongly biased by large variations in surface reservoir ages [e.g., Sikes et al., 2000; Skinner et al., 2010], or radiocarbon-independent age models which commonly rely on matching core parameters to other climate records [Marchitto et $a l ., 2007]$. Additionally, variations in foraminiferal abundance or species composition through time can bias benthic-planktic age offsets [Peng and Broecker, 1984; Magana et al., 2010].

In spite of these difficulties, much effort has been made to identify an isolated carbon reservoir in the glacial ocean. Broecker [2009] has argued that the similarity between planktic-benthic radiocarbon age offsets from today and the Last Glacial Maximum (LGM; 18 - $22 \mathrm{ka}$ ) from a suite of cores in the Pacific has limited the potential volume for an abyssal isolated reservoir, requiring it to be thin, deep, and extremely radiocarbon-depleted. Although direct evidence for such a reservoir has remained elusive Skinner et al. [2010] recently suggested the presence of a 4,000 year old water mass in the deep South Atlantic during the LGM (for reference, the radiocarbon age of the oldest known water in the modern ocean occurs in the North Pacific and amounts to $>2,300$ radiocarbon years; [Key et al., 2004]). It is an intriguing result, although the spatial extent of this water mass is not yet known and the associated age model requires a large 2,000 year surface reservoir age during the glacial and early deglaciation. A series of recent papers showing evidence for extreme radiocarbon depletions at intermediate depths during periods of $\mathrm{CO}_{2}$ rise during the deglaciation [e.g., 
Marchitto et al., 2007; Bryan et al., 2010; Thornalley et al., 2011], have also sparked interest in this isolated reservoir hypothesis. These papers invoke the transfer of extremely old carbon from an isolated reservoir via the Southern Ocean through Antarctic Intermediate Water (AAIW) to locations in the Northern Hemisphere. Here we provide the first glacial and deglacial U-Th dated time-series of radiocarbon from deep-sea corals collected from directly within Upper Circumpolar Deep Water (UCDW) and AAIW in the Southern Ocean. U-Th dates provide an independent calendar age that does not depend on reservoir ages or stratigraphic correlation. Furthermore, the Southern Ocean is the ideal location for this study, as it forms a direct link between the deep ocean and the atmosphere because of mixing and upwelling of major deep water masses.

\section{Sample Description and Results}

Forty solitary deep-sea corals (thirty-seven Desmophyllum dianthus, two Balanophyllia malouinensis, and one Flabellum curvatum) were selected for this study from a suite of dredge-collected corals from the Drake Passage and Burdwood Bank [Fig. 1; Burke et al., 2010; Waller et al., 2011]. Coral samples were screened to identify glacial and deglacial corals using radiocarbon reconnaissance dating [Burke et al., 2010]. These samples were then U-Th dated and those with ages within the time period of $0-35$ ka were precisely radiocarbon dated to calculate past $\Delta^{14} \mathrm{C}$ values of dissolved inorganic carbon (DIC) at dredging depths bathed today by AAIW and UCDW (for more details on samples and methods, see Appendix 2). $\Delta{ }^{14} \mathrm{C}$ is a measure of the relative difference between the radiocarbon activity of an absolute international standard and that of a sample, after correction for both age and isotope fractionation [Appendix 2; Stuiver and Polach, 1977]. For convenience we refer to the radiocarbon records by the names of the water masses at those depths today, while recognizing that different water masses could have occupied those depths in the past.

The reconstructed $\Delta^{14} \mathrm{C}$ values for corals from depths corresponding today to AAIW follow the atmospheric $\Delta^{14} \mathrm{C}$ curve [Reimer et al., 2009] at an offset $\left(\Delta \Delta^{14} \mathrm{C}\right.$, Appendix 2) ranging from -80 to $-190 \%$ (Fig. 2), with modern corals reflecting the $\Delta^{14} \mathrm{C}$ of ambient seawater DIC [Key et al., 2004]. The largest depletions in AAIW occur during the Antarctic Cold Reversal (ACR) at $13.3 \pm 0.1$ and $13.7 \pm 0.1 \mathrm{ka}$, which is a 
pause in the deglacial warming recorded by Antarctic ice core records. The reconstructed $\Delta \Delta^{14} \mathrm{C}$ for corals from depths bathed today by UCDW follow atmospheric $\Delta{ }^{14} \mathrm{C}$ throughout the Holocene, with offsets from the contemporaneous atmosphere ranging from -110 to $-155 \%$, also consistent with nearby water column $\Delta{ }^{14} \mathrm{C}$ measurements [Key et al., 2004]. During the LGM, radiocarbon in UCDW was $230 \%$ depleted from the contemporaneous atmosphere, $\sim 80 \%$ lower than values observed at these sites today. UCDW was even more radiocarbon depleted from the contemporaneous atmosphere prior to the LGM at $25.6 \pm 0.3$ ka during Heinrich Stadial 2 (H2; $24-27 \mathrm{ka}$ ), with an offset of $-370 \%$, and also during Heinrich Stadial 1 (H1; 14.6 - $18 \mathrm{ka}$ ) with offsets of -250 to $-300 \%$. A marked increase in UCDW $\Delta{ }^{14} \mathrm{C}$ occurs at the start of the Bølling-Allerød (BA; $12.8-$ $14.6 \mathrm{ka}$ ) and during the ACR, leading to $\Delta \Delta^{14} \mathrm{C}$ values of only $-140 \%$. The offsets of $\mathrm{UCDW} \Delta{ }^{14} \mathrm{C}$ from the contemporaneous atmosphere then remain relatively constant until the modern, with the exception of slightly enriched radiocarbon values $\left(\Delta \Delta{ }^{14} \mathrm{C}=-87\right.$ to $-105 \%$ ) immediately following the end of the Younger Dryas (YD; $12.8-11.5 \mathrm{ka}$; Fig. 2).

\section{Discussion}

The depleted glacial radiocarbon values that we have detected in glacial UCDW in the Southern Ocean are consistent with the presence of an isolated glacial carbon reservoir and reduced ocean ventilation during the glacial period. The large glacial radiocarbon depletions could result from a reduction in air-sea gas exchange [Stephens and Keeling, 2000; Schmittner, 2003; Butzin et al., 2005], e.g. by extensive sea ice cover [Fischer et al., 2007] at locations where deep waters bathing the dredging sites are formed or increased stratification within the Southern Ocean [e.g., Francois et al., 1997]. Additionally global ocean changes in stratification [Lund et al., 2011] could also contribute to lower $\Delta^{14} \mathrm{C}$ values in the glacial deep ocean by reducing mixing in the abyssal ocean with more ventilated water masses above. A reduction in the flux of wellventilated northern source waters to the Southern Ocean (or advection of radiocarbondepleted water) could also lead to more depleted radiocarbon in UCDW.

The vertical structure of Southern Ocean $\Delta{ }^{14} \mathrm{C}$ can be explored by comparison of our new Drake Passage data to two deep benthic foraminifera radiocarbon records from 
the South Atlantic [Figs. 1 and 2; Barker et al., 2010; Skinner et al., 2010]. These two radiocarbon records are quite different to one another - by up to 290\%o during the glacial (Fig. 2). The deeper site $(4981 \mathrm{~m})$ in modern-day Antarctic Bottom Water [AABW; Barker et al., 2010] is more radiocarbon enriched than the shallower one $(3770 \mathrm{~m})$ in modern-day Lower Circumpolar Deep Water [LCDW; Skinner et al., 2010]. The deeper record is broadly consistent with our UCDW data during the deglaciation, suggesting common influences on the radiocarbon values in the Southern Ocean subsurface regions of UCDW and $\mathrm{AABW}$ formation. The extreme 500\% radiocarbon depletion from the atmosphere in the LGM equivalent of LCDW may have been caused by an increase in the proportion of recirculated deep water from the Pacific which was not seen in AABW or UCDW. Also, some of the offsets between the two cores in the South Atlantic may arise from the large difference in surface reservoir ages used for their age models: allowing the $600 \mathrm{yr}$ reservoir age in the Cape Basin core to increase during the LGM, or reducing the $>2000$ year LGM reservoir age at the Mid-Atlantic Ridge would bring the sediment-core records closer into agreement. The marked 290\% contrast between the extremely depleted radiocarbon in glacial LCDW and UCDW implies a strong stratification in deep Southern Ocean water masses at the LGM, consistent with postulated reduced vertical mixing across water mass boundaries [Lund et al., 2011]. Polar stratification is thought to play a fundamental role in lowering atmospheric $\mathrm{CO}_{2}$ during glacial times by reducing the ventilation of $\mathrm{CO}_{2}$ from the deep ocean [Sigman et al., 2010].

At the end of the glacial, during $\mathrm{H} 1$ and the mystery interval, the $\Delta^{14} \mathrm{C}$ of the Southern Ocean water masses become more similar. The $\Delta \Delta^{14} \mathrm{C}$ of UCDW and AABW decreases and that of LCDW increases until these three water masses are within error at approximately $-275 \%$ (Fig. 2). These changes imply increased deep mixing in the Southern Ocean and a breakdown of the deep vertical stratification that characterizes the LGM. This breakdown is consistent with evidence for increased nutrient upwelling inferred from opal accumulation records (Fig. 3), hypothesized to result from a southern shift in the Westerly winds [Anderson et al., 2009]. The timing of the reduction in stratification is concurrent with the initial deglacial rise in atmospheric $\mathrm{CO}_{2}$ [Fig. 3; Monnin et al., 2001], and lends support to upwelling of deep, carbon-rich waters to shallow depths in the Southern Ocean as a cause of deglacial atmospheric $\mathrm{CO}_{2}$ rise. 
During the same time period, the relatively enriched $\Delta^{14} \mathrm{C}$ of intermediate depth waters in the Drake Passage and off the coast of Chile [De Pol-Holz et al., 2010] imply significant air-sea gas exchange and ventilation of AAIW. Prior to the LGM, at around the time of H2 (25.6 ka), Drake Passage UCDW has a radiocarbon-depleted signature similar to the LCDW site $\left(\Delta \Delta \Delta^{14} \mathrm{C}=-370 \%\right.$; Fig. 2). This similarity between $\Delta{ }^{14} \mathrm{C}$ in UCDW and LCDW during $\mathrm{H} 2$ is also observed during $\mathrm{H} 1$, suggesting that deep vertical mixing in the Southern Ocean correlates with northern Heinrich events and Glacial North Atlantic Deep Water shoaling [Ahn and Brook, 2008].

The timing for which the offset of UCDW $\Delta^{14} \mathrm{C}$ from the atmosphere becomes similar to the modern ocean is constrained by two corals: one with a U-Th age of $15.7 \pm$ $0.1 \mathrm{ka}$, and the other with an age of $14.7 \pm 0.1 \mathrm{ka}$. Thus, it is within error of the onset of the BA at $14.6 \mathrm{ka}$, at the end of the mystery interval. Similar shifts from low to high $\Delta \Delta{ }^{14} \mathrm{C}$ values are observed at the same time in the deep North Pacific [Galbraith et al., 2007], deep North Atlantic [Skinner and Shackleton, 2004], and deep South Atlantic [Barker et al., 2010; Skinner et al., 2010], illustrating the large-scale nature of this ventilation event (Fig. 2). The widespread nature of this signal suggests that by the start of the BA most of the radiocarbon-depleted signal of the glacial deep ocean (the isolated reservoir) had disappeared.

Although the major ventilation event described above is the most significant change observed in deep and Southern Ocean $\Delta^{14} \mathrm{C}$ records, there are still significant changes in the radiocarbon structure of the ocean after the start of the BA/ACR. First, the loss of old carbon from the deep ocean causes smaller $\Delta \Delta^{14} \mathrm{C}$ values in the deep Southern Ocean during the BA/ACR (Fig. 2). This change might have been augmented by a reinvigoration and deepening of North Atlantic Deep Water after Heinrich Event 1 that could have supplied well-ventilated (radiocarbon-enriched) waters to parts of the deep ocean [Barker et al., 2010]. In contrast, the $\Delta \Delta^{14} \mathrm{C}$ of AAIW is more depleted during the BA/ACR, with values that are the same as UCDW (Figs. 2 and 3). This change in the radiocarbon offset between AAIW and UCDW reflects a greater relative influence of the deep ocean than the atmosphere on AAIW $\Delta^{14} \mathrm{C}$ during the BA/ACR than during H1. One way to achieve this change is to decrease air-sea gas exchange, which would also act to limit $\mathrm{CO}_{2}$ outgassing. Indeed, lower opal accumulation fluxes south of the Polar Front 
do support a change in stratification at this time [Fig. 3; Anderson et al., 2009]. An increase in Southern Ocean surface stratification could be due to an increase in sea ice cover [Fischer et al., 2007], and may have contributed to the deglacial pause in atmospheric $\mathrm{CO}_{2}$ rise. Subsequent to this event, during the YD AAIW returns to its more ventilated state, which is consistent with enhanced upper Southern Ocean to atmosphere exchange during periods of atmospheric $\mathrm{CO}_{2}$ rise (Fig. 3).

\subsection{A note on Antarctic Intermediate Water}

Our Southern Ocean AAIW data follow the atmospheric radiocarbon record at relatively constant offsets, with similar absolute values to the sediment-core record from the Chile Margin [Figs. 1 and 2; De Pol-Holz et al., 2010]. Additionally, we do not find evidence for extreme $(>300 \%)$ radiocarbon depletions in any of the Southern Ocean water masses after $14.6 \mathrm{ka}$. These results are in apparent contradiction with several studies that have invoked an extremely radiocarbon-depleted AAIW to explain the large depletions observed at intermediate depths in the North Pacific, South Atlantic, Arabian Sea, and North Atlantic [Marchitto et al., 2007; Bryan et al., 2010; Mangini et al., 2010; Thornalley et al., 2011]. Our new data from the Atlantic sector of the Southern Ocean make the AAIW carbon leakage hypothesis increasingly more unlikely. While our UCDW data do support a Southern Ocean mechanism for the release of carbon during the deglaciation, the radiocarbon-depleted signature does not appear to be transported to the Northern Hemisphere by AAIW. Recent modeling work [Hain et al., 2011] suggests that propagating the signature of an extremely radiocarbon-depleted water mass to the North Pacific via AAIW is improbable since the signal would be rapidly dissipated and diluted by the carbon in rest of the ocean and the atmosphere. Thus it appears that although there is a widespread distribution of extreme radiocarbon depletions at intermediate depths, they are unlikely caused by a common radiocarbon-depleted water mass that was transported over large distances.

\subsection{The Mystery Interval}

One of the more intriguing features in the atmospheric radiocarbon record is the $\sim 190 \%$ drop in radiocarbon beginning at $\sim 16.6 \mathrm{ka}$ and ending at the onset of the BA at 
$\sim 14.6$ ka [Reimer et al., 2009]. Production records from paleomagnetic and ${ }^{10} \mathrm{Be}$ reconstructions can explain, at maximum, 40\% of this drop [Frank et al., 1997; Laj et al., 2002; Muscheler et al., 2004]. Broecker and Barker [henceforth B\&B, 2007] have suggested that this drop in atmospheric $\Delta{ }^{14} \mathrm{C}$ requires a very large, or extremely depleted, oceanic radiocarbon reservoir (Fig. 4); in the absence of evidence for such a widespread old radiocarbon reservoir, as well as other apparent climate contradictions, this event remains unexplained [the 'mystery interval'; Denton et al., 2006].

However, based on seawater $\Delta^{14} \mathrm{C}$ evidence presented in this study, we can justify two modifications to the basic assumptions made in B\&B's calculations to potentially 'de-mystify' this interval. Firstly, B\&B assume that the mean age of the non-isolated ocean remains the same both before and after the mystery interval, at an offset of $1500 \mathrm{y}$ from the surface ocean (equivalent to $1900 \mathrm{y}$ from the atmosphere). However, the data presented and compiled in this study show that by the end of the mystery interval and the start of the BA, ocean radiocarbon values were in fact more enriched compared to the contemporaneous atmosphere (younger) than from before the mystery interval (Fig. 2).

Secondly, B\&B assume that the isolated reservoir is mixed through the entire oceanic reservoir of carbon, establishing a new steady-state that forces the atmospheric $\Delta \Delta^{14} \mathrm{C}$ to drop by $190 \%$. Since the oceanic carbon reservoir is about 60 times larger than that of the atmosphere, this assumption forces the isolated reservoir to be very old or very large. Our data from UCDW, however, indicate that there might be a more direct ventilation of the isolated reservoir to the atmosphere through upwelling in the Southern Ocean. If the Southern Ocean were a direct conduit for the transfer of old carbon to the atmosphere, then we would expect to see a drop in $\Delta^{14} \mathrm{C}$ in these waters over the mystery interval. Additionally, as the isolated reservoir becomes less isolated and is mixed into the rest of the ocean and atmosphere, we would expect to see an increase in the $\Delta{ }^{14} \mathrm{C}$ of the isolated reservoir. Indeed, during the mystery interval between 16.6 and $15.6 \mathrm{ka}$, the radiocarbon in UCDW falls at a rate similar to the rate of change in the atmospheric $\Delta^{14} \mathrm{C}$ record, while the radiocarbon content of the deep South Atlantic [LCDW; Skinner et al., 2010] increases (Fig. 2). These records indicate that UCDW could be a direct ventilation pathway to the atmosphere for the radiocarbon-depleted waters of the isolated reservoir. 
Thus, here we make a modified calculation to the one made in [Broecker and Barker, 2007] by relaxing those two assumptions (see supplementary info for details). We allow the non-isolated ocean ventilation age to decrease after the mystery interval. Additionally we allow some proportion of the isolated reservoir to mix directly with the atmospheric reservoir before being mixed back into the oceanic reservoir. As this proportion is increased, the age required for the isolated reservoir to explain the $190 \%$ drop in atmospheric radiocarbon gets younger (Fig. 4). We do this calculation for a range of proportions (1-100\%) to illustrate the non-linearity of this mixing. The extreme case where $100 \%$ of the carbon from the isolated reservoir is allowed directly into the atmosphere before mixing back into the ocean is, of course, unrealistic, and results in mean ocean ventilation ages that are too young compared to the atmosphere. This is an apparent decrease in age driven by the drop in the $\Delta^{14} \mathrm{C}$ of the atmosphere, without a corresponding drop in the $\Delta^{14} \mathrm{C}$ of the ocean from mixing with the isolated reservoir (Fig. S4 in Appendix 2). The opposite extreme allows only $1 \%$ of the carbon from the isolated reservoir into the atmosphere (noting that the glacial atmospheric carbon reservoir is approximately $1 \%$ of that in the ocean) giving a result that is nearly equivalent to the calculation from B\&B (although without the restriction that the mean ocean ventilation age remain the same after the mystery interval). However, the non-linearity of the mixing is such that small increases in the percentage of isolated carbon mixed directly into the atmosphere drastically reduce the age of the isolated reservoir required to explain the mystery interval. For example, if the isolated reservoir occupied $20 \%$ of the ocean volume, then it would only need an age of 3,670 y to explain the drop in atmospheric $\Delta \Delta^{14} \mathrm{C}$, if $3 \%$ of this isolated reservoir was vented directly into the atmosphere. This deep ocean age is within the boundaries set by the data shown in this study (Fig. 4). Our radiocarbon results from UCDW support this idea of a radiocarbon-depleted glacial ocean that is ventilated directly through the Southern Ocean. By the end of the mystery interval and the onset of the BA, the ocean as a whole is more ventilated, and there is no evidence for the large radiocarbon depletions found in glacial times. 

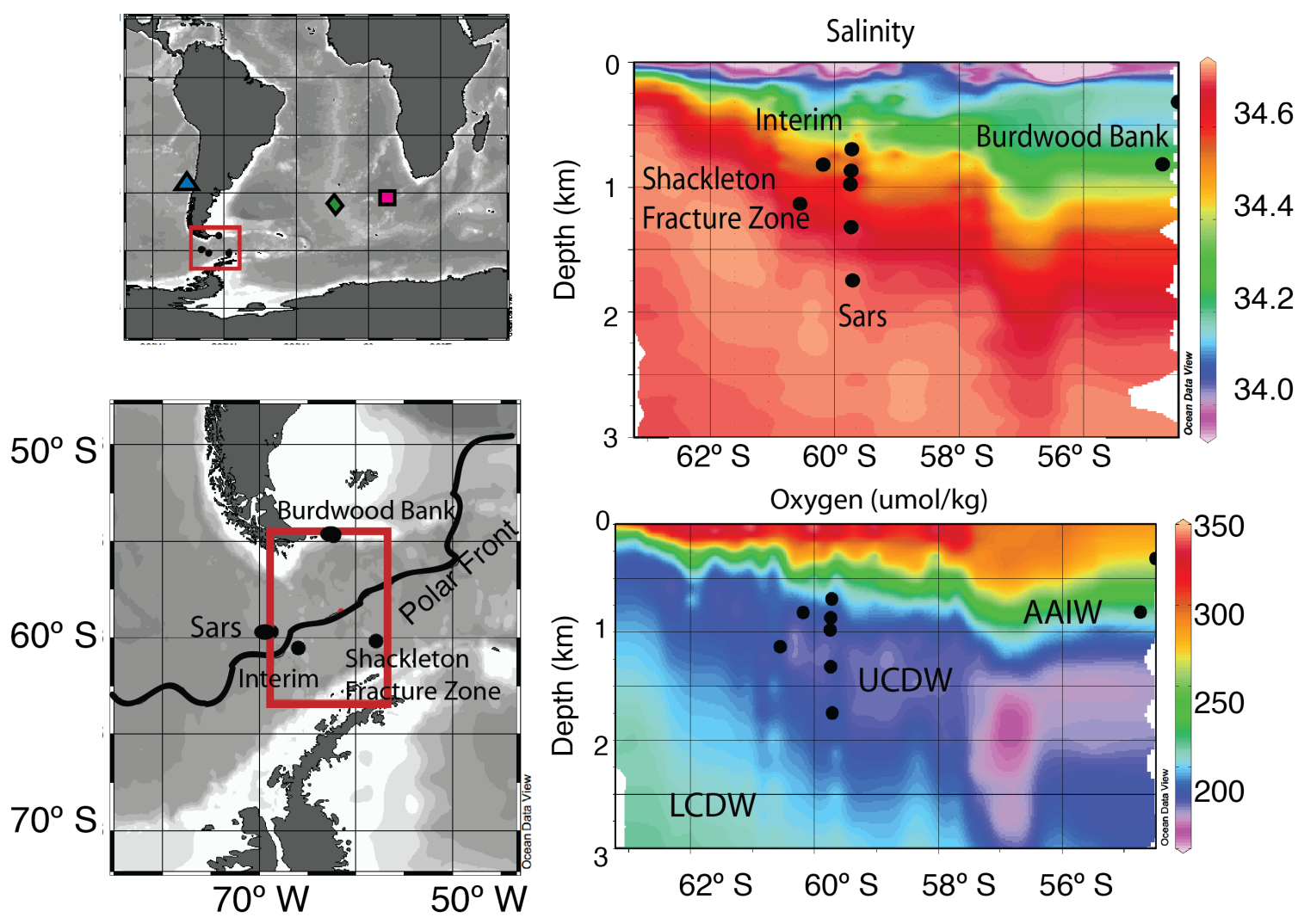

Figure 1. (left) Maps showing locations of dredging sites and sediment cores: core SO161-SL22 (36.2 S, 73.7 $\mathrm{W}, 1000 \mathrm{~m}$; [De Pol-Holz et al., 2010]) is indicated by a blue triangle, core MD07-3076 CQ $\left(44.1^{\circ} \mathrm{S}, 14.2^{\circ} \mathrm{W}, 3770 \mathrm{~m}\right.$; [Skinner et al., 2010]) is indicated by a green diamond, and core TN057-21 $\left(41.1^{\circ} \mathrm{S}, 7.8^{\circ} \mathrm{E}, 4981 \mathrm{~m}\right.$; [Barker et al., 2010] ) is indicated by a pink square. The polar front is indicated by a black line [Orsi et al., 1995]. (right) Depth-latitude sections of salinity (top) and oxygen (bottom) from GLODAP dataset for the latitudinal transect indicated by the red box on the map. [Key et al., 2004]. Corals (black dots) come from depths bathed today by Antarctic Intermediate Water (AAIW) and Upper Circumpolar Deep Water (UCDW). Lower Circumpolar Deep Water is indicated by LCDW. 

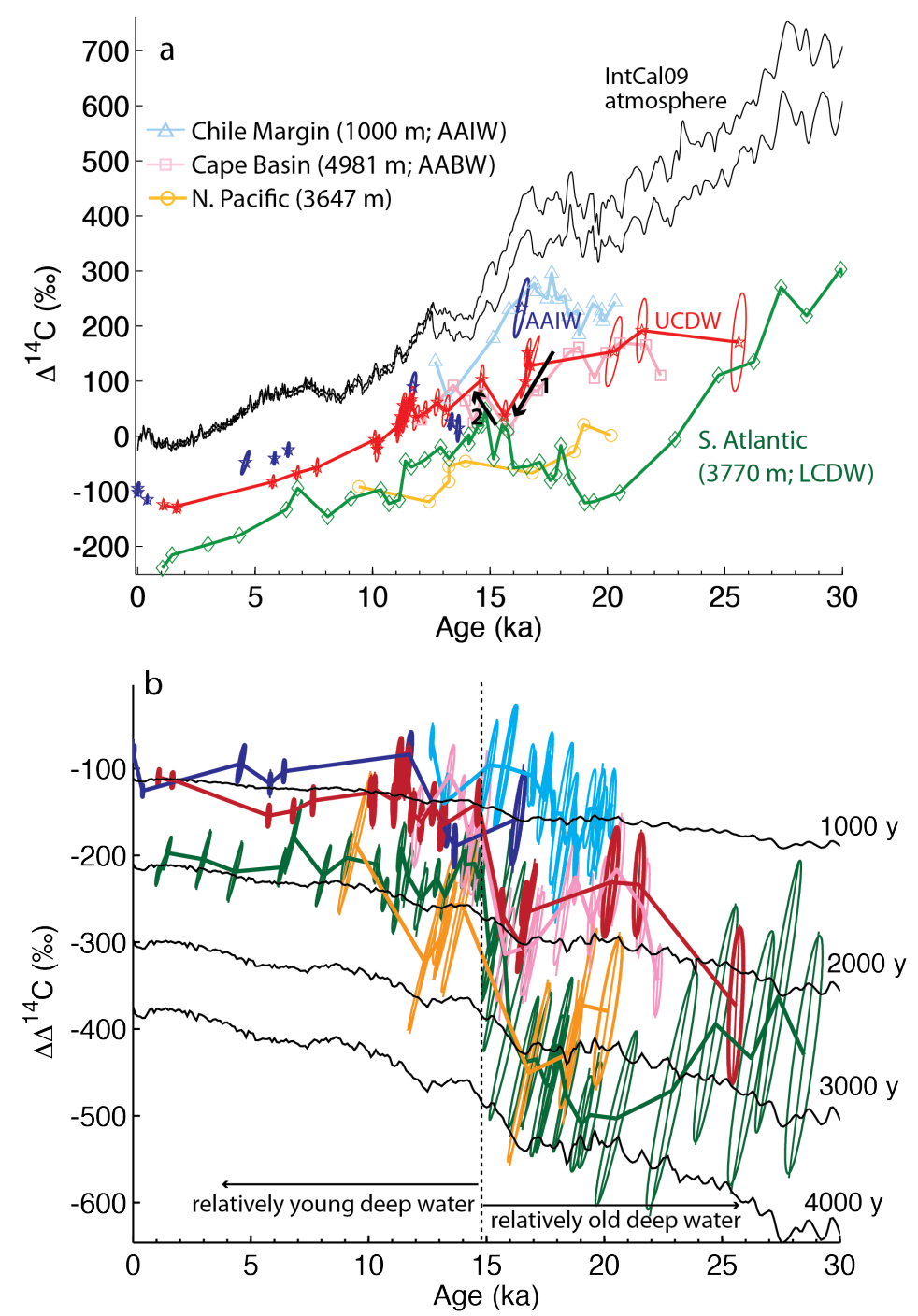

Figure 2. (a) $\Delta^{14} \mathrm{C}$ reconstructed from Drake Passage deep-sea corals from depths bathed today by AAIW (dark blue) and UCDW (red). Ellipses are $2 \sigma$ error ellipses. Two previously dated corals [Goldstein et al., 2001; Robinson and van de Flierdt, 2009] with ages of $\sim 16.5$ and $16.6 \mathrm{ky}$ are included in the UCDW group. Also shown are the reconstructed $\Delta^{14} \mathrm{C}$ records from benthic foraminifera from cores in the South Atlantic [green, Skinner et al., 2010], North Pacific [gold, Galbraith et al., 2007], Cape Basin [pink, Barker et al., 2010], and Chilean margin [light blue, De Pol-Holz et al., 2010]. Atmospheric radiocarbon [IntCa109, Reimer et al., 2009] is shown by the black lines $(2 \sigma)$. Arrow 1 marks the drop in UCDW radiocarbon over the H1/mystery interval that parallels the drop in the atmospheric record. Arrow 2 marks the increase in UCDW radiocarbon after the $\mathrm{H} 1$ /mystery interval. (b) Offset of reconstructed deep-sea coral $\Delta^{14} \mathrm{C}$ from contemporaneous atmosphere $\left(\Delta \Delta^{14} \mathrm{C}\right)$ for AAIW (dark blue) and UCDW (red) corals [this study; Goldstein et al., 2001; Robinson and van de Flierdt, 2009]). Also included are the offsets of the reconstructed $\Delta^{14} \mathrm{C}$ from benthic foraminifera from the same cores in the top panel. All ellipses are $2 \sigma$. Contours of constant radiocarbon age offset from the contemporaneous atmosphere are shown as gray lines to illustrate the effect of the changing atmospheric radiocarbon inventory with time on $\Delta \Delta{ }^{14} \mathrm{C}$ values (Appendix 2). Dashed line at $14.5 \mathrm{ka}$ divides the plot between the relatively old waters of the glacial and the relatively young waters post-mystery interval. 


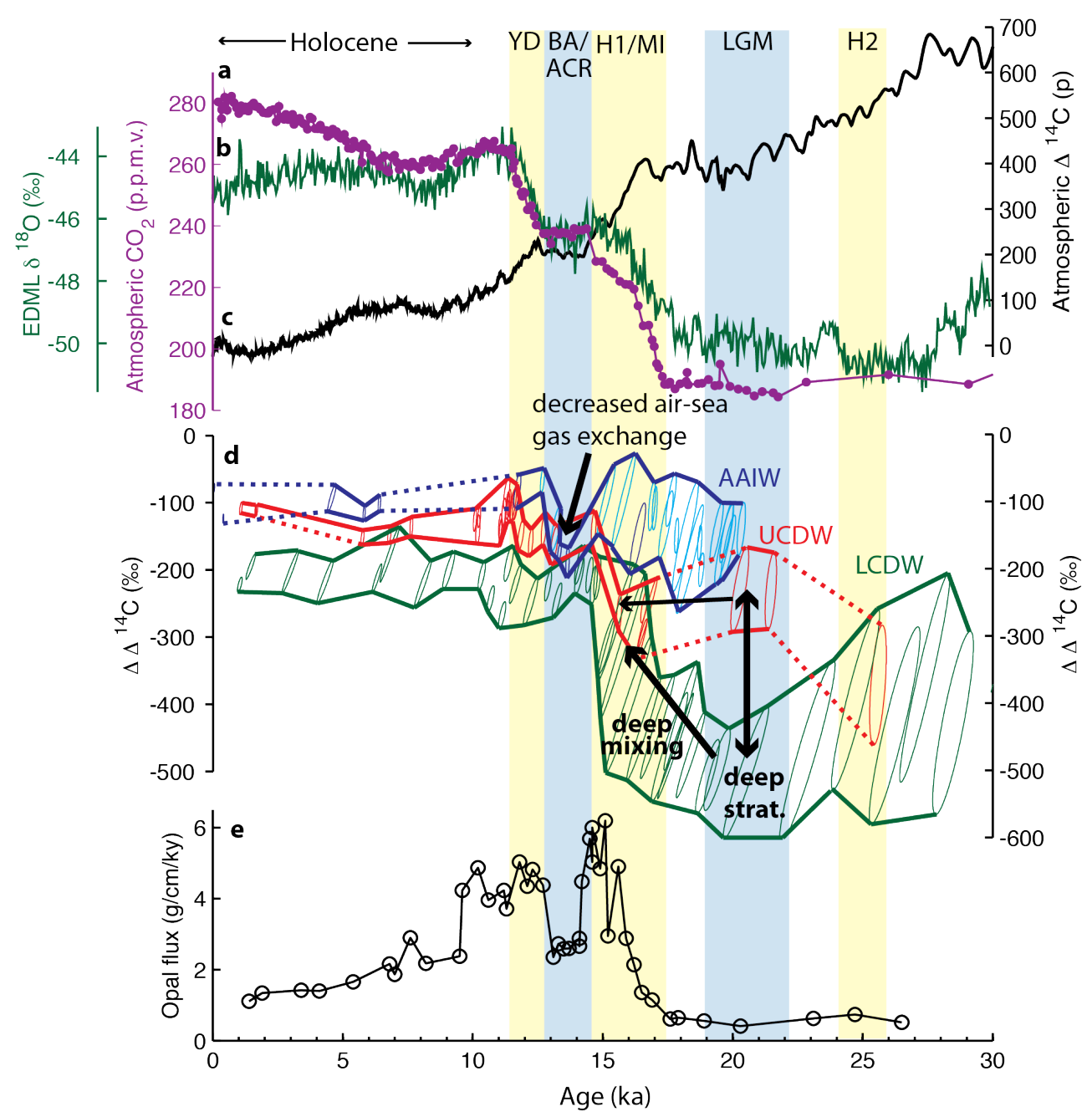

Figure 3. (a) Atmospheric $\mathrm{CO}_{2}$ from EPICA Dome C [Monnin et al., 2001] for data $<22$ $\mathrm{ka}$ on the timescale of Lemieux-Dudon et al. [2010] and from Vostok ice core [Petit et al. 1999] for the data points $>22 \mathrm{ka}$. (b) $\delta^{18} \mathrm{O}$ record from the EDML ice core [EPICA et al., 2006] also placed on the timescale of Lemieux-Dudon et al. [2010]. (c) Atmospheric $\Delta^{14} \mathrm{C}(\%)$ from IntCal09 [Reimer et al., 2009] (d) Offset (\%) of reconstructed radiocarbon $\Delta{ }^{14} \mathrm{C}$ from the contemporaneous atmosphere $\left(\Delta \Delta^{14} \mathrm{C}\right)$ for AAIW (blue), UCDW (red), and LCDW (green). The Younger Dryas (YD), Heinrich Stadial 1/mystery interval (H1/MI), and Heinrich Stadial 2 (H2) are highlighted by yellow vertical bars and the Bolling-Allerod/Antarctic Cold Reversal (BA/ACR) and the Last Glacial Maximum

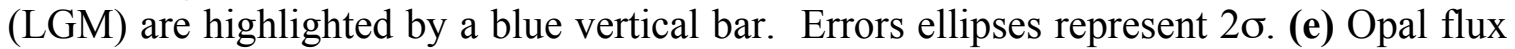
$(\mathrm{g} / \mathrm{cm} / \mathrm{ky})$ south of the Polar Front in the Indian Ocean sector of the Southern Ocean (core TN057-13-4PC; $53.2^{\circ} \mathrm{S}, 5.1^{\circ} \mathrm{E}$ ) as a proxy for Southern Ocean upwelling [Anderson et al., 2009]. 


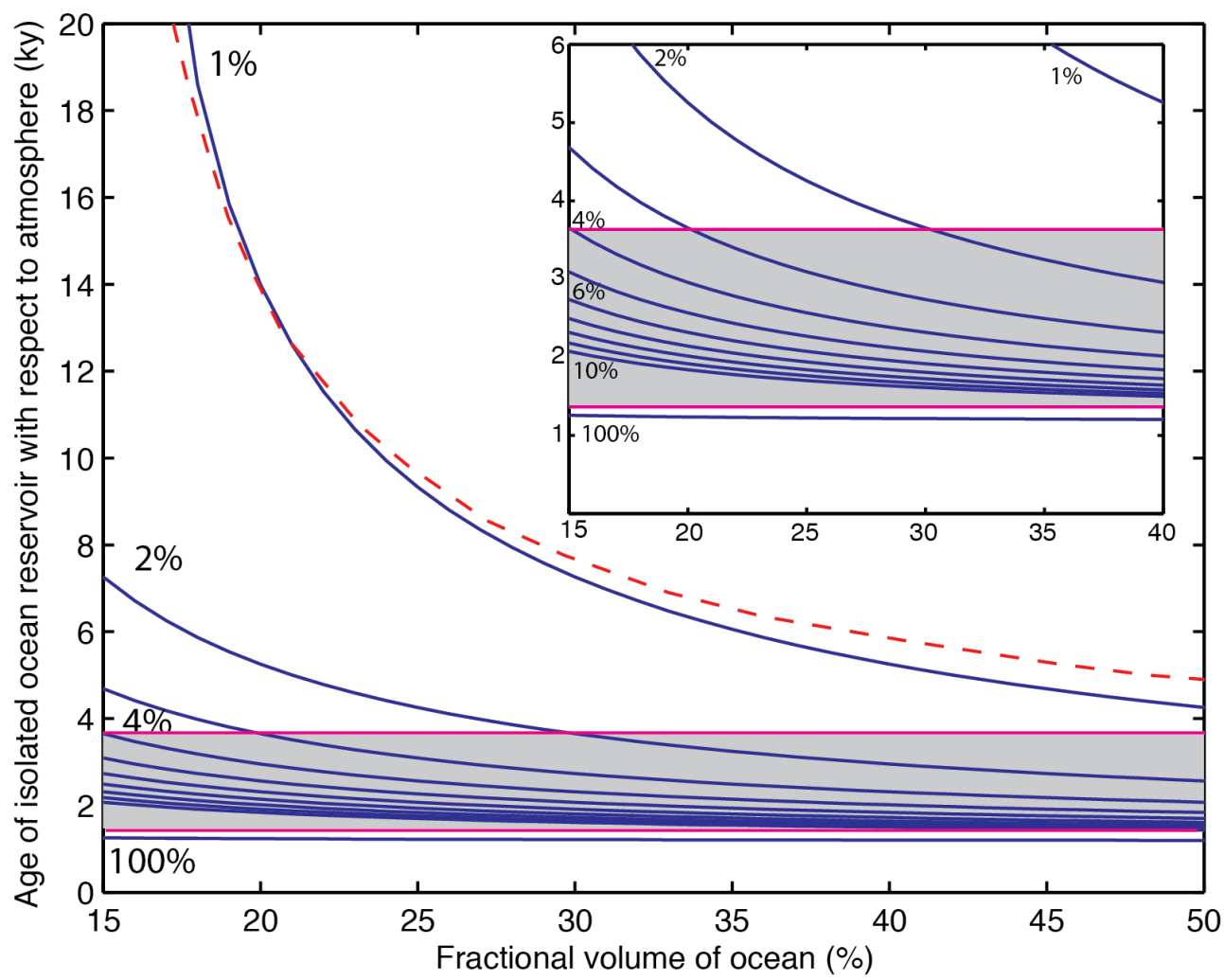

Figure 4. Age (with respect to contemporaneous atmosphere) of the isolated ocean reservoir needed to explain the drop in atmospheric $\Delta^{14} \mathrm{C}$ over the mystery interval plotted as a function of ocean volume occupied by the isolated reservoir. The red dashed line is the solution from Broecker and Barker [2007]. The blue lines are solutions for different percentages (1-10\% and $100 \%)$ of the carbon in the isolated reservoir that are added directly to the atmosphere before being diluted by the oceanic carbon reservoir. The grey box highlights the range of age offsets with respect to the atmosphere of the reconstructed radiocarbon records presented and discussed in this paper immediately prior to the mystery interval [Galbraith et al., 2007; Barker et al., 2010; Skinner et al., 2010]. Inset in the upper right corner is a zoom-in of the same plot. 


\section{References:}

Ahn, J., and E. J. Brook (2008), Atmospheric CO2 and climate on millennial time scales during the last glacial period, Science, 322(5898), Doi 10.1126/Science.1160832, 83-85.

Anderson, R. F., et al. (2009), Wind-Driven Upwelling in the Southern Ocean and the Deglacial Rise in Atmospheric CO2, Science, 323(5920), 10.1126/science.1167441, 1443-1448.

Barker, S., et al. (2010), Extreme deepening of the Atlantic overturning circulation during deglaciation, Nature Geoscience, 3(8), Doi 10.1038/Ngeo921, 567-571.

Broecker, W. (2009), The Mysterious (14)C Decline, Radiocarbon, 51(1), 109-119.

Broecker, W. S., and S. Barker (2007), A 190 per mil drop in atmosphere's D14C during the "Mystery Interval" (17.5 to 14.5 kyrs), Earth and Planetary Science Letters, 256, 90-99.

Bryan, S. P., et al. (2010), The release of (14)C-depleted carbon from the deep ocean during the last deglaciation: Evidence from the Arabian Sea, Earth and Planetary Science Letters, 298(1-2), 10.1016/j.epsl.2010.08.025, 244-254.

Burke, A., et al. (2010), Reconnaissance dating: A new radiocarbon method applied to assessing the temporal distribution of Southern Ocean deep-sea corals, Deep-Sea Research Part I-Oceanographic Research Papers, 57(11), Doi 10.1016/J.Dsr.2010.07.010, 1510-1520.

Butzin, M., et al. (2005), Radiocarbon simulations for the glacial ocean: The effects of wind stress, Southern Ocean sea ice and Heinrich events, Earth and Planetary Science Letters, 235(1-2), 45-61.

De Pol-Holz, R., et al. (2010), No signature of abyssal carbon in intermediate waters off Chile during deglaciation, Nature Geoscience, 3(3), 192-195.

Denton, G. H., et al. (2006), The Mystery Interval 17.5 to 14.5 kyrs ago, Pages News, 14, 14-16.

EPICA, et al. (2006), One-to-one coupling of glacial climate variability in Greenland and Antarctica, Nature, 444(7116), Doi 10.1038/Nature05301, 195-198.

Fischer, H., et al. (2007), Reconstruction of millennial changes in dust emission, transport and regional sea ice coverage using the deep EPICA ice cores from the Atlantic and Indian Ocean sector of Antarctica, Earth and Planetary Science Letters, 260(1-2), Doi 10.1016/J.Eps1.2007.06.014, 340-354.

Francois, R., et al. (1997), Contribution of Southern Ocean surface-water stratification to low atmospheric $\mathrm{CO} 2$ concentrations during the last glacial period, Nature, 389(6654), 929-935.

Frank, M., et al. (1997), A 200 kyr record of cosmogenic radionuclide production rate and geomagnetic field intensity from Be-10 in globally stacked deep-sea sediments, Earth and Planetary Science Letters, 149(1-4), 121-129.

Galbraith, E. D., et al. (2007), Carbon dioxide release from the North Pacific abyss during the last deglaciation, Nature, 449(7164), Doi 10.1038/Nature06227, 890899.

Goldstein, S. J., et al. (2001), Uranium-series and radiocarbon geochronology of deep-sea corals: Implications for Southern Ocean ventilation rates and the oceanic carbon cycle, Earth and Planetary Science Letters, 193(1-2), 167-182. 
Hain, M. P., et al. (2011), Shortcomings of the isolated abyssal reservoir model for deglacial radiocarbon changes in the mid-depth Indo-Pacific Ocean, Geophysical Research Letters, 38, L04604 Doi 10.1029/2010g1046158.

Key, R. M., et al. (2004), A global ocean carbon climatology: Results from Global Data Analysis Project (GLODAP), Global Biogeochemical Cycles, 18(4).

Laj, C., et al. (2002), Geomagnetic field intensity, North Atlantic Deep Water circulation and atmospheric Delta C-14 during the last $50 \mathrm{kyr}$, Earth and Planetary Science Letters, 200(1-2), Pii S0012-821x(02)00618-0, 177-190.

Lemieux-Dudon, B., et al. (2010), Consistent dating for Antarctic and Greenland ice cores, Quaternary Science Reviews, 29(1-2), Doi 10.1016/J.Quascirev.2009.11.010, 8-20.

Lund, D. C., et al. (2011), Abyssal Atlantic circulation during the Last Glacial Maximum: Constraining the ratio between transport and vertical mixing, Paleoceanography, 26, Pa1213 Doi 10.1029/2010pa001938.

Magana, A. L., et al. (2010), Resolving the cause of large differences between deglacial benthic foraminifera radiocarbon measurements in Santa Barbara Basin, Paleoceanography, 115(4), 10.1029/2010pa002011, PA4102.

Mangini, A., et al. (2010), Deep sea corals off Brazil verify a poorly ventilated Southern Pacific Ocean during H2, H1 and the Younger Dryas, Earth and Planetary Science Letters, 293(3-4), 269-276.

Marchitto, T. M., et al. (2007), Marine Radiocarbon Evidence for the Mechanism for deglacial atmospheric CO2 rise, Science, 316, 1456-1459.

Monnin, E., et al. (2001), Atmospheric CO2 concentrations over the last glacial termination, Science, 291(5501), 112-114.

Muscheler, R., et al. (2004), Changes in the carbon cycle during the last deglaciation as indicated by the comparison of Be-10 and C-14 records, Earth and Planetary Science Letters, 219(3-4), 10.1016/s0012-821x(03)00722-2, 325-340.

Orsi, A. H., et al. (1995), On the Meridional Extent and Fronts of the Antarctic Circumpolar Current, Deep-Sea Research Part I-Oceanographic Research Papers, 42(5), 641-673.

Peng, T.-H., and W. S. Broecker (1984), The impacts of bioturbation on the age difference between benthic and planktonic foraminifera in deep sea sediments, Nuclear Instruments and Methods in Physics Research Section B: Beam Interactions with Materials and Atoms, 5(2), 346-352.

Petit, J. R., et al. (1999), Climate and atmospheric history of the past 420,000 years from the Vostok ice core, Antarctica, Nature, 399(6735), 429-436.

Reimer, P. J., et al. (2009), IntCal09 and Marine09 Radiocarbon age calibration curves, 0-50,000 years cal BP, Radiocarbon, 51(4), 1111-1150.

Robinson, L. F., and T. van de Flierdt (2009), Southern Ocean evidence for reduced export of North Atlantic Deep Water during Heinrich event 1, Geology, 37(3), 10.1130/g25363a1, 195-198.

Schmittner, A. (2003), Southern Ocean sea ice and radiocarbon ages of glacial bottom waters, Earth and Planetary Science Letters, 213(1-2), 53-62.

Sigman, D. M., et al. (2010), The polar ocean and glacial cycles in atmospheric CO2 concentration, Nature, 466(7302), Doi 10.1038/Nature09149, 47-55. 
Sikes, E. L., et al. (2000), Old radiocarbon ages in the southwest Pacific Ocean during the last glacial period and deglaciation, Nature, 405(6786), 555-559.

Skinner, L. C., and N. J. Shackleton (2004), Rapid transient changes in northeast Atlantic deep water ventilation age across Termination I, Paleoceanography, 19(2).

Skinner, L. C., et al. (2010), Ventilation of the Deep Southern Ocean and Deglacial CO(2) Rise, Science, 328(5982), 10.1126/science.1183627, 1147-1151.

Stephens, B. B., and R. F. Keeling (2000), The influence of Antarctic sea ice on glacialinterglacial CO2 variations, Nature, 404(6774), 171-174.

Stuiver, M., and H. Polach (1977), Reporting of 14C data, Radiocarbon, 19(3), 355-363.

Thornalley, D. J. R., et al. (2011), The Deglacial Evolution of North Atlantic Deep Convection, Science, 331(6014), 10.1126/science.1196812, 202-205.

Waller, R. G., et al. (2011), Cold-Water Coral Distributions in the Drake Passage Area from Towed Camera Observations - Initial Interpretations, Plos One, 6(1), 10.1371/journal.pone.0016153. 


\title{
Chapter 4. Investigating the source of radiocarbon-depleted intermediate waters during the last deglaciation
}

\begin{abstract}
Reconstructing changes in North Atlantic circulation is important for understanding the link between deep-water formation in the North Atlantic and millennial-scale climate change. We collected deep-sea corals by dredge from the Reykjanes Ridge off Iceland from 672 to $1550 \mathrm{~m}$ water depth. After preliminary radiocarbon age screening, we dated seventeen specimens (including solitary corals Desmophyllum dianthus and Caryophyllia, and the colonial corals Madrepora and Lophelia) using U-series methods. Coral calendar ages range from 1991 A.D. to more than 109,000 y before present (B.P.), and all but one coral (with an age of $69.3 \pm 0.4 \mathrm{ky}$ B.P.) had $\delta^{234} U$ values consistent with closed-system radioactive decay. Here we focus on the corals with ages less then $30,000 \mathrm{y}$ B.P. to reconstruct the radiocarbon activity at depths bathed today by Labrador Sea Water (LSW) during the Bølling-Allerød and the Holocene. We find that at these depths, the radiocarbon depletion from the contemporaneous atmosphere was of a similar magnitude during these time periods as estimates of pre-industrial ${ }^{14} \mathrm{C}$ activity in this region $(\sim 70 \%$ depleted from the atmosphere [Key et al., 2004]). These results agree with other deep-sea coral records from both the eastern and western North Atlantic [Adkins, 1998; Schroder-Ritzrau et al., 2003; Frank et al., 2004; Cao et al., 2007], and further extend the temporal coverage of radiocarbon records from this region. Extreme radiocarbon depletions that have been reported from analysis of benthic foraminifera off Iceland [Thornalley et al., 2011] are not observed in the deep-sea coral records. We use this combined data set to examine the feasibility of Antarctic Intermediate Water being the source for these deglacial radiocarbon depletions, and investigate other potential explanations for the extreme radiocarbon anomalies observed elsewhere [North Pacific, Equatorial Pacific, and Arabian Sea; Marchitto et al., 2007; Stott et al., 2009; Bryan et al., 2010] at intermediate depths during the deglaciation.
\end{abstract}

\section{Introduction}

A strong link between changes in the meridional overturning circulation (MOC) of the Atlantic Ocean and abrupt climate oscillations over the last deglaciation has been postulated in the literature [e.g. Broecker, 1994]. Understanding changes in the spatial extent of intermediate waters from different source regions over this time period is important because intermediate water formation is thought to play an important role in the stability of the MOC on millennial time-scales [Keeling and Stephens, 2001; Weaver et al., 2003]. Reconstructions of past changes in the nutrient content, $\varepsilon \mathrm{Nd}$, and radiocarbon at intermediate depths in the Atlantic show large variations that generally 
correlate with Northern Hemisphere millennial climate change over the last deglaciation [Marchitto et al., 1998; Adkins et al., 1998; Came et al., 2003; Robinson et al., 2005; Eltgroth et al., 2006; Came et al., 2008; Pahnke et al., 2008] supporting this connection between intermediate water formation/extent and climate.

In addition to their importance for MOC stability, intermediate depth records spanning the deglaciation have recently received attention because of their potential connection to deglacial $\mathrm{CO}_{2}$ rise. Marchitto et al. [2007] measured the ${ }^{14} \mathrm{C} /{ }^{12} \mathrm{C}$ ratio of benthic foraminifera over the past 38 thousand years $(\mathrm{ka})$ in a sediment core raised from $705 \mathrm{~m}$ water depth off Baja California. After correction for radioactive decay using an core chronology matched to the GISP2 ice core [Grootes and Stuiver, 1997], the resulting radiocarbon record showed a temporal correlation between extremely radiocarbondepleted waters and increases in atmospheric $\mathrm{CO}_{2}$ during the last deglaciation. Marchitto et al. hypothesized that carbon-rich and radiocarbon-depleted waters upwelled in the Southern Ocean during the last deglaciation, contributing to the increase in atmospheric $\mathrm{CO}_{2}$ and the corresponding decrease in atmospheric $\Delta{ }^{14} \mathrm{C}$.

Following this publication, other radiocarbon records from intermediate depths have been published that also show extremely radiocarbon-depleted waters during the last deglaciation, although the timing of the events are not synchronous, or of the same magnitude (Fig. 1). These intermediate-depth records come from very different locations: the Eastern Equatorial Pacific at $600 \mathrm{~m}$ [Stott et al., 2009], the Arabian Sea at 596 and $820 \mathrm{~m}$ [Bryan et al., 2010], the Brazil Margin at 621 and $781 \mathrm{~m}$ [Mangini et al., 2010], and off Iceland between 1237-2303 m [Thornalley et al., 2011]. The apparently widespread nature of these extreme radiocarbon depletions points towards a common oceanographic phenomenon, in particular the effect of the same water mass. With the exception of the extreme radiocarbon depletion in the Eastern Equatorial Pacific (which was interpreted as indicating a greater proportion of North Pacific Intermediate Water (NPIW)), the large radiocarbon depletions in these records have been interpreted to result from increased influence of radiocarbon-depleted Antarctic Intermediate Water (AAIW) at the core site.

However, a radiocarbon record reconstructed from benthic foraminifera from $1000 \mathrm{~m}$ depth off Chile at a site that is currently located within AAIW does not exhibit 
any evidence of extreme radiocarbon-depletion during the last deglaciation [De Pol-Holz et al., 2010]. Similarly, recent results from U-series dated deep-sea corals that live within AAIW in the Drake Passage region of the Southern Ocean do not exhibit large radiocarbon excursions [Burke and Robinson, in revision]. Both of these records are close to the formation regions of AAIW, and thus any radiocarbon-depleted signal should be expected to be more apparent here than further afield, particularly in the Northern Hemisphere.

Here we present new radiocarbon data from U-Th dated deep-sea corals collected from the Reykjanes Ridge off Iceland and compile other radiocarbon records from intermediate depths in the northern-most Atlantic Ocean. These data yield valuable information regarding the ventilation of the North Atlantic through the Holocene and the deglaciation. We then use these results and data from the Southern, Atlantic, Pacific and Indian oceans to investigate the feasibility of a common water mass to explain the extreme radiocarbon depletions found at intermediate depths during the deglaciation. Finally, we explore other possible explanations for the large radiocarbon depletions found at intermediate depths that may not require a common water mass.

\section{Methods}

Deep-sea coral samples were collected by dredge on cruise CE08-06 from depths ranging from 672 to $2046 \mathrm{~m}$ on the Reykjanes Ridge off Iceland (Fig. 2). Dredges typically sampled 500 to $1000 \mathrm{~m}$ of the seafloor laterally, and no more than $350 \mathrm{~m}$ vertically. A total of 47 solitary corals were collected from these locations. Additionally, more than $5 \mathrm{~kg}$ of the colonial corals Madrepora and Lophelia were collected.

A new radiocarbon technique [McIntyre et al., in press] was used to reconnaissance date all of the solitary corals that were collected, as well as 41 pieces of colonial coral. Briefly, a $30 \mathrm{mg}$ piece of carbonate was cut out of the coral sample and was ultrasonicated in MilliQ water and then in methanol for 20 minutes. $\mathrm{CO}_{2}$ gas was generated by dissolving the sample in $85 \%$ phosphoric acid in a vacutainer tube. The ${ }^{14} \mathrm{C} /{ }^{12} \mathrm{C}$ ratio of the $\mathrm{CO}_{2}$ gas was then measured directly by a continuous-flow accelerator mass spectrometer (CFAMS, [Roberts et al., 2009]). This new method of radiocarbon dating provides approximate ages with percent level uncertainties, and forty samples can 
be prepared and analyzed in 2 working days. Based on the approximate ages from the reconnaissance dating, a subset of corals was selected for traditional hydrolysis radiocarbon analysis and $\mathrm{U}-\mathrm{Th}$ dating.

For the corals selected for further study, a portion of the coral (ranging from 0.05 to $1 \mathrm{~g}$ ) was cut and physically cleaned with a Dremel tool to remove ferro-manganese crusts and areas of recalcification. The carbonate was then chemically cleaned with an oxidative and reducing wash, as described in Cheng et al. [2000]. The samples were dissolved in nitric acid and spiked with a mixed ${ }^{229} \mathrm{Th}-{ }^{236} \mathrm{U}$ spike. The $\mathrm{U}$ and $\mathrm{Th}$ fractions of the coral samples were separated and purified using an iron co-precipitation and anion exchange columns [Edwards et al., 1987]. These fractions were analyzed using bracketing standards on a multi-collector inductively coupled plasma mass spectrometer (MC-ICP-MS), with a typical internal precision of $\sim 1 \%$ o $(2 \sigma)$ for $U$ fractions and better than $2 \%$ for the Th fractions. U was measured following the procedure of Robinson et al. [2002]. Th was measured following the procedure of Burke and Robinson [in revision].

In order to calculate an age from the ${ }^{230} \mathrm{Th} /{ }^{238} \mathrm{U}$ ratios of the corals, we needed to account for initial ${ }^{230} \mathrm{Th}$ that was incorporated into the coral (i.e., the ${ }^{230} \mathrm{Th}$ in the coral that is not from the radioactive decay of ${ }^{234} \mathrm{U}$ ). We assumed that the thorium incorporated into the coral skeleton has a ${ }^{232} \mathrm{Th} /{ }^{230} \mathrm{Th}$ atomic ratio of $12,500 \pm 12,500$, which was based on the range of values observed in modern deep-sea corals collected from the North Atlantic, Pacific, and Southern Oceans [Cheng et al., 2000]. We used the measured ${ }^{232} \mathrm{Th} /{ }^{229} \mathrm{Th}$ ratio to determine the concentration of ${ }^{232} \mathrm{Th}$ in the coral. Since the ${ }^{232} \mathrm{Th}$ concentrations of these corals were relatively low (less than $3.9 \mathrm{ng} / \mathrm{g}$ and typically less than $1 \mathrm{ng} / \mathrm{g}$ ), the initial ${ }^{230} \mathrm{Th}$ correction was small: the corrected ages were no more than 382 y younger than the uncorrected ages.

For the corals that had U-Th ages less than $40 \mathrm{ka}, 40 \mathrm{mg}$ of carbonate was cleaned for traditional radiocarbon analysis with an oxidative wash [Shen and Boyle, 1988; Adkins et al., 2002]. The samples were then etched with $\mathrm{HCl}$ to remove $\sim 50 \%$ of the sample mass, and immediately thereafter, were prepared into graphite targets following the standard hydrolysis protocol for carbonates at the National Ocean Sciences Accelerator Mass Spectrometry (NOSAMS) facility. Radiocarbon results are presented 
as Fraction modern $(\mathrm{Fm})$, whereby the ${ }^{14} \mathrm{C} /{ }^{12} \mathrm{C}$ ratio is normalized to a 'modern ${ }^{14} \mathrm{C} /{ }^{12} \mathrm{C}$ (defined as $95 \%$ of the radiocarbon content of NBS Oxalic Acid I normalized to $\delta^{13} \mathrm{C}=$ $19 \%$ and measured in 1950 A.D. [Olsson, 1970]) and a $\delta^{13} \mathrm{C}$ value $=-25 \%$. A scaling blank correction as described in Burke et al. [2010] was used to correct Fm for modern $\mathrm{CO}_{2}$ that adsorbs onto the coral surface [e.g., Eltgroth et al., 2006]. This correction is based on the average $\mathrm{Fm}(\mathrm{Fm}=0.0040 \pm 0.0016 ; 1$ s.d.; $\mathrm{n}=6)$ of a radiocarbon dead coral that was U-Th dated to be $\sim 220 \mathrm{ka}$. The error propagated for the background corrected Fm uncertainty is the standard deviation of these six replicates. This background corrected Fm is then converted to radiocarbon age using the Libby half-life of 5568 y [Stuiver and Polach, 1977; Stuiver, 1980].

The radiocarbon age and the calendar age of the coral sample were used in the following equation [Adkins and Boyle, 1997] to reconstruct the $\Delta{ }^{14} \mathrm{C}$ of the seawater surrounding the coral at the time it grew:

$$
\Delta \Delta^{14} C_{\text {seawater }}=\left(\frac{e^{-14} \text { C age/ } 8033}{e^{- \text {calendar age/ } 8266}}-1\right) \times 1000 \%
$$

The $\Delta^{14} \mathrm{C}$ is a measure of the relative difference between the absolute international standard and a sample's radiocarbon activity after correction for both age and $\delta^{13} \mathrm{C}$ [Stuiver and Polach, 1977]. In addition to plotting $\Delta{ }^{14} \mathrm{C}$, we also plot $\Delta \Delta^{14} \mathrm{C}$, which is the deviation (\%) of the seawater $\Delta^{14} \mathrm{C}$ from the contemporaneous atmosphere:

$\Delta \Delta^{14} \mathrm{C}=\Delta \Delta^{14} \mathrm{C}_{\text {seawater }}-\Delta^{14} \mathrm{C}_{\text {atmosphere }}$

$\Delta{ }^{14} \mathrm{C}_{\text {atmosphere }}$ was determined by averaging the IntCal09 atmospheric $\Delta{ }^{14} \mathrm{C}$ record [Reimer et al., 2009] over a range of $\pm 2 \sigma$ around the calendar age of the coral sample. The standard deviation of this average was then propagated through the calculation of $\Delta \Delta^{14} \mathrm{C}$ to determine the uncertainty on the final $\Delta \Delta{ }^{14} \mathrm{C}$ value. We also calculate radiocarbon age offsets between the reconstructed DIC value and the contemporaneous atmosphere. This age offset depends on the time since the water was last in contact with the atmosphere and on the variable atmospheric radiocarbon activity [Adkins and Boyle, 1997], as well as 
water mass mixing and diffusion and air-sea gas exchange. We calculate the radiocarbon age offsets using the following equation:

Age offset $={ }^{14} \mathrm{C}$ age of DIC of ambient water $-{ }^{14} \mathrm{C}$ age of $\mathrm{CO}_{2}$ in the atmosphere (3)

where the ${ }^{14} \mathrm{C}$ age of the DIC is from the coral skeleton and the ${ }^{14} \mathrm{C}$ age of the atmosphere is from the IntCal09 curve averaged over a range of $\pm 2 \sigma$ around the calendar age of the coral sample. As with the $\Delta \Delta{ }^{14} \mathrm{C}$ calculation, the standard deviation of the atmospheric average was propagated through the calculation to determine the final uncertainty of the radiocarbon age offset.

\section{Results}

The ages from the radiocarbon reconnaissance dating illustrate differences in the age distributions of solitary and colonial corals from the Reykjanes Ridge (Fig 3). The colonial coral age distribution is skewed to young ages, with most corals having radiocarbon ages less than 1,000 radiocarbon years (Ryr) and all of them with ages less than 10,000 Ryr. None of the colonial coral pieces that we dated had ages between 4,000 and 7,000 Ryr. In contrast, the solitary corals have a mode in their age distribution at around 40,000 Ryr in addition to the modern mode of corals with ages less than 1,000 Ryr. This secondary mode is likely a bias resulting from using radiocarbon as a method to screen coral ages since radiocarbon blanks have ages around 40,000 Ryr, so any fossil coral that is older than $40,000 \mathrm{Ryr}$ is indistinguishable from the background ${ }^{14} \mathrm{C} /{ }^{14} \mathrm{C}$ ratio.

There are only two solitary corals in our collection that lived during the deglaciation. These corals are both of the genus Flabellum and are the only two Flabellum specimens archived from the CE0806 dredges. We measured U-series and precise radiocarbon isotopic ratios on both of these Flabellum specimens as well as seven corals from the Holocene (two Desmophyllum dianthus, one Caryophyllia, and four pieces of colonial coral (Madrepora or Lophelia). In addition, we selected four of the old/radiocarbon-dead D. dianthus specimens for U-series measurements. While these corals are not likely to be useful for reconstructing $\Delta^{14} \mathrm{C}$, we wanted to determine a Useries calendar age for at least some of these corals to ensure that they were indeed older 
than $40 \mathrm{ka}$, and the low radiocarbon content in their skeletons represented their old calendar age as opposed to an anomalously low $\Delta{ }^{14} \mathrm{C}$ of the DIC in the past (Table 2).

The corals that were U-series dated had calendar ages (corrected for initial ${ }^{230} \mathrm{Th}$ and calculated as years before present (B.P.) where present is defined as 1950 A.D.) ranging from -0.041 (1991 A.D.) to $110 \mathrm{ka}$. The four corals that were radiocarbon-dead had calendar ages greater than $68 \mathrm{ka}$. We measured the $\delta^{234} \mathrm{U}$ to monitor the closedsystem behavior of the coral (Fig. 4). With the exception of one D. dianthus specimen with a U-Th age of $69.5 \pm 0.6 \mathrm{ka}$, all corals that were U-series dated had $\delta^{234} \mathrm{U}$ values that fell within the error envelope of closed-system decay from an initial $\delta^{234} U$ value equal to that found in modern seawater (147 $\pm 7 \%$, [Henderson, 2002; Robinson et al., 2004]). The $69.5 \mathrm{ka}$ coral exhibits apparently open system behavior, but it is not considered further in this study as its age is too old for radiocarbon reconstructions.

The $\Delta^{14} \mathrm{C}$ of corals $<30$ ka ranged from -73 to $134 \%$ o (Fig. 5). These values were calculated from the calendar age (U-Th age) and the precise radiocarbon age (Ryr) determined by standard hydrolysis protocol following equation 1. The most recently dead coral that was analyzed was a specimen of Madrepora occulata collected from 768 $\mathrm{m}$ water depth with a calendar age of $-41 \pm 47$ y B.P. (i.e., 1991 A.D.) and a reconstructed $\Delta{ }^{14} \mathrm{C}$ of $9 \pm 12 \%$. The reconstructed $\Delta{ }^{14} \mathrm{C}$ agrees with nearby water column measurements at similar depths ranging from 24 to $-1 \%$ [Key et al., 2004] showing that the skeleton of this species records the $\Delta{ }^{14} \mathrm{C}$ of DIC of ambient water. The other species that are used in this study (Flabellum, Desmophyllum, Caryophyllia, and Lophelia) have already been shown to accurately reflect radiocarbon in DIC [Adkins et al., 2002; Frank et al., 2004]. The offset of the $\Delta^{14} \mathrm{C}$ of corals from that of the contemporaneous atmosphere (i.e., the $\Delta \Delta^{14} \mathrm{C}$ ) during the Holocene ranged from $-52.7 \pm 23.4 \%$ to $-66.2 \pm$ $11.2 \%$ o $(409 \pm 63$ y to $533 \pm 159 \mathrm{y})$, which are within error of the calculated background (pre-1950 bomb spike) radiocarbon at these depths [Key et al., 2004]. The two Flabellum from $14.4 \pm .1 \mathrm{ka}$ and $14.5 \pm .1 \mathrm{ka}$ had $\Delta \Delta^{14} \mathrm{C}$ of $-97.5 \pm 33 \%$ and $-95.0 \pm 34 \%$ respectively, within error of the Holocene corals, and corresponding to age offsets of 643 $\pm 85 \mathrm{y}$ and $668 \pm 95 \mathrm{y}$. The two corals from $\sim 35 \mathrm{ka}$ had $\Delta \Delta \Delta^{14} \mathrm{C}$ of $-158 \pm 90 \%$ to $-235 \pm$ $135 \%$ o $(866 \pm 878$ y to $1322 \pm 861$ y), but the propagated radiocarbon blank correction 
errors for these old corals are too large to allow firm conclusions to be drawn about this time period.

\section{Discussion}

\subsection{North Atlantic ventilation}

The formation of NADW is supplied by the northward transport of warm, saline waters from low latitudes by the North Atlantic Current and is a major component of the MOC. Deep convection in the Nordic Seas results in Iceland-Scotland Overflow Water (ISOW), which flows south along the eastern flank of the Reykjanes Ridge, crosses west into the Irminger Basin at the Gibbs Fracture Zone, and then flows north along the western flank of the Reykjanes Ridge. Labrador Sea Water (LSW) is formed by deep convection in the Labrador Sea and it overlies and mixes with ISOW (as well as Denmark Strait Overflow Water) to form NADW [Dickson and Brown, 1994] (Fig 2).

The boundary between LSW and ISOW along the Reykjanes Ridge is at $\sim 1500 \mathrm{~m}$ [Boessenkool et al., 2007], so the corals used for radiocarbon reconstructions come from depths corresponding to LSW (768-1429 m). LSW (and NADW in general) constitutes some of the most radiocarbon-enriched water in the modern deep ocean $\left(\Delta^{14} \mathrm{C}=10\right.$ to 25\%o, for LSW and around -50\% for NADW [Key et al., 2004]) since the water feeding NADW is at the surface long enough to obtain a high radiocarbon value from air-sea gas exchange with the atmosphere. The presence of bomb radiocarbon in these waters from nuclear testing in the late 1950s/early 1960s [Key et al., 2004] further illustrates the recent connection of these waters to the surface. The most-recently dead coral that was analyzed (1991 A.D.) shows the presence of bomb radiocarbon $\left(\Delta^{14} \mathrm{C}=9 \pm 12 \%\right.$ in this region to a depth of $768 \mathrm{~m}$.

The constant age $\left(\Delta \Delta^{14} \mathrm{C}\right)$ offset from the contemporaneous atmosphere through the Holocene implies similar ventilation of intermediate waters near the Reykjanes Ridge over the last $9.5 \mathrm{ka}$. The age $\left(\Delta \Delta^{14} \mathrm{C}\right)$ offset of these waters at 14.4 and $14.5 \mathrm{ka}$ is slightly larger, but still within error of the values from the Holocene (Fig. 5), indicative of a similar ventilation during the Bølling-Allerød. The deep-sea coral radiocarbon values from the Reykjanes Ridge are also in agreement with previously published deep-sea coral radiocarbon reconstructions from these high northern latitudes - both from Orphan Knoll 
in the Northwest Atlantic [Cao et al., 2007] and from north of $45^{\circ} \mathrm{N}$ in the Northeast Atlantic [Adkins et al., 1998; Schroder-Ritzrau et al., 2003; Frank et al., 2004]. The Orphan Knoll corals are from $1600 \mathrm{~m}$ in the Northwest Atlantic and are currently bathed in LSW, the same water mass as the Reykjanes Ridge corals [Cao et al., 2007]. The corals from the Northeast Atlantic are from 240-745 m depth and are currently bathed in Eastern North Atlantic Water or subsurface waters depending on the depth [Adkins et al., 1998; Schroder-Ritzrau et al., 2003; Frank et al., 2004]. The largest radiocarbon age offset recorded in these high-latitude deep-sea coral records is $886 \pm 167 \mathrm{y}$ at $13.06 \mathrm{ka}$, recorded in a Caryophyllia from $240 \mathrm{~m}$ water depth off the coast of France. These coral records all show relatively similar radiocarbon ages through the Holocene and during the Bølling-Allerød, despite being from different sides of the basin.

Although there is some small millennial scale variability of up to $\sim 300 \mathrm{y}$ in the coral record, the deep-sea corals in the North Atlantic do not record the extreme radiocarbon depletions that have been reported from foraminiferal ${ }^{14} \mathrm{C} /{ }^{12} \mathrm{C}$ at intermediate depths off Iceland (Fig. 5) [Thornalley et al., 2011]. Due to the sample age distribution of the deep-sea corals in this region, the coral record is not continuous, but it is sufficiently well resolved to raise questions about the radiocarbon content of intermediate depth DIC.

The Iceland record is compiled from analyses of benthic foraminifera from three different cores, the shallowest of which (RAPiD-10-1P, $1.2 \mathrm{~km}$ ) comes from a depth corresponding to LSW, and the deeper two cores (RAPiD-15-4P, $2.1 \mathrm{~km}$; RAPiD-17-5P, $2.3 \mathrm{~km}$ ) come from depths corresponding to ISOW [Thornalley et al., 2010]. Today these cores are bathed in relatively radiocarbon-enriched waters [Key et al., 2004]. However, over the last deglaciation, the age-corrected ${ }^{14} \mathrm{C} /{ }^{12} \mathrm{C}$ of the benthic foraminifera indicate high-frequency and large magnitude variations in radiocarbon (shifts of $\sim 300-400 \%$ on sub-millennial timescales), that cannot be explained by the in situ decay. Thus, this radiocarbon-depleted signal must be caused by another mechanism. Thornalley et al. [2011] hypothesize that the extreme deglacial radiocarbon depletions near Iceland resulted from a decrease in the formation of North Atlantic Deep Water, which allowed the intrusion of AAIW to the high northern latitudes. Indeed, various water mass tracers $\left(\delta^{13} \mathrm{C}, \varepsilon \mathrm{Nd}, \mathrm{Cd}\right)$ suggest that the extent of AAIW (or its glacial equivalent) in the Atlantic was greater during the deglaciation than it is today [Pahnke et al., 2008], perhaps even 
extending as far north as $61^{\circ} \mathrm{N}$ on the Björn drift on the eastern flank of the Reykjanes Ridge [Rickaby and Elderfield, 2005], although a record from the Florida Current suggests that the opposite is true [Came et al., 2008]. Additionally, radiocarbon records reconstructed from deep-sea corals collected at intermediate depths on the New England Seamounts have high-frequency variations in $\Delta{ }^{14} \mathrm{C}$ that were explained by switches between northern- and southern- sourced intermediate waters [Robinson et al., 2005; Eltgroth et al., 2006]. However, these variations are on the order of $100 \%$, and $\Delta^{14} \mathrm{C}$ values in intermediate waters in this region never get more than 200\% depleted from the contemporaneous atmosphere. Finally, during the period between $\sim 12.8$ and $13.8 \mathrm{ka}$, the radiocarbon reconstructed from deep-sea corals on Orphan Knoll is at times $>320 \%$ more radiocarbon enriched ( $>3,000$ years younger) than that of the benthic foraminifera off Iceland (Fig 5).

Despite the inconsistency between these North Atlantic records they may all be recording past seawater DIC if these locations were bathed by different water masses

with different ${ }^{14} \mathrm{C}$ content. If this is true, the $>3,000$ radiocarbon year offset between benthic organisms at Orphan Knoll and Iceland, as well as the $>2200$ y reservoir age inferred from the Iceland cores would indicate the presence of extremely large isotopic gradients, thereby illustrating the challenges and limitations of compiling representative records from across a wide region.

\subsection{A common water mass?}

The large radiocarbon depletions recorded by benthic foraminifera at intermediate depths in the Pacific, Atlantic, and Indian oceans remain a conundrum. Are these large radiocarbon depletions sourced from a common water mass as has been postulated? If so, where did this water mass come from and why is its signature observed only at specific locations? In the following sections we investigate the potential explanations for the extremely radiocarbon depleted signals which are observed at distal locations at intermediate depths.

One interpretation of the source of the radiocarbon depletions at intermediate depth is a common water mass that is extremely radiocarbon-poor and transported over 
large distances without losing its depleted signature. Indeed, the similarity ${ }^{1}$ of some of these records [in particular Marchitto et al., 2007; Bryan et al., 2010], as well as the inferred link with climate and $\mathrm{CO}_{2}$ rise, support this idea of a quasi-global process. A likely candidate is AAIW which penetrates northwards into each of the major ocean basins today and was thought to be more extensive at times in the past [Marchitto et al., 2007; Bryan et al., 2010; Mangini et al., 2010; Thornalley et al., 2011]. However, there is no evidence from sites currently located in AAIW today for extremely large glacial or deglacial radiocarbon depletions [De Pol-Holz et al., 2010; Burke and Robinson, in revision]. A third radiocarbon record from a site currently bathed by AAIW off New Zealand is not included in this discussion because the reconstructed $\Delta^{14} \mathrm{C}$ values are not based on independent calendar ages [Rose et al., 2010] $]^{2}$.

Another water mass that has been posited as a potential source of the intermediate depth radiocarbon depletions is the North Pacific Intermediate Water (NPIW) [Stott et al., 2009]. However, other records from intermediate depths within the North Pacific do not show radiocarbon depletions as large as those at the Galapagos site [Okazaki et al., 2010; and references therein]. Additionally, $\varepsilon N d$ results from the core from Baja California suggest that a southern-sourced water mass bathed this site during the deglaciation, implying that NPIW is not a likely source for the radiocarbon depletion observed there (Fig. 6) [Basak et al., 2010].

In order to investigate whether these radiocarbon-depleted signals arise from a common southern-sourced water mass we compare the $\Delta^{14} \mathrm{C}$ records from Iceland and Baja California with $\delta^{13} \mathrm{C}$ [Thornalley et al., 2011] and $\varepsilon \mathrm{Nd}$ [Basak et al., 2010] records from the same cores (Figs. 6a and b) because both $\delta^{13} \mathrm{C}$ and $\varepsilon \mathrm{Nd}$ can be used as tracers of water mass source. In the North Atlantic, a decrease in $\delta^{13} \mathrm{C}$ could imply the increased

\footnotetext{
1 The radiocarbon depletions from off Brazil differ from the other records in that the most depleted values are observed before and after the deglaciation (at $23.5 \mathrm{ka}$ and $8.4 \mathrm{ka}$ ) instead of during the deglaciation [Mangini et al., 2010]. These corals could be recording a radiocarbon-depleted signature from natural gas seeps, as the cores were collected from a pock-marked region of the continental slope of Brazil, and as such we do not include them further in our discussion [Mangini et al., 2010].

${ }^{2}$ In the Rose et al. [2010] record, benthic radiocarbon ages were converted to calendar ages using MARINE04 [Hughen et al., 2004] and assuming a constant age offset from the contemporaneous atmosphere (constant reservoir age). These calendar ages were combined with the radiocarbon ages to determine the $\Delta^{14} \mathrm{C}$, thus returning a constant offset of the $\Delta^{14} \mathrm{C}$ value from the atmospheric $\Delta^{14} \mathrm{C}$ (a circular approach since that is what was originally assumed). They then plot these $\Delta^{14} \mathrm{C}$ values on a different age model (based on oxygen isotope stratigraphy and tephra layers). As a result, each sample has two calendar ages (one used to calculate $\Delta^{14} \mathrm{C}$ and the other used to plot $\Delta^{14} \mathrm{C}$ against time) that do not agree, and can differ by more than 3,500 years in some cases.
} 
influence of high-nutrient southern-sourced water as compared to northern-sourced water. However, the $\delta^{13} \mathrm{C}$ record from Iceland does not have a similar structure to the $\Delta^{14} \mathrm{C}$ record, and at times is even anti-phased. A statistical test based on a rank correlation coefficient [Kendall and Gibbons, 1990] indicates that there is no significant monotonic variation of $\delta^{13} \mathrm{C}$ with $\Delta{ }^{14} \mathrm{C}(\tau=0.17, \mathrm{p}=0.17)$. This result suggests that the large radiocarbon depletions off Iceland are not sourced from AAIW. $\varepsilon N d$ can also be used as a water mass tracer, with negative values indicative of water masses sourced from the Atlantic and more positive values from the Pacific [Goldstein and Hemming, 2003]. The Southern Ocean has $\varepsilon N d$ values in between these two end-members [Piepgras and Wasserburg, 1982] and thus a decrease (increase) of $\varepsilon \mathrm{Nd}$ in the Pacific (Atlantic) would indicate a greater influence of southern-sourced waters. In general, at Baja California, the influence of southern-sourced waters is greater during the deglaciation (and generally during periods of low $\Delta{ }^{14} \mathrm{C}$ at this site), although the $\Delta^{14} \mathrm{C}$ and $\varepsilon \mathrm{Nd}$ records are not in phase $(\tau=-0.08, p=0.52)$. A strict interpretation of $\varepsilon N d$ as relative AAIW influence would require an even more depleted radiocarbon source since the lowest reported values of $\Delta{ }^{14} \mathrm{C}$ have a lower fraction of AAIW. Further, a radiocarbon record from $1268 \mathrm{~m}$ on the Brazil Margin [Sortor and Lund, 2011] does not show any extreme radiocarbondepletions despite showing periods of increased AAIW influence reconstructed from $\varepsilon \mathrm{Nd}$ [Pahnke et al., 2008] at the same time as the Baja California record (Fig. 6c). To summarize, although the Baja and Brazil sites were experiencing a greater influence of southern-sourced water at similar times, their radiocarbon records differ by more than $300 \%$. Comparing all of these far-field records with the data from sites that are currently within AAIW [De Pol-Holz et al., 2010; Burke and Robinson, in revision] and the North Atlantic deep-sea coral records that have been discussed (Fig. 6d) suggest that the extreme radiocarbon depletions are not well explained by AAIW.

Even if there was a depleted AAIW in the Southern Ocean, recent results from a box model [Hain et al., 2011] show that unrealistic oceanographic conditions are required (e.g., no mixing between the North and South Pacific) to explain the magnitude and duration of the radiocarbon depletions observed off Baja California. Additionally, these box model results show that mixing on the time scales it would take to transport this water mass to the various distal locations where these extreme radiocarbon depletions are 
observed would largely dissipate any radiocarbon-depleted signature originally carried by the water mass.

If AAIW is not the source of depleted radiocarbon, then there is still the potential for upwelling from another part of the ocean. This upwelling would still need to be sourced from the deep abyss to explain the increase in $\mathrm{CO}_{2}$ and the decrease of $\Delta^{14} \mathrm{C}$ in the atmosphere. Records of radiocarbon from deep sites (>1750 m) from the last glacial period do indeed show larger depletions than observed at the same locations today [Skinner and Shackleton, 2004; Galbraith et al., 2007; Skinner et al., 2010; Burke and Robinson, in revision], but not as depleted as some of the records from intermediate depths. Moreover, the radiocarbon depletion observed in the abyssal Pacific, Atlantic, and Southern Oceans during the last glacial period is not observed after the start of the Bølling-Allerød ( 14.6 ka), which is presumably due to a large-scale ventilation event at that time [Burke and Robinson, in revision], making it an unlikely source of extremely radiocarbon-depleted waters in the second half of the deglaciation.

\subsection{Potential biases in foraminiferal records}

An alternate explanation for the large decay-corrected radiocarbon depletions that have been reported at intermediate depths during the deglaciation could be biases in the approach of using foraminifera to reconstruct radiocarbon in DIC of ambient water. Such biases may either come from the calendar age or from the ${ }^{14} \mathrm{C} /{ }^{12} \mathrm{C}$ ratio of the foraminifera. For instance, analyses of different benthic species from the same depth in a sediment core have shown that there can be significant radiocarbon offsets between species. Since more than $0.15 \mathrm{mg}$ of foraminifera is typically needed for a ${ }^{14} \mathrm{C}$ measurement [Magana et al., 2010], it is common to combine species of benthic foraminifera for a single measurement. For example, a recent study by Magana et al. [2010] shows that the $\Delta^{14} \mathrm{C}$ of Pyrgo sp. (an infaunal species) can be up to $250 \%$ more depleted than that of other benthic taxa that are epifaunal, likely resulting from pore water carbon that is more radiocarbon depleted than bottom water. Such an artifact could contribute to the large radiocarbon depletions observed in studies that use mixed benthic taxa to reconstruct radiocarbon, e.g. the records from the Arabian Sea and Iceland [Bryan et al., 2010; Thornalley et al., 2011]. This bias could not be an explanation for the large 
depletions reported from Baja California and the Galapagos, since they use single benthic taxa (e.g. Uvigerina, which has not been shown to have a bias) during the times of the large depletions [Marchitto et al., 2007; Stott et al., 2009].

Another potential difficulty for reconstructions of radiocarbon from foraminifera comes from age biases resulting from bioturbation. Peng and Broecker [1984] investigated this issue using a one-dimensional sediment bioturbation model. They found that bioturbation and changing abundances of benthic and planktic foraminifera could bias benthic-planktic radiocarbon age differences by more than $2000 \mathrm{y}$. This effect can be minimized by using high sedimentation rate cores and by sampling from the core depths that correspond to benthic abundance peaks [e.g. Keigwin, 2004]. Bioturbation is unlikely to have been the cause of the large depletions off Baja because of the high sedimentation rate $(\sim 30 \mathrm{~cm} / \mathrm{ky})$ and its presence in a low-oxygen zone. The record from Iceland was constructed from benthic abundance peaks and the core had relatively high sedimentation rates $(10-40 \mathrm{~cm} / \mathrm{ky})$, minimizing the potential influence of bioturbation. The records from the Galapagos and the Arabian Sea are most likely to have been affected by bioturbation, since foraminifera abundance peaks were not utilized and the sedimentation rate of these cores ranged between $\sim 10$ and $15 \mathrm{~cm} / \mathrm{ky}$. Relying on foraminifera abundance peaks makes it difficult to get a continuous radiocarbon record, however abundance peak data adds confidence to the reconstructed radiocarbon values [e.g. Keigwin, 2004].

Finally, and critically, an accurate calendar age is required in order to reconstruct $\Delta{ }^{14} \mathrm{C}$ in the past. This requirement can be fulfilled in a variety of ways. U-series can be used to date deep-sea corals (as was done in this study) giving a precise and independent calendar age, although these ages can be biased by diagenetic alteration resulting in opensystem behavior or by incorrect initial ${ }^{230} \mathrm{Th}$ assumptions. These biases can be minimized by only including corals that have initial $\delta^{234} \mathrm{U}$ that is within error of modern seawater (Fig. 4) and by assuming a large range of initial ${ }^{232} \mathrm{Th} /{ }^{230} \mathrm{Th}$ ratios. For radiocarbon records reconstructed from benthic foraminifera, calendar age can be determined using two different procedures: correlation of an independent proxy (such as diffuse spectral reflectance or $\delta^{15} \mathrm{~N}$ [Marchitto et al., 2007; Bryan et al., 2010]) to a relatively well-dated and high resolution record such as the $\delta^{18} \mathrm{O}$ record from the GISP2 
ice core or Hulu Cave [Grootes and Stuiver, 1997; Wang et al., 2001], or calibration of planktic radiocarbon age to calendar age by making an assumption about reservoir age for that location through time. In other cases [e.g., Thornalley et al., 2011], it is possible to generate age models using radiometrically dated tephra layers.

Generating an accurate age model is a difficult task for sediment cores, but it is especially important for radiocarbon reconstructions because a $\Delta{ }^{14} \mathrm{C}$ value depends both on the radiocarbon age and the calendar age. As a result of this dependency, a bias in the age model not only affects the timing of an event, but also the magnitude of the event. As shown in Figure 7, if the age of a 15 ka marine sample that should have had a 100\%o offset from the atmosphere is too young by 2,500 years, then the reconstructed $\Delta^{14} \mathrm{C}$ from this biased calendar age would be more than $300 \%$ too low. While age errors this large are an unlikely explanation for the full magnitudes of the extreme radiocarbon depletions, it is possible that this could contribute to the observed depletions.

There are other possible explanations for the extreme deglacial radiocarbon depletions observed at intermediate depths that likely differ by location. For instance, Stott and Timmerman [2011] suggest that $\mathrm{CO}_{2}$-rich hydrothermal vent fluids stored in sediments could explain the intermediate depth radiocarbon anomalies. They hypothesize that the glacial to interglacial increase in ocean temperature would have destabilized these $\mathrm{CO}_{2}$ deposits at intermediate depths, thus providing a mechanism for the release radiocarbon depleted DIC at intermediate depths that has a temporal link to climate change. This hypothesis should be tested in particular for sites near active venting or active ridges, such as near Galapagos or Iceland. However, the extent and volume of these $\mathrm{CO}_{2}$-rich deposits is unknown and so the feasibility of this mechanism has yet to be determined.

Still another explanation for the large radiocarbon depletions could come from the remineralization of old organic carbon. The Baja and Arabian Sea sites are similar in that they are both regions of high productivity, and as a result they have pronounced oxygen minimum zones at intermediate depths and high deposition of organic carbon. Ventilation of these sites with oxygenated waters might result in the remineralization of old organic carbon, which could cause a release of DIC with low ${ }^{14} \mathrm{C}$ in the microhabitat of the benthic foraminifera. Old carbon could also be exported from flooded continental 
shelves as sea level rose. Investigating other similarities between sites where radiocarbon depletions are observed could lead to different explanations for the radiocarbon records.

\section{Conclusions}

Deep-sea corals collected from intermediate depths on the Reykjanes Ridge off Iceland provide a record of the $\Delta^{14} \mathrm{C}$ of the North Atlantic through the Holocene and during the Bølling-Allerød. This $\Delta^{14} \mathrm{C}$ record shows a relatively constant offset from the contemporaneous atmosphere, and is in general agreement with other radiocarbon records from North Atlantic deep-sea corals [Adkins, 1998; Schroder-Ritzrau et al., 2003; Frank et al., 2004; Cao et al., 2007]. The deep-sea coral radiocarbon results during the late Bølling-Allerød and into the transition into the Younger Dryas differ from benthic foraminifera radiocarbon results from nearby cores by more than 3,000 years. The large difference in radiocarbon age, as well as the lack of evidence for a radiocarbon-depleted water mass, casts doubt on the likelihood that AAIW could explain the large radiocarbon depletions observed in foraminiferal records at intermediate depths off Iceland and in records from other ocean basins. While species differences and age model errors could bias $\Delta^{14} \mathrm{C}$ results to old ages, these explanations are unlikely to explain the full magnitude of the radiocarbon depletions. Alternative explanations for large radiocarbon depletions at intermediate depth, such as hydrothermal carbon [Stott and Timmermann, in press] for records near active volcanic sources (e.g., Iceland and Galapagos) or old organic carbon remineralized by an increase in oxygen content in high productivity regions (e.g., Baja California and Arabian Sea), should be further investigated. 


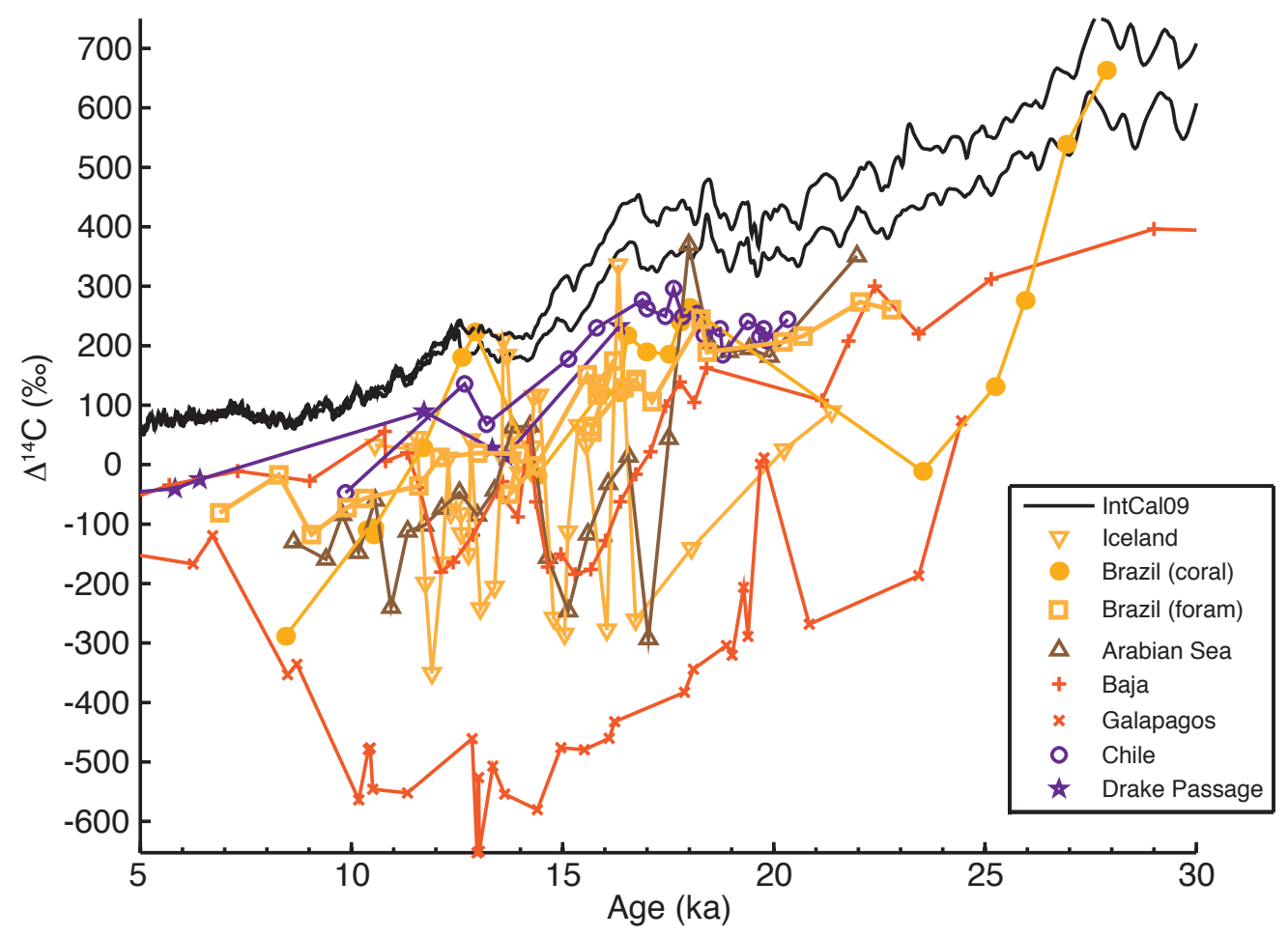

Figure 1. Records of intermediate depth radiocarbon over the last deglaciation reconstructed from foraminifera or deep-sea corals. This compilation includes records that are from modern day locations of Antarctic Intermediate Water (Chile and the Drake Passage) [De Pol-Holz et al., 2010; Burke and Robinson, in revision] plotted in purple and those proposed to record AAIW during the deglaciation (Baja California, Arabian Sea, Brazil, and Iceland) [Marchitto et al., 2007; Bryan et al., 2010; Mangini et al., 2010; Thornalley et al., 2011; Sortor and Lund, 2011] plotted in yellow for the Atlantic, orange for the Pacific, and brown for the Indian Ocean. The record from near the Galapagos Islands [Stott et al., 2009] is proposed to record North Pacific Intermediate Water and is also plotted in orange. 

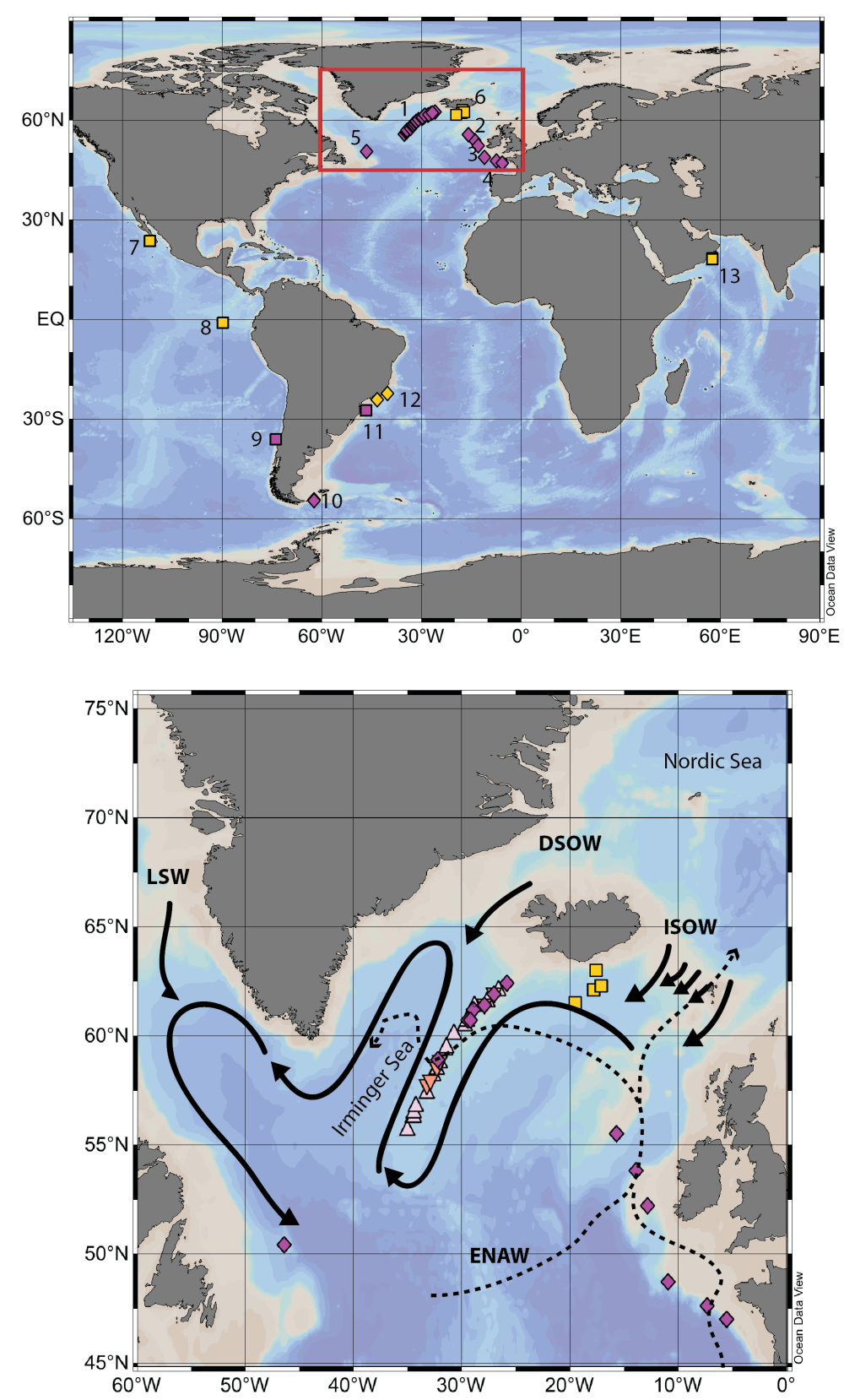

Figure 2. (top) Locations of new deep-sea coral data from off Iceland (1- this study), as well as locations of radiocarbon records discussed in the paper (2- Frank et al., 2004; 3-Adkins, 1998; 4Schroder-Ritzrau et al., 2003; 5- Cao et al., 2007; 6 Thornalley et al., 2011; 7-Marchitto et al., 2007; 8- Stott et al., 2009; 9- De Pol-Holz et al., 2010; 10- Burke and Robinson, in revision; 11Sortor and Lund, 2011; 12- Mangini et al., 2010; 13-Bryan et al., 2011). Benthic foraminifera records are marked by squares, and deep-sea coral data are marked by diamonds. Records that have extreme $(>300 \%)$ radiocarbon depletions are in yellow, the rest are in purple. (bottom) The locations of all corals that were reconnaissance dated are marked with a light pink triangle. If a coral from that location was U-Th dated as well, it is marked with an orange inverted triangle. If a coral from that location was both U-Th dated and radiocarbon dated, it is marked with a purple diamond. Water masses arrows are redrawn from [Dickson and Brown, 1994; New and SmytheWright, 2001]: LSW = Labrador Sea Water; DSOW = Denmark Straits Overflow Water; ISOW = Iceland-Scotland Overflow Water; ENAW = Eastern North Atlantic Water. 

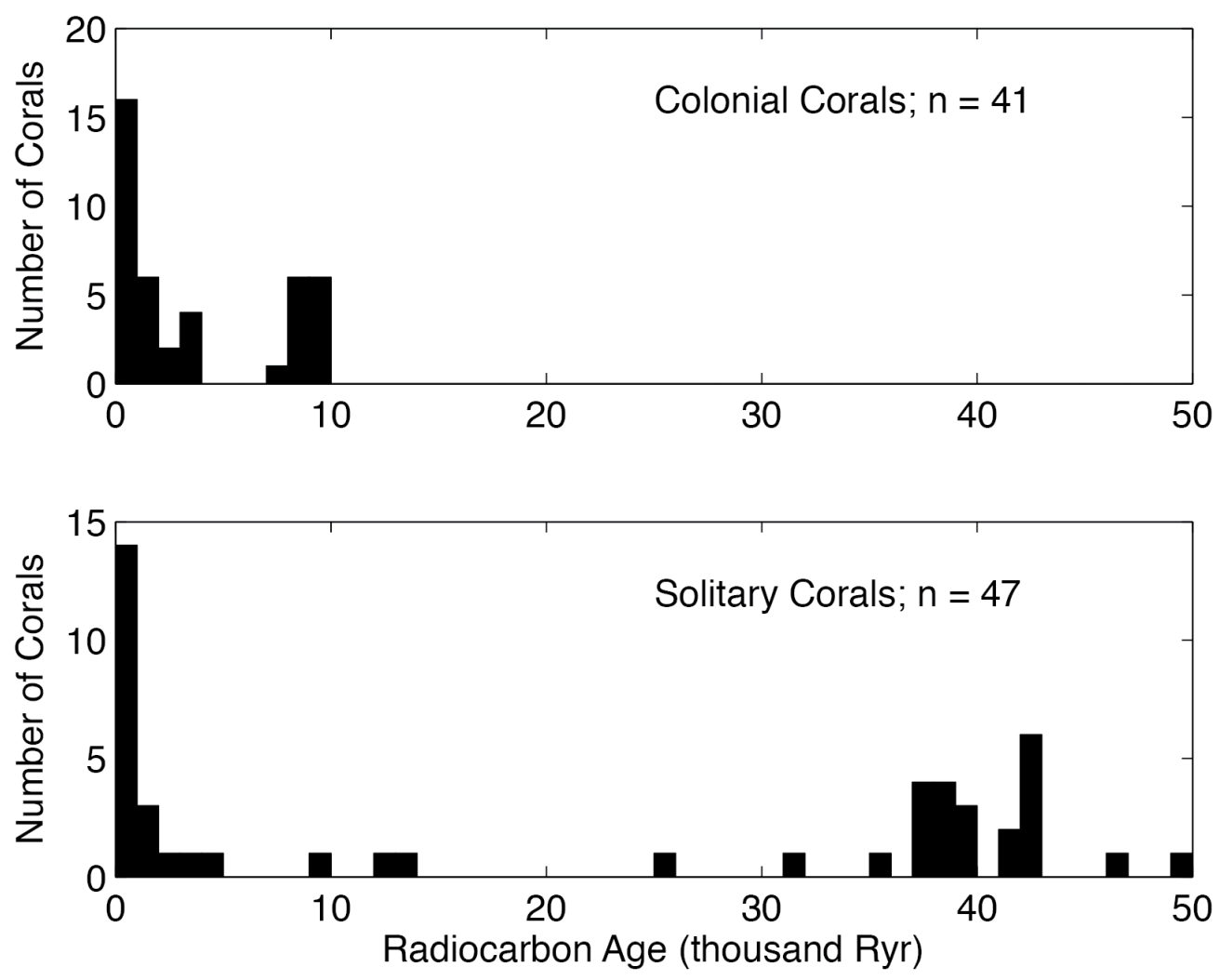

Figure 3. Radiocarbon age distribution of colonial (top) and solitary (bottom) deep-sea corals collected from the Reykjanes Ridge off Iceland. These ages were determined using the reconnaissance gas-bench radiocarbon method developed by McIntyre et al. [in press]. 


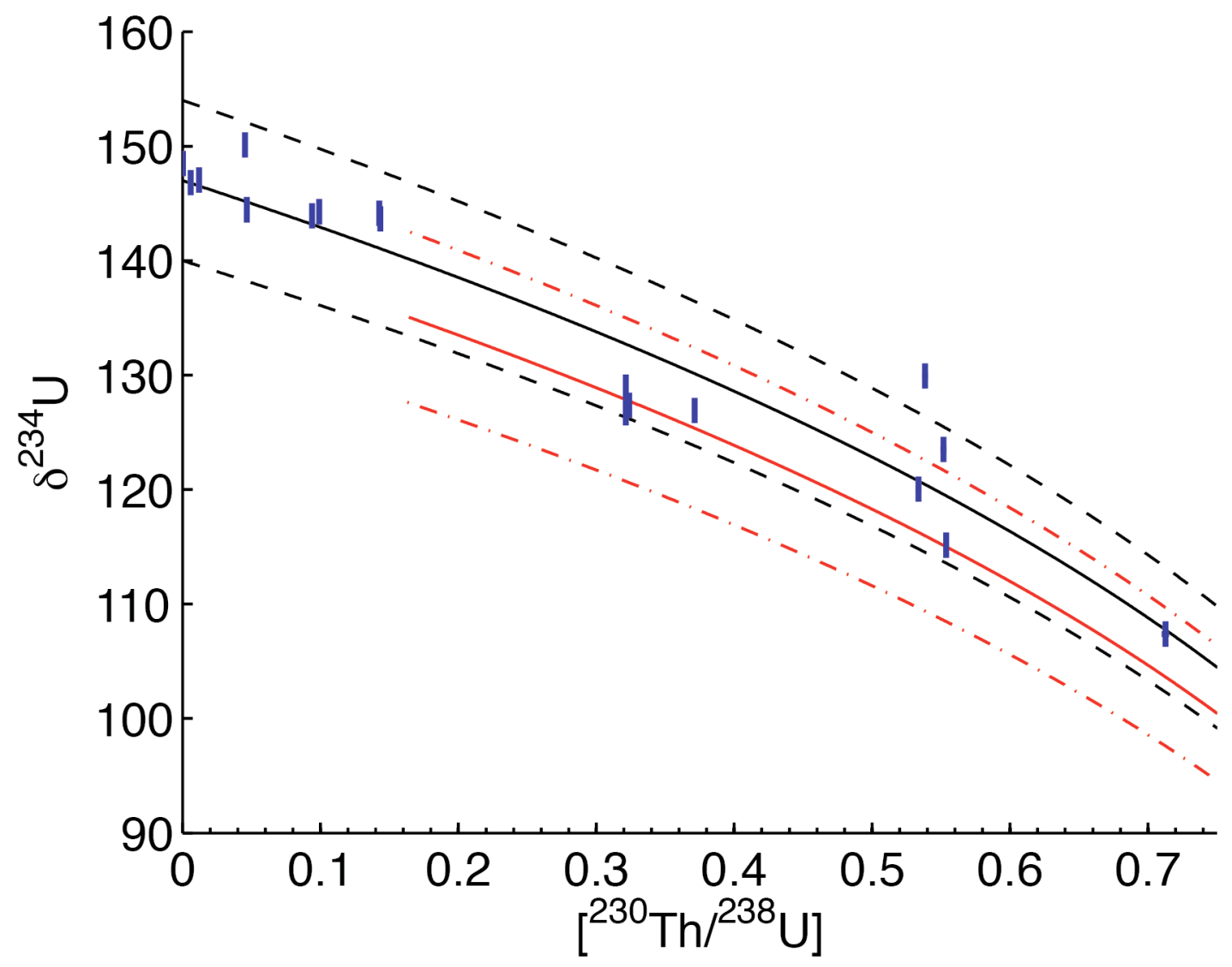

Figure 4. Measured $\delta^{234} \mathrm{U}(\%)$ plotted against the ${ }^{230} \mathrm{Th} /{ }^{238} \mathrm{U}$ activity ratio of the coral skeleton. Errors represent external uncertainty $(1.1 \% ; 2 \sigma)$ which is larger than the internal uncertainty. ${ }^{230} \mathrm{Th} /{ }^{238} \mathrm{U}$ errors are $2 \sigma$ and are smaller than the symbol size. Dashed lines are the error envelopes for seawater $\delta^{234} U$ assuming (1) a constant $\delta^{234} U$ $\left(147 \pm 7 \%\right.$ ) through time (black) or (2) a step decrease in seawater $\delta^{234} \mathrm{U}$ prior to $17 \mathrm{ka}$ (red), as suggested by IntCal09 [Reimer et al., 2009]. One coral (69.5 ka) plotted outside of the error envelope. 

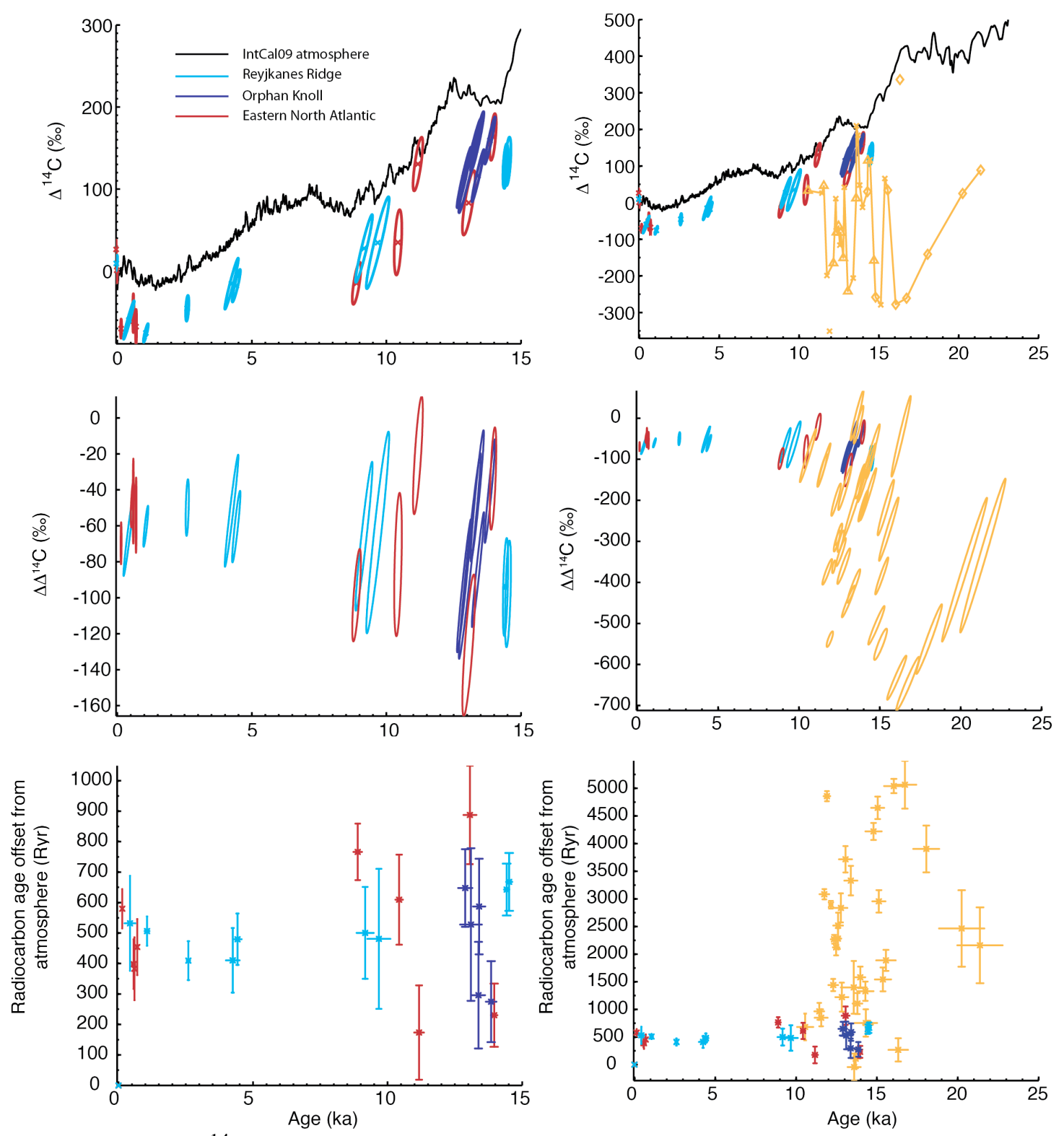

Figure 5. (top) $\Delta^{14} \mathrm{C}$ (plotted as $2 \sigma$ error ellipses) reconstructed from deep-sea corals from the Reykjanes Ridge (cyan, this paper plus one $2.6 \mathrm{ka}$ coral from [Adkins, 1998]), Orphan Knoll (blue, [Cao et al., 2007]), and the Northeast Atlantic (red, [Adkins, 1998; SchroderRitzrau et al., 2003; Frank et al., 2004]). In the right panel, the radiocarbon record reconstructed from benthic foraminifera off Iceland isplotted in gold [Thornalley et al., 2011]. This foraminifera record is distinguished by core: RAPiD-10-1P (1237 m, triangle), RAPiD-15-4P (2133 m, x), and RAPiD-17-5P (2303 m, diamond). The two $\Delta{ }^{14} \mathrm{C}$ values that were excluded from this foraminifera record are plotted, but no line is drawn through them, as in Thornalley et al. [2011]. Atmospheric $\Delta^{14} \mathrm{C}$ from IntCal09 [Reimer et al., 2009] is shown by the black line. Also shown is the $\Delta \Delta^{14} \mathrm{C}$ (middle) and radiocarbon age offset (bottom) between the deep-sea corals plotted above and the contemporaneous atmosphere. 

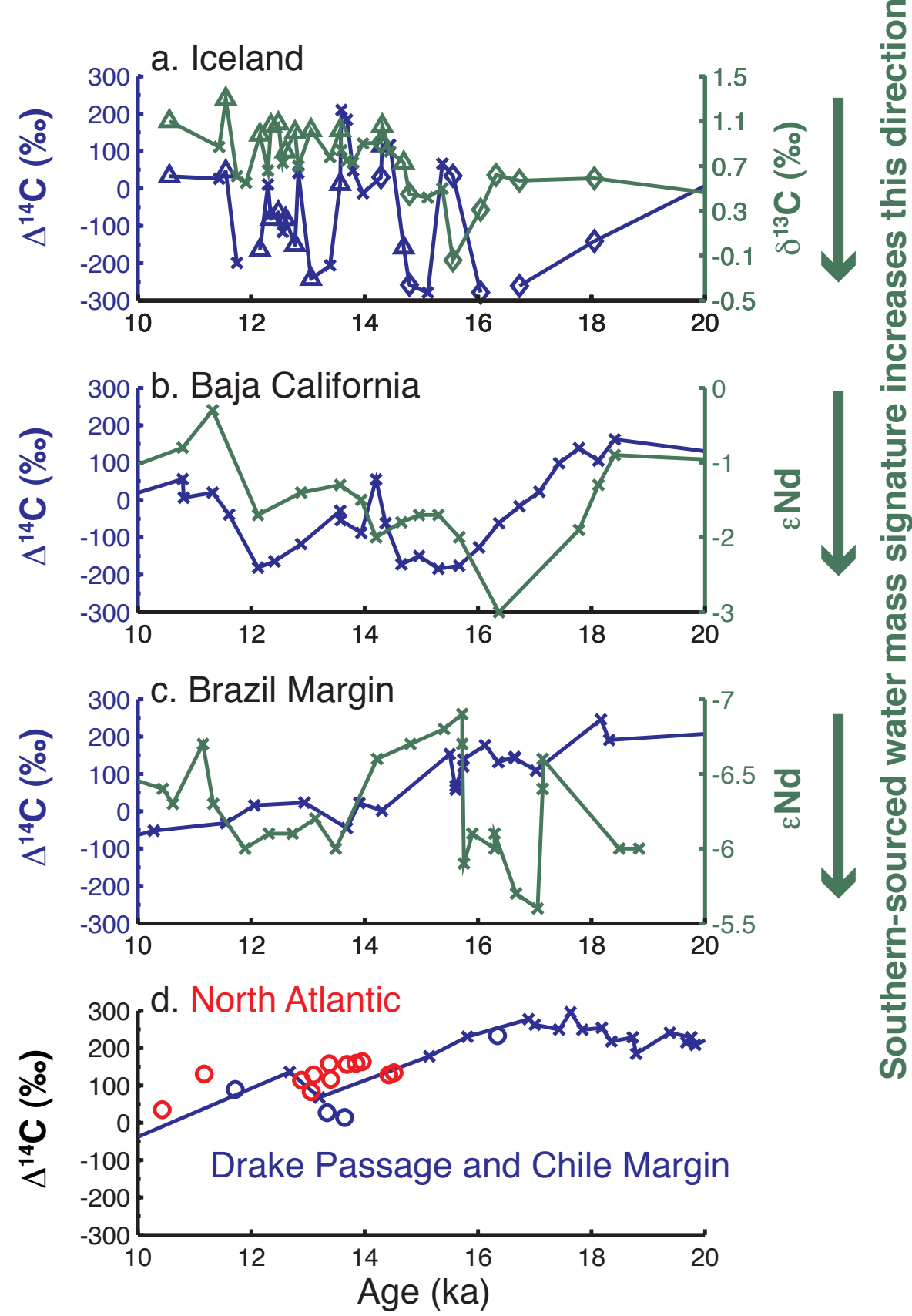

Figure 6. a) $\Delta^{14} \mathrm{C}$ (blue) and $\delta^{13} \mathrm{C}$ (green) from RAPiD-10-1P (1237 m, triangle), RAPiD15-4P (2133 m, x), and RAPiD-17-5P (2303 m, diamond) from Iceland [Thornalley et al., 2011]. b) $\Delta^{14} \mathrm{C}$ (blue) and $\varepsilon N d$ (green) from MC19/GC31/PC08 (705 m) from Baja California [Marchitto et al., 2007; Basak et al., 2010]. c) $\Delta{ }^{14} \mathrm{C}$ (blue) and $\varepsilon \mathrm{Nd}$ (green) from KNR159-5-36GGC (1268 m) from the Brazil Margin [Pahnke et al., 2008; Sortor and Lund, 2011]. d) Deep-sea coral $\Delta^{14} \mathrm{C}$ from the North Atlantic from depths ranging from 240-1445 m (red circles) [Schroder-Ritzrau et al., 2003; Frank et al., 2004; Cao et al., 2007; this paper] and from the Drake Passage from depths (318-816 m) corresponding today to AAIW (blue circles) [Burke and Robinson, in revision]. Also shown is $\Delta^{14} \mathrm{C}$ from SO161-SL22 (1000 m, blue x) [De Pol-Holz et al., 2010]. 


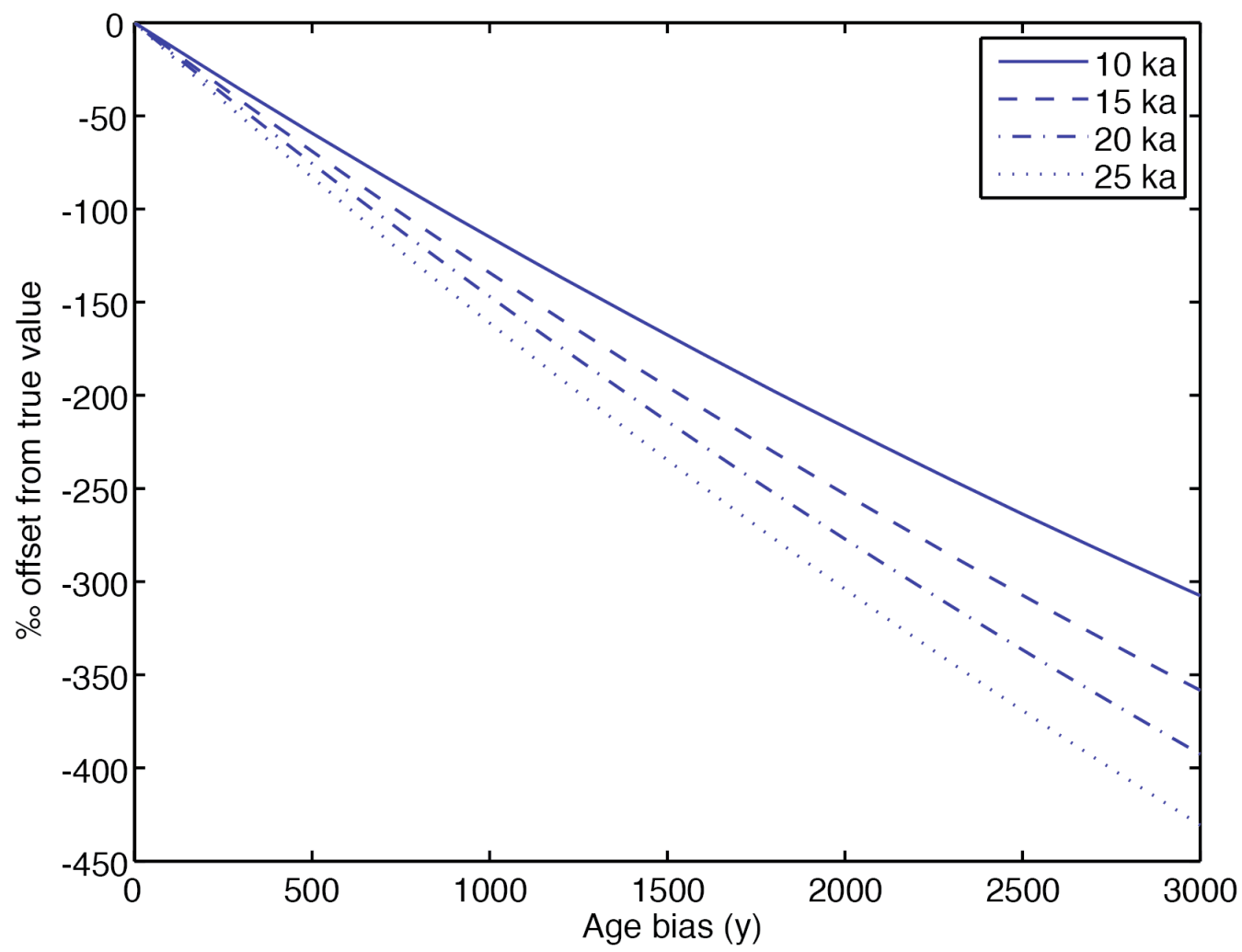

Figure 7. Plot of the $\Delta^{14} \mathrm{C}$ bias (\%) versus the age bias (years too young) of the hypothetical age model for a sample that is $10 \mathrm{ka}$ (solid line), $15 \mathrm{ka}$ (dashed line), $20 \mathrm{ka}$ (dash-dot line), or $25 \mathrm{ka}$ (dotted line). 


\section{References:}

Adkins, J. F. (1998), Deep-sea Corals: A New Oceanic Archive, 234 pp, Massachussetts Institute of Technology/Woods Hole Oceanographic Institution, Cambridge, MA.

Adkins, J. F., and E. A. Boyle (1997), Changing atmospheric Delta C-14 and the record of deep water paleoventilation ages, Paleoceanography, 12(3), 337-344.

Adkins, J. F., et al. (1998), Deep-sea coral evidence for rapid change in ventilation of the deep North Atlantic 15,400 years ago, Science, 280(5364), 725-728.

Adkins, J. F., et al. (2002), Radiocarbon dating of deep-sea corals, Radiocarbon, 44(2), $567-580$.

Basak, C., et al. (2010), Southern Ocean source of superset of 14C-depleted carbon in the North Pacific Ocean during the last deglaciation, Nature Geoscience, 3(11), Doi 10.1038/Ngeo987, 770-773.

Boessenkool, K. P., et al. (2007), North Atlantic climate and deep-ocean flow speed changes during the last 230 years, Geophys. Res. Lett., 34.

Broecker, W. S. (1994), Massive Iceberg Discharges as Triggers for Global ClimateChange, Nature, 372(6505), 421-424.

Bryan, S. P., et al. (2010), The release of (14)C-depleted carbon from the deep ocean during the last deglaciation: Evidence from the Arabian Sea, Earth and Planetary Science Letters, 298(1-2), 10.1016/j.epsl.2010.08.025, 244-254.

Burke, A., and L. F. Robinson (in revision), The Southern Ocean's role in carbon exchange during the last deglaciation.

Burke, A., et al. (2010), Reconnaissance dating: A new radiocarbon method applied to assessing the temporal distribution of Southern Ocean deep-sea corals, Deep-Sea Research Part I-Oceanographic Research Papers, 57(11), Doi 10.1016/J.Dsr.2010.07.010, 1510-1520.

Came, R. E., et al. (2003), Atlantic Ocean circulation during the Younger Dryas: Insights from a new $\mathrm{Cd} / \mathrm{Ca}$ record from the western subtropical South Atlantic, Paleoceanography, 18(4).

Came, R. E., et al. (2008), Deglacial variability in the surface return flow of the Atlantic meridional overturning circulation, Paleoceanography, 23(1), 10.1029/2007PA001450.

Cao, L., et al. (2007), Radiocarbon reservoir age of high latitude North Atlantic surface water during the last deglacial, Quaternary Science Reviews, 26(5-6), 732-742.

Cheng, H., et al. (2000), U-Th dating of deep-sea corals, Geochimica Et Cosmochimica Acta, 64(1-4), 2401-2416.

De Pol-Holz, R., et al. (2010), No signature of abyssal carbon in intermediate waters off Chile during deglaciation, Nature Geoscience, 3(3), Doi 10.1038/Ngeo745, 192195.

Dickson, R. R., and J. Brown (1994), The production of North Atlantic Deep Water: Sources, rates, and pathways, J. Geophys. Res., 99, 12319-12341.

Edwards, R. L., et al. (1987), U-238 U-234-Th-230-Th-232 Systematics and the Precise Measurement of Time over the Past 500000 Years, Earth and Planetary Science Letters, 81(2-3), 175-192. 
Eltgroth, S., et al. (2006), A Deep-sea Coral Record of North Atlantic Radiocarbon through the Younger Dryas, Paleoceanography, 21(4, PA4207), $10.1029 / 2005$ PA001192.

Frank, N., et al. (2004), Eastern North Atlantic deep-sea corals: tracing upper intermediate water Delta C-14 during the Holocene, Earth and Planetary Science Letters, 219(3-4), 297-309.

Galbraith, E. D., et al. (2007), Carbon dioxide release from the North Pacific abyss during the last deglaciation, Nature, 449(7164), Doi 10.1038/Nature06227, 890U899.

Goldstein, S. L., and S. R. Hemming (Eds.) (2003), Long-lived isotopic tracers in oceanography, paleoceanography, and ice-sheet dynamics, Elsevier, Amsterdam.

Grootes, P. M., and M. Stuiver (1997), Oxygen 18/16 variability in Greenland snow and ice with 103 to 105 year time resolution, Journal of Geophysical Research, 102(C12), 26455-26470.

Hain, M. P., et al. (2011), Shortcomings of the isolated abyssal reservoir model for deglacial radiocarbon changes in the mid-depth Indo-Pacific Ocean, Geophysical Research Letters, 38, L04604 Doi 10.1029/2010g1046158.

Henderson, G. M. (2002), Seawater (234U/238U) during the last 800 thousand years, Earth and Planetary Science Letters, 199(1-2), 97-110.

Hughen, K. A., et al. (2004), Marine04 marine radiocarbon age calibration, 0-26 cal kyr BP, Radiocarbon, 46(3), 1059-1086.

Keeling, R. F., and B. B. Stephens (2001), Antarctic sea ice and the control of Pleistocene climate instability, Paleoceanography, 16(1), 112-131.

Keigwin, L. D. (2004), Radiocarbon and stable isotope constraints on Last Glacial Maximum and Younger Dryas ventilation in the western North Atlantic, Paleoceanography, 19(4).

Kendall, M. G., and J. D. Gibbons (1990), Rank correlation methods, 5th ed., vii, 260 p. pp., Oxford University Press, New York.

Key, R. M., et al. (2004), A global ocean carbon climatology: Results from Global Data Analysis Project (GLODAP), Global Biogeochemical Cycles, 18(4).

Magana, A., et al. (2010), Resolving the cause of large differences between deglacial benthic foraminifera radiocarbon measurements in Santa Barbara Basin, Paleoceanography, 115, PA4102.

Mangini, A., et al. (2010), Deep sea corals off Brazil verify a poorly ventilated Southern Pacific Ocean during H2, H1 and the Younger Dryas, Earth and Planetary Science Letters, 293(3-4), 269-276.

Marchitto, T. M., et al. (2007), Marine Radiocarbon Evidence for the Mechanism for deglacial atmospheric CO2 rise, Science, 316, 1456-1459.

Marchitto, T. M., Jr., et al. (1998), Millennial-scale changes in North Atlantic circulation since the last glaciation, Nature, 393(6685), 557-561.

McIntyre, C. P., et al. (in press), Rapid radiocarbon (14C) analysis of coral and carbonate samples using a continuous-flow accelerator mass spectrometry (CFAMS) system, Paleoceanography, doi:10.1029/2011PA002174.

New, A. L., and D. Smythe-Wright (2001), Aspects of the circulation in the Rockall Trough, Continental Shelf Research, 21(8-10), 777-810. 
Okazaki, Y., et al. (2010), Deepwater Formation in the North Pacific During the Last Glacial Termination, Science, 329(5988), Doi 10.1126/Science.1190612, 200204.

Olsson, I. U. (1970), The use of Oxalic acid as a Standard, in Radiocarbon Variations and Absolute Chronology, Nobel Symposium, 12th Proceedings, edited by I. U. Olsson, p. 17, John Wiley \& Sons, New York.

Pahnke, K., et al. (2008), Abrupt changes in Antarctic Intermediate Water circulation over the past 25,000 years, Nature Geoscience, 1(12), 10.1038/ngeo360, 870-874.

Peng, T. H., and W. S. Broecker (1984), The impacts of bioturbation on the age difference between benthic and planktonic foraminifera in deep sea sediments, Nuclear Instruments and Methods in Physics Research Section B: Beam Interactions with Materials and Atoms, 5(2), 346-352.

Piepgras, D. J., and G. J. Wasserburg (1982), Isotopic Composition of Neodymium in Waters from the Drake Passage, Science, 217(4556), 207-214.

Reimer, P. J., et al. (2009), IntCa109 and Marine09 Radiocarbon age calibration curves, 0-50,000 years cal BP, Radiocarbon, 51(4), 1111-1150.

Rickaby, R. E. M., and H. Elderfield (2005), Evidence from the high-latitude North Atlantic for variations in Antarctic Intermediate water flow during the last deglaciation, Geochemistry Geophysics Geosystems, 6.

Roberts, M. L., et al. (2009), A High-performance 14-C accelerator mass spectrometry system, paper presented at 20th International Radiocarbon Conference, Radiocarbon, Kona, HI.

Robinson, L. F., et al. (2002), U-Th dating of marine isotope stage 7 in Bahamas slope sediments, Earth and Planetary Science Letters, 196(3-4), Pii S0012821x(01)00610-0, 175-187.

Robinson, L. F., et al. (2004), U and Th concentrations and isotope ratios in modern carbonates and waters from the Bahamas, Geochimica Et Cosmochimica Acta, $68(8), 1777-1789$.

Robinson, L. F., et al. (2005), Radiocarbon variability in the Western North Atlantic during the last deglaciation, Science, 310, 1469-1473.

Rose, K. A., et al. (2010), Upper-ocean-to-atmosphere radiocarbon offsets imply fast deglacial carbon dioxide release, Nature, 466(7310), Doi 10.1038/Nature09288, 1093-1097.

Schroder-Ritzrau, A., et al. (2003), Deep-sea corals evidence periodic reduced ventilation in the North Atlantic during the LGM/Holocene transition, Earth and Planetary Science Letters, 216(3), 399-410.

Shen, G. T., and E. A. Boyle (1988), Determination of lead, cadmium and other tracemetals in annually-banded corals, Chemical Geology, 67(1-2), 47-62.

Skinner, L. C., and N. J. Shackleton (2004), Rapid transient changes in northeast Atlantic deep water ventilation age across Termination I, Paleoceanography, 19(2).

Skinner, L. C., et al. (2010), Ventilation of the Deep Southern Ocean and Deglacial CO(2) Rise, Science, 328(5982), 10.1126/science.1183627, 1147-1151.

Sortor, R. N., and D. C. Lund (2011), No evidence for a deglacial intermediate water D14C anomaly in the SW Atlantic, Earth and Planetary Science Letters, 310(12), doi:10.1016/j.epsl.2011.07.017, 65-72. 
Stott, L., and A. Timmermann (2011), Hypothesized link between glacial/interglacial atmospheric $\mathrm{CO} 2$ cycles and storage/release of $\mathrm{CO} 2$-rich fluids from the deep sea., AGU Geophysical Monograph Series: Understanding the causes, mechanisms, and extent of the abrupt climate change.

Stott, L., and A. Timmermann (in press), Hypothesized link between glacial/interglacial atmospheric $\mathrm{CO} 2$ cycles and storage/release of $\mathrm{CO} 2$-rich fluids from the deep sea., AGU Geophysical Monograph Series: Understanding the causes, mechanisms, and extent of the abrupt climate change.

Stott, L., et al. (2009), Radiocarbon age anomaly at intermediate water depth in the Pacific Ocean during the last deglaciation, Paleoceanography, 24.

Stuiver, M. (1980), Workshop on 14C data reporting, Radiocarbon, 22, 964-966.

Stuiver, M., and H. Polach (1977), Reporting of 14C data, Radiocarbon, 19(3), 355-363.

Thornalley, D. J. R., et al. (2010), Intermediate and deep water paleoceanography of the northern North Atlantic over the past 21,000 years, Paleoceanography, 25, Pa1211 Doi 10.1029/2009pa001833.

Thornalley, D. J. R., et al. (2011), The Deglacial Evolution of North Atlantic Deep Convection, Science, 331(6014), 10.1126/science.1196812, 202-205.

Wang, Y. J., et al. (2001), A high-resolution absolute-dated Late Pleistocene monsoon record from Hulu Cave, China, Science, 294(5550), 2345-2348.

Weaver, A. J., et al. (2003), Meltwater pulse 1A from Antarctica as a trigger of the bolling-allerod warm interval, Science, 299(5613), 1709-1713. 
Chapter 5. Application of an inverse method to interpret ${ }^{231} \mathrm{~Pa} /{ }^{230} \mathrm{Th}$ observations from marine sediments

Reproduced by permission of American Geophysical Union.

Burke, A., O. Marchal, L. I. Bradtmiller, J. F. McManus, and R. François (2011), Application of an inverse method to interpret ${ }^{231} \mathrm{~Pa} /{ }^{230} \mathrm{Th}$ observations from marine sediments, Paleoceanography, 26, PA1212, doi:10.1029/2010PA002022. 


\title{
Application of an inverse method to interpret ${ }^{231} \mathrm{~Pa} /{ }^{230} \mathrm{Th}$ observations from marine sediments
}

\author{
Andrea Burke, ${ }^{1}$ Olivier Marchal, ${ }^{2}$ Louisa I. Bradtmiller, ${ }^{3}$ Jerry F. McManus, ${ }^{4}$ \\ and Roger François ${ }^{5}$
}

Received 28 June 2010; revised 10 December 2010; accepted 28 December 2010; published 16 March 2011.

[1] Records of ${ }^{231} \mathrm{~Pa} /{ }^{230} \mathrm{Th}$ from Atlantic sediments have been interpreted to reflect changes in ocean circulation during the geologic past. Such interpretations should be tested with due regard to the limited spatial coverage of ${ }^{231} \mathrm{~Pa} /{ }^{230} \mathrm{Th}$ data and the uncertainties in our current understanding of the behavior of both nuclides in the ocean. Here an inverse method is used to evaluate the information contained in ${ }^{231} \mathrm{~Pa} /{ }^{230} \mathrm{Th}$ compilations for the Holocene, Last Glacial Maximum (LGM), and Heinrich Event 1 (H1). An estimate of the abyssal circulation in the modern Atlantic Ocean is obtained by combining hydrographic observations and dynamical constraints. Then sediment ${ }^{231} \mathrm{~Pa} /{ }^{230} \mathrm{Th}$ data for each time interval are combined with an advectionscavenging model in order to determine their (in)consistency with the modern circulation estimate. We find that the majority of sediment ${ }^{231} \mathrm{~Pa} /{ }^{230} \mathrm{Th}$ data for the Holocene, LGM, or H1 can be brought into consistency with the modern circulation if plausible assumptions are made about the large-scale distribution of ${ }^{231} \mathrm{~Pa}$ and about model uncertainties. Moreover, the adjustments in the data needed to reach compatibility with a hypothetical state of no flow (no advection) are positively biased for each time interval, suggesting that the ${ }^{231} \mathrm{~Pa} /{ }^{230} \mathrm{Th}$ data (including that for $\mathrm{H} 1$ ) are more consistent with a persistence of some circulation than with no circulation. Our study does not imply that earlier claims of a circulation change during the LGM or $\mathrm{H} 1$ are inaccurate, but that these claims cannot be given a rigorous basis given the current uncertainties involved in the analysis of the ${ }^{231} \mathrm{~Pa} /{ }^{230} \mathrm{Th}$ data.

Citation: Burke, A., O. Marchal, L. I. Bradtmiller, J. F. McManus, and R. François (2011), Application of an inverse method to interpret ${ }^{231} \mathrm{~Pa} /{ }^{230} \mathrm{Th}$ observations from marine sediments, Paleoceanography, 26, PA1212, doi:10.1029/2010PA002022.

\section{Introduction}

[2] One of the major goals of paleoceanography is to understand past changes in ocean circulation. This is important because the ocean is a major transporter of heat, accounting at maximum for about half of the meridional heat flux of the combined atmosphere-ocean system in the tropics [e.g., Trenberth and Caron, 2001; Wunsch, 2005; Fasullo and Trenberth, 2008]. As a result, changes in ocean circulation can potentially affect climate locally, regionally and/or globally.

[3] Recently, downcore records of the ratio of two radioisotopes in sediment, protactinium-231 and thorium-230, have been used to infer past changes in the strength or structure of the meridional overturning circulation (MOC) in

${ }^{1}$ MIT/WHOI Joint Program in Oceanography, Woods Hole Oceanographic Institution, Woods Hole, Massachusetts, USA

${ }^{2}$ Department of Geology and Geophysics, Woods Hole Oceanographic Institution, Woods Hole, Massachusetts, USA.

${ }^{3}$ Department of Environmental Studies, Macalester College, St. Paul, Minnesota, USA.

${ }^{4}$ Department of Earth and Environmental Science, Lamont-Doherty Earth Observatory, Palisades, New York, USA.

${ }^{5}$ Department of Earth and Ocean Sciences, University of British Columbia, Vancouver, British Columbia, Canada.

Copyright 2011 by the American Geophysical Union. 0883-8305/11/2010PA002022 the Atlantic Ocean [e.g., Yu et al., 1996; McManus et al., 2004; Gherardi et al., 2005; Hall et al., 2006; Gherardi et al., 2009; Guihou et al., 2010; Negre et al., 2010]. ${ }^{231} \mathrm{~Pa}$ and ${ }^{230} \mathrm{Th}$ are produced in seawater in a nearly constant ratio (0.093) from the radioactive decay of ${ }^{235} \mathrm{U}$ and ${ }^{234} \mathrm{U}$, respectively [Yu et al., 1996]. According to current understanding, ${ }^{231} \mathrm{~Pa}$ and ${ }^{230} \mathrm{Th}$ are removed from the water column through a reversible exchange with slowly sinking particles, a process referred to as "particle scavenging" [Nozaki et al., 1981; Bacon and Anderson, 1982]. While both isotopes are particle reactive, ${ }^{230} \mathrm{Th}$ appears in general to be more readily adsorbed onto sinking particles, resulting in a shorter residence time (estimated to $\sim 20-40$ years) than that of ${ }^{231} \mathrm{~Pa}(\sim 100-200$ years) [Anderson et al., 1983; Henderson and Anderson, 2003; McManus et al., 2004]. The residence time of ${ }^{231} \mathrm{~Pa}$ is of the same order of magnitude as the time it would take to ventilate the deep Atlantic basins via replenishment by the southward flowing North Atlantic Deep Water (NADW) [Broecker, 1979]. Thus, a significant fraction $(\sim 45 \%)$ of ${ }^{231} \mathrm{~Pa}$ produced in the Atlantic Ocean would be exported to the Southern Ocean today $[\mathrm{Yu}$ et al., 1996]. Such export would help explain the ${ }^{231} \mathrm{~Pa}$ deficit in core top sediments from the Atlantic, whose ${ }^{231} \mathrm{~Pa}_{\mathrm{xs}, 0}{ }^{230} \mathrm{Th}_{\mathrm{xs}, 0}$ ratios average about half of the production ratio in the water column ([Yu et al., 1996]; the subscript "xs, 0 " refers to excess ${ }^{231} \mathrm{~Pa}$ or ${ }^{230} \mathrm{Th}$ that is not supported by radioactive decay of $U$ present in the mineral 


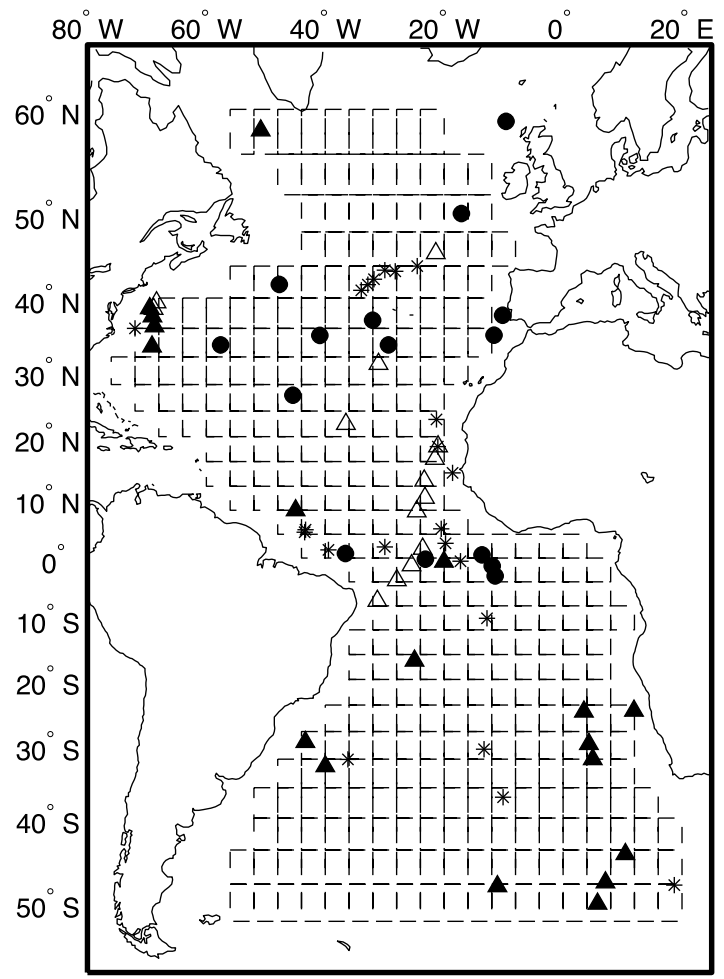

Figure 1. Geographic locations of (1) water column stations with total ${ }^{231} \mathrm{~Pa}$ activity data (filled triangle) or dissolved ${ }^{231} \mathrm{~Pa}$ activity data (open triangle) and (2) sediment cores with ${ }^{231} \mathrm{~Pa} /{ }^{230} \mathrm{Th}$ measurements for the Holocene, LGM, and H1 (filled circle). Locations of cores with only ${ }^{231} \mathrm{~Pa} /{ }^{230} \mathrm{Th}$ measurements for the Holocene and LGM are marked with an asterisk. The model grid is also outlined.

lattices of the sediment, and decay corrected for the time of deposition. Hereafter, ${ }^{231} \mathrm{~Pa}_{\mathrm{xs}, 0} /{ }^{230} \mathrm{Th}_{\mathrm{xs}, 0}$ will be noted as ${ }^{231} \mathrm{~Pa} /{ }^{230} \mathrm{Th}$ ).

[4] Yu et al. [1996] compiled ${ }^{231} \mathrm{~Pa} /{ }^{230} \mathrm{Th}$ ratios measured in Atlantic sediments deposited during the Last Glacial Maximum (LGM) and the Holocene. They found that the average glacial and Holocene ${ }^{231} \mathrm{~Pa} /{ }^{230} \mathrm{Th}$ ratios in the Atlantic Ocean north of the polar front $\left(50^{\circ} \mathrm{S}\right)$ are not significantly different. Hence, $Y u$ et al. inferred that the export of ${ }^{231} \mathrm{~Pa}$ to the Southern Ocean by the MOC was similar during both periods.

[5] Circulation-scavenging models, however, have shown that the Atlantic mean ${ }^{231} \mathrm{~Pa} /{ }^{230} \mathrm{Th}$ might not be a sensitive indicator of the strength of the MOC, and that the spatial distribution of the cores is important. Marchal et al. [2000] showed that the average ${ }^{231} \mathrm{~Pa} /{ }^{230} \mathrm{Th}$ for the whole Atlantic Ocean is less sensitive to changes in the MOC than the average ${ }^{231} \mathrm{~Pa} /{ }^{230} \mathrm{Th}$ for the North Atlantic. Given the uncertainties of these averages, the MOC during the LGM could have been reduced by as much as $30 \%$ compared to present. Siddall et al. [2007] showed that if the Atlantic MOC is slowed or shut down, ${ }^{231} \mathrm{~Pa}$ is scavenged in areas with high particle flux, making those areas the most sensitive to the strength of the MOC. Therefore, unless areas of high particle flux are adequately sampled, the mean ${ }^{23}{ }^{1} \mathrm{~Pa} /{ }^{230} \mathrm{Th}$ of the North Atlantic would be biased to lower values, resulting in an overestimation of the ${ }^{231} \mathrm{~Pa}$ export to the Southern Ocean via the meridional circulation.

[6] Results from a box model [Yu et al., 1996] and a zonally averaged circulation model [Marchal et al., 2000] have suggested that high-resolution ${ }^{231} \mathrm{~Pa} /{ }^{230} \mathrm{Th}$ records from Atlantic sediments could capture variations in the strength of the MOC on centennial to millennial timescales. Thus far, ${ }^{231} \mathrm{~Pa} /{ }^{230} \mathrm{Th}$ records with high resolution have been generated from sediments dating back to about $20 \mathrm{kyr}$ B.P. (before present) in six different cores from the North Atlantic [McManus et al., 2004; Gherardi et al., 2005; Hall et al., 2006; Gherardi et al., 2009] (Figure 1). A notable feature in four of these cores (OCE326-GGC5, SU81-18, SU90-44, and MD95-2027) is the occurrence of high ${ }^{231} \mathrm{~Pa} /{ }^{230}$ Th ratios during Heinrich Event 1 (H1; between 15 and 17 kyr B.P.), nearing the production ratio of these two nuclides in the water column (0.093). Heinrich events are typically identified in North Atlantic sediment cores as layers of coarse-grained lithogenic fragments most likely transported by icebergs, otherwise known as "ice-rafted debris" [Heinrich, 1988; Hemming, 2004]. The increase in sediment ${ }^{231}{ }^{2 a}{ }^{230} \mathrm{Th}$ during $\mathrm{H} 1$ has been interpreted as a reduction in the southward export of ${ }^{231} \mathrm{~Pa}$, owing to a slow down or halting of the MOC [McManus et al., 2004].

[7] However, this interpretation has not gone unchallenged. First, changes in the abundance, vertical flux, and/or chemical composition of particles scavenging $\mathrm{Th}$ and $\mathrm{Pa}$ in the water column could also contribute to downcore variations of ${ }^{231} \mathrm{~Pa} /{ }^{230} \mathrm{Th}$. Elevated sedimentary ${ }^{231} \mathrm{~Pa} /{ }^{230} \mathrm{Th}$ could result from a large abundance or flux of biogenic silica in the water column since biogenic silica (opal) scavenges Pa more readily than Th [e.g., Chase et al., 2002]. Such influence likely occurs in the Southern Ocean [Walter et al., 1997]. It has also been inferred in a core from the eastern North Atlantic, where throughout the Holocene high sedimentary ${ }^{231} \mathrm{~Pa}^{230} \mathrm{Th}$ (ranging from 0.091 to 0.097 ) coincides with elevated diatom flux [Hall et al., 2006]. Note that, in this core, ${ }^{231} \mathrm{~Pa} /{ }^{230} \mathrm{Th}$ stays constant as the diatom flux increases during the Holocene and ${ }^{231} \mathrm{~Pa} /{ }^{230} \mathrm{Th}$ increases as the diatom flux vanishes from 20 to $10 \mathrm{kyr}$ B.P., so a role of biogenic silica in downcore variations of ${ }^{231} \mathrm{~Pa} /{ }^{230} \mathrm{Th}$ remains still to be established. More recently, Lippold et al. [2009] measured ${ }^{231} \mathrm{~Pa} /{ }^{230} \mathrm{Th}$ in a Bermuda Rise core near OCE326-GGC5 [McManus et al., 2004]. They found that the high ${ }^{231} \mathrm{~Pa} /{ }^{230} \mathrm{Th}$ values during $\mathrm{H} 1$ (and also during Heinrich Events 2 and 3) correspond with peaks in diatom abundance. Likewise, Gil et al. [2009] found that the high ${ }^{231} \mathrm{~Pa} /{ }^{230} \mathrm{Th}$ values during H1 in OCE326-GGC5 nearly coincide with an interval of higher diatom content in a nearby core, concluding that opal productivity may have biased earlier interpretation of these values in terms of MOC.

[8] Second, a complete cessation of the Atlantic MOC during $\mathrm{H} 1$ is not consistent with some other sediment data. 
Keigwin and Boyle [2008] reported "apparent ventilation ages" based on the difference in radiocarbon years between deep dwelling bivalves and coeval planktonic foraminifera picked from a sediment core near Bermuda. They found that the apparent ventilation age (assuming constant end-member composition) was about 1000 years during $\mathrm{H} 1$, in contrast to that of about 1500 years during the LGM estimated from the ${ }^{14} \mathrm{C}$ age difference between bivalves and planktonic foraminifera. These results appear inconsistent with ${ }^{231} \mathrm{~Pa} /{ }^{230} \mathrm{Th}$ records from the Bermuda Rise [McManus et al., 2004] if each proxy is interpreted strictly in terms of circulation: ${ }^{231} \mathrm{~Pa} /{ }^{230} \mathrm{Th}$ ratios from the LGM are lower than those from H1, implying a more vigorous circulation during the LGM, whereas the apparent ventilation ages imply that the $\mathrm{H} 1$ circulation was more vigorous. Keigwin and Boyle explained the apparent inconsistency between the two proxy records by hypothesizing that the high ${ }^{231} \mathrm{~Pa} /{ }^{230} \mathrm{Th}$ observed during $\mathrm{H} 1$ result from high diatom (opal) fluxes, as apparently supported by diatom abundance data reported in subsequent work [Gil et al., 2009; Lippold et al., 2009]. Note that the issue of data consistency may not lie solely in reevaluating ${ }^{231} \mathrm{~Pa} /{ }^{230} \mathrm{Th}$ (for a critical discussion of ${ }^{14} \mathrm{C}$ see, e.g., Wunsch [2003]).

[9] The debate about the paleoceanographic significance of ${ }^{231} \mathrm{~Pa} /{ }^{230} \mathrm{Th}$ data from Atlantic sediments is ongoing. For example, Gherardi et al. [2009] showed that similar depths in the North Atlantic Ocean display similar ${ }^{231} \mathrm{~Pa} /{ }^{230} \mathrm{Th}$ at similar times, despite large differences in biogenic silica burial, and concluded that there were significant circulation changes during the deglaciation. Peacock [2010], however, questioned some aspects of this work, in particular the description of the modern MOC in the North Atlantic and the method of making composite vertical profiles of sediment ${ }^{231} \mathrm{~Pa} /{ }^{230} \mathrm{Th}$ for various time slices from widely distant cores. Gherardi et al. [2010] replied that the data assembled in their previous study can best and most simply be explained by changes in ${ }^{231} \mathrm{~Pa}$ export by the circulation. Luo et al. [2010] used a box model to argue that the relationship between sediment ${ }^{231} \mathrm{~Pa} /{ }^{230} \mathrm{Th}$ at any given site and the meridional overturning circulation can be very complex. They claimed that constraining past changes in the MOC from ${ }^{231} \mathrm{~Pa} /{ }^{230} \mathrm{Th}$ at one site is "impossible."

[10] Although past changes in particle composition may be an important control on sediment ${ }^{231} \mathrm{~Pa} /{ }^{230} \mathrm{Th}$ [Hall et al., 2006; Gil et al., 2009; Lippold et al., 2009], these changes remain poorly understood. For example, most of the biogenic silica produced in the sunlit layers of the ocean is dissolved in the water column or near the seafloor [e.g., Nelson et al., 1995], suggesting that past changes in opal production may not be recorded in the sedimentary column. This state of affairs suggests that the interpretation of ${ }^{231} \mathrm{~Pa} /{ }^{230} \mathrm{Th}$ data from deep-sea sediments involve significant uncertainties.

[11] Here an inverse method is used to investigate how (in) consistent sediment ${ }^{231} \mathrm{~Pa} /{ }^{230} \mathrm{Th}$ data for distinct time intervals of the recent geologic past are with the abyssal circulation in the modern Atlantic Ocean. Earlier interpretations of these data are extended in three significant ways: (1) a model of the three-dimensional circulation is used, which is shown to be compatible with hydrographic observations and water column ${ }^{231} \mathrm{~Pa}$ data, (2) earlier compilations of sediment ${ }^{231} \mathrm{~Pa} /{ }^{230} \mathrm{Th}$ data are extended for each interval, and (3) the uncertainties arising from both limited data coverage and incomplete understanding of scavenging are given formal consideration. Note, however, that the major particulate phases carrying $\mathrm{Pa}$ in the ocean (e.g., opal) constitute an important issue that is not addressed here [e.g., Siddall et al., 2005, and references therein].

[12] Our approach of data interpretation follows that of LeGrand and Wunsch [1995], Gebbie and Huybers [2006], and Marchal and Curry [2008]. First, an estimate of the modern circulation is obtained by combining observations with dynamical constraints. Second, the sediment data are adjusted to the modern circulation. If the adjustments to the data are generally larger than the data uncertainties, then compatibility of the sediment data with the modern circulation should be rejected.

[13] This paper is organized as follows. In section 2, the method used to estimate the abyssal circulation in the modern Atlantic Ocean and the sensitivity of the resulting solution to different assumptions are described. In section 3 , a simple model of the transport of ${ }^{231} \mathrm{~Pa}$ in the ocean is described. The consistency of water column ${ }^{231} \mathrm{~Pa}$ data with our modern circulation estimate is tested. In section 4, the (in)compatibility of sediment ${ }^{231} \mathrm{~Pa} /{ }^{230} \mathrm{Th}$ data for the Holocene, LGM, and H1 with the modern circulation and a hypothetical state of no flow is explored. The paleoceanographic implications of our results are discussed in section 5 . Conclusions and perspectives follow in section 6 .

\section{Estimation of the Abyssal Circulation in the Modern Atlantic}

\subsection{Method}

[14] An inverse method is used to provide an estimate of the abyssal circulation in the Atlantic Ocean, which is consistent with hydrographic data, observational estimates of volume transport at specific locations, and dynamical constraints. The model domain extends from $52^{\circ} \mathrm{S}$ to $60^{\circ} \mathrm{N}$ and from $1000 \mathrm{~m}$ to a maximum of $5000 \mathrm{~m}$ water depth (Figure 1). The model grid has a horizontal resolution of $4^{\circ} \times 4^{\circ}$ and a vertical resolution of $1000 \mathrm{~m}$. The model bathymetry is derived by averaging bathymetric data from ETOPO2 (National Geophysical Data Center, National Oceanic and Atmospheric Administration, U.S. Department of Commerce, ETOPO2v2 Global Gridded 2-minute Database, 2006, http://www.ngdc.noaa.gov/mgg/global/etopo2. $\mathrm{html})$. Temperature, salinity, and pressure data from the hydrographic climatology of the World Ocean Circulation Experiment (WOCE [Gourestki and Koltermann, 2004]) are used to calculate in situ density at model grid points from the 1980 International Equation of State (note that model grid points coincide with points of the climatologic grid, so no interpolation is necessary). The standard deviations of temperature and salinity from WOCE climatology are propagated on the density uncertainty using a linear equation of state with $\partial \rho / \partial \mathrm{T}=-2 \times 10^{-4} \rho_{\mathrm{o}} \mathrm{kg} \mathrm{m}^{-3}{ }^{\circ} \mathrm{C}^{-1}\left(\rho_{\mathrm{o}}=\right.$ $1028 \mathrm{~kg} \mathrm{~m}^{-3}$ ) and $\partial \rho / \partial \mathrm{S}=0.8 \mathrm{~kg} \mathrm{~m}^{-3}$. For the error propagation, we assume no pressure error and no correlation between the temperature and salinity deviations. 
Table 1. Prior Uncertainties to Estimate Modern Circulation

\begin{tabular}{lc}
\hline & Uncertainty (Sv) \\
\hline Prior estimate of U, V, W & 1 \\
Volume conservation & 0.01 \\
Thermal wind (V) & 1 \\
Thermal wind (U) & 1 \\
Linear vorticity balance & 1 \\
NADW transport along western & 3 \\
$\quad$ boundary & 3 \\
Integrated meridional transport at & \\
$36^{\circ} \mathrm{N}, 24^{\circ} \mathrm{N}, 32^{\circ} \mathrm{S}$ & 1 \\
AABW transport along western & \\
$\quad$ boundary in South Atlantic & \\
\hline
\end{tabular}

[15] To further constrain the circulation, we consider observational estimates of the volume transport of (1) North Atlantic Deep Water (NADW) along the western boundary between 1000-4000 m (amplitude of $18 \pm 3 \mathrm{~Sv}$, where $1 \mathrm{~Sv}=$ $10^{6} \mathrm{~m}^{3} \mathrm{~s}^{-1}$ [Schmitz and McCartney, 1993]); (2) Mediterranean Outflow Water (MOW) at $12^{\circ} \mathrm{W}$, between $32^{\circ} \mathrm{N}-36^{\circ} \mathrm{N}$ and 1000-2000 m (amplitude of $2 \pm 0.3 \mathrm{~Sv}$ [Ochoa and Bray, 1991; Baringer and Price, 1997]); and (3) Antarctic Bottom Water (AABW) along the western boundary south of the equator between 4000-5000 m (amplitude of $7 \pm 1 \mathrm{~Sv}$ [Hogg et al., 1999; Zenk et al., 1999]). The model bathymetry was deepened to $5000 \mathrm{~m}$ at four locations to accommodate a continuous flow path for AABW (e.g., through the Vema Channel). These locations correspond to grid boxes centered at: $\left(50^{\circ} \mathrm{S}, 50^{\circ} \mathrm{W}\right),\left(30^{\circ} \mathrm{S}, 38^{\circ} \mathrm{W}\right),\left(26^{\circ} \mathrm{S}, 38^{\circ} \mathrm{W}\right)$, and $\left(26^{\circ} \mathrm{S}, 34^{\circ} \mathrm{W}\right)$. We also rely on observational estimates to constrain the integrated meridional volume transport below $1000 \mathrm{~m}$ at three different latitudes. At $36^{\circ} \mathrm{N}$ and $24^{\circ} \mathrm{N}$, the integrated transport is constrained to $-20 \pm 3 \mathrm{~Sv}$, and at $32^{\circ} \mathrm{S}$ it is constrained to $-15 \pm 3 \mathrm{~Sv}$, where the negative values imply a transport to the south [Roemmich and Wunsch, 1985; Talley, 2003; Bryden et al., 2005].

[16] The dynamical constraints are the conservation of volume, the two thermal wind relationships, and the linear vorticity balance (see Appendix 1 in Text S1 in the auxiliary material). ${ }^{1}$ The error for volume conservation is assumed to be $0.01 \mathrm{~Sv}$, and the error for the thermal wind relationships and the linear vorticity balance is taken as $1 \mathrm{~Sv}$. A summary of all of the prior uncertainties used to estimate the modern circulation can be found in Table 1. Note that the dynamical constraints are not imposed at all locations. The thermal wind relationships and the linear vorticity balance, which rely on the geostrophic approximation, are not prescribed between $4^{\circ} \mathrm{S}-4^{\circ} \mathrm{N}$. Furthermore, the linear vorticity balance, which involves the meridional velocity, is not imposed at grid boxes with a meridional boundary or along the western boundary between $1000-4000 \mathrm{~m}$.

[17] The modern circulation is estimated as a least squares solution which jointly satisfies the hydrographic data, the observational estimates of volume transport, and the dynamical constraints given their prior uncertainties [e.g., Wunsch, 1996]. A state vector, $\boldsymbol{x}$, is introduced that consists

${ }^{1}$ Auxiliary materials are available in the HTML. doi:10.1029/ 2010PA002022. of the volume transports $(\mathrm{U}, \mathrm{V}, \mathrm{W})$ defined on the faces of the grid boxes in the zonal, meridional, and vertical directions. A prior estimate of the state, $\boldsymbol{x}_{\boldsymbol{o}}$, is determined by solving the thermal wind equations for $\mathrm{U}$ and $\mathrm{V}$ using the gridded densities from WOCE climatology and assuming a level of no motion at either $3000 \mathrm{~m}$ (as assumed in the inversion of Martel and Wunsch [1993]) or at $4000 \mathrm{~m}$ (approximately the boundary between NADW and AABW in the Brazil Basin, a relatively well studied abyssal basin [e.g., Hogg and Owens, 1999; Morris et al., 2001]). If the local water depth is shallower than the assumed level of no motion, then the seafloor is taken as the level of no motion. After calculating $\mathrm{U}$ and $\mathrm{V}, \mathrm{W}$ is obtained from volume conservation. The error covariance matrix of $\boldsymbol{x}_{\boldsymbol{o}}$ is defined as $\boldsymbol{C}_{\boldsymbol{o}}=\left\langle\left(\boldsymbol{x}-\boldsymbol{x}_{\boldsymbol{o}}\right)\left(\boldsymbol{x}-\boldsymbol{x}_{\boldsymbol{o}}\right)^{\mathrm{T}}\right\rangle$, where brackets denote the expected value and superscript $\mathrm{T}$ denotes the transpose. The diagonal elements of $\boldsymbol{C}_{\boldsymbol{o}}$ are the variances of $\boldsymbol{x}_{\boldsymbol{o}}$, and the off-diagonal elements are the error covariances. Thus, the diagonal elements of $\boldsymbol{C}_{\boldsymbol{o}}$ are the squares of the uncertainty for the prior estimates of the transports $(\mathrm{U}, \mathrm{V}, \mathrm{W})$, that is, $(1 \mathrm{~Sv})^{2}$ (Table 1).

[18] A system of linear algebraic equations, $\boldsymbol{A x}+\boldsymbol{\varepsilon}_{\boldsymbol{A}}=\boldsymbol{b}$, is derived from (1) the observational constraints on NADW transport along the western boundary and on the integrated meridional transport at $36^{\circ} \mathrm{N}, 24^{\circ} \mathrm{N}$, and $32^{\circ} \mathrm{S}$ and (2) the finite difference forms of the dynamical equations. The matrix $\boldsymbol{A}$ includes the coefficients arising from the discretization of these differential equations on the model grid and the vector $\boldsymbol{b}$ includes the climatologic densities at the corners of the grid boxes. The error covariance matrix for this system is $\boldsymbol{C}_{\boldsymbol{A}}=\left\langle(\boldsymbol{A} \boldsymbol{x}-\boldsymbol{b})(\boldsymbol{A} \boldsymbol{x}-\boldsymbol{b})^{\mathrm{T}}\right\rangle$. Thus, the diagonal elements of $\boldsymbol{C}_{\boldsymbol{A}}$ are the squares of the uncertainties of the dynamical constraints (Table 1).

[19] Our problem is to find an estimate of $\boldsymbol{x}$ (i.e., a circulation) that satisfies both the observations and the dynamical constraints given their respective uncertainties. This estimate is provided by the minimum of the objective function:

$$
\mathrm{J}=\left(\boldsymbol{x}-\boldsymbol{x}_{\boldsymbol{o}}\right)^{\mathrm{T}} \boldsymbol{C}_{\boldsymbol{o}}^{-1}\left(\boldsymbol{x}-\boldsymbol{x}_{\boldsymbol{o}}\right)+(\boldsymbol{A} \boldsymbol{x}-\boldsymbol{b})^{\mathrm{T}} \boldsymbol{C}_{\boldsymbol{A}}^{-1}(\boldsymbol{A} \boldsymbol{x}-\boldsymbol{b}) .
$$

The first contribution to $\mathrm{J}$ represents the deviations from the prior estimate of the circulation. The second contribution represents the deviations from the observational estimates of volume transport and the deviations from the dynamical equations. Each contribution is weighted by its corresponding error covariance matrix. Here it is assumed that both $\boldsymbol{C}_{\boldsymbol{o}}$ and $\boldsymbol{C}_{\boldsymbol{A}}$ are diagonal, that is, there are no error covariances. If off-diagonal elements were retained in $\boldsymbol{C}_{o}$ and $\boldsymbol{C}_{\boldsymbol{A}}$, the circulation estimate would be different (e.g., positive error correlations in $\boldsymbol{C}_{\boldsymbol{o}}$ could lead to the estimation of more uniform distributions of $\mathrm{U}, \mathrm{V}$, and $\mathrm{W}$ ).

[20] To find a minimum of $\mathrm{J}$, the gradient $\frac{\partial J}{\partial x}$ is set to zero, which leads to the system of linear algebraic equations

$$
\left(\boldsymbol{C}_{o}^{-1}+\boldsymbol{A}^{T} \boldsymbol{C}_{\boldsymbol{A}}^{-1} \boldsymbol{A}\right) \tilde{\boldsymbol{x}}=\boldsymbol{C}_{o}^{-1} \boldsymbol{x}_{\boldsymbol{o}}+\boldsymbol{A}^{T} \boldsymbol{C}_{\boldsymbol{A}}^{-1} \boldsymbol{b} .
$$

Equation (2) is solved for $\widetilde{\boldsymbol{x}}$ using LU decomposition. The vector $\tilde{\boldsymbol{x}}$ is the state estimate (circulation) at the minimum, that is, the solution of our problem. The uncertainty or error 
Table 2. Integrated Meridional Transports for the Modern Circulation Estimates

\begin{tabular}{lccc}
\hline Latitude & $\begin{array}{c}\text { Prior } \\
\text { Transport } \\
(\mathrm{Sv})\end{array}$ & $\begin{array}{c}\text { Posterior Transport } \\
\text { With Prior LNM } \\
\text { at } 3000 \mathrm{~m}^{\mathrm{a}}(\mathrm{Sv})\end{array}$ & $\begin{array}{c}\text { Posterior Transport } \\
\text { With Prior LNM } \\
\text { at } 4000 \mathrm{~m}^{\mathrm{a}}(\mathrm{Sv})\end{array}$ \\
\hline $36^{\circ} \mathrm{N}$ & $-20 \pm 3$ & $-20 \pm 8$ & $-23 \pm 8$ \\
$24^{\circ} \mathrm{N}$ & $-20 \pm 3$ & $-17 \pm 8$ & $-17 \pm 8$ \\
$32^{\circ} \mathrm{S}$ & $-15 \pm 3$ & $-7 \pm 7$ & $-7 \pm 7$ \\
\hline
\end{tabular}

${ }^{\mathrm{a}}$ Posterior uncertainties are larger than the prior uncertainties because they are calculated from the individual transport uncertainties along the latitude line.

covariance matrix of the solution, $\mathbf{C}=\left\langle(\mathbf{x}-\tilde{\boldsymbol{x}})(\mathbf{x}-\tilde{\boldsymbol{x}})^{\mathrm{T}}\right\rangle$, is calculated by

$$
\mathbf{C}=\left(\mathbf{E}^{\mathrm{T}} \mathbf{E}\right)^{-1} \mathbf{E}^{\mathrm{T}} \mathbf{C}_{\mathbf{o A}} \mathbf{E}\left(\mathbf{E}^{\mathrm{T}} \mathbf{E}\right)^{-1}
$$

where $\boldsymbol{E}=\left[\begin{array}{c}\boldsymbol{I} \\ \boldsymbol{A}\end{array}\right]$ is a partitioned matrix, $\mathbf{I}$ is the identity matrix, and $\boldsymbol{C}_{\boldsymbol{O} \boldsymbol{A}}=\left(\begin{array}{cc}\boldsymbol{C}_{\boldsymbol{o}} & 0 \\ 0 & \boldsymbol{C}_{\boldsymbol{A}}\end{array}\right)$.

\subsection{Results}

[21] We find that the circulations estimated with a prior level of no motion (LNM) at $3000 \mathrm{~m}$ or $4000 \mathrm{~m}$ are both consistent with hydrographic observations and dynamic constraints, given the uncertainties. For the solution with prior $\mathrm{LNM}=3000 \mathrm{~m}$, less than $5 \%$ of the elements of the state vector $(\mathrm{U}, \mathrm{V}, \mathrm{W})$ differ from their prior values by more than two standard deviations (for easier reference these deviations are symbolically noted as $\sqrt{ } \mathrm{C}_{\mathrm{o}}$ ) (Figure $\mathrm{S} 1 \mathrm{a}$ in the auxiliary material). Likewise, less than $5 \%$ of the residuals in the dynamical constraints differ from zero by more than $\pm 2 \sqrt{C_{A}}$ (Figure $\mathrm{S} 1 b$ ). For the solution with prior LNM $=$ $4000 \mathrm{~m}$, similar results hold, although the largest normalized residuals $\left(\tilde{x}-x_{o}\right) / \sqrt{C_{o}}$ and $(A \tilde{x}-b) / \sqrt{C_{A}}$ are greater than for the solution with prior LNM $=3000 \mathrm{~m}$ (not shown). Both the solutions with prior LNM $=3000 \mathrm{~m}$ and $4000 \mathrm{~m}$ have posterior estimates of integrated meridional transports at $36^{\circ} \mathrm{N}, 24^{\circ} \mathrm{N}$, and $32^{\circ} \mathrm{S}$ that are consistent with prior estimates (Table 2). Based on these results, only the solution (circulation) with prior LNM $=3000 \mathrm{~m}$ is chosen for the remainder of our study.

\subsubsection{Circulation With Prior LNM at $3000 \mathrm{~m}$}

[22] Some elements of the estimated circulation with prior LNM at $3000 \mathrm{~m}$ are worth mentioning (Figures 2 and 3). The three upper layers of the model (1000-2000 m, 2000$3000 \mathrm{~m}$, and $3000-4000 \mathrm{~m}$ ) include a strong western boundary current (NADW). There are also intense zonal transports in the South Atlantic, which are associated with large meridional gradients of density. Additionally, the deepest layer shows a distinct northward flow along the western boundary in the Brazil Basin (AABW).

[23] The posterior uncertainties for the horizontal circulation between $2000-3000 \mathrm{~m}$ and $4000-5000 \mathrm{~m}$ are shown in Figures S2 and S3 in the auxiliary material. As expected, the posterior uncertainties are smaller than the prior uncertainties (Table 1). However, they remain comparable to the transport amplitudes in the interior (east of the western boundary), which are generally of the order of $1 \mathrm{~Sv}$. The transports that are the best determined are along the western boundary between 1000-4000 $\mathrm{m}$ and in the southern South Atlantic, where transport amplitudes can reach up to $15 \mathrm{~Sv}$ in the shallowest layer (between 1000-2000 m). The integrated meridional transports at $36^{\circ} \mathrm{N}$ and $24^{\circ} \mathrm{N}$ are also relatively well determined (Table 2).

\subsubsection{Sensitivity to Uncertainties}

[24] The modern circulation is here estimated with different assumptions about the uncertainty for the prior state $\left(\boldsymbol{C}_{\boldsymbol{o}}\right)$. The uncertainty for the individual transports $(\mathrm{U}, \mathrm{V}, \mathrm{W})$ is decreased from $1 \mathrm{~Sv}$ to $0.1 \mathrm{~Sv}$ and then to $0.01 \mathrm{~Sv}$. We find that the decrease in uncertainty results in larger residuals for the observations and the dynamical equations, even though the fraction of residuals larger than $2 \sqrt{C}_{\mathrm{o}}$ (in absolute magnitude) remains less than $5 \%$ (Table 3 ). For an uncertainty of $0.01 \mathrm{~Sv}$, the integrated flow at $24^{\circ} \mathrm{N}$ and $36^{\circ} \mathrm{N}$ is reduced in amplitude, and the flow at $32^{\circ} \mathrm{S}$ is northward (Table 3). The decrease in meridional transport amplitude results from the increased confidence in the prior circulation, which is determined by the density differences via the thermal wind relationships. These density differences are

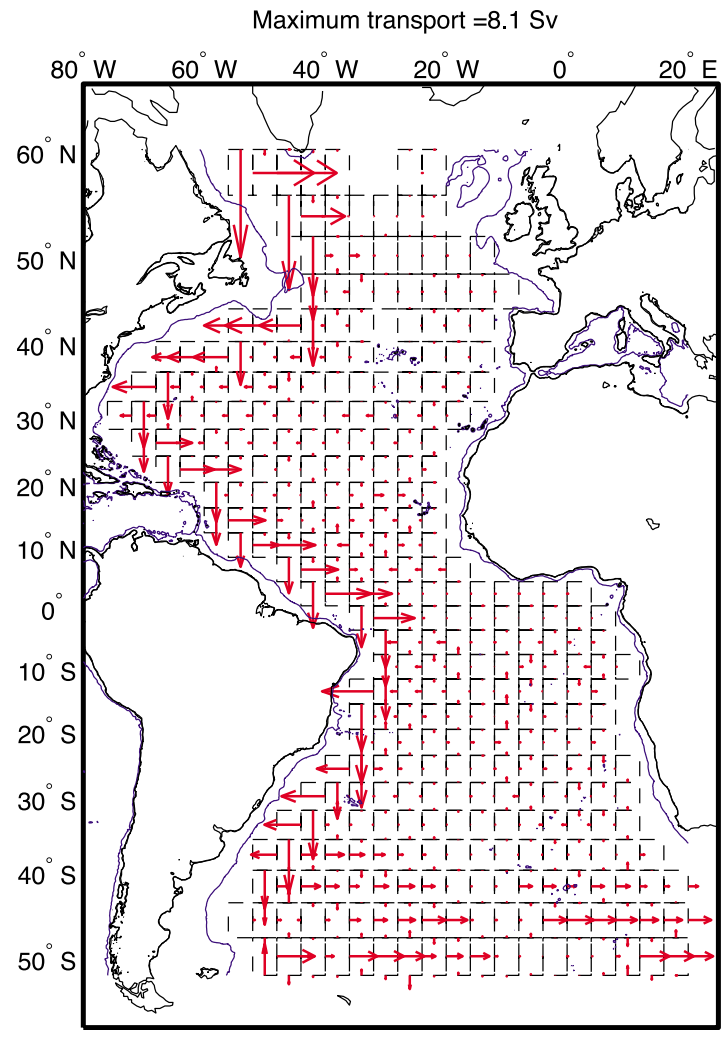

Figure 2. Horizontal circulation between 2000 and $3000 \mathrm{~m}$ (solution with prior LNM at $3000 \mathrm{~m}$ ). Red vectors are volume transports, with a maximum transport of about $8.1 \mathrm{~Sv}$. The blue line is the $1000 \mathrm{~m}$ isobath. The grid is the model grid. 


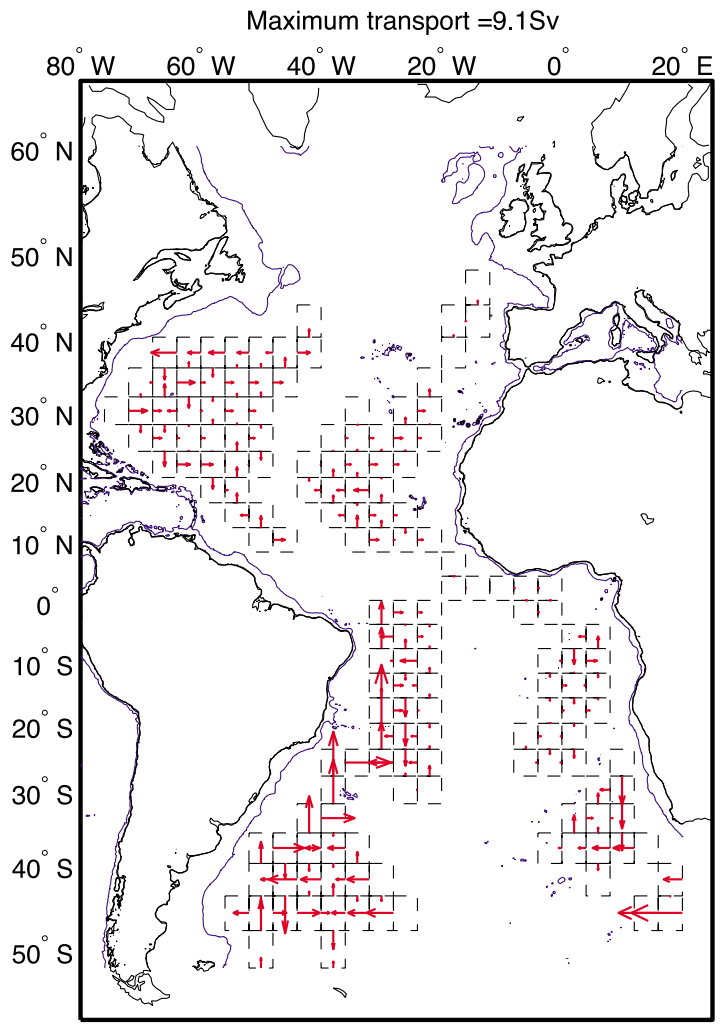

Figure 3. Same as Figure 2 but for circulation between 4000-5000 m

very small at most locations, especially in the interior of the basin, which results in small volume transports.

[25] The modern circulation is then estimated with different assumptions about the uncertainty in the dynamical constraints $\left(\boldsymbol{C}_{\boldsymbol{A}}\right)$. The uncertainty of the geostrophic approximation (thermal wind relationships and linear vorticity balance) is reduced from $1 \mathrm{~Sv}$ to $0.1 \mathrm{~Sv}$ and then to $0.01 \mathrm{~Sv}$. As this uncertainty is decreased, the fraction of residuals greater than $2 \sqrt{C_{A}}$ increases (Table 4). As the uncertainty for geostrophy decreases to $0.01 \mathrm{~Sv}$, the integrated meridional transports decrease in amplitude (Table 4). The decreased uncertainty in geostrophy places a greater emphasis on the small density gradients in the interior of the basin, thus resulting in reduced meridional transport.
[26] Given the difficulty in providing error estimates for the prior circulation $\left(\mathbf{C}_{\mathbf{o}}\right)$ and for geostrophic dynamics in the abyssal ocean $\left(\mathbf{C}_{\mathbf{A}}\right)$, the quantitative elements of our solution should be interpreted with caution. Such a solution, however, will be useful for examining the (in)consistency with the modern circulation of ${ }^{231} \mathrm{~Pa}$ observations from the water column and ${ }^{231} \mathrm{~Pa} /{ }^{230} \mathrm{Th}$ observations from the sediment.

\section{Analysis of Water Column ${ }^{231}$ Pa Data}

\subsection{Data}

[27] Measurements of dissolved, particulate, and total ${ }^{231} \mathrm{~Pa}$ activity in the abyssal Atlantic Ocean (water depths greater than or equal to $1000 \mathrm{~m}$ ) are compiled (Table 5). According to our compilation, dissolved, particulate, and total ${ }^{231} \mathrm{~Pa}$ activity have been measured on water samples collected at 23, 12, and 18 stations, respectively. Our compilation comprises a total number of 236 measurements of dissolved or total ${ }^{231} \mathrm{~Pa}$ activity at 32 stations, where the number of measurements per station ranges from 2 to 14 . The data coverage is poor and uneven (Figure 1).

\subsection{Advection-Scavenging Model}

[28] In order to gauge the (in)consistency of water column ${ }^{231} \mathrm{~Pa}$ data with a given circulation state, a model describing the behavior of ${ }^{231} \mathrm{~Pa}$ in the ocean is necessary. Here, the reversible exchange model [Nozaki et al., 1981; Bacon and Anderson, 1982] is extended to include the effect of advection of ${ }^{231} \mathrm{~Pa}$ by the circulation. Thus, the governing equations for dissolved $\left([\mathrm{Pa}]_{\mathrm{d}}\right)$ and particulate ${ }^{231} \mathrm{~Pa}$ activity $\left([\mathrm{Pa}]_{\mathrm{p}}\right)$ in the ocean are

$$
\vec{u} \cdot \nabla[P a]_{d}=\beta_{231}+k_{d}[P a]_{p}-k_{a}[P a]_{d}+\varepsilon_{d}
$$

and

$$
\vec{u} \cdot \nabla[P a]_{p}+w \frac{\partial[P a]_{p}}{\partial z}=k_{a}[P a]_{d}-k_{d}[P a]_{p}+\varepsilon_{p}
$$

respectively. Here $\vec{u}$ is the fluid velocity, $\beta_{231}=2.4 \times$ $10^{-3} \mathrm{dpm} \mathrm{m}^{-3} \mathrm{y}^{-1}$ is the production of ${ }^{231} \mathrm{~Pa}$ from radioactive decay of ${ }^{235} \mathrm{U}$ [Scholten et al., 1995], $k_{d}\left(k_{a}\right)$ is the desorption (adsorption) rate constant for ${ }^{231} \mathrm{~Pa}$ off/onto particles, $w$ is the sinking velocity of particles that participate in scavenging of $\mathrm{Pa}$, and $\left(\varepsilon_{d}, \varepsilon_{p}\right)$ are errors stemming from various approximations in equations (4) and (5). Summing (4) and (5) gives a governing equation for the

\begin{tabular}{|c|c|c|c|c|c|}
\hline $\begin{array}{l}\text { Prior Uncertainty } \\
\text { in } \mathrm{U}, \mathrm{V}, \mathrm{W}(\mathrm{Sv})\end{array}$ & $\begin{array}{l}\text { Adjustments of } U, V, W \text { Greater } \\
\text { Than or Less Than } 2 \sqrt{ } C_{o}(\%)\end{array}$ & $\begin{array}{l}\text { Linear Constraint } \\
\text { Residuals Greater Than } \\
\text { or Less Than } 2 \sqrt{ } \mathrm{C}_{\mathrm{A}}(\%)\end{array}$ & $\begin{array}{l}\text { Posterior Transport } \\
\text { at } 36^{\circ} \mathrm{N}(\mathrm{Sv})\end{array}$ & $\begin{array}{l}\text { Posterior Transport } \\
\text { at } 24^{\circ} \mathrm{N}(\mathrm{Sv})\end{array}$ & $\begin{array}{l}\text { Posterior Transport } \\
\text { at } 32^{\circ} \mathrm{S}(\mathrm{Sv})\end{array}$ \\
\hline 1 & 0.9 & 1.5 & $-20 \pm 8$ & $-17 \pm 8$ & $-7 \pm 7$ \\
\hline 0.1 & 1.1 & 3.3 & $-15 \pm 2$ & $-10 \pm 1$ & $3 \pm 1$ \\
\hline 0.01 & 1.1 & 3.3 & $-8 \pm 0.5$ & $-3 \pm 0.2$ & $9 \pm 0.2$ \\
\hline
\end{tabular}

Table 3. Sensitivity Tests on the Uncertainty in the Prior Circulation 
Table 4. Sensitivity Tests on the Uncertainty in the Geostrophic Approximation

\begin{tabular}{|c|c|c|c|c|c|}
\hline Uncertainty (Sv) & $\begin{array}{l}\text { Adjustments of U,V,W Greater } \\
\text { Than or Less Than } 2 \sqrt{ } C_{o}(\%)\end{array}$ & $\begin{array}{c}\text { Linear Constraint } \\
\text { Residuals Greater Than } \\
\text { or Less Than } 2 \sqrt{ } \mathrm{C}_{\mathrm{A}}(\%)\end{array}$ & $\begin{array}{l}\text { Posterior Transport } \\
\text { at } 36^{\circ} \mathrm{N}(\mathrm{Sv})\end{array}$ & $\begin{array}{l}\text { Posterior Transport } \\
\text { at } 24^{\circ} \mathrm{N}(\mathrm{Sv})\end{array}$ & $\begin{array}{c}\text { Posterior Transport } \\
\text { at } 32^{\circ} \mathrm{S}(\mathrm{Sv})\end{array}$ \\
\hline 0.1 & 5.6 & 2.8 & $-17 \pm 7$ & $-13 \pm 6$ & $-0.8 \pm 5$ \\
\hline 0.01 & 6.6 & 8.4 & $-16 \pm 7$ & $-13 \pm 6$ & $-0.1 \pm 5$ \\
\hline
\end{tabular}

activity of total ${ }^{231} \mathrm{~Pa},[\mathrm{~Pa}]=[\mathrm{Pa}]_{\mathrm{d}}+[\mathrm{Pa}]_{\mathrm{p}}$. Introducing the partition parameter $k_{P a}=[\mathrm{Pa}]_{\mathrm{p}} /[\mathrm{Pa}]$, this equation becomes

$$
\vec{u} \cdot \nabla[P a]+w \frac{\partial}{\partial z}\left([P a] k_{P a}\right)=\beta_{231}+\varepsilon .
$$

Thus, the transport of total ${ }^{231} \mathrm{~Pa}$ by advection and sinking particles is balanced locally by the production of ${ }^{231} \mathrm{~Pa}$ from the radioactive decay of ${ }^{235} \mathrm{U}$ within an error $\varepsilon$.

\subsection{Scavenging Parameters}

[29] The advection-scavenging model (6) includes two parameters $\left(w\right.$ and $\left.k_{P a}\right)$. The sinking velocity $(w)$ is based on published estimates determined from the vertical distribution of particulate ${ }^{230} \mathrm{Th}$ measured at stations in the Indian and Atlantic oceans [Krishnaswami et al., 1976; Krishnaswami et al., 1981; Rutgers van der Loeff and Berger, 1993; Scholten et al., 1995; Venchiarutti et al., 2008]. A value of $750 \mathrm{~m} \mathrm{yr}^{-1}$ is assumed. Whereas this choice is somewhat arbitrary, it is within the range of values $\left(300-900 \mathrm{~m} \mathrm{yr}^{-1}\right)$ reported in these studies.

[30] The partitioning of $\mathrm{Pa}$ between particulate and dissolved forms (as expressed by $k_{P a}=[\mathrm{Pa}]_{p} /[\mathrm{Pa}]$ ) is expected to vary in the ocean owing to variations in particle concentration and particle composition. Consider the defining relation

$$
\frac{[P a]_{p}}{[P a]} \equiv K_{d} C_{p}
$$

where $C_{p}$ is the concentration of particles (mass of particles/ mass of seawater) and $K_{d}$ is a "pseudo-Kd" partition coefficient [Chase et al., 2002]. Our knowledge about the distribution of suspended particulate matter at abyssal depths in the Atlantic Ocean stems primarily from direct measurements by filtration [e.g., Brewer et al., 1976] or from observations of light scattering or attenuation [e.g., Biscaye and Eittreim, 1977]. Whereas optical measurements are more abundant, uncertainties remain in their conversion to particle concentration [e.g., Bishop, 1999, and references therein]. Nevertheless, both direct and optical measurements indicate that the bottom waters of the western Atlantic generally exhibit large turbidity levels (bottom nepheloid layer) [Brewer et al., 1976; Biscaye and Eittreim, 1977]. Optical observations reveal that turbidity is particularly elevated near the western boundary [Biscaye and Eittreim, 1977].

[31] Based on these observations, we assume that the fraction of ${ }^{231} \mathrm{~Pa}$ in particles $\left(k_{P a}\right)$ is larger near the western boundary than in the interior. The $k_{P a}$ value assigned at grid boxes adjacent to the western boundary is based on paired measurements of particulate and total ${ }^{231} \mathrm{~Pa}$ activity $\left(k_{P a}\right)$ within $300 \mathrm{~m}$ of the seafloor at three stations within the domain: $\left(58.19^{\circ} \mathrm{N}, 50.87^{\circ} \mathrm{W}\right)$ [Moran et al., 2002], $\left(44.48^{\circ} \mathrm{S}\right.$, $\left.10.46^{\circ} \mathrm{E}\right)$ [Rutgers van der Loeff and Berger, 1993], and $\left(33^{\circ} \mathrm{S}, 40^{\circ} \mathrm{W}\right)$ [Moran et al., 2001] (Figure S4a). At each of these stations, $k_{P a}$ measured within $300 \mathrm{~m}$ of the seafloor is much larger than values measured at shallower depths, which likely results from higher concentration of suspended particles in the bottom nepheloid layer. Here $k_{P a}$ in the western boundary is set equal to 0.12 , which is the average $k_{P a}$ measured within $300 \mathrm{~m}$ of the seafloor at these stations.

[32] To constrain $k_{P a}$ east of the western boundary, we consider again paired measurements of particulate and total ${ }^{231} \mathrm{~Pa}$ activity in the water column. Paired measurements from 12 stations in the Atlantic Ocean do not reveal a general dependence of $k_{P a}$ on depth below $1000 \mathrm{~m}$ (Figure S4a). A statistical test based on a rank correlation coefficient [e.g., Kendall and Gibbons, 1990] indicates no significant monotonic variation of $k_{P a}$ with depth (all $p$ values greater than 0.05 ), with the exception of three stations with a significant increase $\left(58.19^{\circ} \mathrm{N}, 50.87^{\circ} \mathrm{W} ; 0.59^{\circ} \mathrm{S}, 20.03^{\circ} \mathrm{W} ; 17^{\circ} \mathrm{S}, 25^{\circ} \mathrm{W}\right)$ and one with a significant decrease $\left(25^{\circ} \mathrm{S}, 3.48^{\circ} \mathrm{E}\right)$. On the other hand, the depth-averaged $k_{P a}$ at stations where paired ${ }^{231} \mathrm{~Pa}$ data are available do suggest a latitudinal dependence, with higher values occurring south of $40^{\circ} \mathrm{S}$ (Figure $\mathrm{S} 4 \mathrm{~b}$ ). The high values of $k_{P a}$ observed at four stations south of this latitude likely reflect the presence of biogenic opal [e.g., Walter et al., 1997, 2001]. Here, in the abyssal region east of the western boundary and south of $40^{\circ} \mathrm{S}, k_{P a}$ is set equal to 0.08 , which is the average $k_{P a}$ for these stations $(\mathrm{n}=10)$. In the abyssal region east of the western boundary and north of $40^{\circ} \mathrm{S}, k_{P a}$ is set equal to 0.02 , which is the average $k_{P a}$ for stations north of this latitude $(\mathrm{n}=53)$. Clearly, more paired ${ }^{231} \mathrm{~Pa}$ measurements are needed to better constrain spatial variations of $k_{P a}$ in the Atlantic Ocean, especially in the northern hemisphere where such measurements are critically lacking.

[33] Finally, the error term $(\varepsilon)$ in the governing equation for total ${ }^{231} \mathrm{~Pa}$ (6) should not be negligible as it accounts for

Table 5. Measurements of Water Column ${ }^{231} \mathrm{~Pa}$ Activity Used in This Study

\begin{tabular}{lccc}
\hline \multicolumn{1}{c}{ Reference } & Dissolved & Particulate & Total \\
\hline $\begin{array}{l}\text { Rutgers van der Loeff and Berger } \\
\quad \text { [1993] }\end{array}$ & $\mathrm{x}$ & $\mathrm{x}$ & $\mathrm{x}$ \\
$\begin{array}{l}\text { Moran et al. }[2001, \text { 2002] } \\
\text { Scholten et al. }[2008]\end{array}$ & $\mathrm{x}$ & $\mathrm{x}$ & $\mathrm{x}$ \\
Luo et al. $[2010]$ & $\mathrm{x}$ & & $\mathrm{x}$ \\
R. François (unpublished data, 2005) & $\mathrm{x}$ & & \\
\hline
\end{tabular}


various approximations in (6), such as the assumption of steady state, the omission of mixing by eddies, and the assumptions of the reversible exchange model. The lack of an explicit representation by eddy mixing [see also LeGrand and Wunsch, 1995; Huybers et al., 2007; Marchal and Curry, 2008] and other model limitations are discussed in section 5.3. In order to account for the significant uncertainties in (6), it is assumed that $\varepsilon$ can be of the same order as the production rate $\beta_{231}$. Since ${ }^{231} \mathrm{~Pa}$ production appears as a first-order term in the basin-scale balance of the tracer [e.g., Yu et al., 1996], this assumption is likely conservative.

\subsection{Inverse Method}

[34] An inverse method identical to that employed in section 2.2 is used to determine how (in)consistent water column measurements of total ${ }^{231} \mathrm{~Pa}$ activity, $[\mathrm{Pa}]$, are with (1) our modern circulation estimate and (2) a hypothetical state of no flow (with no advection). A system of linear algebraic equations, $\boldsymbol{G} \boldsymbol{x}+\boldsymbol{\varepsilon}_{\boldsymbol{G}}=\boldsymbol{h}$, is derived from the finite difference form of equation (6) (see Appendix 1 in Text S1), where $\boldsymbol{G}$ includes the coefficients arising from the discretization of (6), $\boldsymbol{x}$ is the state vector with [Pa] at the grid box centers, $\boldsymbol{h}$ is a source term proportional to $\beta_{231}$, and $\varepsilon_{\boldsymbol{G}}$ is an error. For consistency test $1, \boldsymbol{G}$ includes the individual volume transports $(\mathrm{U}, \mathrm{V}, \mathrm{W}$ ) estimated in section 2.2 (with a prior $\mathrm{LNM}=3000 \mathrm{~m}$ ), whereas for $2, \boldsymbol{G}$ is constructed with $\mathrm{U}=\mathrm{V}=\mathrm{W}=0$. For both cases, $\boldsymbol{C}_{\boldsymbol{G}}=\left\langle(\boldsymbol{G} \boldsymbol{x}-\boldsymbol{h})(\boldsymbol{G} \boldsymbol{x}-\boldsymbol{h})^{\mathrm{T}}\right\rangle$ is taken as diagonal (no error covariances).

[35] An objective function of the same form as equation (1) is minimized, leading again to a linear problem of the type in equation (2). Here the vector $\boldsymbol{x}_{\boldsymbol{o}}$ includes a prior estimate of the distribution of $[\mathrm{Pa}]$ in the deep Atlantic $([\mathrm{Pa}]$ at the center of model grid boxes), and $\boldsymbol{C}_{\boldsymbol{o}}=\left\langle\left(\boldsymbol{x}-\boldsymbol{x}_{\boldsymbol{o}}\right)\left(\boldsymbol{x}-\boldsymbol{x}_{\boldsymbol{o}}\right)^{\mathrm{T}}\right\rangle$ is the error covariance matrix for this estimate. Both $\boldsymbol{x}_{\boldsymbol{o}}$ and $\boldsymbol{C}_{\boldsymbol{o}}$ are determined from water column $[\mathrm{Pa}]$ data at 32 stations in the Atlantic Ocean (Figure 1) using objective mapping [e.g., Bretherton et al., 1976]. At some of these stations, only $[\mathrm{Pa}]_{\mathrm{d}}$ has been measured (Figure 1, open triangles). They are converted to $[\mathrm{Pa}]$ assuming the average $k_{P a}=0.03(\mathrm{n}=61)$ determined from all available paired ${ }^{231} \mathrm{~Pa}$ observations in the deep Atlantic (section 3.3). Although a spatially varying $k_{P a}$ would be more appropriate, the average $k_{P a}$ is used here for simplicity given the small correction (i.e., most ${ }^{231} \mathrm{~Pa}$ is present in dissolved form). Three parameters are required for objective mapping: a horizontal scale $\left(L_{H}\right)$ measuring the covariance between $[\mathrm{Pa}]$ at different geographic locations, a vertical scale $\left(L_{Z}\right)$ measuring the covariance between [Pa] at different depths, and the maximum variance of $[\mathrm{Pa}]$ at locations infinitely far from data locations $\left(r_{0}\right)$ [Marchal et al., 2007]. Here we assume that the covariance between [Pa] at two locations drops exponentially with $L_{H}=10^{6} \mathrm{~m}$ and $L_{Z}=$ $10^{3} \mathrm{~m}$, which are comparable to values assumed in earlier work for mapping the distribution of ${ }^{230} \mathrm{Th}$ [Marchal et al., 2007]. The maximum variance is set equal to 0.017 (dpm $\left.\mathrm{m}^{-3}\right)^{2}$, which is the variance of $[\mathrm{Pa}]$ measurements in the deep Atlantic (Table 5).

[36] The objective mapping of $[\mathrm{Pa}]$ based on these parameter values is assessed a posteriori by comparing the mapped $[\mathrm{Pa}]$ at data locations with the measured $[\mathrm{Pa}]$ (Figure S5). We find that all of the mapped $[\mathrm{Pa}]$ values are within two standard deviations of the measured values, indicating that the mapping is consistent with the existing set of water column [Pa] data. Note that far from data locations the mapped $[\mathrm{Pa}]$ tends to the average of the $[\mathrm{Pa}]$ measurements and its uncertainty tends to the relatively large value $\sqrt{r_{0}}$. Thus far from data locations, the mapping leads to considerable smoothing (with large uncertainties in mapped [Pa]) and does not elucidate high tracer gradients which may be present in reality.

[37] The objectively mapped distributions of $[\mathrm{Pa}]$ and of its uncertainty in the deep Atlantic $(z=1500 \mathrm{~m})$ are displayed in Figure 4. There is a general increase in $[\mathrm{Pa}]$ from north to south (Figure 4a). Zonal variations in $[\mathrm{Pa}]$ are present as well, in particular in the South Atlantic where measurements in the Angola and Cape basins [Scholten et al., 2008] appear particularly large. As expected, the uncertainties in $[\mathrm{Pa}]$ are smallest near data locations and increase with distance from these locations (Figure $4 \mathrm{~b}$ ).

[38] Our analysis of [Pa] data in the deep Atlantic requires knowledge of $[\mathrm{Pa}]$ near the open lateral boundaries $\left(52^{\circ} \mathrm{S}\right.$; $60^{\circ} \mathrm{N} ; 20^{\circ} \mathrm{E}$ for latitudes south of $40^{\circ} \mathrm{S}$; and at $12^{\circ} \mathrm{W}$ between $32^{\circ} \mathrm{N}-36^{\circ} \mathrm{N}$ for MOW) and the upper boundary $(\mathrm{z}=1000 \mathrm{~m})$; such requirement arises from the definition of [Pa] at the center of grid boxes (see Appendix 1 in Text S1). The $[\mathrm{Pa}]$ values near the lateral boundaries are derived from objective mapping as described above. The activity of total ${ }^{23 \mathrm{P}} \mathrm{Pa}$ at $500 \mathrm{~m}$ is estimated from $[\mathrm{Pa}]$ measurements in the upper $1000 \mathrm{~m}$ in the Atlantic Ocean. These measurements suggest a linear trend with depth (not shown), consistent with a reversible exchange with particles. A linear regression of these data with depth gives a slope of $(2.14 \pm 0.35) \times$ $10^{-4} \mathrm{dpm} \mathrm{m} \mathrm{m}^{-4}$ and an intercept of $(0.057 \pm 0.016) \mathrm{dpm} \mathrm{m}^{-3}$ $(\mathrm{n}=32)$. The $[\mathrm{Pa}]$ value at $500 \mathrm{~m}$ obtained from this regression is $0.164 \mathrm{dpm} \mathrm{m}^{-3}$, which provides the upper boundary condition.

[39] Finally, the uncertainty in the discretized form of the advection-scavenging model is set equal to the production rate of ${ }^{231} \mathrm{~Pa}$ integrated over the volume of the grid box, that is, $\sqrt{ } C_{G}=\beta_{231} \mathrm{~V}$, which is equal to about $10^{4} \mathrm{dpm} \mathrm{s}{ }^{-1}$. As stipulated above, this assumption is probably conservative. The sensitivity of the results to the boundary condition at $\mathrm{z}=$ $500 \mathrm{~m}$ and to the assumptions about objective mapping $\left(L_{H}\right.$, $\left.L_{Z}, r_{0}\right)$ is examined in section 3.5 .

\subsection{Results}

[40] The (in)consistency of the water column [Pa] data with the two circulation schemes (modern circulation and state of no flow) is measured by the normalized adjustment or residual, $\left(\tilde{x}-x_{o}\right) / \sqrt{C_{o}}$, at the grid points near data locations $(\mathrm{n}=83$, where $\mathrm{n}$ is the number of grid points near $[\mathrm{Pa}]$ data). These adjustments are nondimensional and represent the deviations from the original, objectively mapped [Pa] values $\left(x_{o}\right)$ divided by the standard deviations of these values $\left(\sqrt{ } \mathrm{C}_{\mathrm{o}}\right)$. Thus an adjustment of $+2 \sqrt{ } \mathrm{C}_{\mathrm{o}}\left(-2 \sqrt{ } \mathrm{C}_{\mathrm{o}}\right)$ at a given location means that the ${ }^{231} \mathrm{~Pa}$ activity at that location as estimated by objective mapping must be increased (decreased) by two times its standard deviation to be consistent with the circulation scheme.

[41] We find that $8 \%$ of [Pa] values near data locations are modified by more than $2 \sqrt{C_{0}}$ to reach consistency with the 

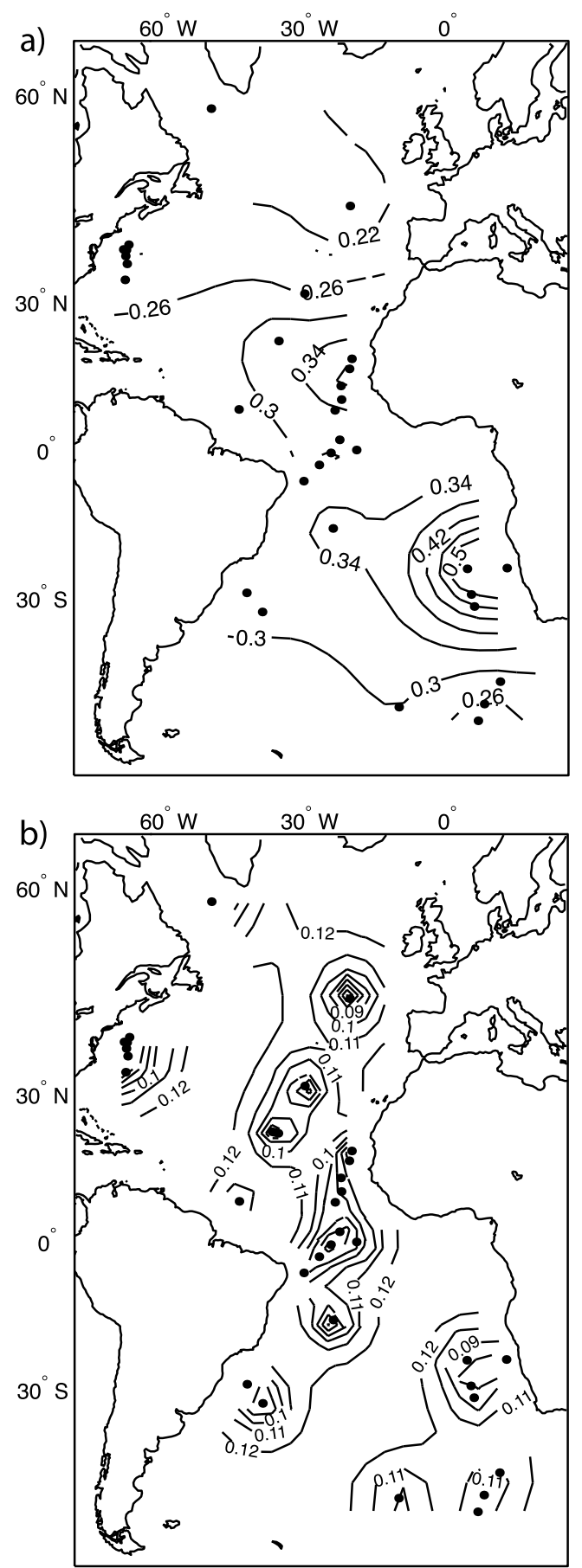

modern circulation, as compared to $34 \%$ for the state of no flow (Figure 5). The [Pa] adjustments needed to comply with the modern circulation show a geographic pattern. All six of the negative residuals which are more negative than $-2 \sqrt{C_{o}}$ occur in the eastern South Atlantic (Figure 1). As mentioned above, compared to other locations in the Atlantic Ocean, [Pa] measurements from the eastern South Atlantic [Scholten et al., 2008] have the highest values (Figure 4a). Strong negative adjustments are needed to bring these measurements into consistency with our estimate of the modern circulation.

[42] The adjustments needed to bring the $[\mathrm{Pa}]$ values near data locations into consistency with the modern circulation are skewed toward negative, with an average residual of -0.51 . When the measurements from the eastern South Atlantic [Scholten et al., 2008] are excluded from the analysis, the average residual becomes -0.16 . In contrast, the adjustments to a state of no flow (average $=1.24$ considering all measurements) show a strong positive bias that increases with depth. Positive residuals imply that the $[\mathrm{Pa}]$ observations are too low to be explained without advection. The positive bias is expected because a reversible exchange of ${ }^{231} \mathrm{~Pa}$ without any advection would require a linear increase of $[\mathrm{Pa}]$ with depth, that is, relatively large $[\mathrm{Pa}]$ in deep water. In the modern Atlantic, $[\mathrm{Pa}]$ in deep water is generally lower than predicted by pure reversible exchange, and this offset is larger at greater depths [e.g., Moran et al., 2002; Luo et al., 2010]. Thus, large positive adjustments in deep water (increases in the objectively mapped $[\mathrm{Pa}]$ data) are generally needed to bring the water column [Pa] data into consistency with a state of no flow.

[43] The above results appear to be essentially independent of the boundary value of $[\mathrm{Pa}]$ at $500 \mathrm{~m}$ water depth. Increasing (decreasing) $[\mathrm{Pa}]$ at $500 \mathrm{~m}$ by a factor of two results in only $7 \%(12 \%)$ of the $[\mathrm{Pa}]$ values near data locations being modified by more than $2 \sqrt{ } \mathrm{C}_{\mathrm{o}}$ to reach consistency with the modern circulation, as compared to $61 \%(37 \%)$ for the state of no flow.

[44] On the other hand, the above results are sensitive to some of the parameters assumed in the objective mapping of $[\mathrm{Pa}]$ in the Atlantic Ocean. Generally, it is expected that lower values of $\left(L_{H}, L_{Z}\right)$ and higher values of $r_{0}$ lead to higher uncertainties in the mapped distribution. Consider first the variance $r_{0}$, which above was set equal to the variance of the $[\mathrm{Pa}]$ measurements in the Atlantic Ocean. If $r_{0}$ is taken instead as half of the range of these measurements, only 2 out of the $83[\mathrm{~Pa}]$ values $(2 \%)$ near data locations need to be modified by more than $2 \sqrt{ } C_{o}$ to comply with our modern circulation estimate, compared to only 10 out of 83 $(12 \%)$ for the state of no flow (if $r_{0}$ is equal to the variance in $[\mathrm{Pa}]$ measurements, we found that those numbers are 7

Figure 4. (a) Distribution of total ${ }^{231} \mathrm{~Pa}$ activity, $[\mathrm{Pa}]$, at $1500 \mathrm{~m}$ water depth determined by objective mapping. Contour interval is $0.04 \mathrm{dpm} \mathrm{m}^{-3}$. (b) Distribution of the uncertainty of $[\mathrm{Pa}]\left(\mathrm{dpm} \mathrm{m}^{-3}\right)$ at $1500 \mathrm{~m}$ water depth determined by objective mapping. Contour interval is $0.01 \mathrm{dpm} \mathrm{m}^{-3}$. Station locations are indicated by dots. 

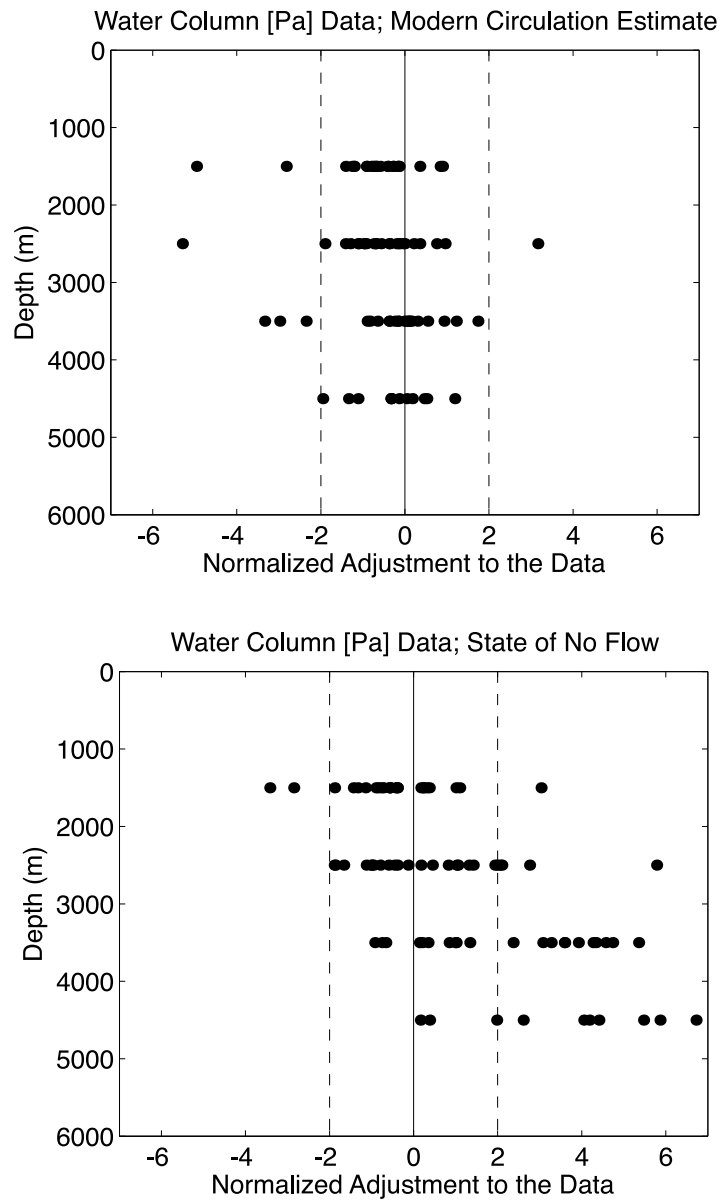

Figure 5. Adjustments of water column ${ }^{231} \mathrm{~Pa}$ activity to (top) the modern circulation or (bottom) a hypothetical state of no flow. The adjustments are normalized to uncertainties. The dashed lines represent the $2 \sqrt{ } \mathrm{C}_{\mathrm{o}}$ band.

and 28 ( $8 \%$ and $34 \%)$, respectively). As expected, when the uncertainties in the tracer distribution are increased, the tracer data become more consistent with a given circulation scheme, and it becomes more difficult for these data to distinguish between different circulations.

[45] A similar effect is observed by decreasing the length scale $L_{H}$. If $L_{H}$ is decreased by a factor of two (hence reducing the correlation between tracer values at different geographic locations), slightly more of the $[\mathrm{Pa}]$ values near data locations appear consistent with the modern circulation (state of no flow); only 6 (24) of the 83 adjustments ( $7 \%$ or $29 \%$, respectively) exceed $2 \sqrt{C_{o}}$ in absolute magnitude. Decreasing $L_{Z}$ by a factor of two (reducing the correlation between tracer values at different depths) does not change the percentage consistent with either circulation scheme.

[46] In summary, most measurements of $[\mathrm{Pa}]$ in the Atlantic Ocean can be brought into consistency with the modern circulation if plausible assumptions are made about the $[\mathrm{Pa}]$ distribution and model uncertainties. The level of consistency is largely insensitive to the boundary value of [Pa] at $500 \mathrm{~m}$, but is sensitive to some of the assumptions made in the objective mapping. In all cases, however, the [Pa] measurements are less consistent with the state of no flow, indicating that advection is needed to explain the modern water column data.

\section{Analysis of Sediment ${ }^{231} \mathrm{~Pa} /{ }^{230} \mathrm{Th}$ Data}

\subsection{Data}

[47] The ${ }^{231} \mathrm{~Pa} /{ }^{230} \mathrm{Th}$ data for the Holocene (core tops) and Last Glacial Maximum (LGM) come from a total of 39 cores (Figure 1). While there are additional cores with Holocene ${ }^{231} \mathrm{~Pa}^{230} \mathrm{Th}$ data that are used to evaluate the conversion of ${ }^{231} \mathrm{~Pa} /{ }^{230} \mathrm{Th}$ to $[\mathrm{Pa}$ ] (see section 4.3 .1 ), only those cores that have both LGM and Holocene ${ }^{231} \mathrm{~Pa} /{ }^{230} \mathrm{Th}$ are considered for analysis. Data from twenty-seven of these cores come from the thesis of $Y u$ [1994]. For the other twelve cores, data come either from more recent studies [McManus et al., 2004; Gherardi et al., 2005; Hall et al., 2006; Bradtmiller et al., 2007; Gherardi et al., 2009] or are unpublished (L. Bradtmiller, unpublished data, 2009). For these twelve cores, Holocene is defined as the time interval 0-6 kyr B.P. and LGM is defined as the time interval 18-21 kyr B.P., as by Gherardi et al. [2005]. For each core, the average of the ${ }^{231} \mathrm{~Pa} /{ }^{230} \mathrm{Th}$ data within those intervals is used, and the uncertainty is taken as the larger of (1) the average of the uncertainties reported for those data points within the interval and (2) the standard error of the ${ }^{231} \mathrm{~Pa} /{ }^{230} \mathrm{Th}$ values within the interval.

[48] The ${ }^{231} \mathrm{~Pa}^{230} \mathrm{Th}$ data for the Heinrich Event 1 (H1) from fifteen cores are used [McManus et al., 2004; Gherardi et al., 2005; Hall et al., 2006; Bradtmiller et al., 2007; Gherardi et al., 2009]. For four of these cores, unpublished data are provided by L. Bradtmiller (unpublished data, 2009). All fifteen cores are from the north and equatorial Atlantic (Figure 1). H1 is defined as the time interval 15-17 kyr B.P., as by Gherardi et al. [2005], and the averages and uncertainties are calculated as for the LGM values.

\subsection{Conversion of ${ }^{231} \mathrm{~Pa} /{ }^{230} \mathrm{Th}$ Into [Pa]}

[49] The inverse method described in section 3.4 is used to test the (in)consistency of Holocene, LGM, or H1 ${ }^{231} \mathrm{~Pa} /{ }^{230} \mathrm{Th}$ observations with both the modern circulation and a state of no flow. To this end, the activity of total ${ }^{231} \mathrm{~Pa}$ in bottom water at the core location is estimated from ${ }^{231} \mathrm{~Pa} /{ }^{230} \mathrm{Th}$ in the sediment:

$$
[P a]=\frac{[P a]_{p}}{k_{P a}}=\frac{1}{k_{P a}}\left(\frac{231 P a}{{ }^{230} \mathrm{Th}}\right)_{\text {sed }}[\mathrm{Th}]_{p} .
$$

Here $k_{P a}$ is the partition parameter introduced in section 3.2, $\left({ }^{231} \mathrm{~Pa} /{ }^{230} \mathrm{Th}\right)_{\text {sed }}$ is the radionuclide ratio in the sediment, and $[\mathrm{Th}]_{\mathrm{p}}$ is the activity of particulate ${ }^{230} \mathrm{Th}$ in bottom water (in $\mathrm{dpm} \mathrm{m} \mathrm{m}^{-3}$ ). Thus, provided that an estimate of $k_{P a}$ and $[\mathrm{Th}]_{\mathrm{p}}$ is available, $[\mathrm{Pa}]$ can be reconstructed from the sediment ${ }^{231} \mathrm{~Pa} /{ }^{230} \mathrm{Th}$. 


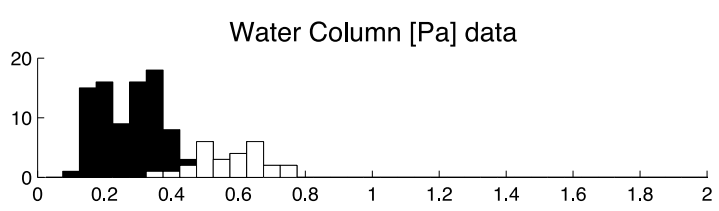

[Pa] Reconstructed from Holocene Sediments
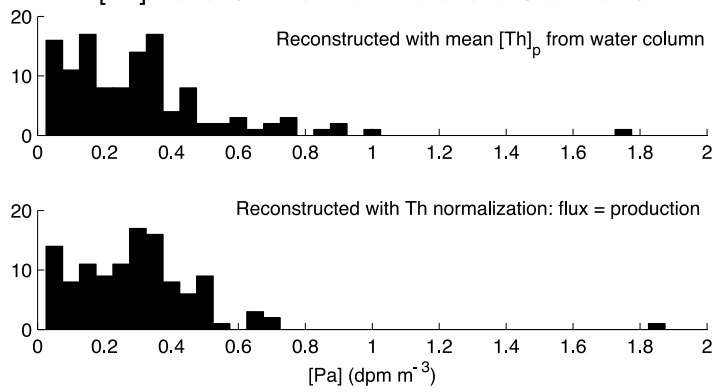

Figure 6. Frequency distribution of the water column $[\mathrm{Pa}]$ data $(z>1000 \mathrm{~m})$ for 18 stations in the Atlantic Ocean (data from Scholten et al. [2008] are in white) compared to the frequency distribution of bottom water $[\mathrm{Pa}]$ reconstructed from Holocene sediment ${ }^{231} \mathrm{~Pa} /{ }^{230} \mathrm{Th}$ estimated using either (1) mean $[\mathrm{Th}]_{\mathrm{p}}$ from water column data or (2) $[\mathrm{Th}]_{\mathrm{p}}=\beta_{230} \mathrm{z} / \mathrm{w}$ (see text).

[50] The partition $k_{P a}$ used in (8) is the spatially variable distribution based on paired water column data (section 3.3). On the other hand, two different approaches are used to estimate $[\mathrm{Th}]_{\mathrm{p}}$. First, $[\mathrm{Th}]_{\mathrm{p}}$ is set equal to the average of all water column measurements of $[\mathrm{Th}]_{\mathrm{p}}$ at depths greater than $1000 \mathrm{~m}$ in the Atlantic Ocean [Rutgers van der Loeff and Berger, 1993; Moran et al., 2001; Moran et al., 2002; Scholten et al., 2008]. Based on the limited [Th $]_{\mathrm{p}}$ data available, no obvious geographic trend of $[\mathrm{Th}]_{\mathrm{p}}$ is apparent (Figure S4c), justifying our approach of using an average value for $[\mathrm{Th}]_{\mathrm{p}}$. This average in the Atlantic Ocean amounts to $0.113 \mathrm{dpm} \mathrm{m}^{-3}(\mathrm{n}=77)$. The second approach assumes that the flux of scavenged ${ }^{230} \mathrm{Th}$ to the sediment is equal to the production of ${ }^{230} \mathrm{Th}$ in the water column overlying the sediment. This assumption is at the core of the " ${ }^{230} \mathrm{Th}$ normalization method," which relies on ${ }^{230}$ Th measurements in the sediment to correct apparent downcore changes in the vertical flux of material for the effects of lateral sediment redistribution [François et al., 2004]. Thus, $[\mathrm{Th}]_{\mathrm{p}}$ is derived from the following relationship

$$
[T h]_{p} w=\beta_{230} z .
$$

Here $w$ is the sinking velocity of the particles that scavenge ${ }^{230} \mathrm{Th}, \boldsymbol{\beta}_{230}$ is the production rate of ${ }^{230} \mathrm{Th}$, and $\mathrm{z}$ is the water depth of the sediment core. The activity, $[\mathrm{Th}]_{\mathrm{p}}$, is obtained from equation (9), assuming $w=750 \mathrm{~m} \mathrm{yr}^{-1}$ (section 3.3) and $\beta_{230}=2.67 \times 10^{-2} \mathrm{dpm} \mathrm{m}^{-3} \mathrm{yr}^{-1}$ [e.g., Cheng et al., 2000].

[51] The propagated error for bottom water [Pa] at core locations reconstructed from (8) using $[\mathrm{Th}]_{\mathrm{p}}$ measurements or the normalization method (9) only takes into account the uncertainty of ${ }^{231} \mathrm{~Pa} /{ }^{230} \mathrm{Th}$ measurements, leading to an underestimation of the total error. This assumption is motivated by (1) the fact that the uncertainties of parameters such as $w$ and $k_{P a}$ are difficult to estimate for the past and (2) our willingness to give sediment ${ }^{231} \mathrm{~Pa}^{230} \mathrm{Th}$ data the best chance to reject consistency with the modern circulation.

[52] Estimates of total ${ }^{231} \mathrm{~Pa}$ activity and of its uncertainty at the centers of model grid boxes are derived from bottom water $[\mathrm{Pa}]$ at core locations using objective mapping (section 3.4). For all three sediment data sets (Holocene, LGM, and $\mathrm{H} 1$ ), less than $3 \%$ of the mapped [Pa] values at core locations are greater or less than two standard deviations from the reconstructed $[\mathrm{Pa}]$ values, indicating that the mapping parameters are consistent with the reconstructed values. The mapped $[\mathrm{Pa}]$ values are assigned to the prior state $\left(\boldsymbol{x}_{\boldsymbol{o}}\right)$, and their variances and error covariances are assigned to the error covariance matrix $\left(\boldsymbol{C}_{\boldsymbol{o}}\right)$.

\subsection{Results}

4.3.1. Comparison of Holocene and Water Column [Pa] [53] It is instructive to compare the bottom water [Pa] at core locations reconstructed from Holocene (core top) sediments with the direct measurements of $[\mathrm{Pa}]$ in the water column, even though these do not occur at the same geographic locations. For this comparison, we consider (1) all 121 cores within the domain that have Holocene ${ }^{231} \mathrm{~Pa} /{ }^{230} \mathrm{Th}$ data (for a list of references see Appendix 2 in Text S1 in the auxiliary material) and (2) measurements of total (dissolved + particulate) ${ }^{231} \mathrm{~Pa}$ activity at depths greater than $1000 \mathrm{~m}$ in the Atlantic Ocean (109 measurements at eighteen stations). The frequency distribution of the water column measurements is compared with the frequency distribution of the reconstructed bottom water $[\mathrm{Pa}]$ from the Holocene ${ }^{231} \mathrm{~Pa} /{ }^{230} \mathrm{Th}$ data using the two methods of estimating $[\mathrm{Th}]_{\mathrm{p}}$ described in section 4.2 (Figure 6).

[54] The frequency distributions of both measured $[\mathrm{Pa}]$ and reconstructed $[\mathrm{Pa}]$ suggest the presence of more than one mode in their respective underlying distributions. The presence of several modes suggests that a classical (parametric) statistical procedure would not be appropriate for testing differences between the distributions of measured and reconstructed $[\mathrm{Pa}]$, since such procedures typically assume that the underlying distributions are Gaussian or normal (i.e., unimodal). Here, a nonparametric procedure, which makes weaker assumptions about the underlying distributions, is used to test such differences. A MannWhitney-Wilcoxon test suggests that the measured [Pa] values and the $[\mathrm{Pa}]$ values reconstructed from $\left({ }^{231} \mathrm{~Pa} /{ }^{230} \mathrm{Th}\right)_{\text {sed }}$ do not come from the same underlying distributions using either the average observed $[\mathrm{Th}]_{\mathrm{p}}$ or the $[\mathrm{Th}]_{\mathrm{p}}$ calculated from (9) ( $p=0.01$ and 0.03 , respectively). As mentioned previously, the water column $[\mathrm{Pa}]$ data from the eastern South Atlantic [Scholten et al., 2008] are high compared to data from other areas in the Atlantic Ocean. These data could bias the frequency distribution of water column $[\mathrm{Pa}]$ measurements toward high values since they make up $25 \%$ of the water column data set (in contrast $\left({ }^{231} \mathrm{~Pa} /{ }^{230} \mathrm{Th}\right)_{\text {sed }}$ measurements from the eastern South Atlantic constitute only $15 \%$ of our sediment data set). When water column and sediment data from the eastern South Atlantic are disregarded, the frequency distributions 
Reconstructed Holocene; Modern Circulation Estimate
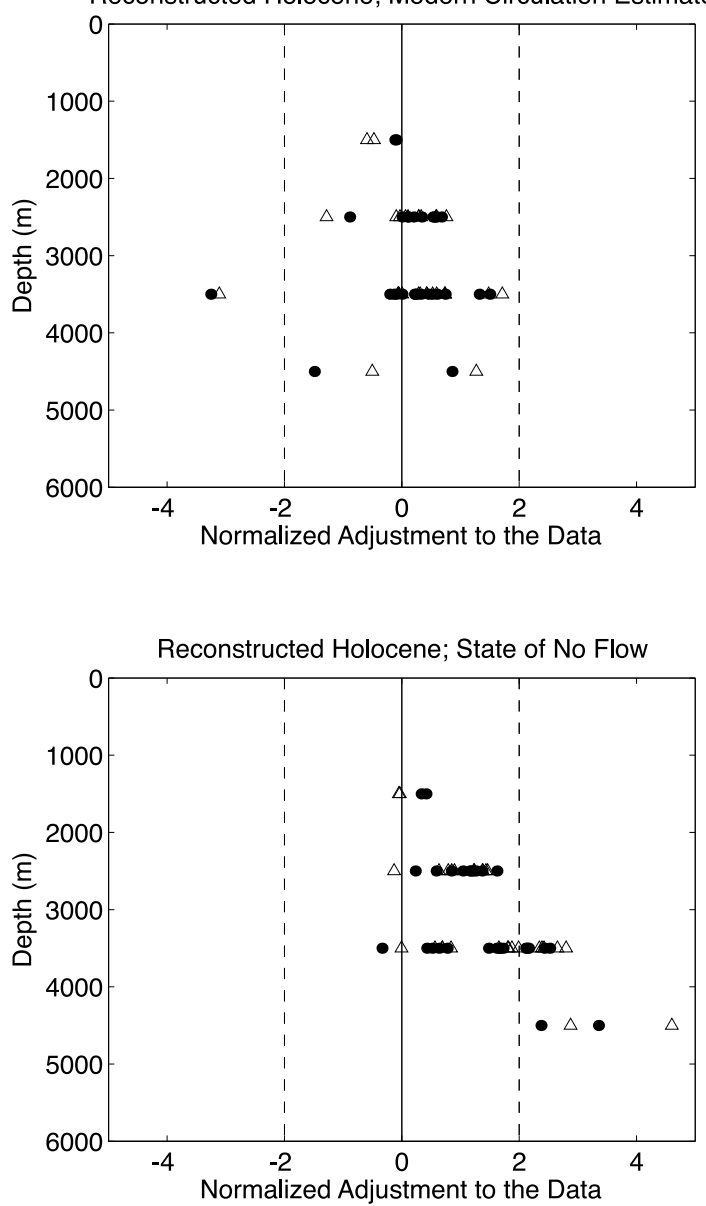

Figure 7. Adjustment of reconstructed ${ }^{231} \mathrm{~Pa}$ activity in bottom water near core locations during the Holocene to (top) the modern circulation and (bottom) a hypothetical state of no flow. The ${ }^{231} \mathrm{~Pa}$ activity is reconstructed from sediment ${ }^{231} \mathrm{~Pa} /{ }^{230} \mathrm{Th}$ assuming (1) mean $[\mathrm{Th}]_{\mathrm{p}}$ from water column data (open triangle) or (2) $[\mathrm{Th}]_{\mathrm{p}}=\beta_{230} \mathrm{z} / \mathrm{w}$ (filled circle). In both panels the adjustments are normalized to the uncertainties.

of reconstructed $[\mathrm{Pa}]$ appear no longer different from the frequency distribution of measured $[\mathrm{Pa}](p=0.26$ and 0.71 for the two approaches to estimate $[\mathrm{Th}]_{\mathrm{p}}$ ). Since there are apparent differences in the frequency distribution of $[\mathrm{Pa}]$ reconstructed using the two different approaches for estimating $[\mathrm{Th}]_{\mathrm{p}}$, each analysis is done twice, once with each approach.

4.3.2. Test of Consistency of Sediment ${ }^{231} \mathrm{~Pa} /{ }^{230} \mathrm{Th}$

[55] To test the consistency of sediment ${ }^{231} \mathrm{~Pa} /{ }^{230} \mathrm{Th}$ data with the modern circulation or a state of no flow, we assume the same uncertainty for the ${ }^{231} \mathrm{~Pa}$ transport equation (6) as for the analysis of water column $[\mathrm{Pa}]$ data $\left(\sqrt{ } C_{G}=\beta_{231} \mathrm{~V}\right)$.
Likewise, the normalized adjustment or residual, $\left(\tilde{x}-x_{o}\right) /$ $\sqrt{C_{o}}$, is used as a measure of the consistency of the data with each circulation scheme.

[56] We find that for the modern circulation, only 3\% (1 of 30) of the adjustments in the Holocene [Pa] values near core locations exceed $2 \sqrt{ } C_{o}$ (in absolute magnitude) for both approaches of estimating $[\mathrm{Th}]_{\mathrm{p}}$ (Figure 7). Thus, the Holocene ${ }^{231} \mathrm{~Pa}^{230} \mathrm{Th}$ data show a comparable degree of consistency with the modern circulation as the water column [Pa] data which have $8 \%$ (7 of 83 ) of its adjustments exceeding $2 \sqrt{ } C_{o}$ (section 3.4). For both approaches of estimating $[\mathrm{Th}]_{\mathrm{p}}$, the normalized adjustments in $[\mathrm{Pa}]$ values near core locations average to less than 0.2 , indicating a small bias.

[57] In contrast, the adjustments of Holocene [Pa] values near core locations to the state of no flow are positively biased, with $23 \%$ ( 7 of 30 ) of the adjustments greater than $2 \sqrt{ } C_{o}$ and an average normalized adjustment of 1.4 or 1.3 , depending on whether $[\mathrm{Th}]_{\mathrm{p}}$ is taken as the average of measured values or estimated by (9) (Figure 7). The positive adjustments in $[\mathrm{Pa}]$ values near core locations indicate that the $[\mathrm{Pa}]$ values reconstructed from the sediment are generally too low to be consistent with a state of no flow.

[58] Importantly, the inversions of [Pa] estimates for the LGM lead to adjustments with a similar distribution to that of Holocene $[\mathrm{Pa}]$ estimates. If $[\mathrm{Th}]_{\mathrm{p}}$ is set equal to the average of water $[\mathrm{Th}]_{\mathrm{p}}$ measurements, none of the $[\mathrm{Pa}]$ estimates near core locations must be altered by more than $2 \sqrt{ } C_{o}$ to be compatible with the modern circulation. If $[\mathrm{Th}]_{\mathrm{p}}$ is calculated from (9), only 1 of the $30[\mathrm{~Pa}]$ estimates near core locations $(3 \%)$ must be altered by more than $2 \sqrt{ } C_{o}$ to comply with the modern circulation (Figure 8 ). As found with the water column $[\mathrm{Pa}]$ data and the $[\mathrm{Pa}]$ values reconstructed from core tops, the adjustments of $[\mathrm{Pa}]$ estimates for the LGM to a state of no flow are positively biased, with 12 out of $30(40 \%)$ total adjustments greater than $2 \sqrt{ } C_{o}$.

[59] Finally, the combination of [Pa] estimates for $\mathrm{H} 1$ with the modern circulation requires that only 2 out of 14 $(14 \%)$ of $[\mathrm{Pa}]$ reconstructed near core locations be modified by more than $2 \sqrt{ } C_{o}$ if [Th $]_{\mathrm{p}}$ is set equal to the average of water column $[\mathrm{Th}]_{\mathrm{p}}$ data (Figure 9$)$. This number decreases to $1(7 \%)$ if $[\mathrm{Th}]_{\mathrm{p}}$ is obtained from (9). Importantly, a state of no flow is less consistent with the [Pa] estimates, with 5 or 8 adjustments out of $14(35 \%$ or $57 \%)$ exceeding $2 \sqrt{ } C_{o}$, depending on the method of estimating $[\mathrm{Th}]_{\mathrm{p}}$.

\section{Discussion}

\subsection{Water Column ${ }^{231}$ Pa Data}

[60] Measurements of $[\mathrm{Pa}]$ in the water column in the Atlantic Ocean can be brought into consistency with the modern circulation if plausible assumptions are made about (1) the large-scale distribution of the tracer and (2) the uncertainties in our current understanding of the transport of ${ }^{231} \mathrm{~Pa}$ in the deep sea. The $[\mathrm{Pa}]$ measurements from the Angola and Cape basins in the eastern South Atlantic [Scholten et al. [2008] are the least consistent with our estimate of the modern circulation. The values of total ${ }^{231} \mathrm{~Pa}$ activity measured in these basins are the highest in the Atlantic Ocean (Figure 4a). Scholten et al. [2008] invoked 

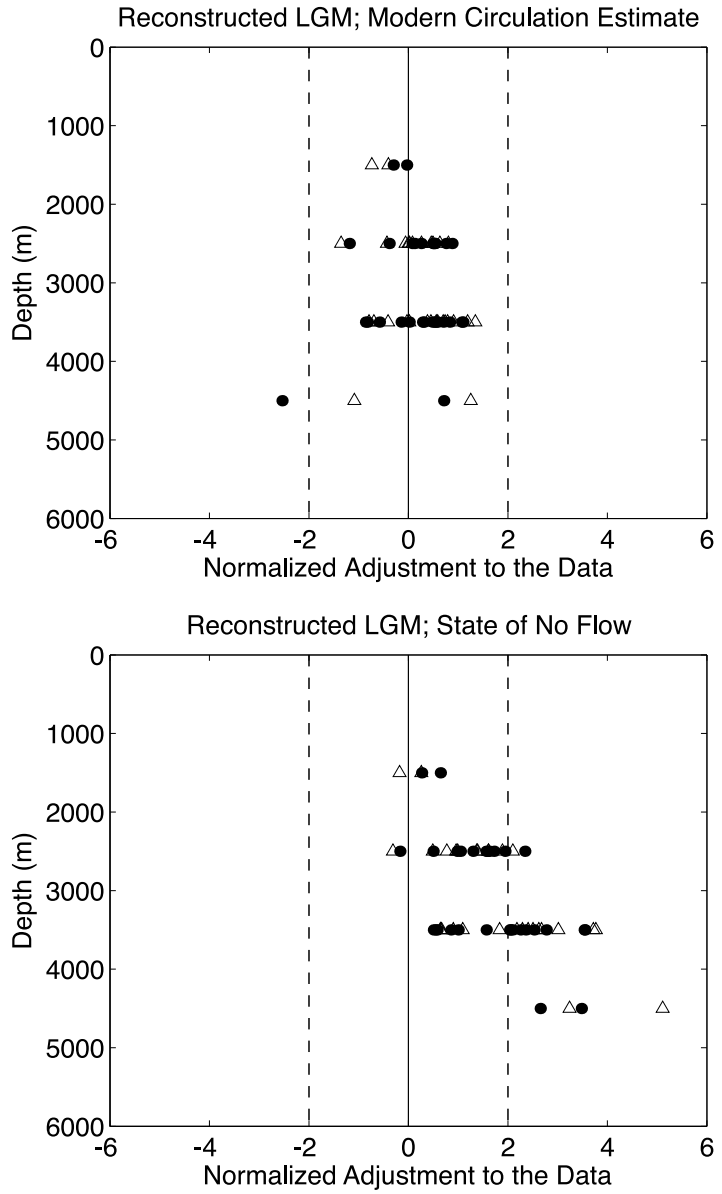

Figure 8. Same as Figure 7 but with LGM data.

the export of ${ }^{231} \mathrm{~Pa}$ to the South Atlantic from the north to explain the factor of two difference between their $[\mathrm{Pa}]$ data and [Pa] data for the Labrador Sea [Moran et al., 2002]. On the other hand, at similar latitudes, the values of [Pa] are much lower in the western Atlantic Ocean than in the eastern Atlantic Ocean (Figure 4a). Observational evidence has been reported for (1) southward transport of NADW along the western boundary in the Brazil Basin [e.g., De Madron and Weatherly, 1994; Hogg and Owens, 1999; Weatherly et al., 2000] and (2) a northward transport into the Cape Basin of Antarctic Bottom Water [Stramma and England, 1999] and Upper Circumpolar Deep Water [Arhan et al., 2003]. Additional measurements of [Pa] in these different water masses may improve understanding of the pronounced zonal difference in $[\mathrm{Pa}]$ in the South Atlantic.

\subsection{Sediment ${ }^{231} \mathrm{~Pa} /{ }^{230} \mathrm{Th}$ Data}

[61] The sediment ${ }^{231} \mathrm{~Pa} /{ }^{230} \mathrm{Th}$ data for the Holocene, LGM, and $\mathrm{H} 1$ can also be brought into consistency with the modern circulation if plausible assumptions are made about the uncertainties involved in the analysis of these data. For each time interval, the adjustments of [Pa] estimates near core locations show similar distributions, diminishing the need for different circulations to explain these data. For each interval the adjustments to a state of no flow are generally more positive than the adjustments to the modern circulation, indicating the $[\mathrm{Pa}]$ values implied by the sediment ${ }^{231}{ }^{2 a}{ }^{230} \mathrm{Th}$ data are too low to be explained purely by particle scavenging. Thus, each sediment data set (Holocene, LGM, and H1) appears to be more compatible with the modern circulation than with a state of no circulation.

[62] These results are consistent with previous studies which concluded that sediment ${ }^{231} \mathrm{~Pa} /{ }^{230} \mathrm{Th}$ measurements in LGM sediments from the Atlantic Ocean do not require a circulation different from today [Yu et al., 1996; Marchal et al., 2000]. These studies are expanded here in three significant ways. First, our results are based on a threedimensional model of the modern circulation which is shown to be consistent, in the least squares sense, with both hydrographic observations and water column ${ }^{231} \mathrm{~Pa}$ mea-
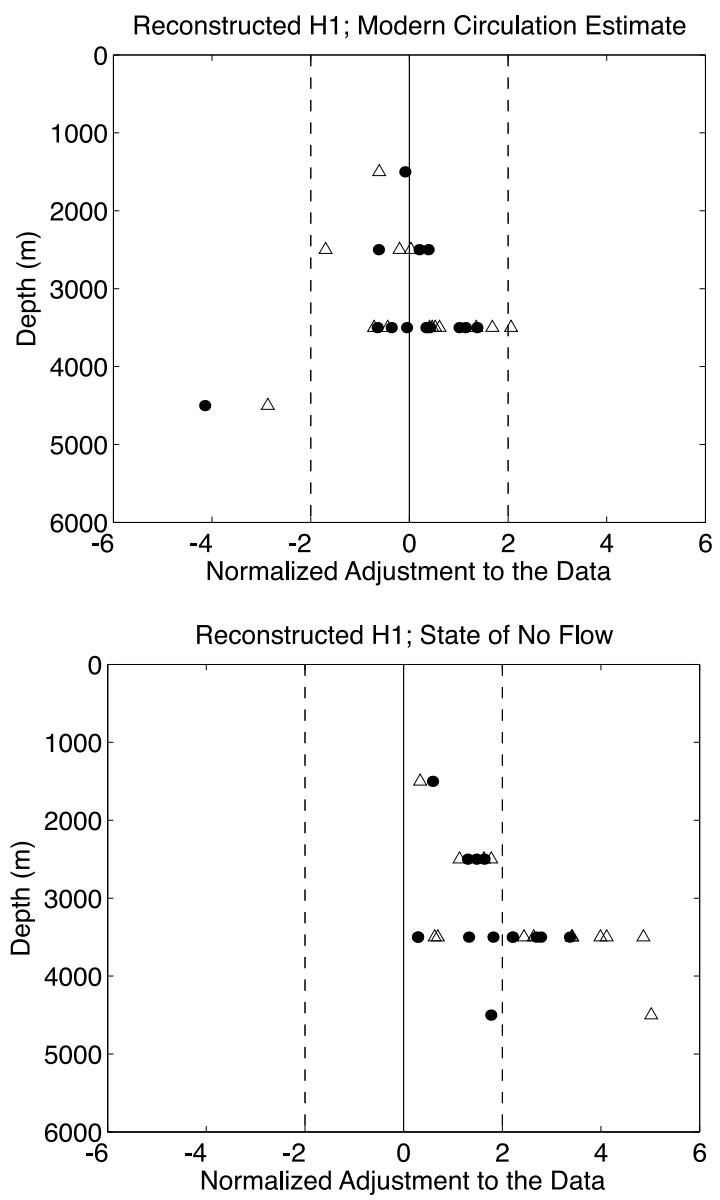

Figure 9. Same as Figure 7 but with $\mathrm{H} 1$ data. 
surements. Second, they are based on an extended set of ${ }^{231} \mathrm{~Pa} /{ }^{230} \mathrm{Th}$ data from sediment cores with improved chronologies [McManus et al., 2004; Gherardi et al., 2005; Hall et al., 2006; Bradtmiller et al., 2007; Gherardi et al., 2009; Bradtmiller, unpublished data, 2009]. Finally, our analysis relies on an inverse method that formally considers the uncertainties both in the distribution of the water property ([Pa]) reconstructed from the sediment and in our understanding of the transport of this property in the ocean. Thus, the conclusion that ${ }^{231} \mathrm{~Pa} /{ }^{230} \mathrm{Th}$ data for Atlantic LGM sediments do not require a circulation different from the modern is likely given a more rigorous basis.

[63] Additionally, our analysis has been extended to include sediment ${ }^{231} \mathrm{~Pa} /{ }^{230} \mathrm{Th}$ measurements from the Atlantic Ocean during H1 (Figure 9). Our results show that, while $[\mathrm{Pa}]$ reconstructed from ${ }^{231} \mathrm{~Pa} /{ }^{230} \mathrm{Th}$ measurements in Bermuda Rise sediments (core OCE326-GGC5) appears too high to be consistent with the modern circulation as previously claimed [McManus et al., 2004], the majority of sediment ${ }^{231} \mathrm{~Pa} /{ }^{230} \mathrm{Th}$ data for $\mathrm{H} 1$ actually appear consistent with the modern circulation. It is likely that ${ }^{231} \mathrm{~Pa}^{230} \mathrm{Th}$ data for core OCE326-GGC5 could also be brought into consistency with the modern circulation, should a relatively high value of $k_{P a}$ be assumed near the core location (a higher $k_{P a}$ would imply a lower $[\mathrm{Pa}]$ in the bottom water and hence a better consistency with the modern circulation). Whereas evidence exists for high abundance of diatom frustules in Bermuda Rise sediments during H1 [Gil et al., 2009; Lippold et al., 2009], its implication for the partition $K_{d}$, and hence $k_{P a}$, remains unclear. Nevertheless, our results underscore (1) the potential pitfall in making inferences from ${ }^{231} \mathrm{~Pa} /{ }^{230} \mathrm{Th}$ data at a single site, and (2) the importance of an extensive set of data for providing useful constraints on paleocirculations [e.g., Luo et al., 2010].

[64] Our result that Atlantic sediment ${ }^{231} \mathrm{~Pa} /{ }^{230} \mathrm{Th}$ data for the LGM and $\mathrm{H} 1$ do not require a circulation different from the modern is in apparent contradiction with conclusions reached in recent studies. Gherardi et al. [2009] concluded that elements of the circulation in the North Atlantic Ocean were different during LGM and $\mathrm{H} 1$ by visually comparing vertical profiles of ${ }^{231} \mathrm{~Pa} /{ }^{230} \mathrm{Th}$ established from measurements on cores originating from very different longitudes (from $9^{\circ} 36^{\prime} \mathrm{W}$ to $57^{\circ} 35^{\prime} \mathrm{W}$ ) and latitudes (from $33^{\circ} 42^{\prime} \mathrm{N}$ to $58^{\circ} 58^{\prime} \mathrm{N}$ ). Additionally, as this paper was in revision, Negre et al. [2010] published a new sediment ${ }^{231} \mathrm{~Pa} /{ }^{230} \mathrm{Th}$ record from the Cape Basin $\left(17^{\circ} 20^{\prime} \mathrm{E}, 34^{\circ} 43^{\prime} \mathrm{S}\right.$, water depth $\left.2440 \mathrm{~m}\right)$. This ${ }^{231} \mathrm{~Pa} /{ }^{230} \mathrm{Th}$ record (not included in our above analysis) was compared with ${ }^{231} \mathrm{~Pa}^{230} \mathrm{Th}$ data from North Atlantic cores to argue for the dominance of a northward flow from the Southern Ocean during the LGM, that is, a reversed situation compared to the dominance of the southward flow of NADW from the North Atlantic today. We have checked that the addition of this record in our analysis does not change our above results (the fractions of $[\mathrm{Pa}]$ adjustments larger than $2 \sqrt{ } C_{o}$ which are reported above are modified by less than $1 \%$ for each time interval: Holocene, LGM, and H1) (see Figure S6 in the auxiliary material). Our work does not imply that the conclusions in these studies are not accurate. Rather it implies that they are sensitive to uncertainties in the spatial distribution of ${ }^{231} \mathrm{~Pa}$ during these time intervals, as well as to uncertainties in our understanding of ${ }^{231} \mathrm{~Pa}$ transport in the ocean (e.g., effects of particle scavenging).

\subsection{Limitations of ${ }^{231} \mathrm{~Pa}$ Model}

[65] A major limitation and source of uncertainty in our ${ }^{231} \mathrm{~Pa}$ model is that the effects of eddy mixing are not represented explicitly. This approach [see also LeGrand and Wunsch, 1995; Huybers et al., 2007; Marchal and Curry, 2008] is largely motivated by simplicity. Microstructure observations suggest that diapycnal diffusivity can vary by orders of magnitude in the abyssal Atlantic with highest values near rough topography [Polzin et al., 1997; St. Laurent et al., 2001; Kunze et al., 2006]. Likewise, results from float trajectories and eddy resolving models indicate that lateral or isopycnal transport by oceanic eddies is very complex: the lateral diffusivity can exhibit very large horizontal variations [e.g., Figueroa, 1994; Berloff et al., 2002; Kamenkovich et al., 2009], lateral diffusion can be anisotropic with a dominant zonal component [e.g., Figueroa and Olson, 1994; Ollitrault and Colin de Verdière, 2002], and the direction of eddy tracer flux can be downgradient in some regions and upgradient in others [e.g., Lee et al., 1997; Wilson and Williams, 2006]. Ladd and Thompson [1998] concluded from results with an eddy-resolving model that in order to realistically reproduce the effects of eddies on tracer transport in an abyssal basin, one of two ingredients is needed: either a realistic mean flow field (including the eddy-driven mean flow) or an anisotropic eddy diffusivity that in some sense reflects the eddy-driven mean flow field. In spite of this complexity, future studies based on inverse methods could build upon this work by exploring the role of eddy mixing in the interpretation of sediment ${ }^{231} \mathrm{~Pa} /{ }^{230} \mathrm{Th}$ data.

[66] The model is further limited by uncertainties in the scavenging of ${ }^{231} \mathrm{~Pa}$ in the ocean. Although an effort is made to incorporate present knowledge about particle distribution and $k_{P a}$ in the Atlantic Ocean, it is likely that our description of the removal of $\mathrm{Pa}$ from the water column remains approximate. For example, a simple representation of the distribution of $k_{P a}$ is used, whereby a distinct but uniform value of $k_{P a}$ is assumed in three abyssal regions (along the western boundary, and north and south of $40^{\circ} \mathrm{S}$ ) based on data from a few locations. Given the sparse coverage of these data, this approach appears appropriate, however it should be refined as more data become available. Observational estimates of the partitioning between dissolved and particulate forms, as well as of the concentration of suspended particles, are critically needed to better understand the removal of ${ }^{231} \mathrm{~Pa}$ to the sediment. Such estimates should lead to more detailed descriptions of particle scavenging for use in large-scale models [e.g., Siddall et al., 2005; Dutay et al., 2009] and better estimates of model uncertainties. Particularly valuable would be paired measurements of dissolved and particulate ${ }^{231} \mathrm{~Pa}$ activity in bottom nepheloid layers.

\section{Conclusions and Perspectives}

[67] Atlantic sediment ${ }^{231} \mathrm{~Pa} /{ }^{230} \mathrm{Th}$ data for the Holocene, LGM, and $\mathrm{H} 1$ all appear to be generally consistent with the 
modern circulation given the uncertainties involved in the analysis of these data. This result resonates with the findings of earlier studies which showed, based on other types of sediment data $\left(\delta^{13} \mathrm{C}\right.$ and $\delta^{18} \mathrm{O}$ in benthic foraminifera), that the bulk of the data for the Atlantic during the LGM appears compatible with the modern circulation if due regard is given to data and/or model errors [LeGrand and Wunsch, 1995; Gebbie and Huybers, 2006; Marchal and Curry, 2008]. It must be emphasized that we do not conclude that the ${ }^{231} \mathrm{~Pa} /{ }^{230} \mathrm{Th}$ data sets imply the $\mathrm{H} 1$ and LGM circulations to be the same as modern. Rather, we conclude that given the significant uncertainties in (1) the spatial distribution of ${ }^{231} \mathrm{~Pa}$ activity in the Atlantic Ocean during $\mathrm{H} 1$ and the LGM and (2) our understanding of ${ }^{231} \mathrm{~Pa}$ transport in the deep sea, the ${ }^{231} \mathrm{~Pa} /{ }^{230} \mathrm{Th}$ data sets from these two time intervals do not require different circulations from the modern. It is also shown here that the sediment ${ }^{231} \mathrm{~Pa} /{ }^{230} \mathrm{Th}$ data for the Holocene, LGM, and H1 all appear less consistent with a state of no flow than they are with the modern circulation.

[68] Thus, earlier claims from sediment ${ }^{231} \mathrm{~Pa} /{ }^{230} \mathrm{Th}$ data that elements of the circulation in the Atlantic Ocean during H1 or LGM have been different from the modern [McManus et al., 2004; Gherardi et al., 2009; Negre et al., 2010] are not as robust as originally thought. Although our results do not imply that these claims are inaccurate, they do indicate that, presently, such conclusions cannot be given a rigorous foundation given the uncertainties involved in the analysis of sedimentary ${ }^{231} \mathrm{~Pa} / 230 \mathrm{Th}$ data (i.e., in both the distribution and modeling of ${ }^{231} \mathrm{~Pa}$ ).

[69] Perhaps the greatest merit of our study is that the assumptions needed to interpret sediment ${ }^{231} \mathrm{~Pa}^{230} \mathrm{Th}$ data in terms of circulation are clarified. Hence our study allows one to identify and legitimate several perspectives. First, significant uncertainties remain in the estimation of the modern, climatologic circulation at abyssal depths due, for example, to uncertainties in the density distribution and in the geostrophic approximation. This state of affairs is detrimental to the interpretation of sediment records because the reference state, the modern circulation, to which these data should be compared is not completely understood. Thus, more hydrographic observations, including direct measurements of velocity [e.g., Hogg and Owens, 1999], are needed to better constrain the time-mean circulation in the subthermocline region. Second, more measurements of ${ }^{231} \mathrm{~Pa}$ and ${ }^{230} \mathrm{Th}$ in the water column, such as those provided by the ongoing program GEOTRACES (http://www.geotraces. org), are required to further our understanding of the distribution and behavior of these nuclides and to enhance the effectiveness of their use in chemical oceanography and paleoceanography. A more extensive database of seawater ${ }^{230} \mathrm{Th}$ measurements would also help constrain the modern abyssal circulation [e.g., Marchal et al., 2007]. Finally, increased spatial coverage of ${ }^{231} \mathrm{~Pa} /{ }^{230} \mathrm{Th}$ data for well-dated sediment cores is also required to help determine possible differences in circulation for different time intervals of the recent geologic past.

[70] Acknowledgments. We would like to thank Mark Siddall, Carl Wunsch, Jake Gebbie, and three anonymous reviewers for helpful comments on an earlier version of this manuscript. Jeanne Gherardi and Ian Hall kindly made their sediment core data available to us. O.M. acknowledges the support from the U.S. National Science Foundation. J.F.M. acknowledges support from the U.S. National Science Foundation and the Comer Research and Education Foundation.

\section{References}

Anderson, R. F., M. P. Bacon, and P. G. Brewer (1983), Removal of ${ }^{230} \mathrm{Th}$ and ${ }^{231} \mathrm{~Pa}$ from the open ocean, Earth Planet. Sci. Lett., 62(1), 7-23, doi:10.1016/0012-821X(83)90067-5.

Arhan, M., H. Mercier, and Y.-H. Park (2003), On the deep water circulation of the eastern south Atlantic Ocean, Deep Sea Res., Part I, 50, 889-916, doi:10.1016/S0967-0637(03) 00072-4.

Bacon, M. P., and R. F. Anderson (1982), Distribution of thorium isotopes between dissolved and particulate forms in the deep sea, J. Geophys. Res., 87, 2045-2056, doi:10.1029/ JC087iC03p02045.

Baringer, M. O., and J. F. Price (1997), Mixing and spreading of the Mediterranean outflow, J. Phys. Oceanogr., 27(8), 1654-1677, doi:10.1175/1520-0485(1997)027<1654: MASOTM $>2.0 . \mathrm{CO} ; 2$.

Berloff, P. S., J. C. McWilliams, and A. Bracco (2002), Material transport in oceanic gyres. Part I: Phenomenology, J. Phys. Oceanogr. 32(3), 764-796, doi: 10.1175/1520-0485 (2002)032<0764:MTIOGP $>2.0$. CO;2.

Biscaye, P. E., and S. L. Eittreim (1977), Suspended particulate loads and transports in nepheloid layer of abyssal Atlantic Ocean, Mar. Geol., 23(1-2), 155-172, doi:10.1016 0025-3227(77)90087-1.

Bishop, J. K. B. (1999), Transmissometer measurement of POC, Deep Sea Res., Part I,
46, 353-369, doi:10.1016/S0967-0637(98) 00069-7.

Bradtmiller, L. I., R. F. Anderson, M. Q. Fleisher, and L. H. Burckle (2007), Opal burial in the equatorial Atlantic Ocean over the last $30 \mathrm{ka}$ : Implications for glacial-interglacial changes in the ocean silicon cycle, Paleoceanography, 22, PA4216, doi:10.1029/2007PA001443.

Bretherton, F. P., R. E. Davis, and C. B. Fandry (1976), Technique for objective analysis and design of oceanographic experiments applied to MODE-73, Deep Sea Res. Oceanogr. Abstr., 23, 559-582.

Brewer, P. G., D. W. Spencer, P. E. Biscaye, A. Hanley, P. L. Sachs, C. L. Smith, S. Kadar, and J. Fredericks (1976), Distribution of particulate matter in Atlantic Ocean, Earth Planet. Sci. Lett., 32(2), 393-402, doi:10.1016/0012 Sci. Lett., 32(2), 393
821X(76)90080-7.

Broecker, W. S. (1979), A revised estimate for the radiocarbon age of North Atlantic deep water, J. Geophys. Res., 84, 3218-3226, doi:10.1029/JC084iC06p03218.

Bryden, H. L., H. R. Longworth, and S. A Bryden, H. L., H. R. Longworth, and S. A.
Cunningham (2005), Slowing of the Atlantic meridional overturning circulation at $25^{\circ} \mathrm{N}$ Nature, 438,655-657, doi:10.1038 nature 04385 .

Chase, Z., R. F. Anderson, M. Q. Fleisher, and P. W. Kubik (2002), The influence of particle composition and particle flux on scavenging of $\mathrm{Th}, \mathrm{Pa}$ and $\mathrm{Be}$ in the ocean, Earth Planet. Sci. Lett., 204(1-2), 215-229, doi:10.1016/ S0012-821X(02)00984-6.

Cheng, H., R. L. Edwards, J. Hoff, C. D. Gallup, D. A. Richards, and Y. Asmerom (2000), The half-lives of uranium-234 and thorium-230, Chem. Geol., 169(1-2), 17-33, doi:10.1016/ S0009-2541(99)00157-6.

De Madron, X. D., and G. Weatherly (1994), Circulation, transport and bottom boundarylayers of the deep currents in the Brazil Basin, J. Mar. Res., 52(4), 583-638, doi:10.1357/ 0022240943076975.

Dutay, J.-C., F. Lacan, M. Roy-Barman, and L. Bopp (2009), Influence of particle size and type on ${ }^{231} \mathrm{~Pa}$ and ${ }^{230} \mathrm{Th}$ simulation with a global coupled biogeochemical-ocean general circulation model: A first approach, Geochem. Geophys. Geosyst., 10, Q01011, doi:10.1029/ 2008GC002291.

Fasullo, J. T., and K. E. Trenberth (2008), The annual cycle of the energy budget. Part II: Meridional structures and poleward transports, J. Clim., 21(10), 2313-2325, doi:10.1175/ 2007JCLI1936.1.

Figueroa, H. A. (1994), Eddy resolution versus eddy diffusion in a double gyre GCM. Part II: Mixing of passive tracers, J. Phys. Oceanogr., 24(2), 387-402, doi:10.1175/1520-0485 (1994)024<0387:ERVEDI >2.0.CO;2. 
Figueroa, H. A., and D. B. Olson (1994), Eddy resolution versus eddy diffusion in a double gyre GCM. Part I: The Lagrangian and Eulerian description, J. Phys. Oceanogr., 24(2), 371-386, doi:10.1175/1520-0485(1994) 024<0371:ERVEDI $>2.0$. CO; 2 .

François, R., M. Frank, M. M. Rutgers van der Loeff, and M. P. Bacon (2004), ${ }^{230} \mathrm{Th}$ normalization: An essential tool for interpreting sedimentary fluxes during the late Quaternary,
Paleoceanography, 19, PA1018, doi:10.1029/ 2003PA000939.

Gebbie, G., and P. Huybers (2006), Meridional circulation during the Last Glacial Maximum explored through a combination of South Atlantic $\delta^{18} \mathrm{O}$ observations and a geostrophic inverse model, Geochem. Geophys. Geosyst. 7, Q11N07, doi:10.1029/2006GC001383.

Gherardi, J. M., L. Labeyrie, J. F. McManus,

R. Francois, L. C. Skinner, and E. Cortijo (2005), Evidence from the northeastern Atlantic basin for variability in the rate of the meridional overturning circulation throug the last deglaciation, Earth Planet. Sci. Lett. 240(3-4), 710-723, doi:10.1016/j.epsl.2005. 09.061

Gherardi, J.-M., L. Labeyrie, S. Nave, R. Francois, J. F. McManus, and E. Cortijo (2009), Glacialinterglacial circulation changes inferred from ${ }^{231} \mathrm{~Pa} /{ }^{230} \mathrm{Th}$ sedimentary record in the North Atlantic region, Paleoceanography, 24, PA2204, doi:10.1029/2008PA001696.

Gherardi, J.-M., Y. Luo, R. Francois, J. F. McManus, S. E. Allen, and L. Labeyri (2010), Reply to comment by S. Peacock on "Glacial-interglacial circulation changes inferred from ${ }^{231} \mathrm{~Pa} /{ }^{230} \mathrm{Th}$ sedimentary record in the North Atlantic region", Paleoceanography, 25, PA2207, doi:10.1029/2009PA001867.

Gil, I. M., L. D. Keigwin, and F. G. Abrantes (2009), Deglacial diatom productivity and surface ocean properties over the Bermuda Rise, northeast Sargasso Sea, Paleoceanography, 24, PA4101, doi:10.1029/2008PA001729.

Gourestki, V. V., and K. P. Koltermann (2004),

WOCE global hydrographic climatology, Tech. Rep. 35, 54 pp., Bundesamtes fü Seeschifffahrt und Hydrogr., Hamburg, Germany.

Guihou, A., S. Pichat, S. Nave, A. Govin, L. Labeyrie, E. Michel, and C. Waelbroeck (2010), Late slowdown of the Atlantic Meridional Overturning Circulation during the Las Glacial Inception: New constraints from sedimentary $\left.{ }^{231} \mathrm{~Pa}^{230} \mathrm{Th}\right)$, Earth Planet. Sci. Lett. 289(3-4), 520-529, doi:10.1016/j.epsl.2009. 11.045

Hall, I. R., S. B. Moran, R. Zahn, P. C. Knutz, C.-C. Shen, and R. L. Edwards (2006), Accelerated drawdown of meridional overturning in the late-glacial Atlantic triggered by transient pre-H event freshwater perturbation, Geophys. Res. Lett., 33, L16616, doi:10.1029/ 2006GL026239.

Heinrich, H. (1988), Origin and consequences of cyclic ice rafting in the northeast AtlanticOcean during the past 130,000 years, Quat. Res., 29(2), 142-152, doi:10.1016/0033-5894 (88)90057-9.

Hemming, S. R. (2004), Heinrich events: Massive late Pleistocene detritus layers of the North Atlantic and their global climate imprint, Rev. Geophys., 42, RG1005, doi:10.1029/2003RG000128.

Henderson, G. M., and R. F. Anderson (2003),

The U-series toolbox for paleoceanography,
Rev. Mineral. Geochem., 52, 493-531, doi: $10.2113 / 0520493$

Hogg, N. G., and W. B. Owens (1999), Direct measurement of the deep circulation within the Brazil Basin, Deep Sea Res., Part II, 46, 335-353, doi:10.1016/S0967-0645(98)00097-6.

Hogg, N. G., G. Siedler, and W. Zenk (1999), Circulation and variability at the southern boundary of the Brazil Basin, J. Phys. Ocea nogr., 29(2), 145-157, doi:10.1175/1520 0485(1999)029<0145:CAVATS $>2.0$. CO 2 .

Huybers, P., G. Gebbie, and O. Marchal (2007), Can paleoceanographic tracers constrain meridional circulation rates?, J. Phys. Oceanogr. 37(2), 394-407, doi:10.1175/JPO3018.1.

Kamenkovich, I., P. Berloff, and J. Pedlosk (2009), Anisotropic material transport by eddies and eddy-driven currents in a model of the North Atlantic, J. Phys. Oceanogr., 39(12), 3162-3175, doi:10.1175/2009JPO4239.1.

Keigwin, L. D., and E. A. Boyle (2008), Did North Atlantic overturning halt 17,000 year ago?, Paleoceanography, 23, PA1101, doi:10.1029/2007PA001500.

Kendall, M. G., and J. D. Gibbons (1990), Rank Correlation Methods, 5th ed., 260 pp., Oxford Univ. Press, New York.

Krishnaswami, S., D. Lal, B. L. K. Somayajulu, R. F. Weiss, and H. Craig (1976), Largevolume in situ filtration of deep pacific waters: Mineralogical and radioisotope studies, Earth Planet. Sci. Lett., 32(2), 420-429, doi:10.1016/ 0012-821X(76)90082-0.

Krishnaswami, S., M. M. Sarin, and B. L. K. Somayajulu (1981), Chemical and radiochemical investigations of surface and deep particles of the Indian Ocean, Earth Planet. Sci. Lett., 54(1), 81-96, doi:10.1016/0012-821X (81) $90071-6$.

Kunze, E., E. Firing, J. M. Hummon, T. K. Chereskin, and A. M. Thurnherr (2006) Global abyssal mixing inferred from lowere ADCP shear and CTD strain profiles, J. Phys. Oceanogr., 36(8), 1553-1576, doi:10.1175 JPO2926.1.

Ladd, C., and L. Thompson (1998), The influence of eddies on tracer transport in the abyssal ocean, J. Phys. Oceanogr., 28(9), 1717-1738, doi: $10.1175 / 1520-0485(1998) 028<1717$ : TIOEOT $>2.0 . \mathrm{CO} ; 2$

Lee, M. M., D. P. Marshall, and R. G. Williams (1997), On the eddy transfer of tracers: Advective or diffusive?, J. Mar. Res., 55(3), 483-505, doi: $10.1357 / 0022240973224346$

LeGrand, P., and C. Wunsch (1995), Constraint from paleotracer data on the North Atlantic circulation during the Last Glacial Maximum, Paleoceanography, 10, 1011-1045, doi:10.1029/95PA01455.

Lippold, J., J. Grützner, D. Winter, Y. Lahaye, A. Mangini, and M. Christl (2009), Does sedimentary ${ }^{231} \mathrm{~Pa} /{ }^{230} \mathrm{Th}$ from the Bermuda Rise monitor past Atlantic Meridional Overturning Circulation?, Geophys. Res. Lett., 36 , L12601, doi:10.1029/2009GL038068.

Luo, Y., R. Francois, and S. E. Allen (2010), Sediment ${ }^{231} \mathrm{~Pa} /{ }^{230} \mathrm{Th}$ as a recorder of the rate of the Atlantic meridional overturning circulation: Insights from a 2-D model, Ocean Sci., 6 , 381-400, doi:10.5194/os-6-381-2010.

Marchal, O., and W. B. Curry (2008), On the abyssal circulation in the glacial Atlantic, J. Phys. Oceanogr., 38(9), 2014-2037, doi:10.1175/2008JPO3895.1.

Marchal, O., R. Francois, T. F. Stocker, and F. Joos (2000), Ocean thermohaline circulation and sedimentary ${ }^{231} \mathrm{~Pa} /{ }^{230} \mathrm{Th}$ ratio, Paleocea- nography, 15,625-641, doi:10.1029/ 2000PA000496.

Marchal, O., R. Francois, and J. Scholten (2007), Contribution of ${ }^{230} \mathrm{Th}$ measurements to the estimation of the abyssal circulation, Deep Sea Res., Part I, 54, 557-585, doi:10.1016/j. dsr.2007.01.002.

Martel, F., and C. Wunsch (1993), The North Atlantic Circulation in the early $1980 \mathrm{~s}-\mathrm{An}$ estimate from inversion of a finite-difference model, J. Phys. Oceanogr., 23(5), 898-924, doi: $10.1175 / 1520-0485(1993) 023<0898$. TNACIT $>2.0 . \mathrm{CO} ; 2$.

McManus, J. F., R. Francois, J. M. Gherardi, L. D. Keigwin, and S. Brown-Leger (2004), Collapse and rapid resumption of Atlantic meridional circulation linked to deglacial climate changes, Nature, 428, 834-837, doi: 10.1038 /nature02494.

Moran, S. B., C.-C. Shen, S. E. Weinstein, L. H. Hettinger, J. H. Hoff, H. N. Edmonds, and R. L. Edwards (2001), Constraints on deep water age and particle flux in the equatorial and South Atlantic Ocean based on seawater ${ }^{231} \mathrm{~Pa}$ and ${ }^{230} \mathrm{Th}$ data, Geophys. Res. Lett. 28, 3437-3440, doi:10.1029/2001GL013339.

Moran, S. B., C. C. Shen, H. N. Edmonds, S. E. Weinstein, J. N. Smith, and R. L. Edwards (2002), Dissolved and particulate ${ }^{231} \mathrm{~Pa}$ and ${ }^{30} \mathrm{Th}$ in the Atlantic Ocean: Constraints on intermediate/deep water age, boundary scavenging, and ${ }^{231} \mathrm{~Pa} /{ }^{230} \mathrm{Th}$ fractionation, Earth Planet. Sci. Lett., 203(3-4), 999-1014, doi:10.1016/S0012-821X(02)00928-7.

Morris, M. Y., M. M. Hall, L. C. St. Laurent, and N. G. Hogg (2001), Abyssal mixing in the Brazil Basin, J. Phys. Oceanogr., 31(11), 3331-3348, doi:10.1175/1520-0485(2001) 031<3331:AMITBB >2.0.CO;2.

Negre, C., R. Zahn, A. L. Thomas, P. Masque, G. M. Henderson, G. Martinez-Mendez, I. R Hall, and J. L. Mas (2010), Reversed flow of Atlantic deep water during the Last Glacial Maximum, Nature, 468, 84-88, doi:10.1038/ nature 09508

Nelson, D. M., P. Treguer, M. A. Brzezinski, A. Leynaert, and B. Queguiner (1995), Production and dissolution of biogenic silica in the ocean: Revised global estimates, comparison with regional data and relationship to biogenic sedimentation, Global Biogeochem. Cycles, 9, 359-372, doi:10.1029/95GB01070.

Nozaki, Y., Y. Horibe, and H. Tsubota (1981), The water column distributions of thorium isotopes in the western North Pacific, Earth Planet Sci. Lett., 54(2), 203-216, doi:10.1016/0012821X(81)90004-2.

Ochoa, J., and N. A. Bray (1991), Water mass exchange in the Gulf of Cadiz, Deep Sea Res., Part A, 38, S465-S503.

Ollitrault, M., and A. Colin de Verdière (2002), SOFAR floats reveal midlatitude intermediate North Atlantic general circulation. Part I: A Lagrangian descriptive view, J. Phys. Oceanogr., 32(7), 2020-2033, doi:10.1175/1520 0485(2002)032<2020:SFRMIN>2.0.CO;2

Peacock, S. (2010), Comment on "Glacialinterglacial circulation changes inferred from ${ }^{231} \mathrm{~Pa} /{ }^{230} \mathrm{Th}$ sedimentary record in the North Atlantic region" by J.-M. Gherardi et al. Paleoceanography, 25, PA2206, doi:10.1029/ 2009PA001835.

Polzin, K. L., J. M. Toole, J. R. Ledwell, and R. W. Schmitt (1997), Spatial variability of turbulent mixing in the abyssal ocean, Science, 276(5309), 93-96, doi:10.1126/science.276. 5309.93 . 
Roemmich, D., and C. Wunsch (1985), Two transatlantic sections: Meridional circulation and heat flux in the subtropical North Atlantic Ocean, Deep Sea Res., Part A, 32, 619-664, doi:10.1016/0198-0149(85)90070-6.

Rutgers van der Loeff, M. M., and G. W. Berger (1993), Scavenging of ${ }^{230} \mathrm{Th}$ and ${ }^{231} \mathrm{~Pa}$ near the antarctic polar front in the South-Atlantic, Deep Sea Res., Part I, 40, 339-357, doi:10.1016/0967-0637(93)90007-P.

Schmitz, W. J., Jr., and M. S. McCartney (1993), On the North Atlantic Circulation, Rev. Geophys., 31, 29-49, doi:10.1029/92RG02583.

Scholten, J. C., M. M. Rutgers van der Loeff, and A. Michel (1995), Distribution of ${ }^{230} \mathrm{Th}$ and ${ }^{231} \mathrm{~Pa}$ in the water column in relation to the ventilation of the deep Arctic basins, Deep Sea Res., Part II, 42, 1519-1531, doi:10.1016/ 0967-0645(95)00052-6.

Scholten, J. C., J. Fietzke, A. Mangini, C. D. Garbe-Schbnberg, A. Eisenhauer, R. Schneider, and P. Stoffers (2008), Advection and scavenging: Effects on ${ }^{230} \mathrm{Th}$ and ${ }^{231} \mathrm{~Pa}$ distribution off Southwest Africa, Earth Planet. Sci. Lett., 271 (1-4), 159-169, doi:10.1016/j.epsl.2008.03.060.

Siddall, M., G. M. Henderson, N. R. Edwards, M. Frank, S. A. Muller, T. F. Stocker, and F. Joos (2005), 231Pa-231/Th-210 fractionation by ocean transport, biogenic particle flux and particle type, Earth Planet. Sci. Lett., 237(1-2), 135-155, doi:10.1016/j.epsl.2005.05.031.

Siddall, M., T. F. Stocker, G. M. Henderson, F. Joos, M. Frank, N. R. Edwards, S. P. Ritz, and S. A. Muller (2007), Modeling the relationship between ${ }^{231} \mathrm{~Pa} /{ }^{230}$ Th distribution in North Atlantic sediment and Atlantic meridional overturning circulation, Paleoceanography, 22, PA2214, doi:10.1029/2006PA001358.

St. Laurent, L. C., J. M. Toole, and R. W Schmitt (2001), Buoyancy forcing by turbulence above rough topography in the abyssal Brazil Basin, J. Phys. Oceanogr., 31(12), 3476-3495, doi:10.1175/1520-0485(2001) 031<3476:BFBTAR $>2.0 . \mathrm{CO} ; 2$.

Stramma, L., and M. England (1999), On the water masses and mean circulation of the
South Atlantic Ocean, J. Geophys. Res., 104 20,863-20,883, doi:10.1029/1999JC900139. Talley, L. D. (2003), Shallow, intermediate, and deep overturning components of the global heat budget, J. Phys. Oceanogr., 33(3), 530 560, doi:10.1175/1520-0485(2003)033<0530 SIADOC $>2.0 . \mathrm{CO} ; 2$.

Trenberth, K. E., and J. M. Caron (2001), Estimates of meridional atmosphere and ocean hea transports, J. Clim., 14(16), 3433-3443, doi: $10.1175 / 1520-0442(2001) 014<3433$ : EOMAAO $>2.0 . \mathrm{CO} ; 2$

Venchiarutti, C., C. Jeandel, and M. Roy-Barman (2008), Particle dynamics study in the wake of Kerguelen Island using thorium isotopes, Deep Sea Res., Part I, 55, 1343-1363, doi:10.1016/J. dsr.2008.05.015.

Walter, H. J., M. M. Rutgers van der Loeff, and H. Hoeltzen (1997), Enhanced scavenging of ${ }^{231} \mathrm{~Pa}$ relative to ${ }^{230} \mathrm{Th}$ in the south Atlantic south of the Polar front: Implications for the use of the ${ }^{231} \mathrm{~Pa} /{ }^{230} \mathrm{Th}$ ratio as a paleoproductivity proxy, Earth Planet. Sci. Lett., 149(1-4), 85-100, doi:10.1016/S0012-821X(97)00068-X. Walter, H. J., W. Geibert, M. M. Rutgers van der Loeff, G. Fischer, and U. Bathmann (2001), Shallow vs. deep-water scavenging of ${ }^{231} \mathrm{~Pa}$ and ${ }^{230} \mathrm{Th}$ in radionuclide enriched waters of the Atlantic sector of the Southern Ocean, Deep Sea Res., Part I, 48, 471-493, doi:10.1016/S0967-0637(00)00046-7.

Weatherly, G. L., Y. Y. Kim, and E. A. Kontar (2000), Eulerian measurements of the North Atlantic Deep Water deep western boundary current at $18^{\circ} \mathrm{S}, J$. Phys. Oceanogr., 30(5), 971-986, doi:10.1175/1520-0485(2000) $030<0971$ :EMOTNA $>2.0 . \mathrm{CO} ; 2$

Wilson, C., and R. G. Williams (2006), When are eddy tracer fluxes directed downgradient? J. Phys. Oceanogr., 36(2), 189-201, doi:10.1175/JPO2841.1.

Wunsch, C. (1996), The Ocean Circulation Inverse Problem, 442 pp., Cambridge Univ. Press, Cambridge, U. K., doi:10.1017/ CBO9780511629570.
Wunsch, C. (2003), Determining paleoceanographic circulations, with emphasis on the Las Glacial Maximum, Quat. Sci. Rev., 22(2-4) 371-385, doi:10.1016/S0277-3791(02)00177-4.

Wunsch, C. (2005), The total meridional heat flux and its oceanic and atmospheric partition, J. Clim., 18(21), 4374-4380, doi:10.1175 JCLI3539.1.

Yu, E.-F. (1994), Variations in the particulate flux of ${ }^{230} \mathrm{Th}$ and ${ }^{231} \mathrm{~Pa}$ and paleoceanograhpic applications of the ${ }^{231} \mathrm{~Pa} /{ }^{230} \mathrm{Th}$ ratio, $\mathrm{Ph} . \mathrm{D}$. thesis, 269 pp, Mass. Inst. of Technol. and Woods Hole Oceanogr. Inst., Woods Hole, Mass.

Yu, E. F., R. Francois, and M. P. Bacon (1996) Similar rates of modern and last-glacial ocean thermohaline circulation inferred from radiochemical data, Nature, 379, 689-694, doi: $10.1038 / 379689 \mathrm{a} 0$.

Zenk, W., G. Siedler, B. Lenz, and N. G. Hogg (1999), Antarctic Bottom Water flow through the Hunter channel, J. Phys. Oceanogr., 29(11) 2785-2801, doi:10.1175/1520-0485(1999) 029<2785:ABWFTT>2.0.CO;2.

L. I. Bradtmiller, Department of Environmental Studies, Macalester College, 1600 Grand Ave., St. Paul, MN 55105, USA.

A. Burke, MIT/WHOI Joint Program in Oceanography, Woods Hole Oceanographic Institution, MS 24 Woods Hole, MA 02543 , USA. (aburke@whoi.edu)

R. François, Department of Earth and Ocean Sciences, University of British Columbia, 6270 University Blvd., Vancouver, BC V6T 1Z4, Canada.

O. Marchal, Department of Geology and Geophysics, Woods Hole Oceanographic Institution, Quissett Campus, MS 23, Woods Hole, MA 02543, USA.

J. F. McManus, Department of Earth and Environmental Science, Lamont-Doherty Earth Observatory, 239 Comer Geochemistry Bldg., Palisades, NY 10964, USA. 


\section{Conclusions and Perspectives}

This thesis has provided insights into the role of the ocean during the climate changes that occurred during the transition between glacial and interglacial conditions. I used radionuclides (uranium series and radiocarbon) both as dating tools and as tracers to further our understanding of the complex sequence of events that occurred over the last

deglaciation. Specifically, I developed a new technique for rapid ${ }^{14} \mathrm{C}$ dating of corals, generated deglacial radiocarbon records from uranium-series dated corals from the Southern Ocean and North Atlantic, and tested the ability of sedimentary ${ }^{231} \mathrm{~Pa} /{ }^{230} \mathrm{Th}$ ratios to constrain deglacial circulation changes using an inverse model. The combination of modeling and data generation provides a multifaceted oceanographic changes and gives a framework for future studies using these tracers.

Deep-sea corals have great potential for providing paleoceanographic proxy data, but their use is made difficult by their variable distribution through time and the lack of $a$ priori knowledge of the relative ages of samples. The reconnaissance radiocarbon dating technique developed in this thesis allows rapid age determinations on large numbers of deep-sea coral samples. These age surveys allowed me to determine which samples would be appropriate for studies of oceanic change during the deglaciation.

Radiocarbon reconstructions from deep-sea corals collected from the Drake Passage at depths corresponding to modern-day Antarctic Intermediate Water (AAIW) and Upper Circumpolar Deep Water (UCDW) and combined with a radiocarbon record from the deep South Atlantic [Skinner et al., 2010] suggest increased vertical stratification in the Southern Ocean during the last glacial period. This stratification would have helped to maintain the low atmospheric $\mathrm{CO}_{2}$ during the glacial period since the deep carbon-rich waters would have had limited connection with the atmosphere in a more stratified Southern Ocean. At the start of the deglaciation, during Heinrich Stadial 1 (H1), Southern Ocean water masses were more homogenized with respect to radiocarbon, suggesting stronger mixing. Upwelling of deep waters to the surface during this time period could have contributed to the rise in atmospheric $\mathrm{CO}_{2}$, as well as the drop in radiocarbon activity of the atmosphere over this time period. During the Antarctic Cold Reversal/Bølling-Allerød (ACR/BA), at the time of the hiatus of the deglacial rise in atmospheric $\mathrm{CO}_{2}$, our radiocarbon records from the Southern Ocean suggest decreased 
air-sea gas exchange, further corroborating this link between carbon cycling in the Southern Ocean and the atmosphere. After the ACR/BA, there is no evidence for reduced air-sea gas exchange in the Southern Ocean, nor any large radiocarbon depletions such as those found during the glacial period and first half of the deglaciation.

In contrast, radiocarbon reconstructions from deep-sea corals in the North Atlantic off Iceland show a similar ventilation rate of this region during the ACR/BA and the Holocene. The age distribution of the deep-sea corals collected from Iceland does not allow for a continuous record of North Atlantic ventilation throughout the deglaciation, with the majority of these coral samples having reconnaissance dates of $<10 \mathrm{ka}$ (Holocene) or $>40 \mathrm{ka}$ (radiocarbon-dead). The two deglacial corals collected from Iceland grew during the Bølling-Allerød, and thus do not put constraints on North Atlantic ventilation during $\mathrm{H} 1$ or the Younger Dryas.

Previous studies [McManus et al., 2004; Gherardi et al., 2009] have suggested that North Atlantic ventilation was significantly different during $\mathrm{H} 1$ and the Younger Dryas based on increases in sedimentary ${ }^{231} \mathrm{~Pa} /{ }^{230} \mathrm{Th}$ ratios during these periods. I tested this hypothesis using an inverse modeling technique to quantitatively assess the consistency of sedimentary ${ }^{231} \mathrm{~Pa} /{ }^{230} \mathrm{Th}$ ratios from the Holocene, $\mathrm{H} 1$, and the Last Glacial Maximum with the modern circulation. I found that given the uncertainties in the past distribution and behavior of these nuclides, the ${ }^{231} \mathrm{~Pa} /{ }^{230} \mathrm{Th}$ data do not require a circulation significantly different from the modern-day circulation at any of these time intervals. These findings highlight the importance of giving due regard to uncertainties in the spatial distribution of paleoceanographic tracers, as well as the uncertainties in modeling the behavior of tracers in the modern ocean.

Future extensions of this thesis may seek to fill in the temporal data gaps in the radiocarbon records from the Drake Passage and Iceland. To accomplish this, one would need more samples, more reconnaissance dates, and a bit of luck that corals grew during the time periods of interest. A better understanding of the radiocarbon blank in deep-sea corals would also be helpful, as the relatively large uncertainty on radiocarbon blank correction currently limits useful radiocarbon reconstructions to samples that are younger than $\sim 30$ ka. Uncertainties associated with the use of sedimentary ${ }^{231} \mathrm{~Pa} /{ }^{230} \mathrm{Th}$ ratios as a circulation proxy may be reduced by efforts to understand the modern distribution and 
behavior of ${ }^{231} \mathrm{~Pa}$ and ${ }^{230} \mathrm{Th}$ in the water column (e.g. by the GEOTRACES program). Finally, incorporating radiocarbon into the inverse model used here for ${ }^{231} \mathrm{~Pa} /{ }^{230} \mathrm{Th}$ would provide an additional rate tracer that could improve the extent to which deglacial circulation changes could be constrained.

Gherardi, J. M., et al. (2009), Glacial-interglacial circulation changes inferred from Pa231/Th-230 sedimentary record in the North Atlantic region, Paleoceanography, 24.

McManus, J. F., et al. (2004), Collapse and rapid resumption of Atlantic meridional circulation linked to deglacial climate changes, Nature, 428, 824-837.

Skinner, L. C., et al. (2010), Ventilation of the Deep Southern Ocean and Deglacial CO2 Rise, Science, 328(5982), 1147-1151. 


\section{Appendix A1}

\section{Data Table for Chapter 2.}

Originally published as online auxiliary material for:

Burke, A., Robinson, L.F., McNichol, A.P., Jenkins, W.J., Scanlon, K.M., and Gerlach, D.S. (2010), Reconnaissance dating: A new radiocarbon method applied to assessing the temporal distribution of Southern Ocean deep-sea corals, Deep-Sea Research Part I-Oceanographic Research Papers, 57(11), Doi 10.1016/J.Dsr.2010.07.010, 1510-1520.

Table 1. Radiocarbon reconnaissance and hydrolysis data for deep-sea corals. 


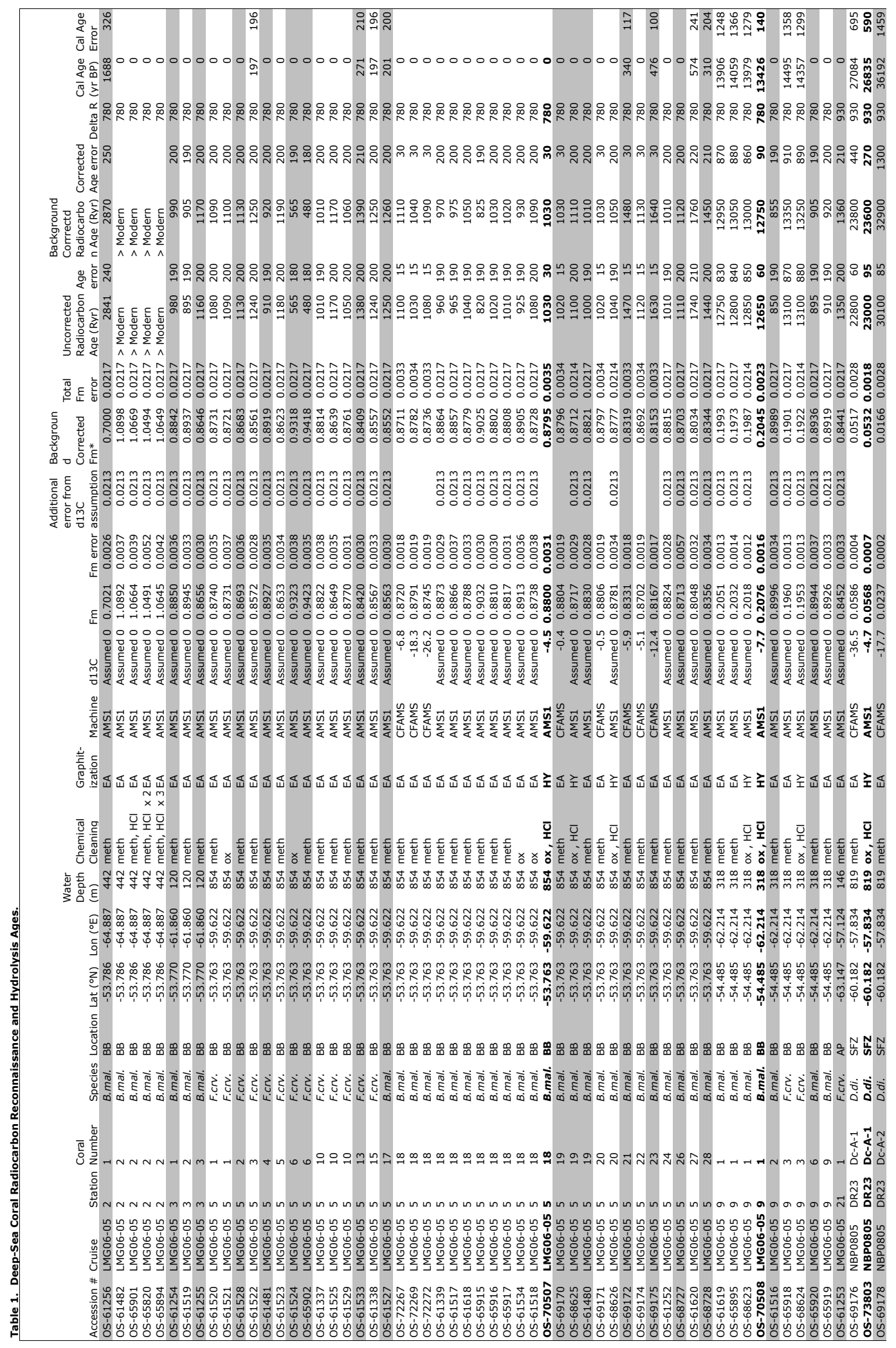




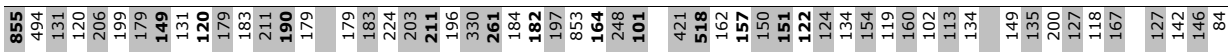

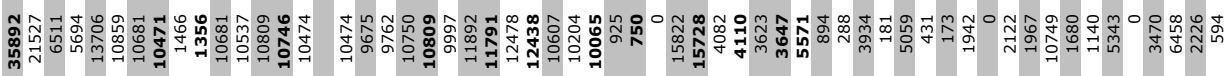

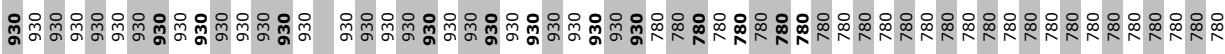

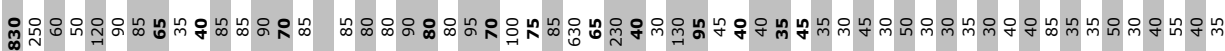

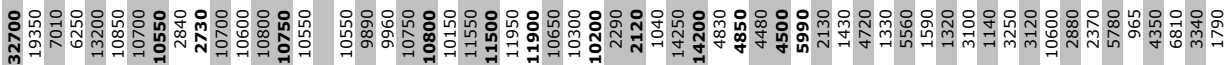

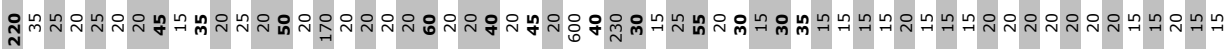

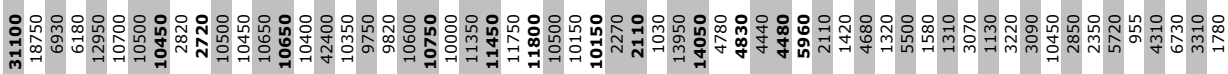

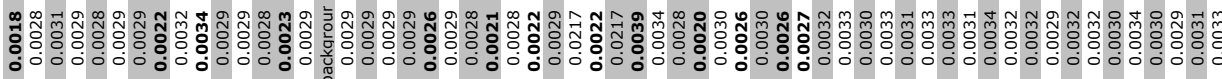

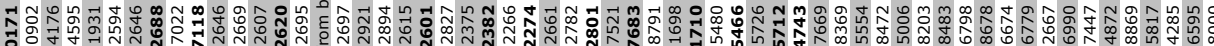

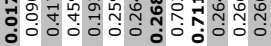

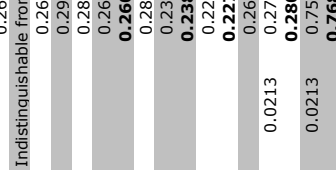

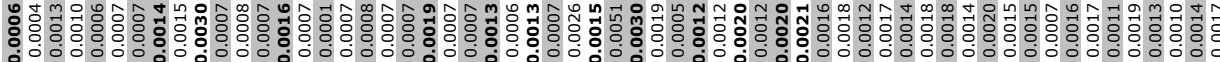

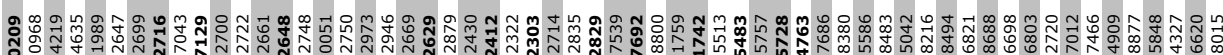

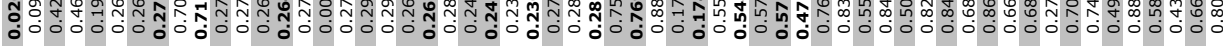

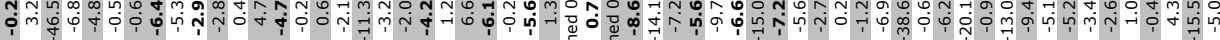

变要

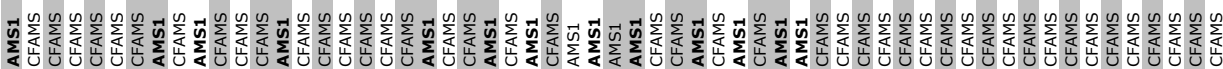

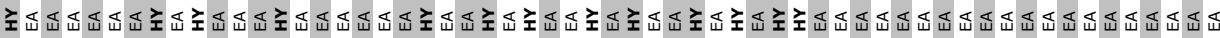

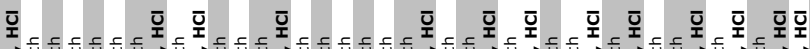

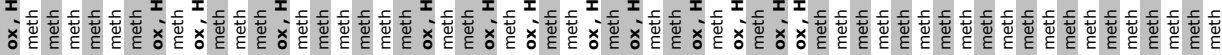

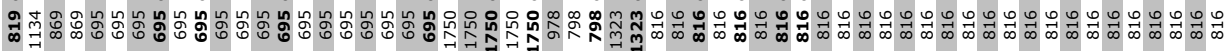

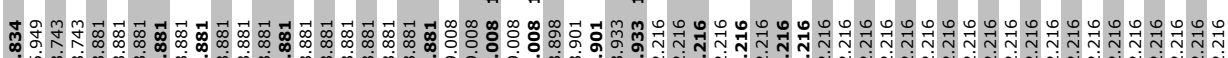

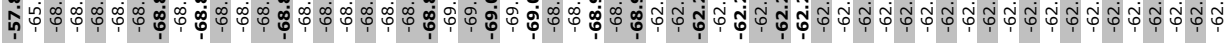

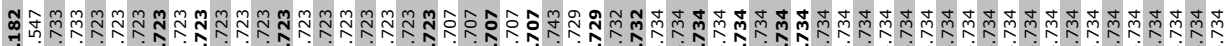

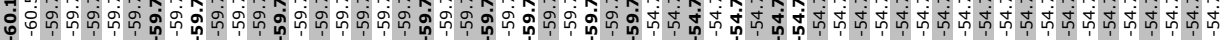

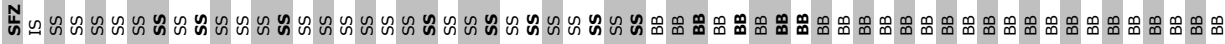

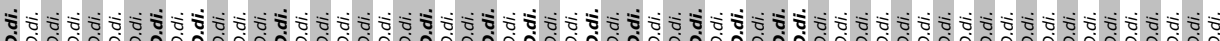

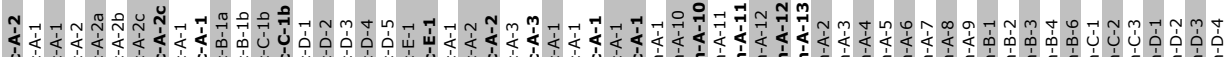

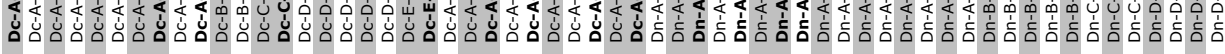

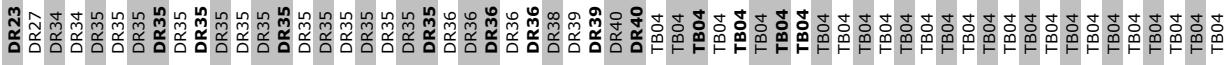

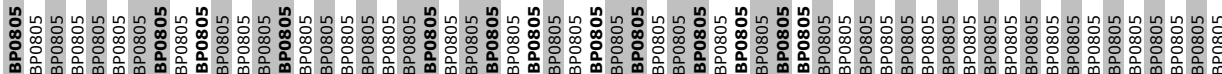

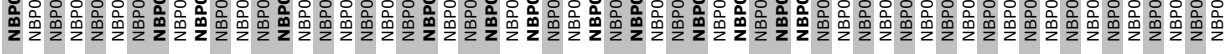

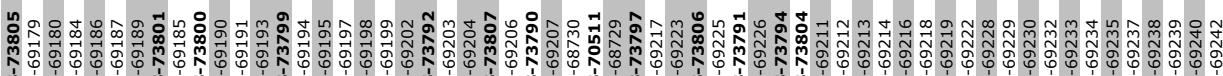

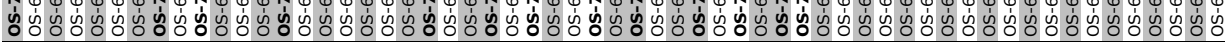




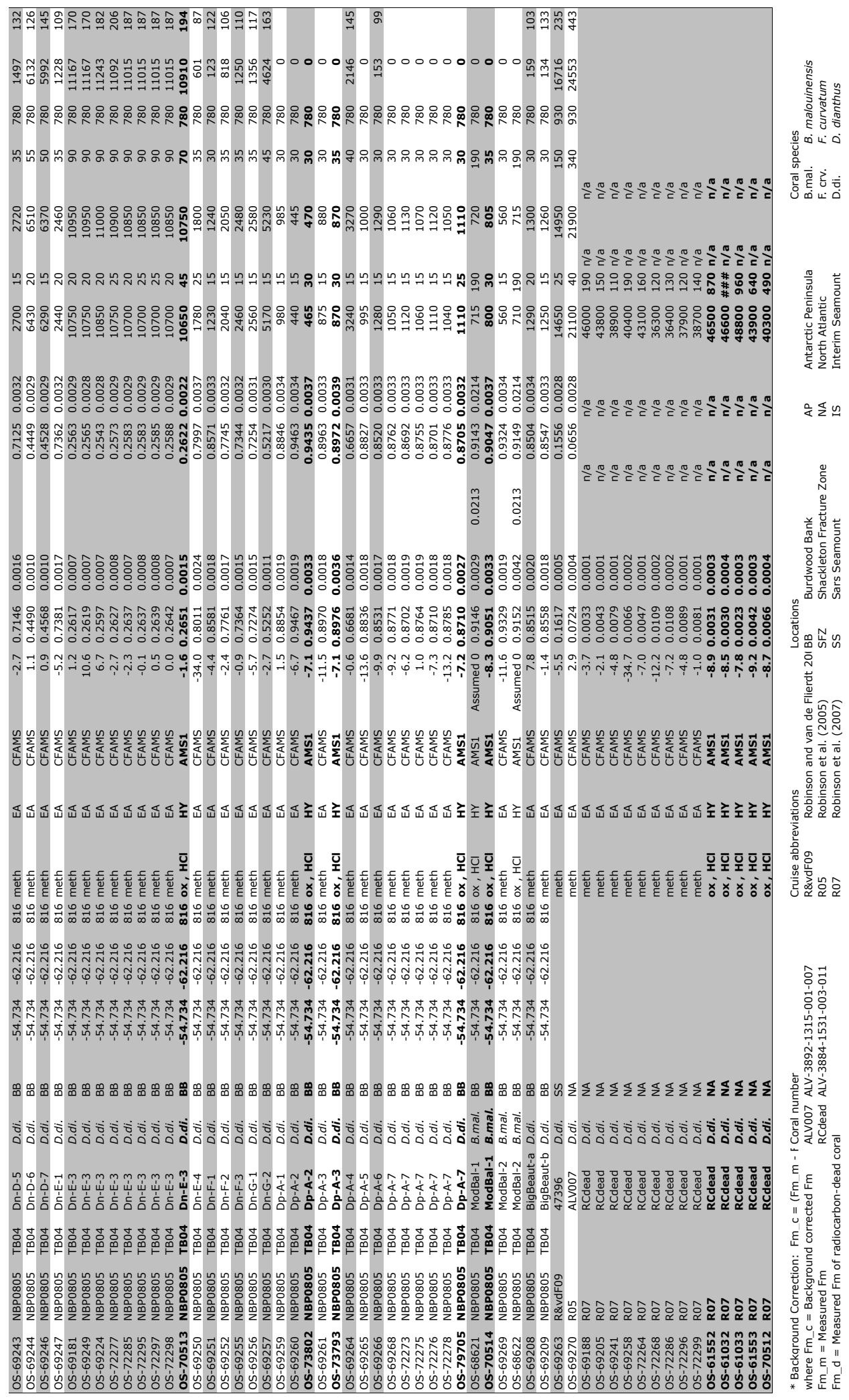




\section{Appendix A2}

\section{Supplementary Information and Data Tables for Chapter 3: The Southern Ocean's role in carbon exchange during the last deglaciation}

Text 1. Sample description, uranium series and radiocarbon methods, and explanations of calculations

Figures S1 through S4.

Table 1. Uranium and thorium data

Table 2. Radiocarbon data 


\section{Text 1.}

\section{Sample description}

All corals were collected by dredge from the Drake Passage [Burke et al., 2010]. Vertical depth ranges did not exceed $120 \mathrm{~m}$. Eight of the forty corals analyzed in this study were from Burdwood Bank from depths between 804 and $828 \mathrm{~m}$ and two were from Burdwood Bank at $318 \mathrm{~m}$. These depths today correspond to depths of AAIW[Guerrero et al., 1999]. These ten corals from Burdwood Bank have ages ranging from modern to $16.4 \pm 0.3 \mathrm{ka}$. The remaining corals come from depths corresponding to UCDW today. Twenty-two corals come from Sars Seamount from depths between 672 and $1781 \mathrm{~m}$. Two additional $D$. dianthus from this location were previously dated and are included in the discussion [Goldstein et al., 2001; Robinson and van de Flierdt, 2009]. Seven corals come from Shackleton Fracture Zone (772 to $866 \mathrm{~m} \mathrm{depth}$ ) and one coral comes from a seamount south of Sars Seamount ('Interim Seamount', 1113 to 1154 m depth) (Figure 1). The thirty corals collected from depths corresponding to UCDW have ages ranging from $1.14 \pm 0.05 \mathrm{ka}$ to $226.0 \pm 3.4 \mathrm{ka}$, but the paper is limited to the 26 corals with ages less than $35 \mathrm{ka}$, where the radiocarbon uncertainties are sufficiently small for $\Delta^{14} \mathrm{C}$ reconstructions. Here, as in other deep-sea coral studies [e.g., Adkins et al., 2002], we found that the reconstructed $\Delta^{14} \mathrm{C}$ of a $B$. malouinensis collected live from $816 \mathrm{~m}$ depth on Burdwood Bank $(-95 \pm 6 \%)$ is within error of the nearest gridded GLODAP $\Delta^{14} \mathrm{C}$ value at that depth [-92\%; Key et al., 2004], further substantiating the ability to reconstruct the $\Delta^{14} \mathrm{C}$ of these water masses using deep-sea corals.

\section{Uranium series methods}

Approximately $0.6 \mathrm{~g}$ of coral was cut and physically cleaned of visible ferromanganese crusts and areas of recalcification with a Dremel tool, and then further cleaned with an oxidizing and reducing chemical procedure [Cheng et al., 2000a]. The coral was dissolved in nitric acid and spiked with $\sim 0.08 \mathrm{~g}$ of a ${ }^{236} \mathrm{U}_{-}^{229} \mathrm{Th}$ mix spike that was calibrated using isotope dilution with gravimetric standards: a 388 ppb U solution (CRM-145) diluted at WHOI, and a 58 ppt ${ }^{232} \mathrm{Th}$ solution diluted at Caltech. The

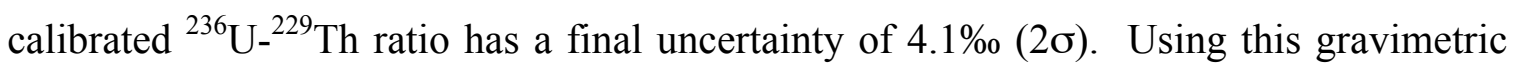


calibration, the ${ }^{230} \mathrm{Th} /{ }^{238} \mathrm{U}$ ratio of a Harwell uraninite standard (HU-1; [Cheng et al., 2000b]) is within error of secular equilibrium.

The $\mathrm{U}$ and $\mathrm{Th}$ fractions of the coral samples were separated and purified using an iron co-precipitation and anion exchange columns [Edwards et al., 1987] and were analyzed using bracketing standards on a multi-collector inductively coupled plasma mass spectrometer (MC-ICP-MS), with a typical internal precision of $\sim 1 \%$ o $(2 \sigma)$ for $\mathrm{U}$ fractions and better than $2 \%$ for the Th fractions. Uranium was measured following the procedure of Robinson et al. [Robinson et al., 2002]. Thorium was measured with ${ }^{232} \mathrm{Th}$ on Faraday cups and alternating between measuring ${ }^{229} \mathrm{Th}$ and ${ }^{230} \mathrm{Th}$ on the secondary electron multiplier (SEM). There are three ways to determine the ${ }^{230} \mathrm{Th} /{ }^{229} \mathrm{Th}$ ratio. The first is to directly ratio the ${ }^{230} \mathrm{Th}$ and ${ }^{229} \mathrm{Th}$ counts from the SEM measurements. The second is to ratio the ${ }^{232} \mathrm{Th}$-normalized ${ }^{230} \mathrm{Th}$ and ${ }^{229} \mathrm{Th}$ counts (i.e., ${ }^{230} \mathrm{Th} /{ }^{229} \mathrm{Th}=$ $\left.\left({ }^{230} \mathrm{Th} /{ }^{232} \mathrm{Th}\right) /\left({ }^{229} \mathrm{Th} /{ }^{232} \mathrm{Th}\right)\right)$. The ${ }^{232} \mathrm{Th}$-normalized method generally gave smaller uncertainties because it accounts for beam instability. Additionally, we added pure ${ }^{236} \mathrm{U}$ spike to the Th fraction and measured ${ }^{236} \mathrm{U}$ on a Faraday cup to provide another isotope with which the ${ }^{230} \mathrm{Th}$ and ${ }^{229} \mathrm{Th}$ could be normalized, and giving a third way to determine the ${ }^{230} \mathrm{Th} /{ }^{229} \mathrm{Th}$ ratio. This ${ }^{236} \mathrm{U}$-normalized ratio was particularly useful for the samples that had low ${ }^{232} \mathrm{Th}$ that could not easily be measured on the Faradays. In general, all three of these methods generated ${ }^{230} \mathrm{Th} /{ }^{229} \mathrm{Th}$ ratios that were within $1 \%$ of each other, and within the analytical uncertainties. When all three methods generated ${ }^{230} \mathrm{Th} /{ }^{229} \mathrm{Th}$ ratios that were within $1 \%$ of each other, the ratio with the smallest uncertainty was used. In the rare case $(<5 \%$ of measurements) where one of the three methods was off by more than $1 \%$, that particular ${ }^{230} \mathrm{Th} /{ }^{229} \mathrm{Th}$ ratio was ignored and the ratio with the smallest uncertainty of the remaining two was used. Full procedural replicates of a HU-1 standard were run with every batch of column chemistry ( 6 unknown samples and 1 blank). These give an external reproducibility of $2.3 \%$ using the direct method and $2.7 \%$ using the ${ }^{236} \mathrm{U}$-normalized method (low concentrations of ${ }^{232} \mathrm{Th}$ in the HU-1 standard result in large uncertainties from the ${ }^{232}$ Th-normalized method), and the larger of the two was used for the final ratio uncertainties.

In order to calculate an age, an assumption needs to be made about the initial ${ }^{230} \mathrm{Th}$ incorporated into the coral skeleton. We use modern day ratios of ${ }^{230} \mathrm{Th}$ to ${ }^{232} \mathrm{Th}$ 
measured in unfiltered seawater collected at depths near the dredge sites [Bradtmiller et al., 2009] (atom ratio of 5,000, with a range between 500 and 15,000) and use the measured ${ }^{232} \mathrm{Th}$ concentration (less than $3.0 \mathrm{ng} / \mathrm{g}$ in all corals used for $\Delta^{14} \mathrm{C}$ reconstruction, Figure S1) to estimate initial ${ }^{230} \mathrm{Th}$. The final error for ages and associated with the calculated $\Delta{ }^{14} \mathrm{C}$ values is dominated by the correction for initial ${ }^{230} \mathrm{Th}$, with typical final precisions of $\sim 1.4 \%$, although they can be as precise as $0.5 \%(2 \sigma)$ for samples with the lowest ${ }^{230} \mathrm{Th}$. However, at the old end of the radiocarbon range, the final error of $\Delta{ }^{14} \mathrm{C}$ is dominated by the error in the ${ }^{14} \mathrm{C} /{ }^{12} \mathrm{C}$ ratio because of the uncertainty on the radiocarbon background correction. Procedural replicates were made on four corals and generated ages within error of one another, with offsets between replicates ranging from $0.3 \%$ to $1.4 \%$, consistent with propagated errors. For corals that had procedural replicates, the replicate with the lowest ${ }^{232} \mathrm{Th}$ concentration was used for calculation of $\Delta{ }^{14} \mathrm{C}$.

The $\delta^{234} \mathrm{U}$ values were calculated for the corals to test for closed system behavior. $\delta^{234} \mathrm{U}$ is the deviation (\%) of the ${ }^{234} \mathrm{U} /{ }^{238} \mathrm{U}$ ratio from secular equilibrium . Open system behavior is suspected if the initial $\delta^{234} \mathrm{U}$ of the coral (i.e., back corrected for the age of the coral) is not within error of modern seawater $\delta^{234} U(147 \%)$. Seawater $\delta^{234} U$ might have been lower during the last glacial period $\left(142 \%\right.$ ), so we checked if our coral $\delta^{234} U$ values were consistent with a step-change in the $\delta^{234} \mathrm{U}$ of seawater to lower values prior to 17 $\mathrm{ky}$, following the IntCal09 group [Reimer et al., 2009]. All corals used for radiocarbon reconstructions lie within $\delta^{234} \mathrm{U}$ measurement uncertainty (external $2 \sigma \mathrm{SD}=2.3 \%$ ) of the error envelope of the $\delta^{234} \mathrm{U}$ seawater curve established by the IntCal09 group [Reimer et al., 2009]. Corals are also within error of a constant $\delta^{234} U$ seawater curve (Figure S2).

\section{Radiocarbon methods}

For radiocarbon analyses, $40 \mathrm{mg}$ of coral were cut and cleaned with an abbreviated oxidative cleaning [Shen and Boyle, 1988; Adkins et al., 2002]. The coral was etched with $\mathrm{HCl}$ to remove at least $50 \%$ of the mass immediately prior to its conversion to $\mathrm{CO}_{2}$ by hydrolysis [Adkins et al., 2002]. A split of the $\mathrm{CO}_{2}$ gas was taken for analysis of $\delta^{13} \mathrm{C}$ on a VG Prism-II Stable Isotope Ratio Mass Spectrometer (SIRMS). 
The remaining $\mathrm{CO}_{2}$ gas was converted to graphite by heating it in the presence of $\mathrm{H}_{2}$ gas and an iron catalyst and the ${ }^{14} \mathrm{C} /{ }^{12} \mathrm{C}$ of the graphite was measured on the accelerator mass spectrometer at the National Ocean Science Accelerator Mass Spectrometer (NOSAMS) facility. Radiocarbon results are normalized to a $\delta^{13} \mathrm{C}=-25 \%$ and are reported as Fraction modern (Fm) where 'modern' is defined as $95 \%$ of the $1950 \mathrm{AD}$ radiocarbon concentration of NBS Oxalic Acid I (NIST-SRM-4990) normalized to a $\delta^{13} \mathrm{C}=-19 \%$ [Olsson, 1970].

Radiocarbon-dead deep-sea corals have a larger Fm than the radiocarbon-dead IAEA C-1 calcite standard used for blank correction, perhaps due to an adsorption of modern $\mathrm{CO}_{2}$ onto the surface of the coral [e.g., Eltgroth et al., 2006]. A scaled blank correction was made prior to calculating radiocarbon ages of the corals, as described in [Burke et al., 2010], based on the average Fm of a radiocarbon-dead coral that was U-Th dated to $225.2 \mathrm{ky}(\mathrm{Fm}=0.0040 \pm 0.0031$ ( 2 standard deviations); $\mathrm{n}=6$ ). For this blank correction it is assumed that the contaminating carbon has $\mathrm{Fm}=1$, and the scaling is such that a coral with $\mathrm{Fm}=1$ does not change with the blank correction (Fm remains equal to 1) and a radiocarbon-dead coral yields a $\mathrm{Fm}=0$.

\section{Calculation of $\Delta^{14} C$ and $\Delta \Delta^{14} C$}

Both the radiocarbon age of the coral and the amount of time elapsed since the death of the coral (the U-Th calendar age) are needed to reconstruct the $\Delta{ }^{14} \mathrm{C}$ of seawater:

$$
\left.\Delta^{14} C_{\text {sea water }}=\left(\frac{e^{-14} \text { cage/ } / 8033}{e^{- \text {cal age } / 8266}}-1\right) \times 1000 \quad \text { [Adkins and Boyle, } 1997\right] .
$$

To calculate $\Delta \Delta{ }^{14} \mathrm{C}$, the reconstructed $\Delta{ }^{14} \mathrm{C}$ was subtracted from the contemporaneous atmosphere:

$\Delta \Delta^{14} \mathrm{C}=\Delta{ }^{14} \mathrm{C}_{\text {seawater }}-\Delta^{14} \mathrm{C}_{\text {atmosphere. }}$

The IntCal09 atmospheric $\Delta^{14} \mathrm{C}$ record was averaged over $\pm 2 \sigma$ around the calendar age to

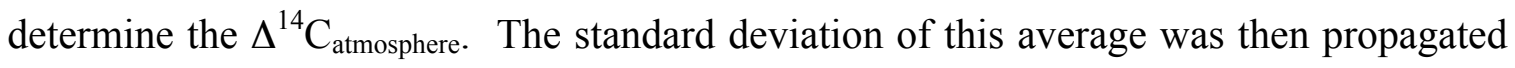
through the calculation of $\Delta \Delta^{14} \mathrm{C}$ to determine the uncertainty on the final $\Delta \Delta^{14} \mathrm{C}$ value. When considering $\Delta{ }^{14} \mathrm{C}$ or $\Delta \Delta^{14} \mathrm{C}$ data, it is important to recognize that the absolute offset between $\Delta{ }^{14} \mathrm{C}$ values (\%) translates into different radiocarbon age offsets depending on 
the calendar age, since the inventory of radiocarbon changes with time. For instance, during the LGM, the atmosphere was $\sim 35 \%$ higher in radiocarbon than modern (1950 A.D). As a result, a 100\% offset from the atmosphere during the LGM corresponds to a radiocarbon age offset of $618 \mathrm{y}$, as opposed to $846 \mathrm{y}$ at modern. Thus, on Figure 2, we plot contour lines of constant age offset to give a sense of the magnitude of change in $\Delta \Delta^{14} \mathrm{C}$ that can be attributed to changing radiocarbon inventory.

\section{Mystery interval radiocarbon budget calculations}

We did a simple mass budget calculation to determine the radiocarbon depletion needed in an isolated abyssal reservoir of a given volume to explain the $\sim 190 \%$ drop in atmospheric radiocarbon over the time period between 17.5 -14. $5 \mathrm{ka}$ and compared it to a similar calculation from Broecker and Barker [B\&B, 2007]. B\&B assume that the mean non-isolated ocean radiocarbon age is the same $(1900 \mathrm{y}$ older than contemporaneous atmosphere) before and after the mystery interval, and they calculate how old the isolated reservoir needs to be to sustain that age offset from the atmosphere if the isolated carbon is mixed through the entire ocean reservoir. In contrast, our calculation allows some proportion of the isolated carbon to be directly mixed with the atmosphere before being mixed back into the ocean. This direct mixing into the atmosphere results in younger ocean radiocarbon ages compared to the contemporaneous atmosphere at the end of the mystery interval than before, since atmospheric $\Delta^{14} \mathrm{C}$ drops more than ocean $\Delta^{14} \mathrm{C}$.

We assume that the production rate of radiocarbon over the mystery interval is constant as suggested by ${ }^{10} \mathrm{Be}$ accumulation rates in Greenland ice cores [Muscheler et $a l ., 2004]$. If we had instead used the production rates predicted by either paleomagnetic records or ${ }^{10} \mathrm{Be}$ accumulation in marine sediments [Frank et al., 1997; Laj et al., 2002], the drop in atmospheric ${ }^{14} \mathrm{C}$ over the mystery interval would be easier to reconcile since these production records indicate that the geomagnetic field strength increased slightly over this time period (resulting in a decrease in ${ }^{14} \mathrm{C}$ production). We also assume that the concentration of carbon in the ocean is uniform to convert easily between the percent of the ocean volume occupied by the isolated reservoir and the percent of the total oceanic carbon budget. While clearly incorrect, a more realistic distribution of carbon in the 
ocean (i.e., greater at depth) would again make it easier to explain the decrease in atmospheric $\Delta^{14} \mathrm{C}$ over the mystery interval: an abyssal isolated reservoir would have a higher carbon concentration than the mean oceanic value, so a given amount of carbon would occupy a smaller volume. The total oceanic carbon budget that is used for the start of the mystery interval $(39,600 \mathrm{Pg} \mathrm{C})$ is $2 \%$ greater than the pre-industrial value of $38,700 \mathrm{Pg} \mathrm{C}$ to account for the $\sim 80 \mathrm{ppm}$ decrease in atmospheric $\mathrm{CO}_{2}$ and the $\sim 700 \mathrm{Pg}$ decrease in the terrestrial $\mathrm{C}$ reservoir between the Holocene and the LGM [Sigman and Boyle, 2000]. We deliberately simplify the process of air-sea gas exchange to keep the calculation similar to B\&B's calculation, and do not include carbon isotope fractionation due to air-sea gas exchange. Including this process makes the mystery interval even easier to explain since ${ }^{14} \mathrm{C}$ would preferentially stay in the ocean as DIC compared to ${ }^{12} \mathrm{C}$. Inclusion of air-sea gas exchange isotope fractionation would decrease the age required for the isolated ocean reservoir by less than 180 years.

As mentioned above, our calculation differs from that of Broecker and Barker [2007] because we do not require that the mean age of the non-isolated ocean remains the same before and after the mystery interval. Radiocarbon records presented here and in other studies [e.g., Skinner and Shackleton, 2004; Galbraith et al., 2007; Barker et al., 2010; Skinner et al., 2010] show younger radiocarbon age offsets at the transition between the end of the mystery interval and the beginning of the Bølling-Allerød as illustrated in Chapter 3 (Fig. 2). Our calculation also differs from that of Broecker and Barker [2007] in that we relax the strict requirement that the carbon from the isolated reservoir must be mixed through the entire ocean. In our calculation, we allow some (varying) percentage of the carbon from the isolated reservoir to be directly mixed into the atmosphere from the abyssal isolated reservoir, as would happen if the isolated reservoir was being ventilated directly to the atmosphere through upwelling in the Southern Ocean (Figure S3). The carbon from the isolated reservoir that is not vented directly into the ocean is mixed into the rest of the ocean. Any excess carbon vented to the atmosphere via this mechanism that is greater than the observed rise in atmospheric $\mathrm{CO}_{2}$ over the course of the mystery interval [i.e. never greater than 40 p.p.m.v.; Monnin et al., 2001] is put back into the oceanic reservoir. 
For our calculation, we first determine the number of moles of ${ }^{12} \mathrm{C}$ in the hypothetical isolated reservoir. A fraction of this carbon is then distributed (mixed in) to the atmosphere ranging from 1\% (i.e. $99 \%$ remains and is mixed into the rest of the ocean) to $100 \%$ (Figure S3). The amount of carbon added to the atmosphere from the isolated reservoir via this mechanism is much more than the observed $\mathrm{CO}_{2}$ rise over this time interval [ 40 ppm; Monnin et al., 2001], so the excess $\mathrm{CO}_{2}$ is transferred from atmosphere back into the ocean with the ${ }^{14} \mathrm{C} /{ }^{12} \mathrm{C}$ isotopic ratio of the atmosphere. For the purposes of this calculation, we ignore the terrestrial reservoir as a sink for the excess $\mathrm{C}$ added to the atmosphere. Including the terrestrial reservoir would make the mystery interval easier to explain, as it would reduce the amount of ${ }^{14} \mathrm{C}$ added back into the ocean, i.e., the deep ocean would be less ventilated by the atmosphere. As a result, it would be easier to maintain a reasonable age offset (>1000 y; Fig. 4) between the atmosphere and the ocean.

Since atmospheric $\mathrm{CO}_{2}$ and $\Delta{ }^{14} \mathrm{C}$ values are relatively well-constrained aspects of this system, we use them to constrain the value of ${ }^{14} \mathrm{C} /{ }^{12} \mathrm{C}$ of the isolated ocean reservoir $\left(R_{\text {ior }}\right)$ with the following equation:

$$
\begin{aligned}
R_{\text {ior }} & =\frac{{ }^{14} C_{\text {added to atmosphere }}}{{ }^{12} C_{\text {added to atmosphere }}} \\
& =\frac{{ }^{14} C_{f}-{ }^{14} C_{i}}{{ }^{12} C_{\text {added }}} \\
& =\frac{R_{f}\left({ }^{12} C_{\text {added }}+{ }^{12} C_{i}\right)-R_{i}^{12} C_{i}}{{ }^{12} C_{\text {added }}}
\end{aligned}
$$

where $R_{\text {ior }}$ is the ${ }^{14} \mathrm{C} /{ }^{12} \mathrm{C}$ ratio of the isolated reservoir, $R_{i}$ and $R_{f}$ are the initial (premystery interval) and final (post-mystery interval) atmospheric ${ }^{14} \mathrm{C} /{ }^{12} \mathrm{C}$ ratios, ${ }^{12} C_{\text {added }}$ is the number of moles of ${ }^{12} \mathrm{C}$ added to the atmosphere from the isolated reservoir, and ${ }^{12} C_{i}$ is the number of moles of ${ }^{12} \mathrm{C}$ present in the atmosphere prior to the mystery interval.

If we then make the assumption that the mean age of the non-isolated ocean reservoir compared to the atmosphere prior to the mystery interval was $1900 \mathrm{y}$ [400 y reservoir age +1500 y offset from surface water; Broecker and Barker, 2007], we can 
then calculate the ${ }^{14} \mathrm{C} /{ }^{12} \mathrm{C}$ ratio of the ocean after the mystery interval. For this calculation we need the carbon budgets and isotopic ratios of (a) the isolated ocean reservoir, (b) the non-isolated ocean prior to the mystery interval, and (c) the excess carbon added to the atmosphere beyond the observed rise in atmospheric $\mathrm{CO}_{2}$ over this time period that is removed from the atmosphere and added back to the ocean reservoir. This relationship can be expressed as follows:

$$
\begin{aligned}
R_{\text {ocean }} & =\frac{{ }^{14} C_{\text {ocean }}}{{ }^{12} C_{\text {ocean }}} \\
& =\frac{{ }^{14} C_{\text {NOR }}+\left({ }^{14} C_{I O R}-{ }^{14} C_{\text {added to atmosphere }}\right)+{ }^{14} C_{\text {atmosphere excess }}}{{ }^{12} C_{\text {NOR }}+\left({ }^{12} C_{I O R}-{ }^{12} C_{\text {added to atmosphere }}\right)+{ }^{12} C_{\text {atmosphere excess }}}
\end{aligned}
$$

Here the subscript 'ocean' refers to the post-mystery interval ocean after the isolated ocean reservoir $(I O R)$ and the non-isolated ocean reservoir $(N O R)$ have been mixed together. The subscript 'added to atmosphere' refers to the carbon added to the atmosphere from the isolated ocean reservoir, and the subscript 'atmosphere excess' refers to the excess carbon added to the atmosphere above the 40 ppmv rise that is mixed back into the ocean. A plot of these ocean ventilation ages after the mystery interval as a function of both the volume of the isolated ocean reservoir and the percentage of carbon from the isolated ocean reservoir that was mixed directly into the atmosphere is shown in Figure S4.

The main conclusion of this calculation is that if carbon from the isolated ocean reservoir is not forced to be mixed through the entire ocean (by allowing direct transfer of some percentage of carbon from the isolated reservoir to the atmosphere or by allowing the ocean to get relatively younger after the mystery interval), then the isolated reservoir does not have to be as old as previously thought and is within the boundaries of existing data sets. 


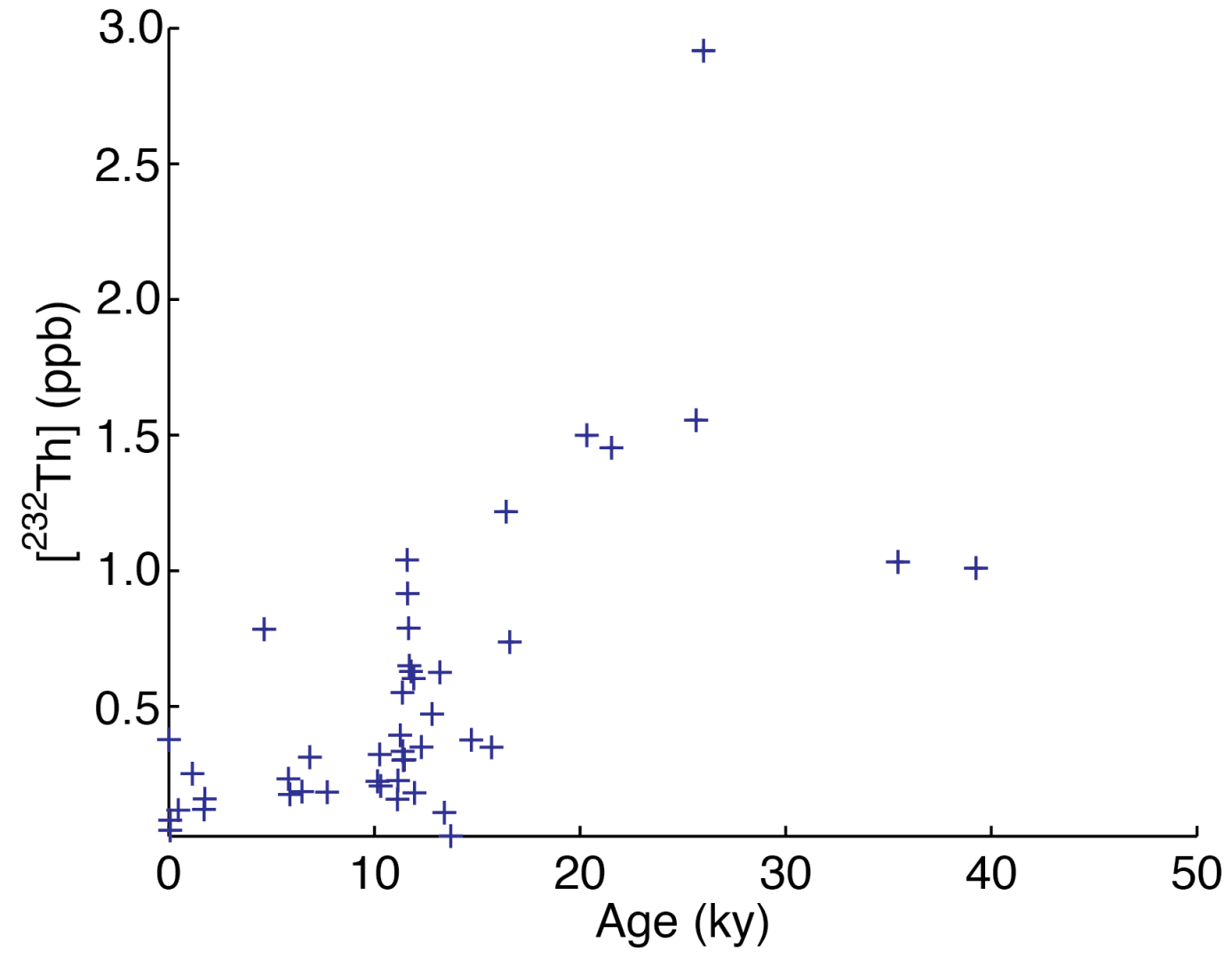

Figure S1. ${ }^{232} \mathrm{Th}$ concentration (in $\mathrm{ppb}$, or $\mathrm{ng} / \mathrm{g}$ ) as a function of calendar age of corals used in $\Delta^{14} \mathrm{C}$ reconstructions. Error bars are smaller than the symbols. 


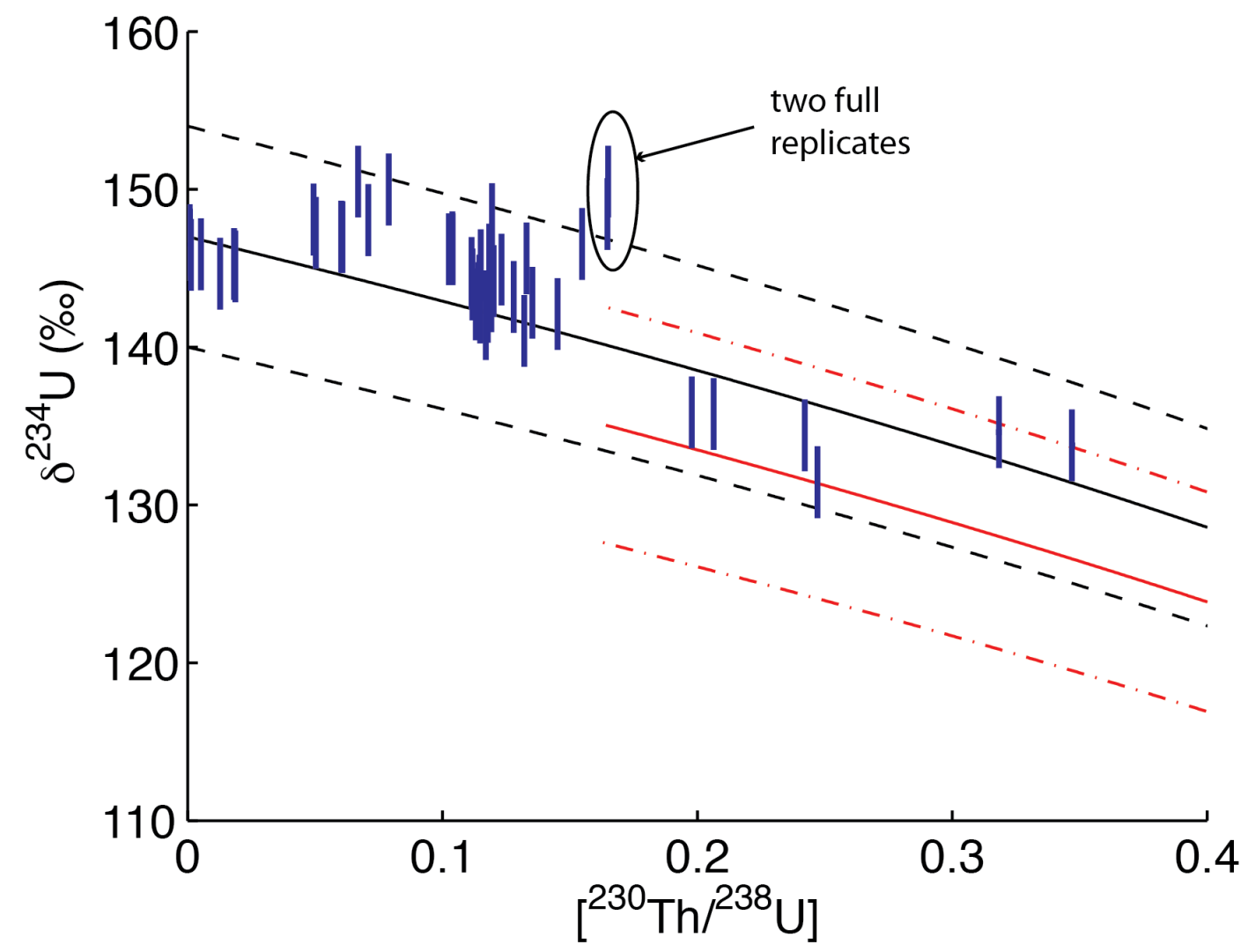

Figure S2. Measured $\delta^{234} \mathrm{U}(\%)$ plotted against the ${ }^{230} \mathrm{Th} /{ }^{238} \mathrm{U}$ activity ratio for all corals young enough for radiocarbon measurement. Errors represent external uncertainty $(2.3 \% ; 2 \sigma)$ which is larger than the internal uncertainty (see Supplementary Table 1).

${ }^{230} \mathrm{Th} /{ }^{238} \mathrm{U}$ errors are $2 \sigma$ and are smaller than the symbol width. Dashed lines are the error envelopes for seawater $\delta^{234} U$ assuming (1) a constant $\delta^{234} U$ through time (black) or (2) a step decrease in seawater $\delta^{234} \mathrm{U}$ prior to $17 \mathrm{ka}(\mathrm{red})$, as suggested by IntCal09 [Reimer et al., 2009]. One coral plotted outside of the error envelope, but a full procedural replicate on a separate piece of the same coral plotted within error of the error envelope. This result is not surprising as different subsamples of individual corals have been shown to exhibit a range of $\delta^{234} \mathrm{U}$ values, with minimal effect on the final age [Robinson et al., 2006]. Both replicates are plotted in the above graph (circled), but are within error of each other in both $\delta^{234} \mathrm{U}$ and ${ }^{230} \mathrm{Th} /{ }^{238} \mathrm{U}$, so they are indistinguishable on the scale plotted. 


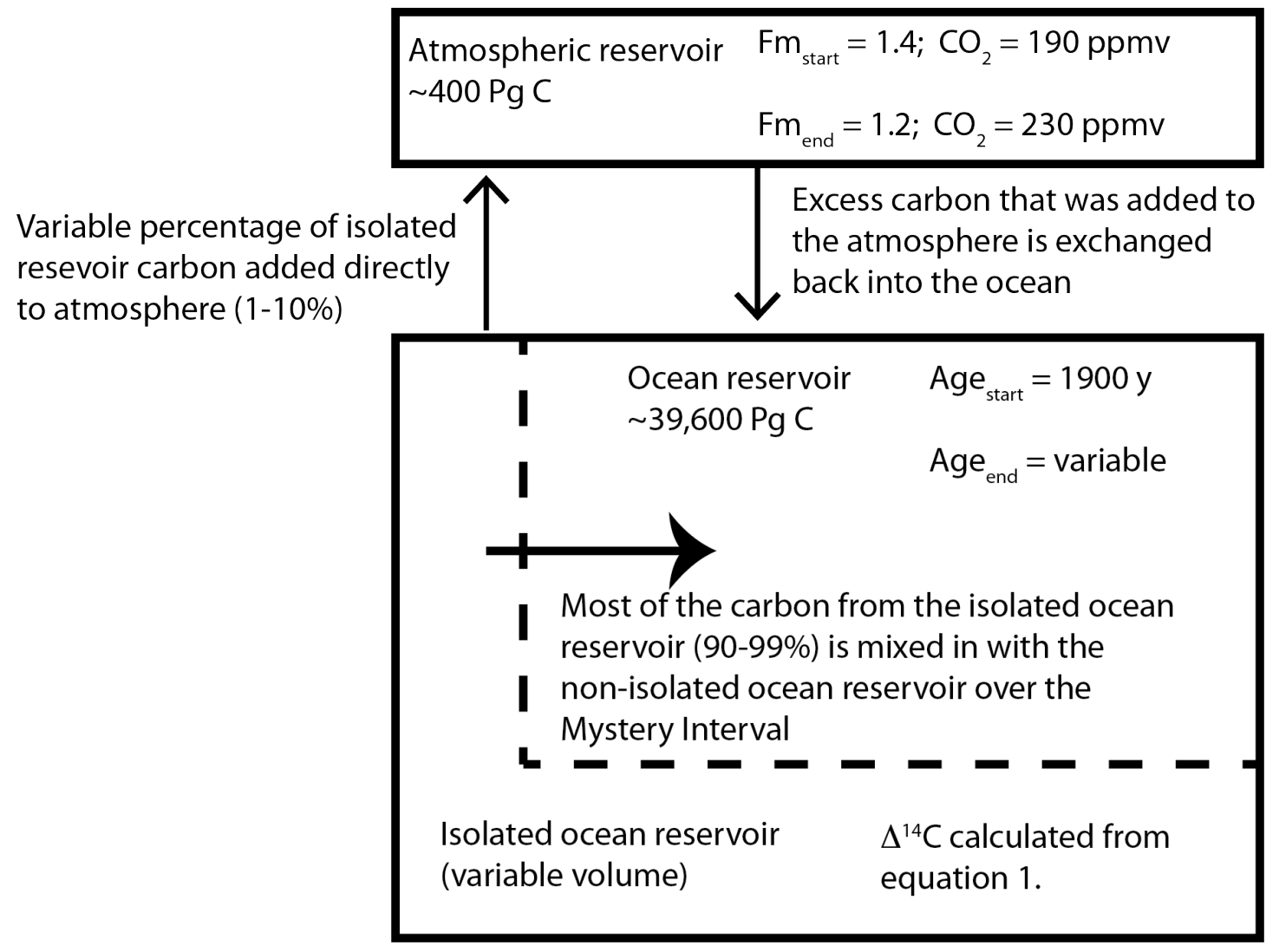

Figure S3. Schematic for radiocarbon budget calculation over the mystery interval. In this calculation we calculate the age of the isolated reservoir that is needed to explain the drop in atmospheric $\Delta^{14} \mathrm{C}$ over the mystery interval for a given volume occupied by the isolated reservoir. We also allow a variable percentage of this reservoir to be mixed in directly with the atmosphere. 


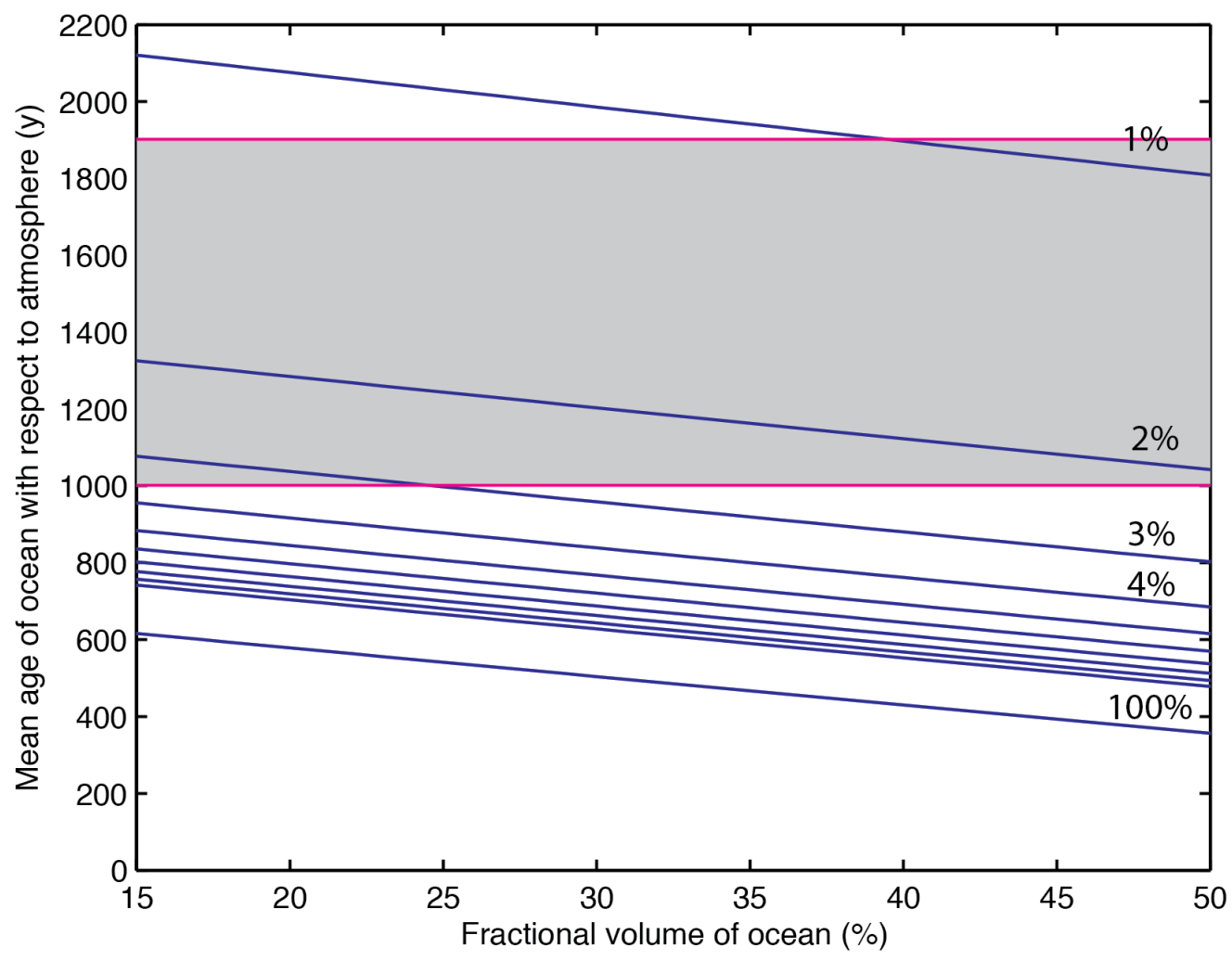

Figure S4. Calculated mean age of the total oceanic carbon reservoir with respect to the contemporaneous atmosphere after mixing in the isolated reservoir with the non-isolated reservoir during the mystery interval as a function of volume of the isolated reservoir. As in Fig. 4, the blue contours represent the solution given different percentages of the isolated carbon ventilated directly into the atmosphere (1-10\% and $100 \%)$. This calculation assumes a mean ocean age with respect to the atmosphere of $1900 \mathrm{y}$ prior to the mystery interval. The grey box highlights the range of age offsets with respect to the atmosphere of the reconstructed radiocarbon records discussed in this paper immediately after the mystery interval [Galbraith et al., 2007; Barker et al., 2010; Skinner et al., 2010]. 


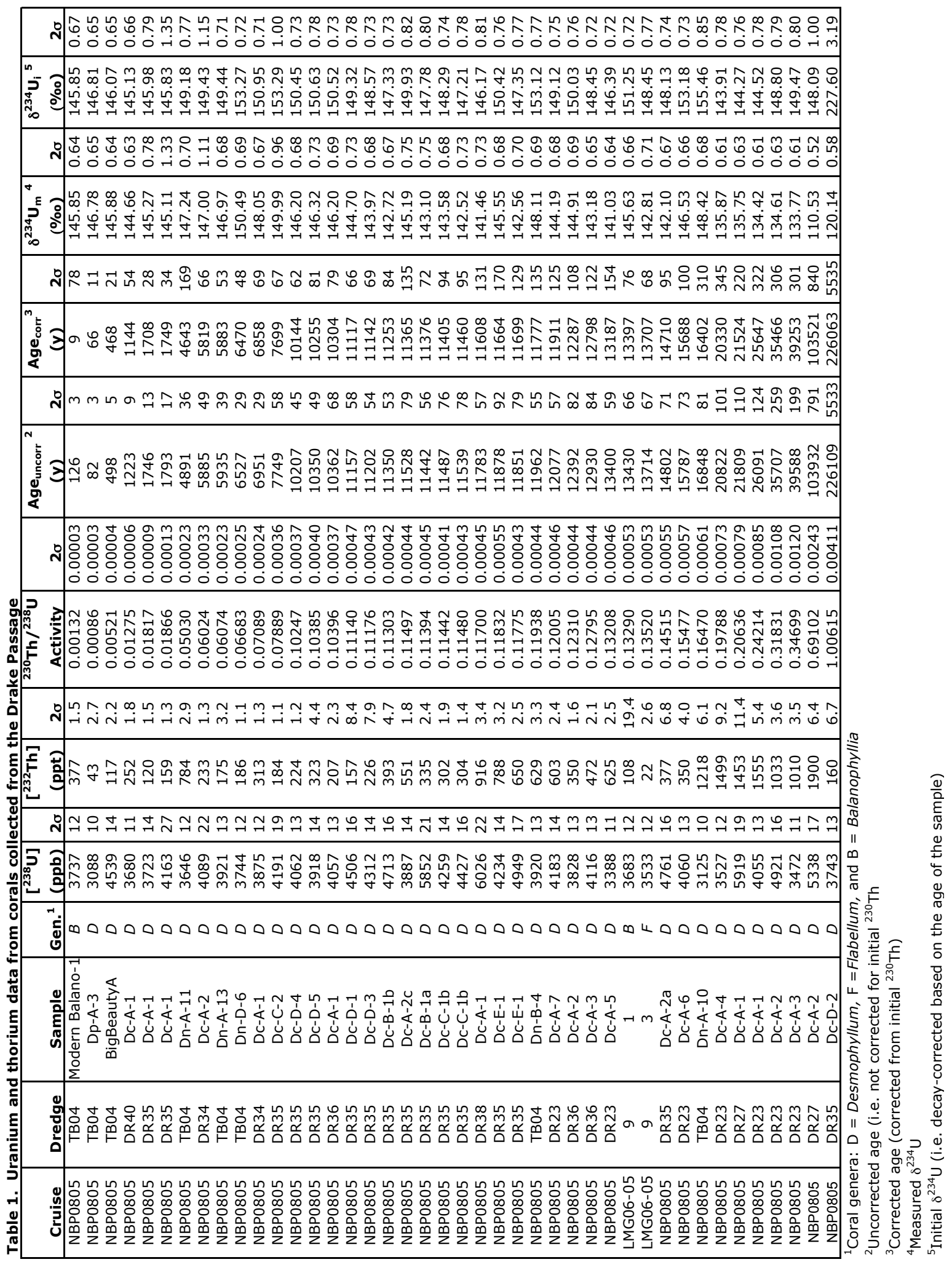




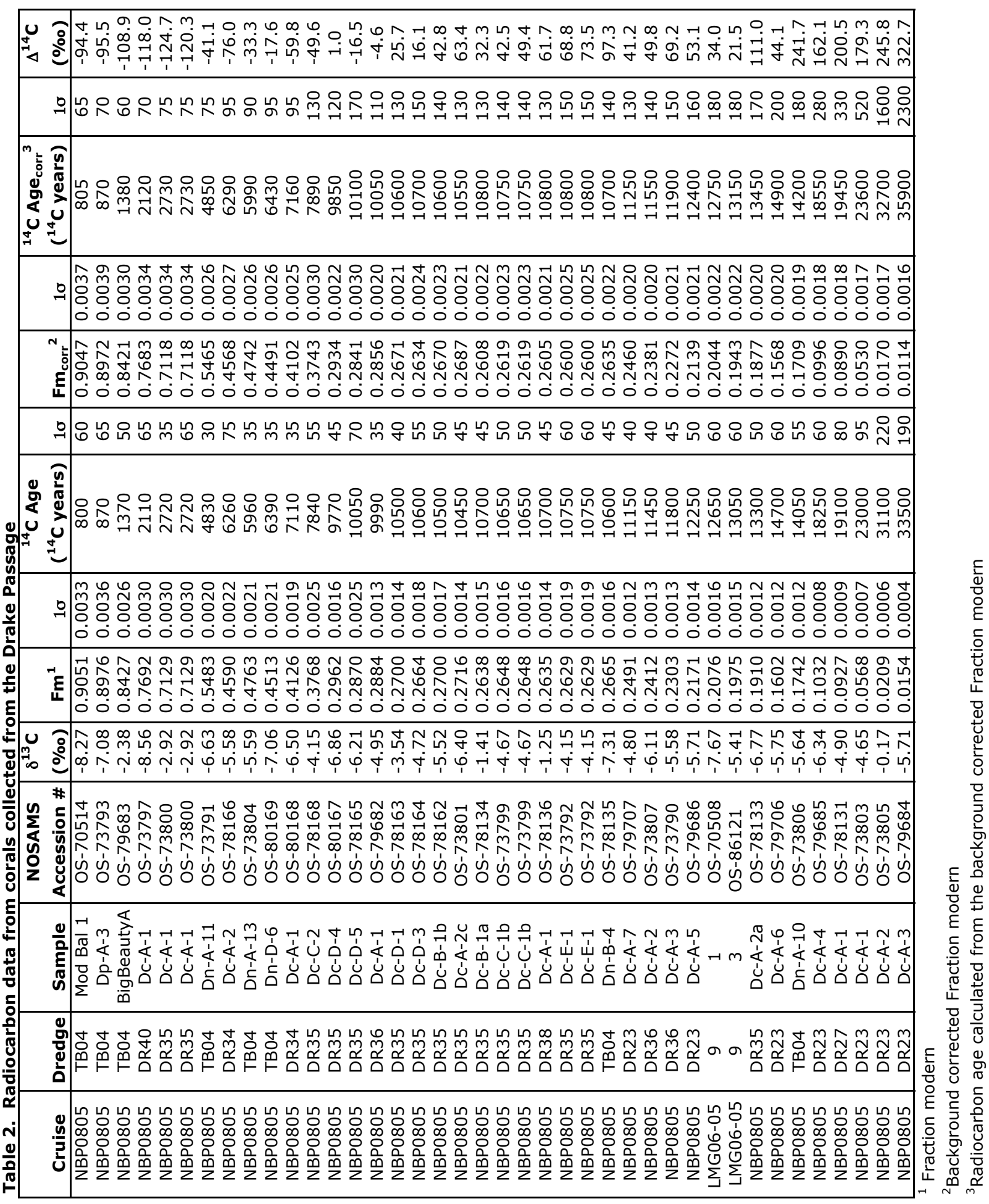




\section{References}

Adkins, J. F., and E. A. Boyle (1997), Changing atmospheric Delta C-14 and the record of deep water paleoventilation ages, Paleoceanography, 12(3), 337-344.

Adkins, J. F., et al. (2002), Radiocarbon dating of deep-sea corals, Radiocarbon, 44(2), 567-580.

Barker, S., et al. (2010), Extreme deepening of the Atlantic overturning circulation during deglaciation, Nature Geoscience, 3(8), Doi 10.1038/Ngeo921, 567-571.

Bradtmiller, L. I., et al. (2009), The distribution of Pa-231 and Th-230 in paired water column and surface sediment samples, Geochimica et Cosmochimica Acta, 73(13), A154-A154.

Broecker, W. S., and S. Barker (2007), A 190 per mil drop in atmosphere's D14C during the "Mystery Interval" (17.5 to 14.5 kyrs), Earth and Planetary Science Letters, 256, 90-99.

Burke, A., et al. (2010), Reconnaissance dating: A new radiocarbon method applied to assessing the temporal distribution of Southern Ocean deep-sea corals, Deep-Sea Research Part I-Oceanographic Research Papers, 57(11), Doi 10.1016/J.Dsr.2010.07.010, 1510-1520.

Cheng, H., et al. (2000a), U-Th dating of deep-sea corals, Geochimica et Cosmochimica Acta, 64(1-4), 2401-2416.

Cheng, H., et al. (2000b), The half-lives of uranium-234 and thorium-230, Chemical Geology, 169(1-2), 17-33.

Edwards, R. L., et al. (1987), U-238 U-234-Th-230-Th-232 Systematics and the Precise Measurement of Time over the Past 500000 Years, Earth and Planetary Science Letters, 81(2-3), 175-192.

Eltgroth, S., et al. (2006), A Deep-sea Coral Record of North Atlantic Radiocarbon through the Younger Dryas, Paleoceanography, 21(4, PA4207), 10.1029/2005PA001192.

Frank, M., et al. (1997), A 200 kyr record of cosmogenic radionuclide production rate and geomagnetic field intensity from Be-10 in globally stacked deep-sea sediments, Earth and Planetary Science Letters, 149(1-4), 121-129.

Galbraith, E. D., et al. (2007), Carbon dioxide release from the North Pacific abyss during the last deglaciation, Nature, 449(7164), Doi 10.1038/Nature06227, 890U899.

Goldstein, S. J., et al. (2001), Uranium-series and radiocarbon geochronology of deep-sea corals: Implications for Southern Ocean ventilation rates and the oceanic carbon cycle, Earth and Planetary Science Letters, 193(1-2), 167-182.

Guerrero, R. A., et al. (1999), Oceanographic conditions at the southern end of the Argentine continental slope, in INIDEP Documento Cientifico, edited, pp. 7-22.

Key, R. M., et al. (2004), A global ocean carbon climatology: Results from Global Data Analysis Project (GLODAP), Global Biogeochemical Cycles, 18(4), - .

Laj, C., et al. (2002), Geomagnetic field intensity, North Atlantic Deep Water circulation and atmospheric Delta C-14 during the last $50 \mathrm{kyr}$, Earth and Planetary Science Letters, 200(1-2), Pii S0012-821x(02)00618-0, 177-190. 
Monnin, E., et al. (2001), Atmospheric CO2 concentrations over the last glacial termination, Science, 291(5501), 112-114.

Muscheler, R., et al. (2004), Changes in the carbon cycle during the last deglaciation as indicated by the comparison of Be-10 and C-14 records, Earth and Planetary Science Letters, 219(3-4), 325-340.

Olsson, I. U. (1970), The use of Oxalic acid as a Standard, in Radiocarbon Variations and Absolute Chronology, Nobel Symposium, 12th Proceedings, edited by I. U. Olsson, p. 17, John Wiley \& Sons, New York.

Reimer, P. J., et al. (2009), IntCal09 and Marine09 Radiocarbon age calibration curves, 0-50,000 years cal BP, Radiocarbon, 51(4), 1111-1150.

Robinson, L. F., and T. van de Flierdt (2009), Southern Ocean evidence for reduced export of North Atlantic Deep Water during Heinrich event 1, Geology, 37(3), 10.1130/g25363a1, 195-198.

Robinson, L. F., et al. (2002), U-Th dating of marine isotope stage 7 in Bahamas slope sediments, Earth and Planetary Science Letters, 196(3-4), Pii S0012821x(01)00610-0, 175-187.

Robinson, L. F., et al. (2006), Primary U-distribution in scleractinian corals and its implications for U-series dating, Geochemistry Geophysics Geosystems, 7, Q05022, doi:05010.01029/02005GC001138.

Shen, G. T., and E. A. Boyle (1988), Determination of lead, cadmium and other tracemetals in annually-banded corals, Chemical Geology, 67(1-2), 47-62.

Sigman, D. M., and E. A. Boyle (2000), Glacial/interglacial variations in atmospheric carbon dioxide, Nature, 407(6806), 859-869.

Skinner, L. C., and N. J. Shackleton (2004), Rapid transient changes in northeast Atlantic deep water ventilation age across Termination I, Paleoceanography, 19(2).

Skinner, L. C., et al. (2010), Ventilation of the Deep Southern Ocean and Deglacial CO(2) Rise, Science, 328(5982), 10.1126/science.1183627, 1147-1151. 


\section{Appendix A3 \\ Data Tables for Chapter 4: \\ Investigating the source of radiocarbon-depleted intermediate waters during the last deglaciation}

Table 1. Locations and depths of coral samples from cruise CE08-06 on the Reykjanes Ridge off Iceland

Table 2. Reconnaissance radiocarbon ages

Table 3. Uranium and thorium data

Table 4. Radiocarbon data 
Table 1. Cruise CE08-06 Dredge Locations

\begin{tabular}{|c|c|c|c|}
\hline Dredge & Latitude $\left({ }^{\circ} \mathrm{N}\right)$ & Longitude $\left({ }^{\circ} \mathrm{E}\right)$ & Depth $(\mathrm{m})$ \\
\hline Dr2A & 55.7 & -35.0 & 2022 \\
Dr4 & 56.3 & -34.5 & 1290 \\
Dr4A & 56.3 & -34.4 & 1621 \\
Dr6 & 56.5 & -34.4 & 1792 \\
Dr9 & 56.8 & -34.2 & 1464 \\
Dr14 & 57.4 & -33.2 & 1795 \\
Dr15 & 57.7 & -33.2 & 1361 \\
Dr16 & 57.9 & -32.9 & 1680 \\
Dr17 & 58.2 & -32.6 & 1284 \\
Dr18 & 58.5 & -32.3 & 1385 \\
Dr18A & 58.5 & -32.3 & 1369 \\
Dr19 & 58.8 & -32.0 & 1646 \\
Dr19A & 58.8 & -32.0 & 1545 \\
Dr19B & 58.9 & -32.2 & 1429 \\
Dr20 & 59.4 & -31.5 & 1528 \\
Dr21 & 59.5 & -31.4 & 1410 \\
Dr21A & 59.5 & -31.4 & 1427 \\
Dr22A & 60.1 & -30.7 & 1607 \\
Dr24 & 60.5 & -29.7 & 1038 \\
Dr25 & 60.7 & -29.2 & 1416 \\
Dr26 & 60.7 & -29.5 & 1210 \\
Dr26A & 60.7 & -29.4 & 1142 \\
Dr27 & 61.2 & -28.9 & 1314 \\
Dr28 & 61.4 & -28.8 & 1211 \\
Dr29 & 61.4 & -27.9 & 994 \\
Dr29A & 61.4 & -27.9 & 997 \\
Dr30A & 61.6 & -27.6 & 944 \\
Dr31A & 61.9 & -27.0 & 768 \\
Dr32A & 62.1 & -26.6 & 843 \\
\hline
\end{tabular}


Table 2. Reconnaissance Radiocarbon Ages

\begin{tabular}{|c|c|c|c|c|c|c|}
\hline Cruise & Dredge & Sample & Fm & 1 sigma & Libby age & 1 sigma \\
\hline CE0806 & Dr02A & 1 & 0.8754 & 0.0066 & 1070 & 60 \\
\hline CE0806 & Dr02A & 2 & 0.9424 & 0.0067 & 475 & 55 \\
\hline CE0806 & Dr02A & 3 & 0.9224 & 0.0127 & 650 & 110 \\
\hline CE0806 & Dr02A & 4 & 0.9071 & 0.0064 & 785 & 55 \\
\hline CE0806 & Dr02A & 5 & 0.9344 & 0.0065 & 545 & 55 \\
\hline CE0806 & Dr02A & 7 & 0.6921 & 0.0101 & 2960 & 120 \\
\hline CE0806 & Dr02A & 8 & 0.8474 & 0.0060 & 1330 & 55 \\
\hline CE0806 & Dr02A & 9 & 0.9313 & 0.0096 & 570 & 85 \\
\hline CE0806 & Dr04 & 1 & 0.9379 & 0.0097 & 515 & 85 \\
\hline CE0806 & Dr04 & 4 & 0.3315 & 0.0077 & 8870 & 190 \\
\hline CE0806 & Dr04 & 6 & 0.7423 & 0.0108 & 2390 & 120 \\
\hline CE0806 & Dr04 & 7 & 0.8162 & 0.0117 & 1630 & 110 \\
\hline CE0806 & Dr04 & 11 & 0.3120 & 0.0072 & 9360 & 190 \\
\hline CE0806 & Dr04A & 1 & 0.9355 & 0.0066 & 535 & 55 \\
\hline CE0806 & Dr09 & 1 & 0.0093 & 0.0048 & 37600 & 4100 \\
\hline CE0806 & Dr09 & 2 & 0.0085 & 0.0048 & 38300 & 4500 \\
\hline CE0806 & Dr09 & 3 & 0.9346 & 0.0067 & 545 & 55 \\
\hline CE0806 & Dr09 & 5 & 0.3160 & 0.0072 & 9250 & 180 \\
\hline CE0806 & Dr09 & 6 & 0.3109 & 0.0072 & 9390 & 190 \\
\hline CE0806 & Dr09 & 7 & 0.3192 & 0.0072 & 9170 & 180 \\
\hline CE0806 & Dr09 & 8 & 0.2899 & 0.0072 & 9950 & 200 \\
\hline CE0806 & Dr09 & 10 & 0.3336 & 0.0074 & 8820 & 180 \\
\hline CE0806 & Dr09 & 12 & 0.9649 & 0.0099 & 285 & 85 \\
\hline CE0806 & Dr09 & 14 & 0.9400 & 0.0098 & 495 & 85 \\
\hline CE0806 & Dr15 & 1 & 0.0121 & 0.0021 & 35500 & 1400 \\
\hline CE0806 & Dr15 & 2 & 0.0099 & 0.0021 & 37000 & 1700 \\
\hline CE0806 & Dr15 & 3 & 0.0080 & 0.0021 & 38800 & 2100 \\
\hline CE0806 & Dr15 & 4 & 0.0083 & 0.0023 & 38500 & 2200 \\
\hline CE0806 & Dr15 & 5 & 0.9309 & 0.0128 & 575 & 110 \\
\hline CE0806 & Dr15 & 6 & 0.7125 & 0.0107 & 2720 & 120 \\
\hline CE0806 & Dr15 & 7 & 0.7904 & 0.0113 & 1890 & 110 \\
\hline CE0806 & Dr15 & 8 & 0.3647 & 0.0076 & 8100 & 170 \\
\hline CE0806 & Dr15 & 9 & 0.6849 & 0.0101 & 3040 & 120 \\
\hline CE0806 & Dr15 & 10 & 0.9927 & 0.0136 & 60 & 110 \\
\hline CE0806 & Dr16 & 1 & \multicolumn{4}{|c|}{ Indistinguishable from radiocarbon dead coral } \\
\hline CE0806 & Dr16 & 2 & 0.0178 & 0.0025 & 32400 & 1100 \\
\hline CE0806 & Dr16 & 3 & 0.9274 & 0.0097 & 605 & 85 \\
\hline CE0806 & Dr16 & 5 & 0.0192 & 0.0048 & 31700 & 2000 \\
\hline CE0806 & Dr16 & 6 & \multicolumn{4}{|c|}{ Indistinguishable from radiocarbon dead coral } \\
\hline CE0806 & Dr16 & 10 & 0.6803 & 0.0101 & 3100 & 120 \\
\hline CE0806 & Dr16 & 11 & 0.3356 & 0.0074 & 8770 & 180 \\
\hline CE0806 & Dr16 & 12 & 0.9356 & 0.0129 & 535 & 110 \\
\hline CE0806 & Dr16 & 13 & 0.6304 & 0.0097 & 3710 & 120 \\
\hline CE0806 & Dr16 & 16 & \multicolumn{4}{|c|}{ Indistinguishable from radiocarbon dead coral } \\
\hline CE0806 & Dr16 & 19 & 0.3611 & 0.0076 & 8180 & 170 \\
\hline CE0806 & Dr16 & 20 & 0.8995 & 0.0126 & 850 & 110 \\
\hline CE0806 & Dr16 & 22 & 0.9502 & 0.0131 & 410 & 110 \\
\hline
\end{tabular}




\begin{tabular}{|c|c|c|c|c|c|c|}
\hline CE0806 & Dr16 & 23 & 0.8287 & 0.0118 & 1510 & 110 \\
\hline CE0806 & Dr16 & 24 & 0.9796 & 0.0100 & 165 & 80 \\
\hline CE0806 & Dr16 & 25 & 0.0093 & 0.0048 & 37600 & 4100 \\
\hline CE0806 & Dr16 & 26 & 0.9466 & 0.0130 & 440 & 110 \\
\hline CE0806 & Dr17 & 2 & 0.3094 & 0.0073 & 9420 & 190 \\
\hline CE0806 & Dr17 & 3 & 0.8754 & 0.0123 & 1070 & 110 \\
\hline CE0806 & Dr17 & 4 & 0.9623 & 0.0132 & 310 & 110 \\
\hline CE0806 & Dr18 & 1 & \multirow{2}{*}{\multicolumn{4}{|c|}{$\begin{array}{l}\text { Indistinguishable from radiocarbon dead coral } \\
\text { Indistinguishable from radiocarbon dead coral }\end{array}$}} \\
\hline CE0806 & Dr18 & 2 & & & & \\
\hline CE0806 & Dr18 & 4 & 0.9628 & 0.0133 & 305 & 110 \\
\hline CE0806 & Dr18 & 5 & 0.3720 & 0.0076 & 7940 & 160 \\
\hline CE0806 & Dr18 & 6 & \multicolumn{4}{|c|}{ Indistinguishable from radiocarbon dead coral } \\
\hline CE0806 & Dr18 & 9 & 0.6587 & 0.0101 & 3350 & 120 \\
\hline CE0806 & Dr18 & 10 & 0.9950 & 0.0137 & 40 & 110 \\
\hline CE0806 & Dr18A & 1 & 1.0143 & 0.0142 & $>$ Mod & \\
\hline CE0806 & Dr18A & 2 & 0.9230 & 0.0128 & 645 & 110 \\
\hline CE0806 & Dr18A & 3 & 0.9182 & 0.0128 & 685 & 110 \\
\hline CE0806 & Dr18A & 4 & 0.8050 & 0.0115 & 1740 & 110 \\
\hline CE0806 & Dr19A & 2 & 1.0100 & 0.0022 & $>$ Mod & \\
\hline CE0806 & Dr19A & 3 & \multicolumn{4}{|c|}{ Indistinguishable from radiocarbon dead coral } \\
\hline CE0806 & Dr19A & 4 & Indistingu & able from & ocarbor & coral \\
\hline CE0806 & Dr19A & 5 & \multicolumn{4}{|c|}{ Indistinguishable from radiocarbon dead coral } \\
\hline CE0806 & Dr19A & 6 & 1.0234 & 0.0139 & $>$ Mod & \\
\hline CE0806 & Dr19A & 7 & 0.9919 & 0.0138 & 65 & 110 \\
\hline CE0806 & Dr19A & 8 & 0.0060 & 0.0048 & 41100 & 6500 \\
\hline CE0806 & Dr19A & 9 & 0.9651 & 0.0136 & 285 & 110 \\
\hline CE0806 & Dr19A & 10 & \multicolumn{4}{|c|}{ Indistinguishable from radiocarbon dead coral } \\
\hline CE0806 & Dr19A & $1 \mathrm{a}$ & 1.0039 & 0.0025 & $>$ Mod & \\
\hline CE0806 & Dr19B & 1 & \multirow{2}{*}{\multicolumn{4}{|c|}{$\begin{array}{l}\text { Indistinguishable from radiocarbon dead coral } \\
\text { Indistinguishable from radiocarbon dead coral }\end{array}$}} \\
\hline CE0806 & Dr19B & 2 & & & & \\
\hline CE0806 & Dr19B & 4 & 0.9725 & 0.0101 & 225 & 85 \\
\hline CE0806 & Dr19B & 5 & 0.3342 & 0.0055 & 8800 & 130 \\
\hline CE0806 & Dr19B & 6 & 0.8647 & 0.0094 & 1170 & 85 \\
\hline CE0806 & Dr19B & 9 & \multicolumn{4}{|c|}{ Indistinguishable from radiocarbon dead coral } \\
\hline CE0806 & Dr19B & 10 & Indistingu & able from & ocarbor & coral \\
\hline CE0806 & Dr25 & 7 & 0.1995 & 0.0049 & 12950 & 200 \\
\hline CE0806 & Dr26 & 1 & \multicolumn{4}{|c|}{ Indistinguishable from radiocarbon dead coral } \\
\hline CE0806 & Dr26 & 2 & \multicolumn{4}{|c|}{ Indistinguishable from radiocarbon dead coral } \\
\hline CE0806 & Dr26A & 1 & 0.5788 & 0.0053 & 4390 & 75 \\
\hline CE0806 & Dr26A & 6 & \multicolumn{4}{|c|}{ Indistinguishable from radiocarbon dead coral } \\
\hline CE0806 & Dr29 & 1 & 0.6745 & 0.0057 & 3160 & 70 \\
\hline CE0806 & Dr29 & 2 & 0.7994 & 0.0061 & 1800 & 60 \\
\hline CE0806 & Dr29 & 3 & 0.1977 & 0.0029 & 13000 & 120 \\
\hline CE0806 & Dr29A & 1 & 0.9213 & 0.0067 & 660 & 60 \\
\hline CE0806 & Dr29A & 2 & 0.0411 & 0.0023 & 25600 & 450 \\
\hline CE0806 & Dr31A & 1 & 0.3215 & 0.0035 & 9120 & 85 \\
\hline CE0806 & Dr32 & 3 & 0.9210 & 0.0105 & 660 & 90 \\
\hline
\end{tabular}




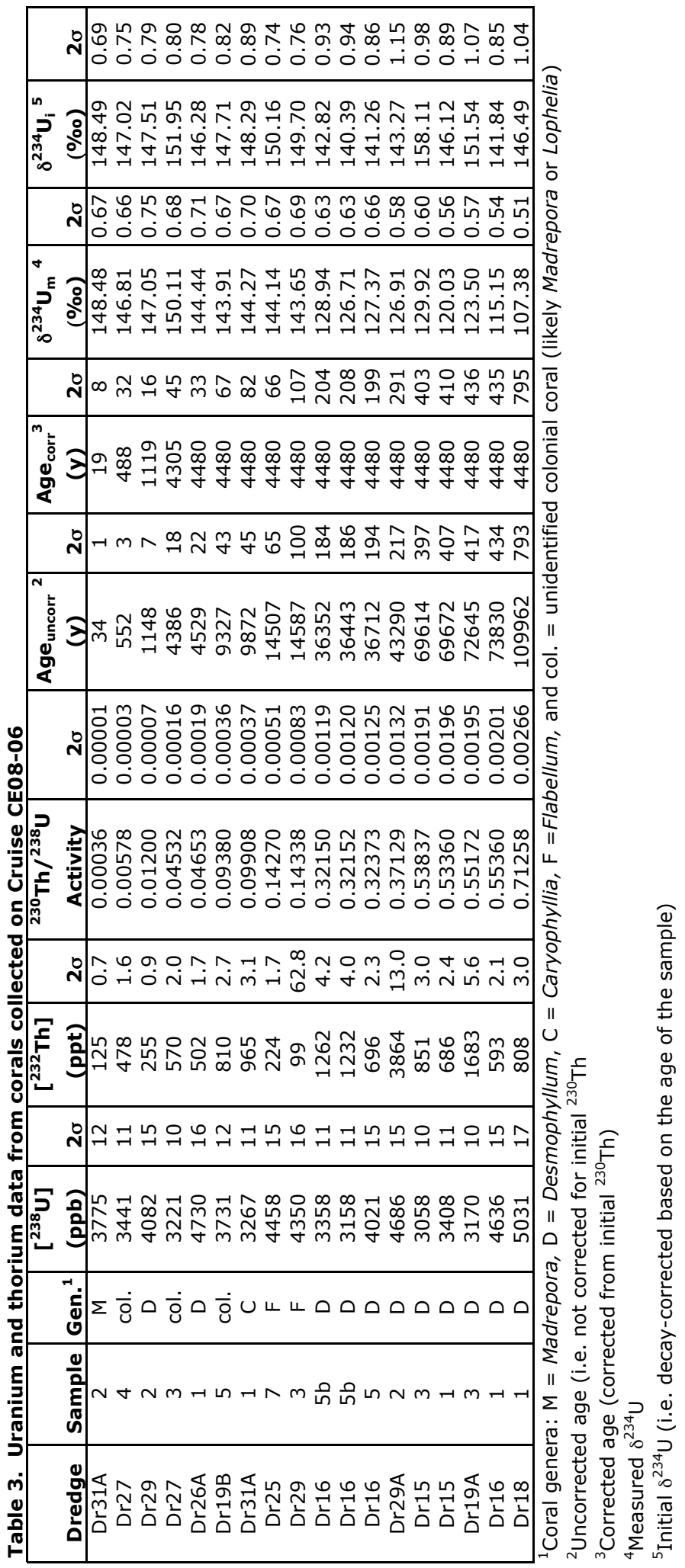




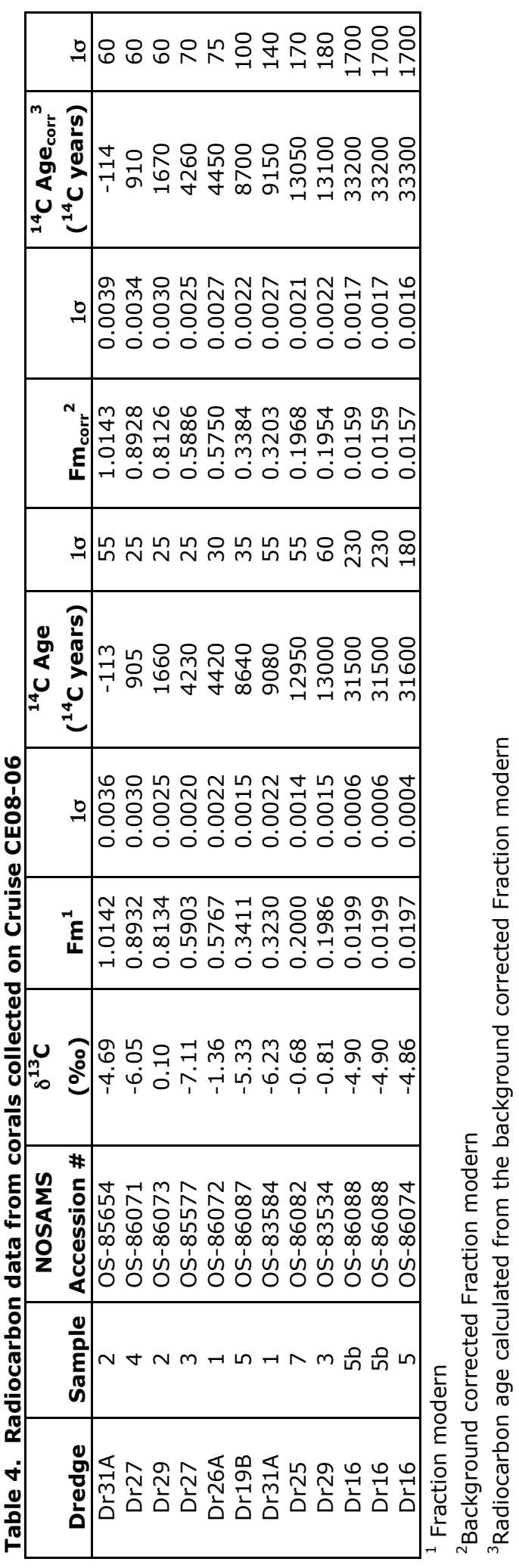




\section{Appendix A4}

\section{Supplementary Information for Chapter 5.}

Originally published as online auxiliary material for:

Burke, A., O. Marchal, L. I. Bradtmiller, J. F. McManus, and R. François

(2011), Application of an inverse method to interpret ${ }^{231} \mathrm{~Pa} /{ }^{230} \mathrm{Th}$

observations from marine sediments, Paleoceanography, 26, PA1212, doi:10.1029/2010PA002022.

Text 1. Finite difference forms of the equations used to constrain the modern circulation and our model of scavenging of ${ }^{231} \mathrm{~Pa}$ by particles.

Text 2. References for additional ${ }^{231} \mathrm{~Pa} /{ }^{230} \mathrm{Th}$ data from Holocene sediments used to compare to water column $[\mathrm{Pa}]$.

Figures S1 to S6. 


\section{Text 1. Finite Difference Forms}

\section{Circulation Model}

The differential equations of the circulation model are the equations of volume conservation, the thermal wind relationships, and the linear vorticity balance. These equations are expressed in spherical coordinates. They are discretized on a grid with a longitudinal spacing $\Delta \phi=4^{\circ}$, a latitudinal spacing $\Delta \theta=4^{\circ}$, and a vertical spacing $\Delta \mathrm{z}=$ $1000 \mathrm{~m}$. The components of volume transport are defined at the faces of the grid boxes and the density is defined at the corners of these boxes.

Consider a box with its southwest bottom corner designated with the indices $(\mathrm{i}, \mathrm{j}, \mathrm{k})$, which increase in the zonal, meridional, and vertical direction, respectively. The finite difference form of the equation for volume conservation for this box is

$$
U_{i, j+\frac{1}{2}, k+\frac{1}{2}}-U_{i+1, j+\frac{1}{2}, k+\frac{1}{2}}+V_{i+\frac{1}{2}, j, k+\frac{1}{2}}-V_{i+\frac{1}{2}, j+1, k+\frac{1}{2}}+W_{i+\frac{1}{2}, j+\frac{1}{2}, k}-W_{i+\frac{1}{2}, j+\frac{1}{2}, k+1}=0
$$

Here $U, V$, and $W$ are the components of volume transport (Sv) in the zonal, meridional, and vertical direction, respectively.

The finite difference analogs of the thermal wind relationships are

$$
\begin{aligned}
& V_{i+\frac{1}{2}, j, k+\frac{1}{2}}-V_{i+\frac{1}{2}, j, k-\frac{1}{2}}=-\frac{g \Delta z^{2}}{2 \Omega \rho_{o}} \frac{\rho_{i+1, j, k}-\rho_{i, j, k}}{\sin \theta_{j}} \\
& U_{i, j+\frac{1}{2}, k+\frac{1}{2}}-U_{i, j+\frac{1}{2}, k-\frac{1}{2}}=-\frac{g \Delta z^{2} \Delta \theta}{2 \Omega \rho_{o}} \frac{\rho_{i, j+1, k}-\rho_{i, j, k}}{\left.\Delta(\cos \theta)\right|_{j} ^{j+1}}
\end{aligned}
$$

where $g=9.8 \mathrm{~m} / \mathrm{s}^{2}$ is the gravitational acceleration, $\rho$ is in situ density $\left(\rho_{o}=1028 \mathrm{~kg} / \mathrm{m}^{3}\right.$ is a reference value), $\Omega=7.29 \times 10^{-5} \mathrm{~s}^{-1}$ is the angular velocity of the rotation of the earth, and $\theta$ is latitude.

Finally, the finite difference form of the linear vorticity balance is

$$
\frac{\left.\Delta(\sin \theta)\right|_{j} ^{j+1}}{2}\left(\frac{V_{i+\frac{1}{2}, j, k+\frac{1}{2}}}{\sin \theta_{j}}+\frac{V_{i+\frac{1}{2}, j+1, k+\frac{1}{2}}}{\sin \theta_{j+1}}\right)-W_{i+\frac{1}{2}, j+\frac{1}{2}, k+1}+W_{i+\frac{1}{2}, j+\frac{1}{2}, k}=0
$$

Equations (A1-A3) constitute a set of linear algebraic equations which can be expressed in compact form as $\mathbf{A x}=\mathbf{b}$ (see section 2.1). 


\section{Advection-Scavenging Model}

The equation of the advection-scavenging model is discretized on the same grid as the equations of the circulation model. The activity of total ${ }^{231} \mathrm{~Pa},(\mathrm{C}$ below $)$, is defined at the center of the grid boxes. The finite difference form of the equation of the advectionscavenging model is

$$
\begin{aligned}
& -C_{i, j, k}^{W} U_{i, j+\frac{1}{2}, k+\frac{1}{2}}+C_{i, j, k}^{E} U_{i+1, j+\frac{1}{2}, k+\frac{1}{2}}-C_{i, j, k}^{S} V_{i+\frac{1}{2}, j, k+\frac{1}{2}}+C_{i, j, k}^{N} V_{i+\frac{1}{2}, j+1, k+\frac{1}{2}} \\
& -C_{i, j, k}^{B} W_{i+\frac{1}{2}, j+\frac{1}{2}, k}+C_{i, j, k}^{T} W_{i+\frac{1}{2}, j+\frac{1}{2}, k+1}+C_{i, j, k} W^{*}-C_{i, j, k+1} W^{*}=\beta_{231} V o l
\end{aligned}
$$

where $\beta_{231}=2.4 \times 10^{-3} \mathrm{dpm} \mathrm{m}^{-3} \mathrm{y}^{-1}$ is the production of ${ }^{231} \mathrm{~Pa}$ from the radioactive decay of ${ }^{235} \mathrm{U}, W^{*}$ is the product $w$ and $k_{P a}$ ( $w$ being the sinking velocity of scavenging particles and $k_{P a}$ the partition parameter for $\mathrm{Pa}$ ) integrated over the lower or upper surface area of the grid box, and Vol is the volume of the grid box.

The values of $\left(\mathrm{C}^{\mathrm{W}}, \mathrm{C}^{\mathrm{E}}, \mathrm{C}^{\mathrm{S}}, \mathrm{C}^{\mathrm{N}}, \mathrm{C}^{\mathrm{B}}, \mathrm{C}^{\mathrm{T}}\right)$ depend on the sign of the transport components $(\mathrm{U}, \mathrm{V}, \mathrm{W})$. If the transport is into the box, then $\left(\mathrm{C}^{\mathrm{W}}, \mathrm{C}^{\mathrm{E}}, \mathrm{C}^{\mathrm{S}}, \mathrm{C}^{\mathrm{N}}, \mathrm{C}^{\mathrm{B}}, \mathrm{C}^{\mathrm{T}}\right)$ is the ${ }^{231} \mathrm{~Pa}$ activity from the box to the (west, east, south, north, bottom, top) of the box. If the transport is out of the box then it is the ${ }^{231} \mathrm{~Pa}$ activity of the box.

Equations (A4) (there is one such equation for each box) constitute a set of linear algebraic equations which can be expressed in compact form as $\mathbf{G x}=\mathbf{h}$ (see section 3.4). 
Text 2. References for additional ${ }^{231} \mathrm{~Pa} /{ }^{230} \mathrm{Th}$ data from Holocene sediments used to compare to water column [Pa]

Anderson, R. F., M. P. Bacon, and P. G. Brewer (1983), Removal of Th-230 and Pa-231 from the Open Ocean, Earth and Planetary Science Letters, 62(1), 7-23.

Anderson, R. F., M. Q. Fleisher, P. E. Biscaye, N. Kumar, B. Ditrich, P. Kubik, and M. Suter (1994), Anomalous Boundary Scavenging in the Middle Atlantic Bight Evidence from Th-230, Pa-231, Be-1o and Pb-210, Deep-Sea Research Part IiTopical Studies in Oceanography, 41(2-3), 537-561.

Asmus, T., M. Frank, C. Koschmieder, N. Frank, R. Gersonde, G. Kuhn, and A. Mangini (1999), Variations of biogenic particle flux in the southern Atlantic section of the Subantarctic Zone during the late Quaternary: Evidence from sedimentary Pa231(ex) and Th-230(ex), Marine Geology, 159(1-4), 63-78.

Bacon, M. P., and J. N. Rosholt (1982), Accumulation Rates of Th-230, Pa-231, and Some Transition-Metals on the Bermuda Rise, Geochimica Et Cosmochimica Acta, 46(4), 651-666.

DeMaster, D. J., (1979), The marine budget of silica and Si-32, Ph.D. thesis, Yale University, New Haven.

François, R., unpublished data

$\mathrm{Ku}$, T.-L.,(1996), Uranium-series disequilibrium in deep-sea sediments, $\mathrm{Ph} . \mathrm{D}$. thesis, Columbia University, New York.

Ku, T. L., A. Boersma, and J. L. Bischoff (1972), Age Studies of Mid-Atlantic Ridge Sediments near 42 Degrees N and 20 Degrees N, Deep-Sea Research, 19(3), 233 247.

Kumar, N., (1994), Trace metals and natural radionuclides as tracers of ocean productivity, Ph.D. thesis, Columbia University, New York.

Legeleux, F., (1994), Relation entre particules marines et message sédimentaire: Flux de matière dans la colonne d'eau et transformations à l'interface eau-sédiment dans l'Océan Atlantique tropical de nord-est, Ph.D. thesis, University of Paris, Paris.

Mangini, A., Dieter-Haas, L. (1983): Excess Th-230 in sediments off NW Africa traces upwelling in the past. In: Coastal upwelling: its sedimentary records, Plenum, New York, pp. 455-470.

Scholten, J. C., J. Fietzke, A. Mangini, C. D. Garbe-Schbnberg, A. Eisenhauer, R. Schneider, and P. Stoffers (2008), Advection and scavenging: Effects on Th-230 and Pa-231 distribution off Southwest Africa, Earth and Planetary Science Letters, 271(1-4), 159-169.

Walter, H. J., M. M. R. van der Loeff, and H. Hoeltzen (1997), Enhanced scavenging of $\mathrm{Pa}-231$ relative to Th-230 in the south Atlantic south of the Polar front: Implications for the use of the $\mathrm{Pa}-231 / \mathrm{Th}-230$ ratio as a paleoproductivity proxy, Earth and Planetary Science Letters, 149(1-4), 85-100. 


\section{Supplementary Figure Captions}

Figure S1. Diagnostics of the modern circulation inversion (with prior LNM $=3000 \mathrm{~m}$ ). (a) Adjustments to the prior estimates of the individual volume transports $(\mathrm{U}, \mathrm{V}, \mathrm{W})$. (b) Residuals in the dynamical constraints and adjustments to the observational estimates of the volume transports of NADW and of the integrated meridional transport at $36^{\circ} \mathrm{N}, 24^{\circ}$ $\mathrm{N}$, and $32^{\circ} \mathrm{S}$. In both panels $(\mathrm{a}, \mathrm{b})$ the adjustments or residuals are normalized to the corresponding prior uncertainty (Chapter 5, Table 1) and the abscissa is an arbitrary counter.

Figure S2. Posterior uncertainties for the horizontal circulation between 2000 and 3000 $\mathrm{m}$ (solution with prior LNM = 3000).

Figure S3. Posterior uncertainties for the horizontal circulation between 4000 and $5000 \mathrm{~m}$ (solution with prior LNM $=3000$ ).

Figure S4. (a) Partition coefficient $\left(k_{P a}\right)$ at 12 stations in the Atlantic Ocean (deeper than $1000 \mathrm{~m}$ ) computed from paired measurements of particulate and total ${ }^{231} \mathrm{~Pa}$ activity. The rank correlation coefficient (Kendall tau or $\tau$ ) and its $p$-value are shown for stations where $\mathrm{n}>2$. $p$-values greater than 0.05 indicate that $k_{P a}$ data do not increase or decrease with depth at the 5\% significance level.

(b) Geographic locations of stations in the Atlantic Ocean with paired measurements of particulate and total ${ }^{231} \mathrm{~Pa}$ activity labeled with the depth averaged value of $k_{\mathrm{Pa}}$ (dimensionless). $40^{\circ} \mathrm{S}$ is shown by a solid line.

(c) Geographic locations of stations in the Atlantic Ocean with measurements of particulate ${ }^{230} \mathrm{Th}$ activity $\left([\mathrm{Th}]_{\mathrm{P}}\right.$, in $\left.\mathrm{dpm} / \mathrm{m}^{3}\right)$ labeled with the depth averaged value of $[\mathrm{Th}]_{\mathrm{P}}$.

Figure S5. Plot of measured $[\mathrm{Pa}]\left(\mathrm{dpm} / \mathrm{m}^{3}\right)$ against the objectively mapped $[\mathrm{Pa}]$ at the same same data locations.

Figure S6. Adjustment of reconstructed ${ }^{231} \mathrm{~Pa}$ activity, $[\mathrm{Pa}]$, in bottom water near core locations to the modern circulation for the Holocene (top), LGM (middle), and H1 (bottom) $(+) .[\mathrm{Pa}]$ was objectively mapped from an extended data set that includes the recent ${ }^{231} \mathrm{~Pa} /{ }^{230} \mathrm{Th}$ record from the Cape Basin [Negre et al., 2010]. The adjustments to the modern circulation of the objectively mapped $[\mathrm{Pa}]$ from the sediment data sets excluding data of Negre et al. [2010] are shown for comparison (black triangles). In both cases, $[\mathrm{Pa}]$ is reconstructed from sedimentary ${ }^{231} \mathrm{~Pa} /{ }^{230} \mathrm{Th}$ using equation (9) and taking an average value of water column particulate ${ }^{230} \mathrm{Th}$ measured in the Atlantic Ocean. 
Figure S1.

a)

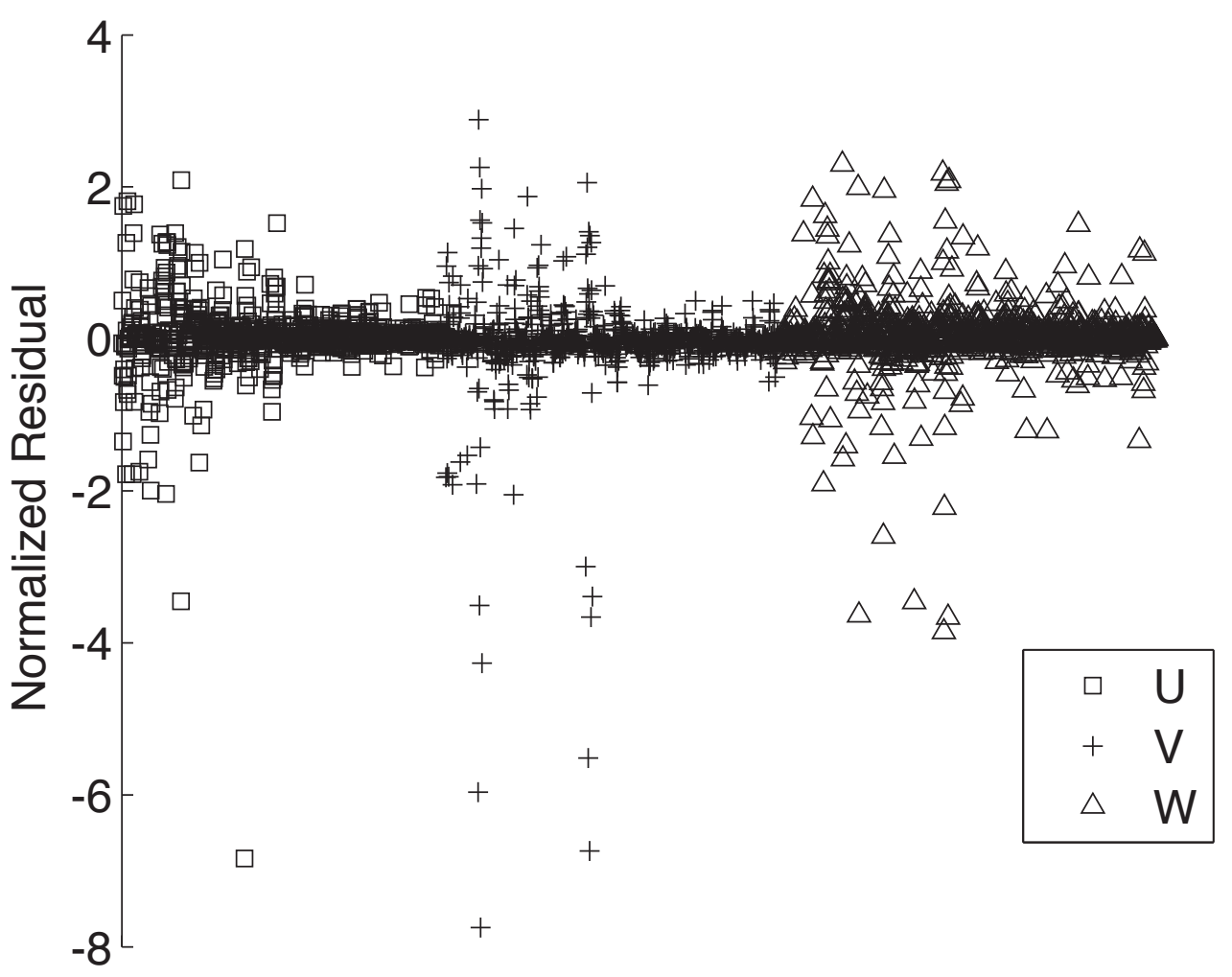

b)

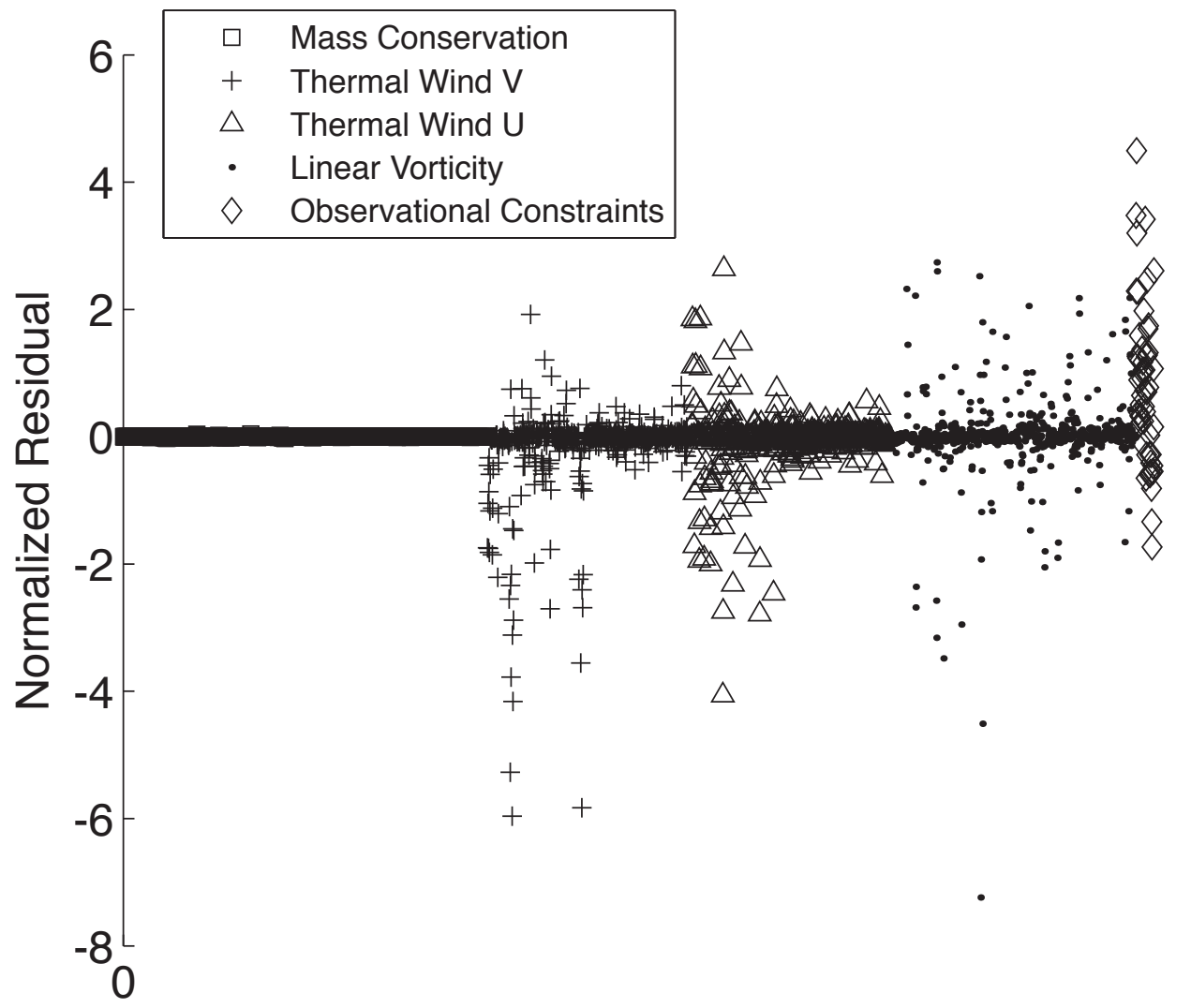


Figure S2.

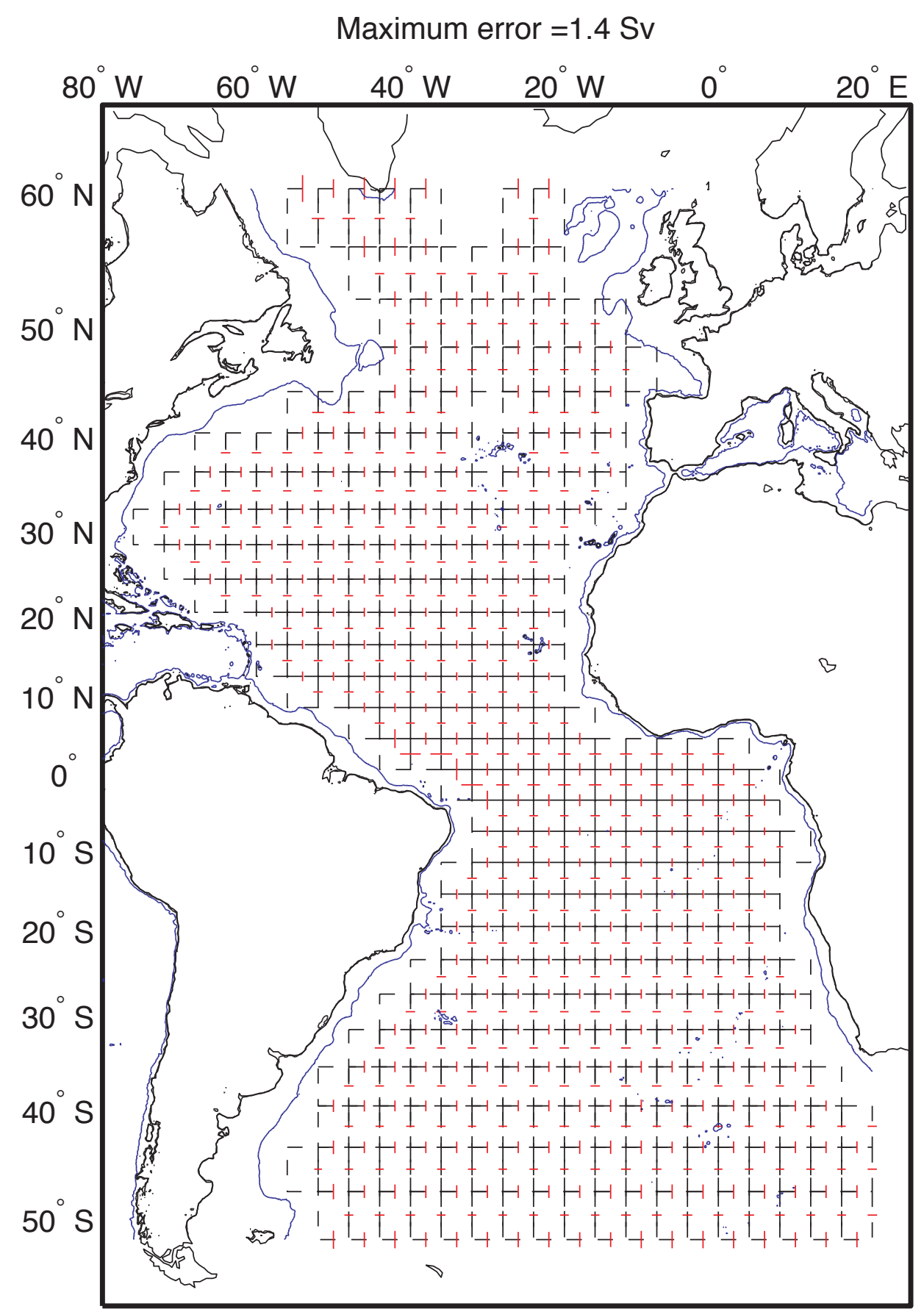


Figure S3.

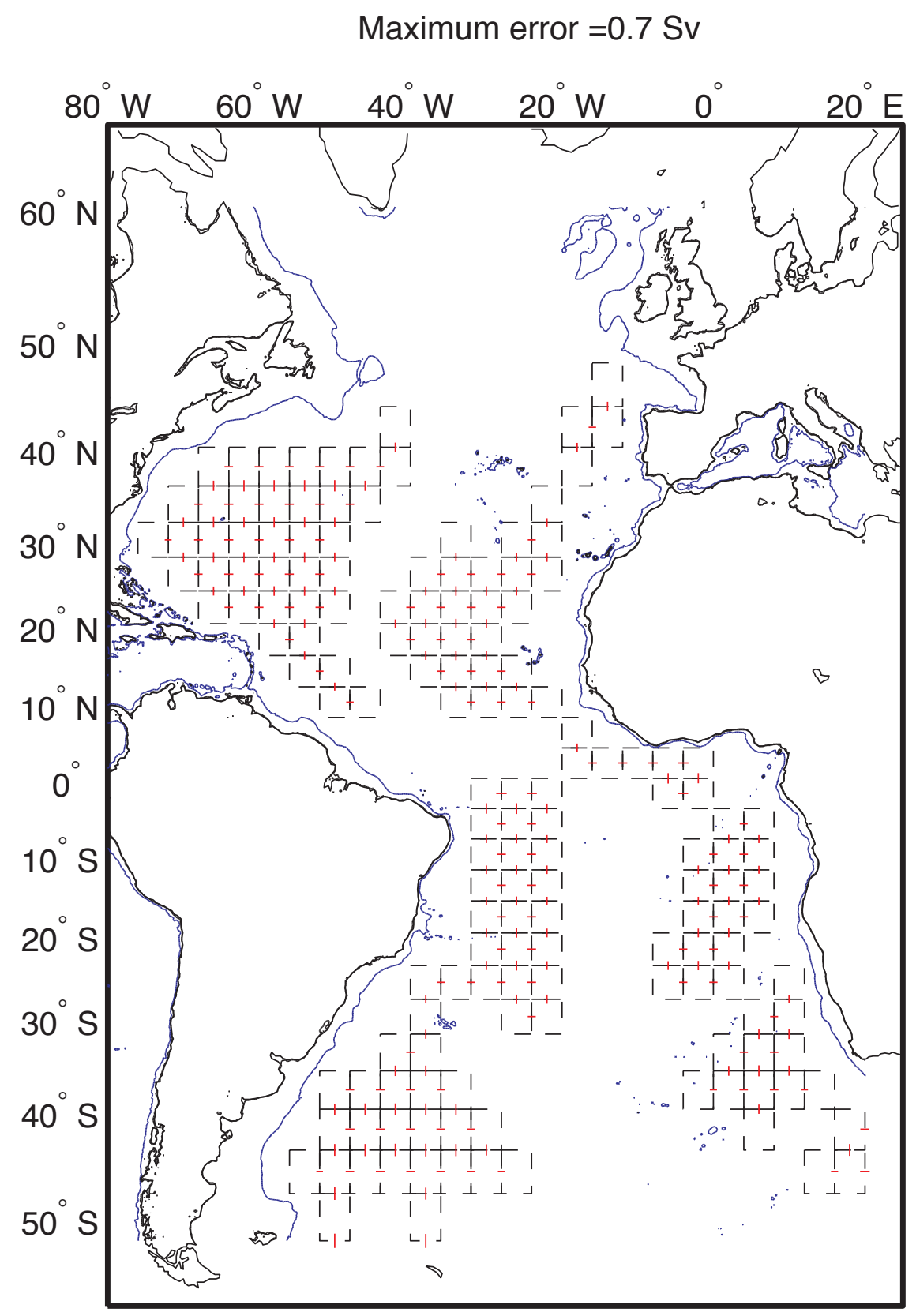


Figure S4.

a
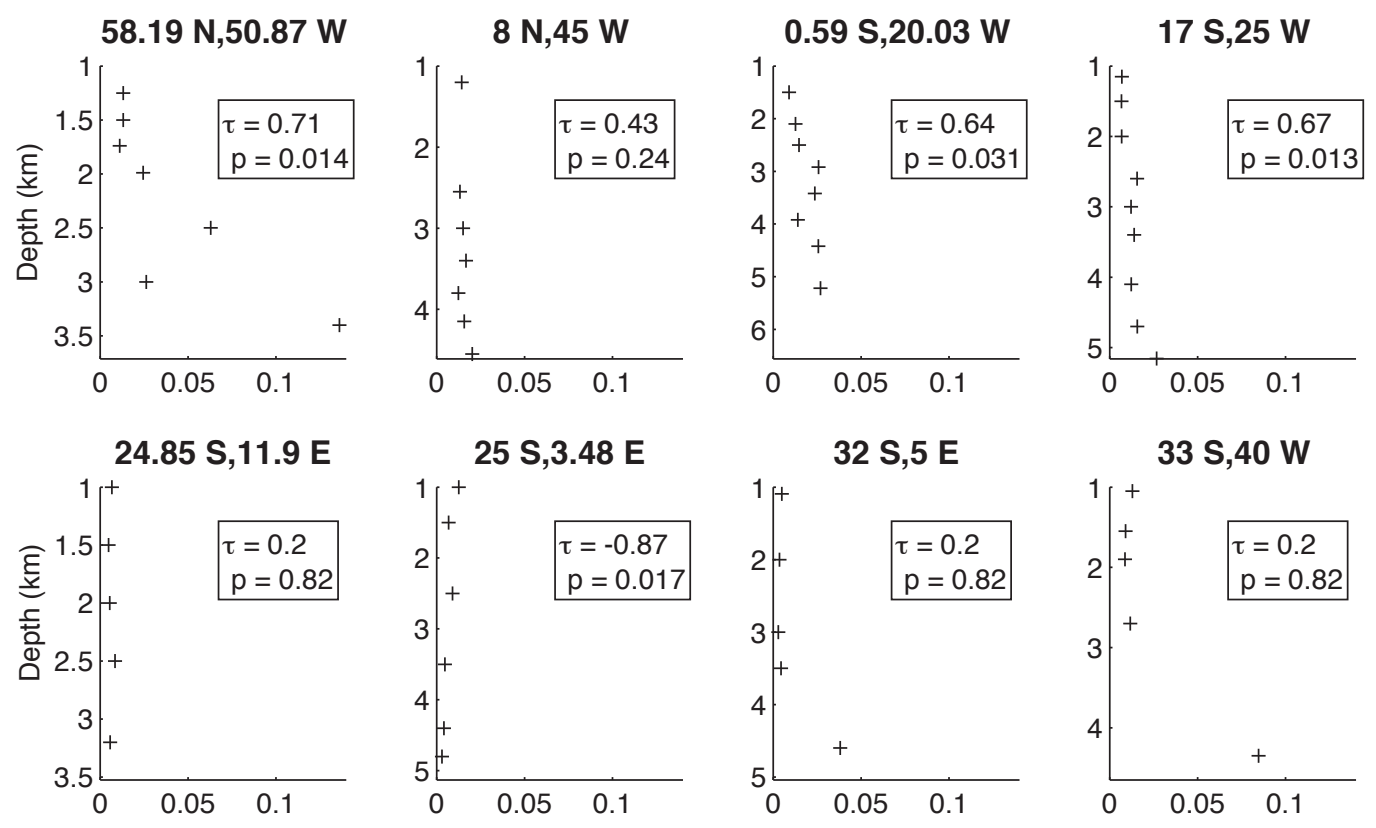

44.48 S,10.46 E
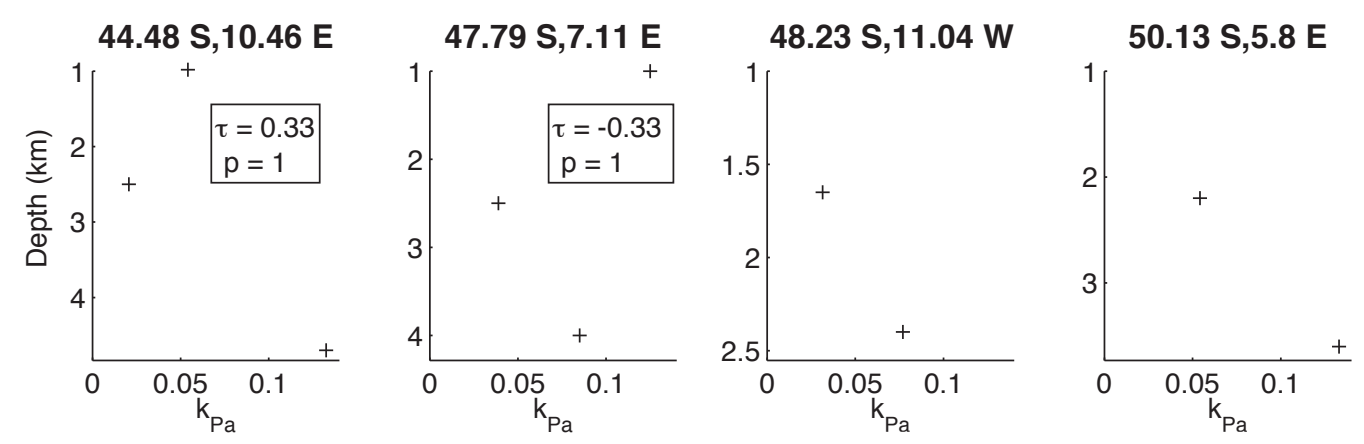

b
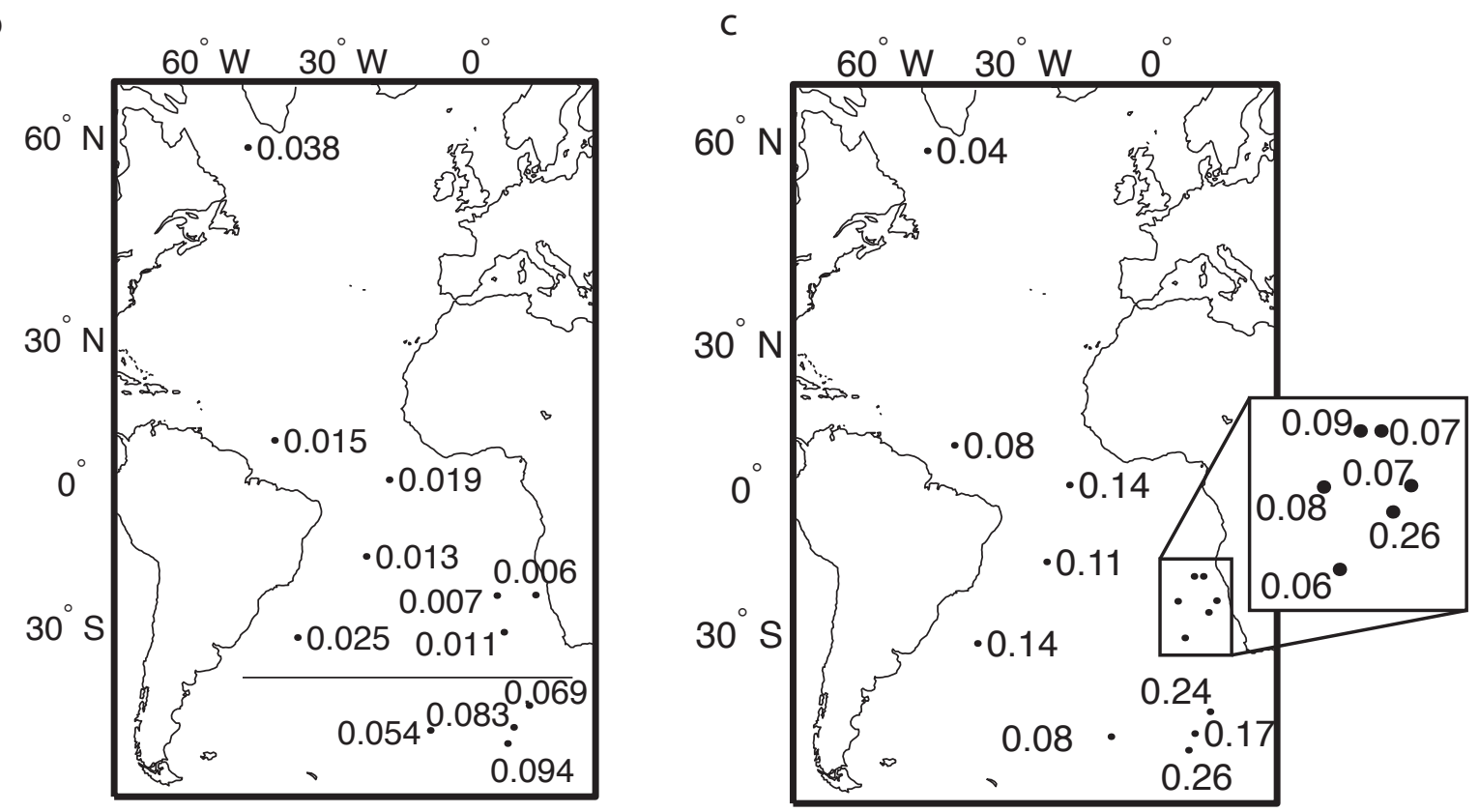
Figure S5.

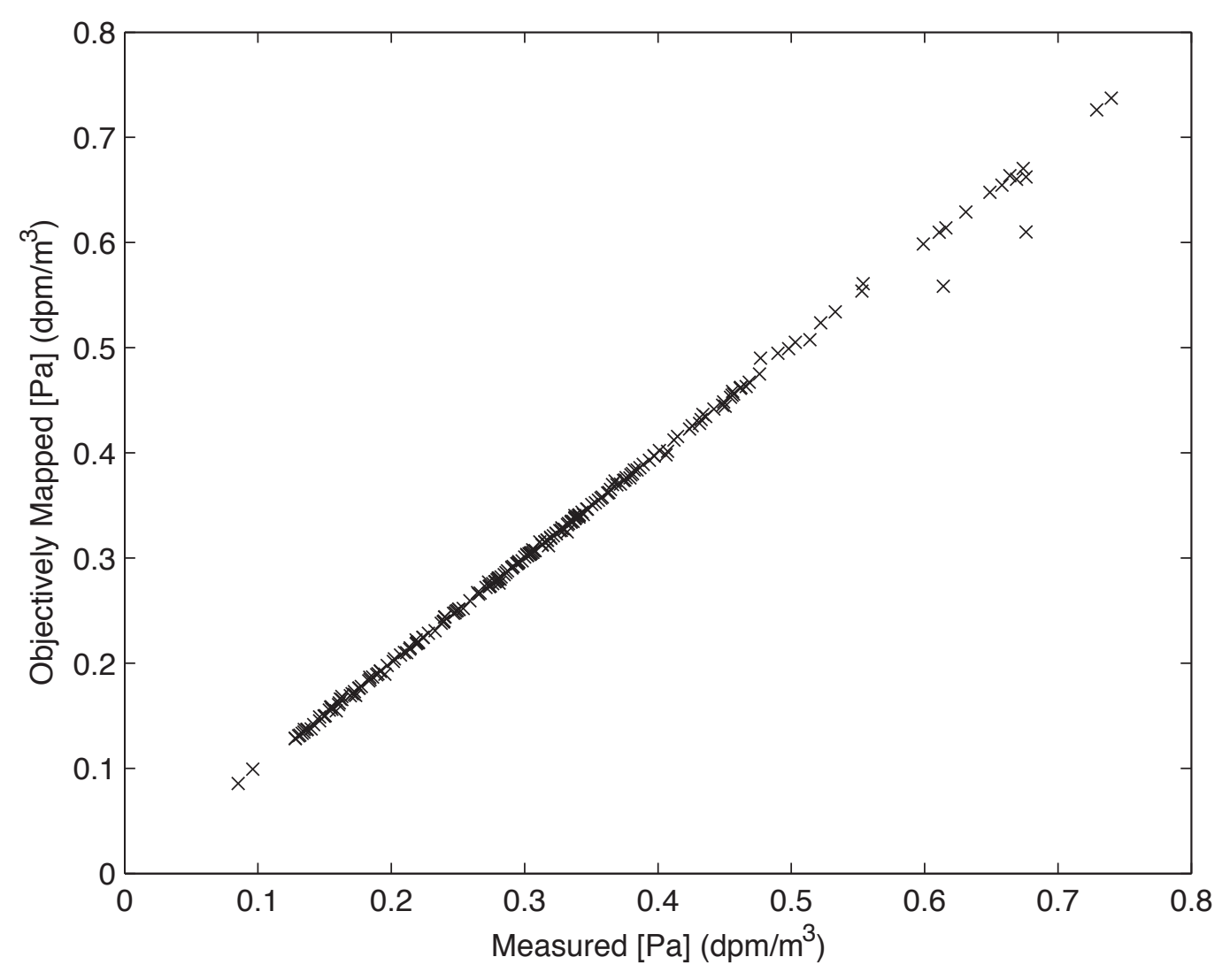


Figure S6.

Reconstructed Holocene; Modern Circulation Estimate

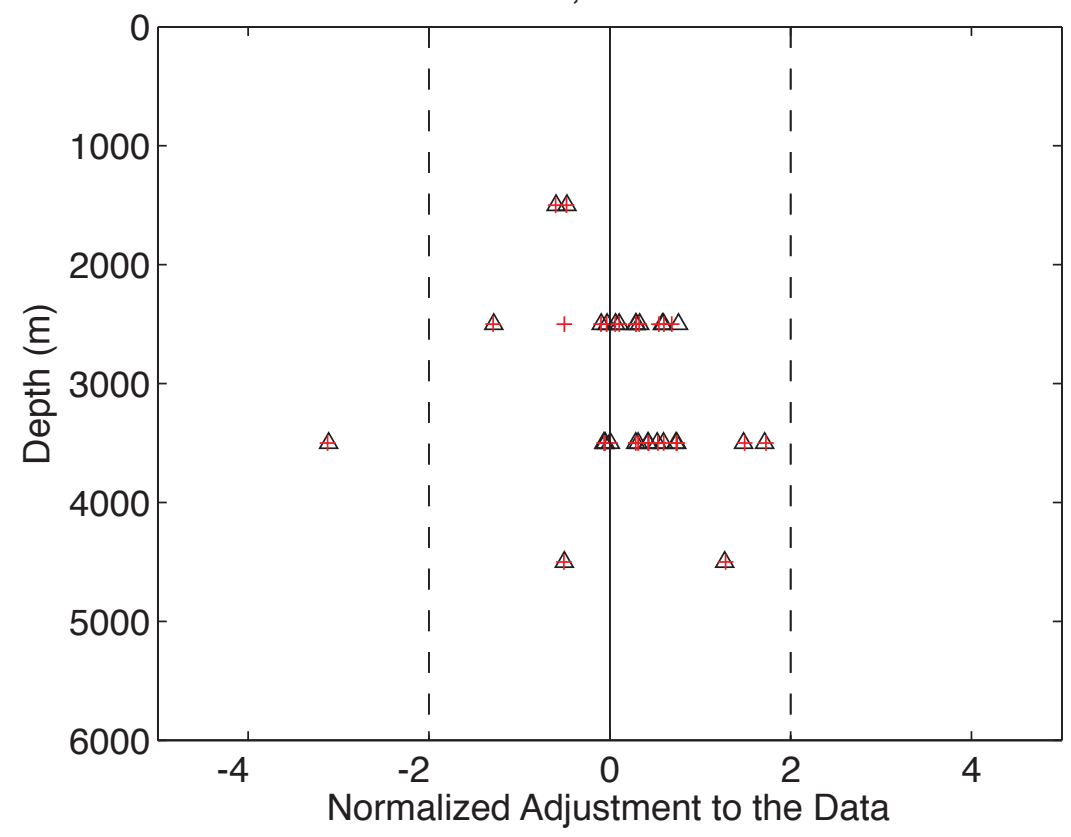

Reconstructed LGM; Modern Circulation Estimate

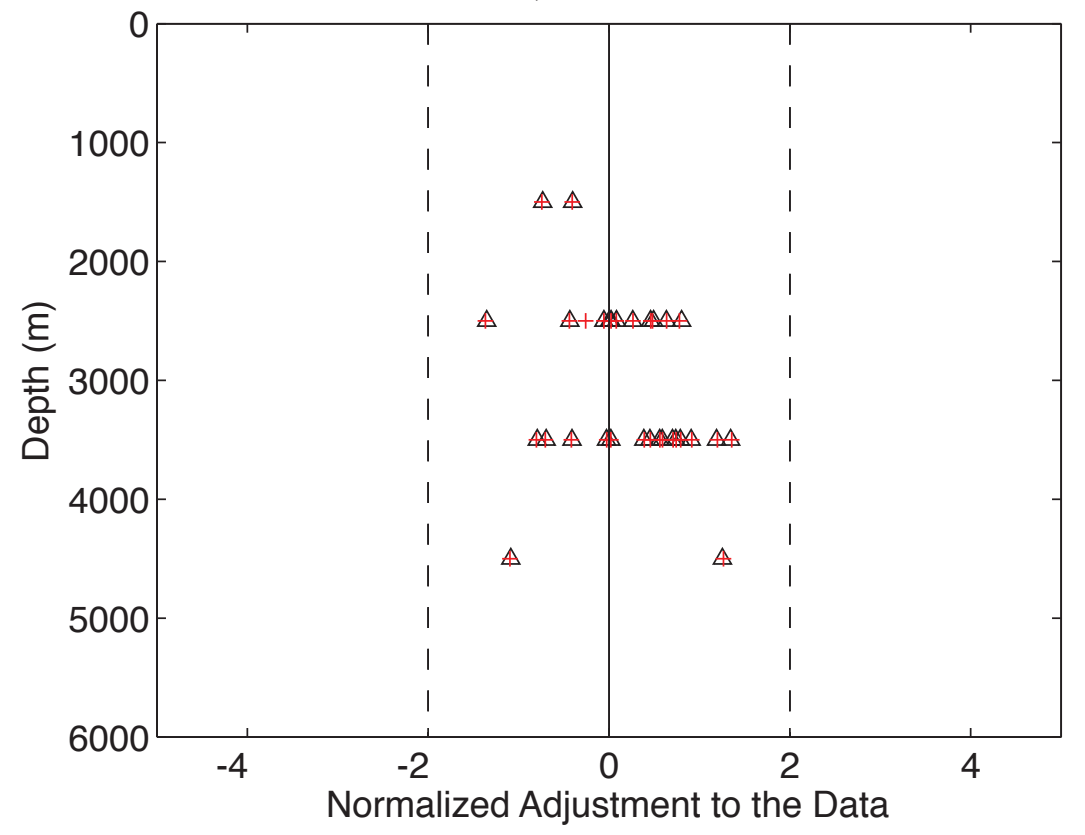

Reconstructed H1; Modern Circulation Estimate

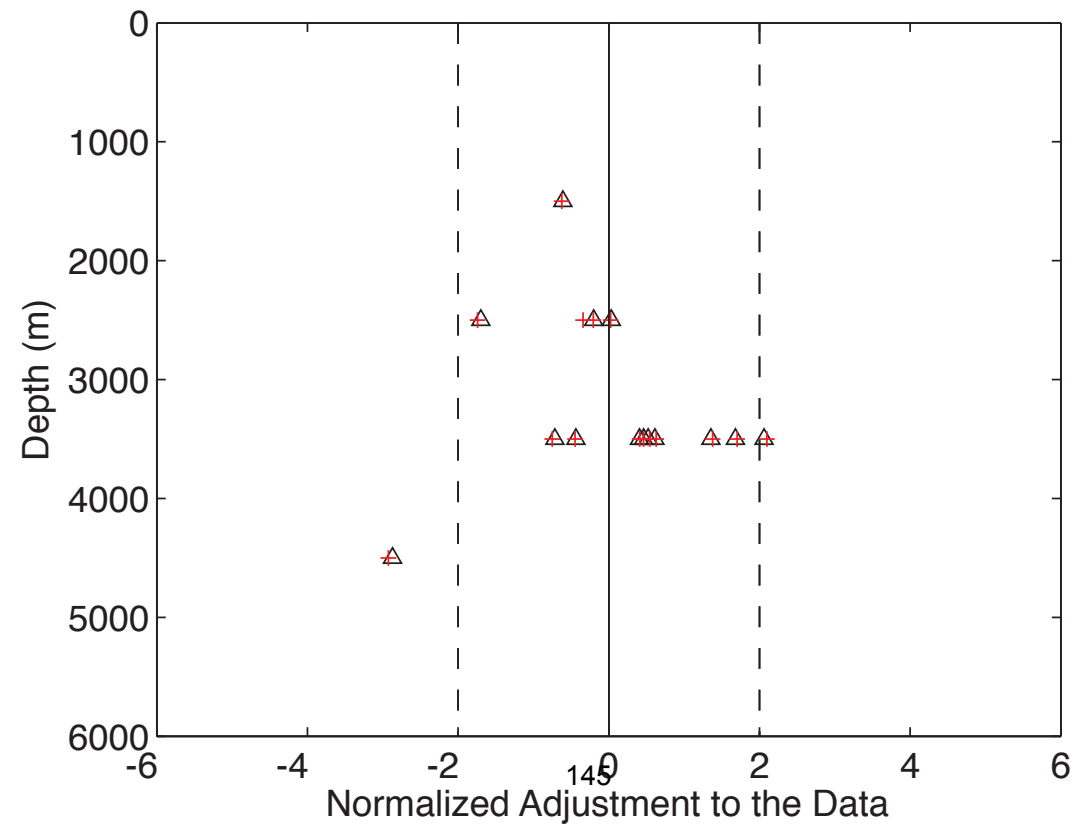




\section{Appendix A5}

\section{Reconnaissance ${ }^{14} \mathrm{C}$ data and uranium series data on Galapagos corals}

More than 200 pieces of scleractinian colonial corals $(>11 \mathrm{~kg})$ and 5 solitary fossil corals were collected from the Galapagos on cruise MV1007. Corals came from dredges D03 $\left(0.46^{\circ} \mathrm{N}, 90.71^{\circ} \mathrm{W}, 610 \mathrm{~m}\right)$ and D09 $\left(0.79^{\circ} \mathrm{N}, 91.3^{\circ} \mathrm{W}, 495 \mathrm{~m}\right)$. A subset of 50 of these corals were dated using the radiocarbon age survey techniques described in McIntyre et al. [accepted]. Five of the colonial corals were also dated with uranium series. No corals had deglacial reconnaissance ages so these corals are not discussed further in this thesis. This appendix includes the following tables and figure:

Table 1. Reconnaissance radiocarbon ages

Table 2. Uranium and thorium data

Figure 1. Histogram of reconnaissance radiocarbon ages.

McIntyre, C. P., et al. (accepted), Rapid radiocarbon (14C) analysis of coral and carbonate samples using a continuous-flow accelerator mass spectrometry (CFAMS) system. 
Table 1. Reconnaissance Radiocarbon Ages

\begin{tabular}{|c|c|c|c|c|c|c|}
\hline Cruise & Dredge & Sample* & $\mathbf{F m}$ & $1 \sigma$ & Libby age & $1 \sigma$ \\
\hline MV1007 & D03 & $1-1$ & 0.0066 & 0.0048 & 40300 & 5900 \\
\hline MV1007 & D03 & $1-2$ & 0.0149 & 0.0048 & 33800 & 2600 \\
\hline MV1007 & D03 & $1-3$ & 0.0165 & 0.0048 & 33000 & 2300 \\
\hline MV1007 & D03 & $1-4$ & \multicolumn{4}{|c|}{ Indistinguishable from radiocarbon dead coral } \\
\hline MV1007 & D03 & $1-10$ & \multicolumn{4}{|c|}{ Indistinguishable from radiocarbon dead coral } \\
\hline MV1007 & D03 & $2-10 a$ & \multicolumn{4}{|c|}{ Indistinguishable from radiocarbon dead coral } \\
\hline MV1007 & D03 & $2-10 b$ & \multicolumn{4}{|c|}{ Indistinguishable from radiocarbon dead coral } \\
\hline MV1007 & D03 & $2-10 c$ & \multicolumn{4}{|c|}{ Indistinguishable from radiocarbon dead coral } \\
\hline MV1007 & D03 & $2-18 a$ & \multicolumn{4}{|c|}{ Indistinguishable from radiocarbon dead coral } \\
\hline MV1007 & D03 & $2-18 b$ & 0.0087 & 0.0073 & 38100 & 6700 \\
\hline MV1007 & D03 & $2-18 c$ & 0.0133 & 0.0072 & 34700 & 4400 \\
\hline MV1007 & D03 & $3-10$ & 0.0146 & 0.0072 & 34000 & 4000 \\
\hline MV1007 & D03 & $3-15 a$ & 0.8683 & 0.0090 & 1100 & 85 \\
\hline MV1007 & D03 & $3-15 b$ & 0.0194 & 0.0072 & 31700 & 3000 \\
\hline MV1007 & D03 & $3-26 a$ & 0.8600 & 0.0088 & 1200 & 80 \\
\hline MV1007 & D03 & $3-26 b$ & 0.0229 & 0.0072 & 30300 & 2500 \\
\hline MV1007 & D03 & $3-29 a$ & 0.8450 & 0.0074 & 1400 & 70 \\
\hline MV1007 & D03 & $3-29 b$ & 0.8495 & 0.0143 & 1300 & 140 \\
\hline MV1007 & D03 & 4-11 & 0.0166 & 0.0072 & 32900 & 3500 \\
\hline MV1007 & D03 & $4-7$ & 0.8610 & 0.0052 & 1200 & 50 \\
\hline MV1007 & D03 & $4-8 a$ & \multicolumn{4}{|c|}{ Indistinguishable from radiocarbon dead coral } \\
\hline MV1007 & D03 & $4-8 b$ & \multicolumn{4}{|c|}{ Indistinguishable from radiocarbon dead coral } \\
\hline MV1007 & D03 & $5-1$ & \multicolumn{4}{|c|}{ Indistinguishable from radiocarbon dead coral } \\
\hline MV1007 & D03 & $5-11$ & \multicolumn{4}{|c|}{ Indistinguishable from radiocarbon dead coral } \\
\hline MV1007 & D03 & $5-19$ & 0.0105 & 0.0072 & 36600 & 5500 \\
\hline MV1007 & D03 & Desmo1 & \multicolumn{4}{|c|}{ Indistinguishable from radiocarbon dead coral } \\
\hline MV1007 & D03 & Desmo2 & 0.8688 & 0.0094 & 1100 & 85 \\
\hline MV1007 & D03 & Desmo3 & 0.8495 & 0.0090 & 1300 & 85 \\
\hline MV1007 & D03 & Desmo4 & 0.0069 & 0.0048 & 40000 & 5600 \\
\hline MV1007 & D03 & Desmo5 & 0.8583 & 0.0091 & 1200 & 85 \\
\hline MV1007 & D09 & 1 & 0.8496 & 0.0096 & 1300 & 90 \\
\hline MV1007 & D09 & 3 & 0.8770 & 0.0102 & 1100 & 95 \\
\hline MV1007 & D09 & 4 & 0.8488 & 0.0054 & 1300 & 50 \\
\hline MV1007 & D09 & 5 & 0.8332 & 0.0097 & 1500 & 95 \\
\hline MV1007 & D09 & 6 & 0.8772 & 0.0094 & 1100 & 85 \\
\hline MV1007 & D09 & 8 & 0.8614 & 0.0096 & 1200 & 90 \\
\hline MV1007 & D09 & 9 & 0.8787 & 0.0090 & 1000 & 80 \\
\hline MV1007 & D09 & 10 & 0.9568 & 0.0106 & 400 & 90 \\
\hline MV1007 & D09 & 11 & 0.9973 & 0.0135 & 0 & 110 \\
\hline MV1007 & D09 & $12 a$ & 0.8659 & 0.0101 & 1200 & 95 \\
\hline MV1007 & D09 & $12 b$ & 0.8945 & 0.0107 & 900 & 95 \\
\hline MV1007 & D09 & 13 & 0.8902 & 0.0101 & 900 & 90 \\
\hline MV1007 & D09 & 14 & 0.8951 & 0.0092 & 900 & 85 \\
\hline MV1007 & D09 & 15 & 0.9053 & 0.0090 & 800 & 80 \\
\hline MV1007 & D09 & 16 & 0.8609 & 0.0106 & 1200 & 100 \\
\hline MV1007 & D09 & $17 a$ & 0.8718 & 0.0096 & 1100 & 90 \\
\hline MV1007 & D09 & $17 b$ & 0.8876 & 0.0093 & 1000 & 85 \\
\hline MV1007 & D09 & 18 & 0.8766 & 0.0100 & 1100 & 90 \\
\hline MV1007 & D09 & 19 & 0.8396 & 0.0102 & 1400 & 100 \\
\hline MV1007 & D09 & 20 & 0.8854 & 0.0099 & 1000 & 90 \\
\hline
\end{tabular}

*All samples are unidentified colonial scleratinian corals, except for Desmo1 through Desmo5 which are Desmophyllum dianthus 


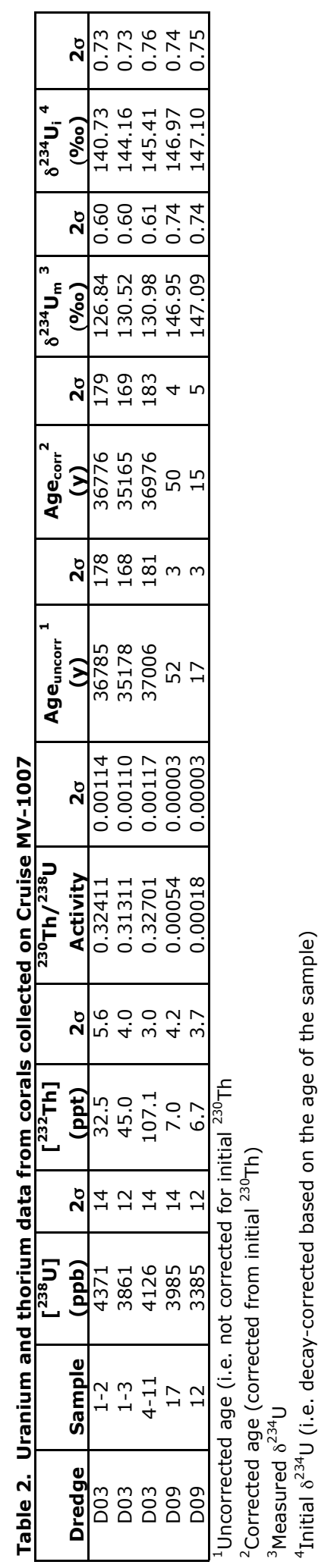




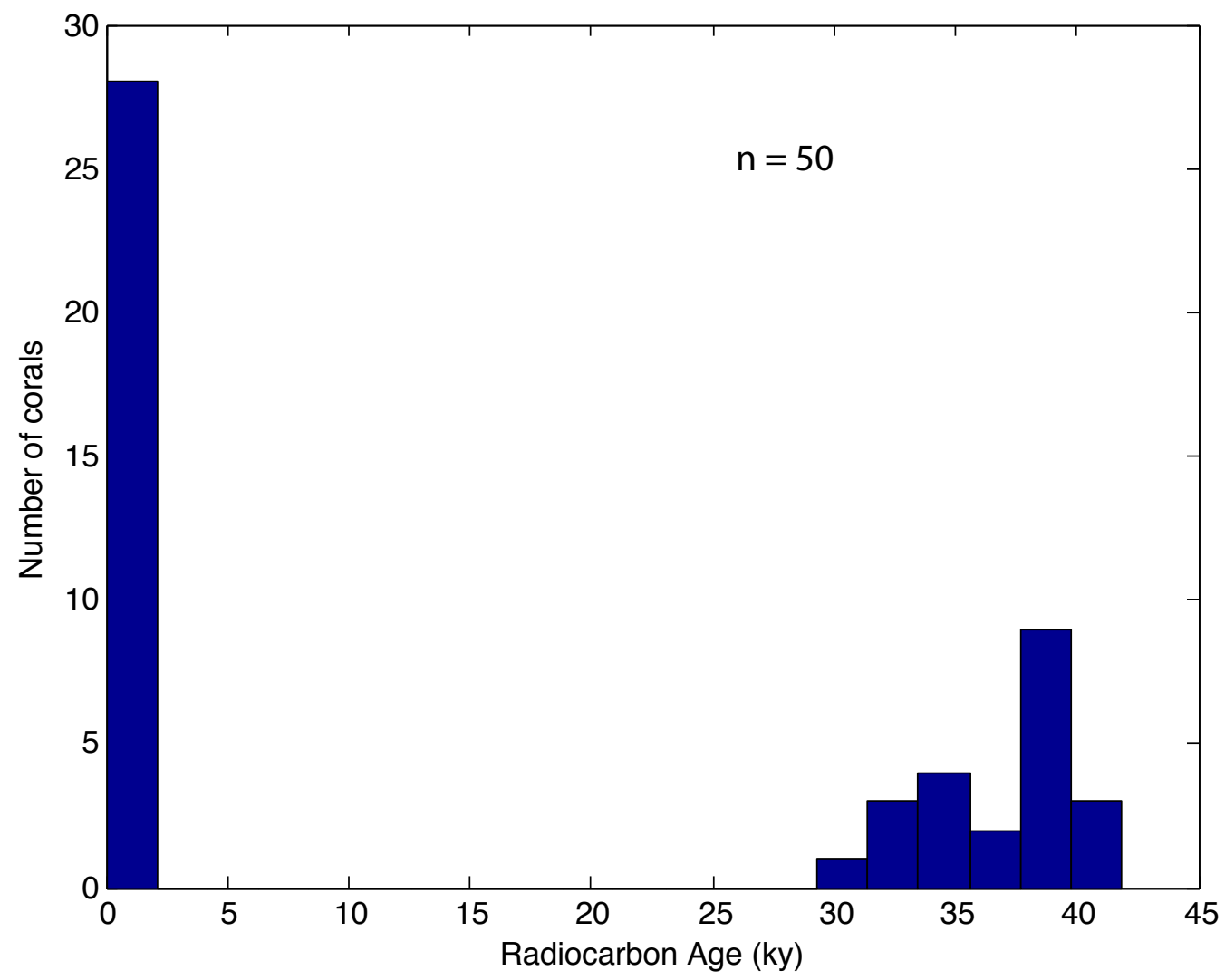

Figure 1. Radiocarbon age distribution of corals collected from Galapagos on cruise MV-1007 